Portland State University

PDXScholar

\title{
An Inquiry into Developing College Student Socially- Responsible Leadership: Ethics of Justice and Care in the Midst of Conflict and Controversy
}

Jill Frances Childress

Portland State University

Follow this and additional works at: https://pdxscholar.library.pdx.edu/open_access_etds

Part of the Educational Leadership Commons, Higher Education Commons, and the Higher Education Administration Commons

Let us know how access to this document benefits you.

\section{Recommended Citation}

Childress, Jill Frances, "An Inquiry into Developing College Student Socially-Responsible Leadership: Ethics of Justice and Care in the Midst of Conflict and Controversy" (2020). Dissertations and Theses. Paper 5472.

https://doi.org/10.15760/etd.7344

This Dissertation is brought to you for free and open access. It has been accepted for inclusion in Dissertations and Theses by an authorized administrator of PDXScholar. Please contact us if we can make this document more accessible: pdxscholar@pdx.edu. 
An Inquiry into Developing College Student Socially-Responsible Leadership:

Ethics of Justice and Care in the Midst of Conflict and Controversy

by

Jill Frances Childress

A dissertation submitted in partial fulfillment of the requirements for the degree of

Doctor of Education

in

Educational Leadership: Postsecondary Education

Dissertation Committee:

Christine Cress, Chair

Karen Haley

Andrew Job

Matthew Gebhardt

Portland State University

2020 
(C) 2020 Jill Frances Childress 


\begin{abstract}
Colleges not only educate students in academic discipline knowledge, but also help them develop skills to meaningfully lead and participate in our complex democracy as socially responsible citizens. All campuses have formal and informal opportunities to engage students in roles that challenge and develop students' socially responsible leadership skills including commitment, common purpose, and collaboration. However, individual and organizational elements such as differences in perspectives and hostile climates can quell leadership and educational participation, inhibit critical student development skills, and result in disempowerment, especially for those students from underserved communities. Given this, a critical question is how can colleges foster conditions that promote the formation of complex and pluralistic democratic and socially responsible leadership skills within the context of contemporary societal political, ideological, and social polarization that are replicated and enacted on today's campuses? To address this question, this qualitative inquiry examined how diverse student leaders navigated conflict and controversy and their resulting dilemmas with their peers, and how such experiences affected their democratic learning and leadership development. Study participants identified both the value of constructive conflict that leads to more advanced moral reasoning and equitable practices, and the harm of destructive controversy that further polarizes and entrenches opposition. The latter experiences resulted in deleterious effects on participants' interpersonal and psychological wellbeing, whereas the former experiences, while challenging, served as an opportunity for student leaders to develop
\end{abstract}


and practice resilient and interculturally insightful skills of perspective taking, emotional intelligence, and advanced conflict resolution strategies that served to empower individual and group commitment toward common purpose and shared goals. Emerging from the data is a new definitional model of socially responsible leadership (SRL) that is both a process and product of a blended ethic of care and ethic of justice approach in realizing democratic attitudes, knowledge, skills, and outcomes. Specifically, the four interconnected and dynamic dimensions of the SRL conceptual model are self-efficacy, group accountability, shared power, and empathetic conflict resolution. Implications and meaningful strategies for colleges to help facilitate growth through conflict across individual, group, and organizational domains are discussed. 


\section{DEDICATION}

For Leah, Charis, and Everly. May you always stand firm in your commitment to what is right, and do so with the most important value in mind: demonstrating unwavering love, kindness, and empathy to others. I love you. 


\section{ACKNOWLEDGEMENTS}

A doctoral journey is a lengthy one of trials and joys, unexpected turns, and an interminable number of steps, but for a weary traveler, the journey is made easier thanks to some very supportive folks along the way. I want to acknowledge those that eased my journey in this process of scholarship and empowerment.

First, and above all, to God. I prayed long and hard before and during this process, and all of those prayers were answered in a tremendous way. This doctoral journey has certainly become a part of my personal testimony.

To my participants: your willingness to engage in deep, reflective, and highly personal conversations about sensitive topics with someone you do not know well allowed for a deep exploration in a previously under-studied area. Your stories have led to insights and knowledge with the potential for a great positive impact for practice, and your wisdom, thoughtfulness, and vulnerability is a gift that I cherish. Thank you for your contributions of time, mental and emotional energy, and insights for this scholarship.

To my advisor, Dr. Christine Cress: you are one of the most brilliant people I have ever known. Your ability to find connections and make meaning, along with your investment in me as a student, professional, and scholar, were invaluable tools to that allowed me to make the most of this journey. I am a better thinker, writer, and practitioner thanks to your influence. Thank you.

To the rest of my committee: I am incredibly grateful for your time and support in this process. Dr. Karen Haley, your quick responses to questions, nuts-and-bolts support for how to analyze and code qualitative data, and overall support helped me feel more 
confident in my journey. Dr. Matthew Gebhardt and Dr. Andy Job, I am indebted to you for your willingness to serve on the committee of a student that you did not even know. Thank you for taking a risk by participating in my committee and for providing insights into my study. Dr. Jesse Nelson: you have been a mentor, cheerleader, and friend from day one, while I was still mustering the courage and wherewithal to apply to doctoral programs in the first place. Your friendship, insights, and validation have meant so much to me.

Several colleagues and friends played an indispensable role through direct support and encouragement in this research. I am particularly indebted to Drew Desilet, Leslie Schacht-Drey, Dr. Damoni Wright, Natalie Rooney, Regan Le, Emily Bowling, Candace Baltz-Smylie, Dr. Leah Hall Dorothy, Teresita Alvarez-Cortez, Carina Buzo, Sara Caldwell-Kan, the Residential Education team, Esther Henry, Dr. Ann Marie Klotz, Dr. Stephen Jenkins, Dr. Susan Rowe, Dr. Jimmy Howard, Dr. Jeff Kenney, Charlene Martinez, Dr. Jordan Windholz, and Erin Windholz, who met with me, shared ideas, helped me think critically about various aspects of my study, and overall cheered me on.

To my colleagues at work, especially my supervisor, Drew Morgan, my fellow RLT members, Benjamin Medeiros and Christopher Hughbanks, and my direct reports over the years in my program, Pamela Altmaier, Wiliama Sanchez, Jess Tallant, and Brittany Griffin, I am grateful for your patience and flexibility as I pivoted between work and school life. To everyone in UHDS who took time to ask questions about my progress and scholarship, to chat about my study findings, and who encouraged me along the 
way - those small hallway conversations were motivating and energizing. Thank you for showing kindness by taking interest.

Very few other people understand the shared unique experience of navigating this particular process, and my cohort was a significant source of support at every stage along the journey. I feel fortunate to know the amazing and talented scholars and professionals in my cohort. I am especially indebted to my dear friends Marleigh Perez, Heather Kropf, Sarah Kutten, and Trish Dorman, for hours of conversation, support, and commiseration.

To my best friends, Leslee Mayers and Jennifer Viña and your sweet families: you are an incredible blessing in my life and I am glad to call you the family we chose for ourselves. Your support and belief in me along every step of this path has meant everything. Thank you for helping be a presence and support for Jeremy and the girls when I was otherwise occupied with school - the offers to watch the girls, get together, do dinners, and more were invaluable gifts and sustaining sources of support that allowed us to not feel alone in this journey. To my in-laws, Patty and Travis: thank you for the free and unfettered use of your retirement home in Newport. I was blessed to be a caretaker of the space while we were there and have fond memories of writing lots of my dissertation against the backdrop of the mighty, wonderful, awesome Pacific Ocean. To my parents, Kathy and Doug: you raised me to be resilient and confident, and also to show kindness and love others. All of those were necessary to stay focused on the longterm goal of a terminal degree. I had the tools I needed to complete this journey thanks to how you love and raised me. I will never not need the support of my Mom and Dad in my life. 
To my daughters, Leah, Charis, and Everly, you were my littlest and most vocal cheerleaders, and bore the impact of a mama stretched very thin with grace and love. Leah, who, when given the choice of being at school or traveling to watch my (probably boring) proposal defense, chose to attend because "I might want to do this someday." And Charis, who looked at me warily and half-smirking, not entirely sure if I was kidding or not when I said “when I'm done, you can call me 'Dr. Mom,' or just 'Doctor' for short." And Everly, who has spent more than half of her life with her mom in school, normalized to the point where dinner conversations began in your tiny 5-year-old voice: “So, how's your dissertation going?” (You know, normal preschooler topics.) You all were a grounding force for me, a strong anchor despite your age and size, and my constant reminder of why I even bothered with this journey in the first place.

Finally, and most importantly, to my husband, helpmate, and best friend, Jeremy. We knew going into this process that it would be a sacrifice for our entire family; a shortterm trade-off for long-term gain. I could not have done this degree at all without you. Your willingness to single parent nearly every weekend and many weeknights, the countless hours and nights of cooking dinner, cleaning up, doing the bedtime routine, negotiating life with the girls so I had space and peace to write, taking our kids to activities and parties and the list goes on, all allowed me to stay focused and timely in reaching this family goal—and you did it all unblinkingly. Without your confidence and belief in me, and your literal unconditional love and servant's heart, I could not have gotten this degree. Everything I do, I do for you and for our daughters. This degree belongs to our entire family. I love you. 


\title{
TABLE OF CONTENTS
}

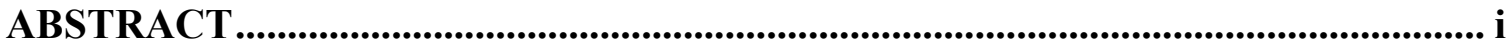

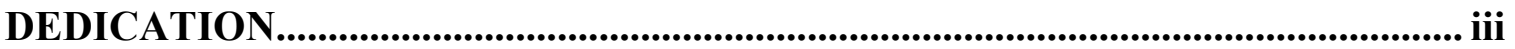

ACKNOWLEDGEMENTS ........................................................................................... iv

LIST OF TABLES .................................................................................................. xii

LIST OF FIGURES ............................................................................................... xiii
\end{abstract}

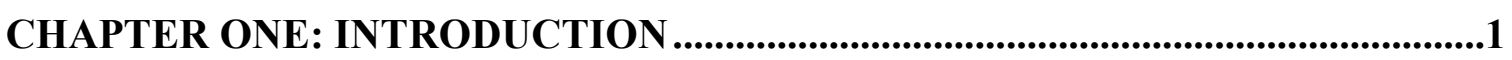

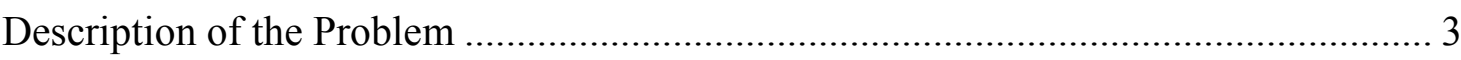

Goals of Liberal Education to Prepare Future Leaders .............................................. 4

Benefits of Exposure to Diverse Environments ..................................................... 5

Inhibitors of Development for White Students...................................................... 7

Microaggressive Campus Climate and Harm to Students of Color ................................ 9

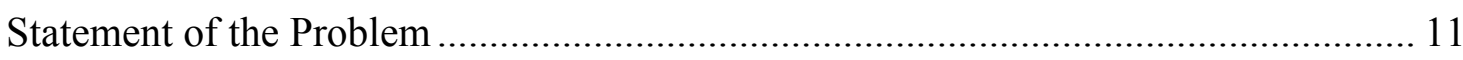

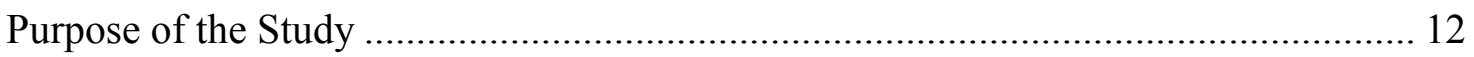

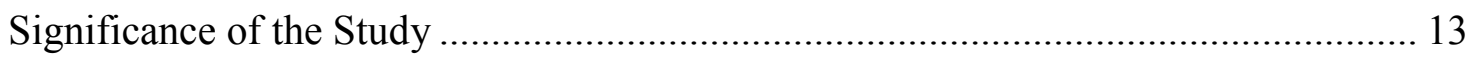

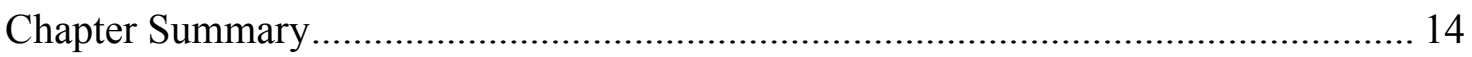

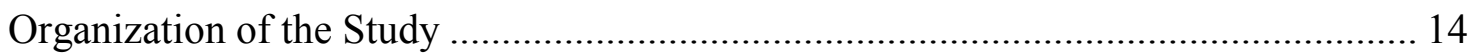

CHAPTER TWO: LITERATURE REVIEW ...........................................................16

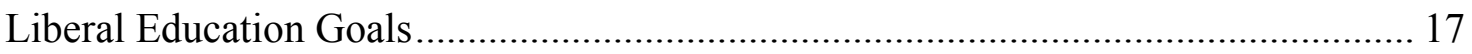

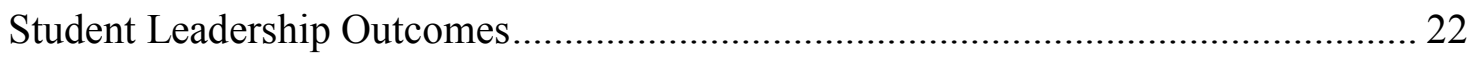

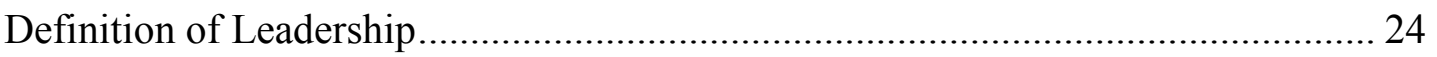

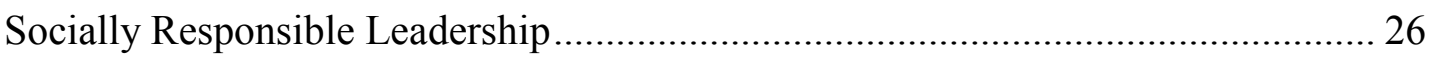

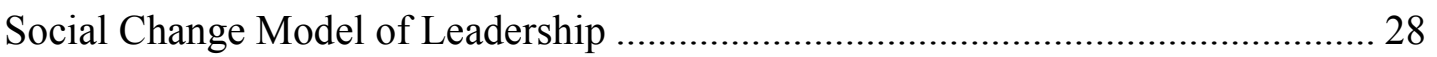

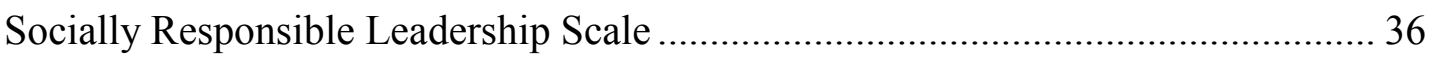

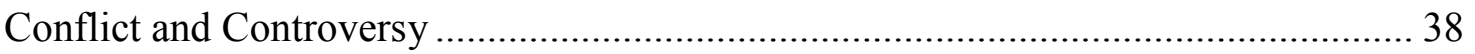

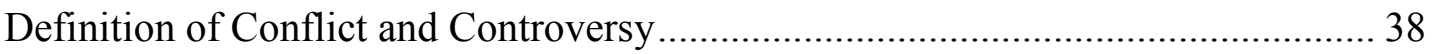

Challenges of Conflict and Controversy ……………............................................ 40

Growth Opportunities of Conflict and Controversy ................................................. 49

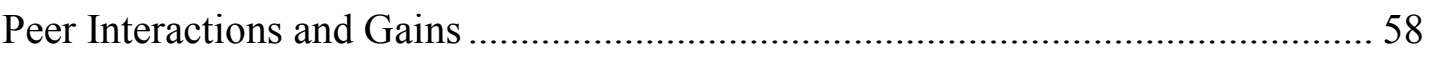

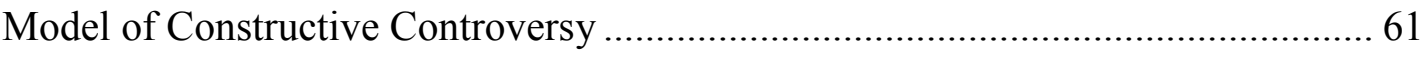

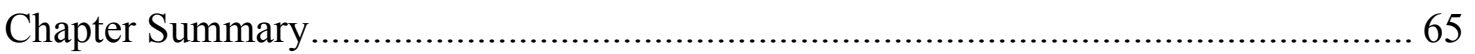

CHAPTER THREE: METHODOLOGY ......................................................................68 


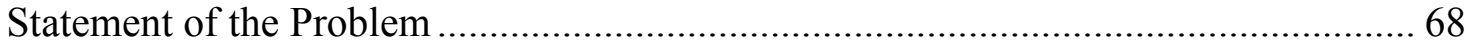

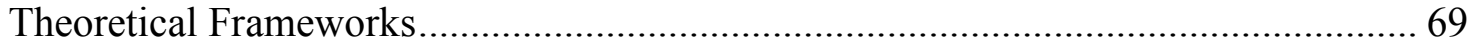

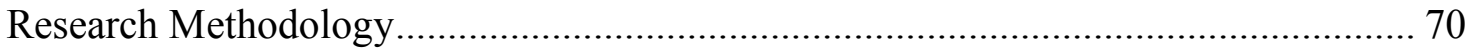

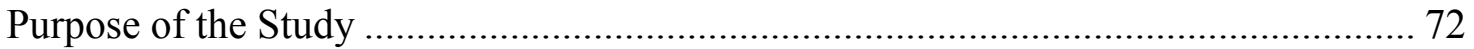

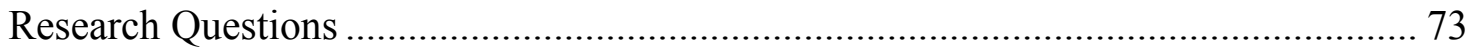

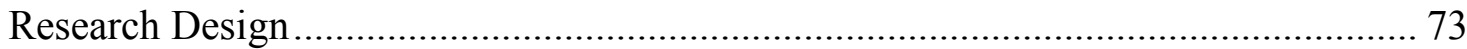

Research Participants/ Population and Sampling Procedure....................................... 74

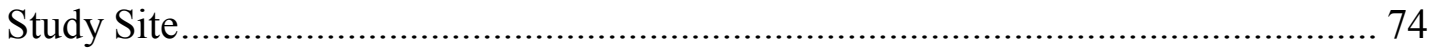

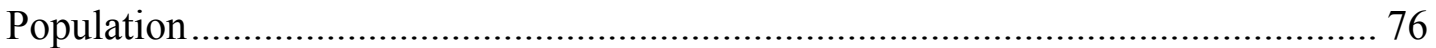

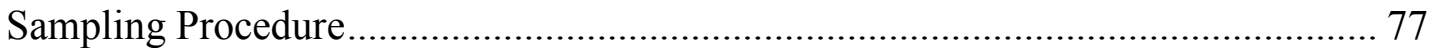

Negotiating Access to Site and Participants .......................................................... 80

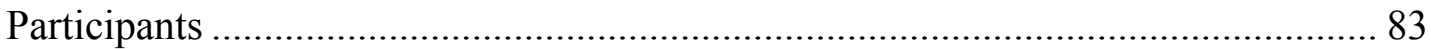

Instrumentation/Sources of Data and Collection Strategies.................................... 85

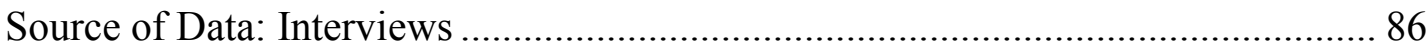

Data Collection Procedure ......................................................................................... 94

Ensuring Ethical Collection of the Data ............................................................... 96

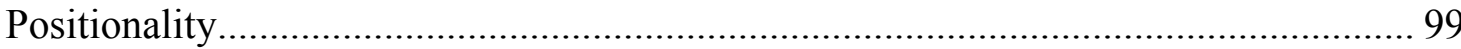

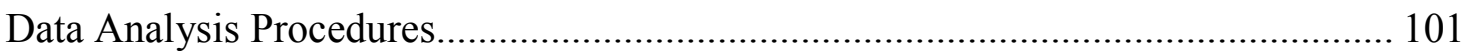

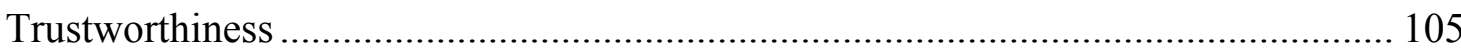

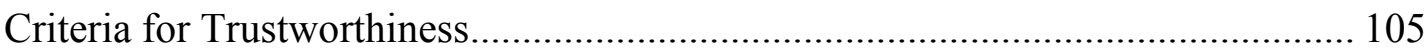

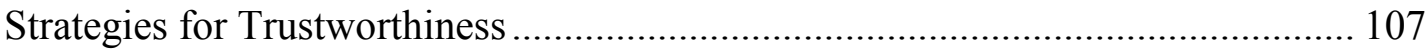

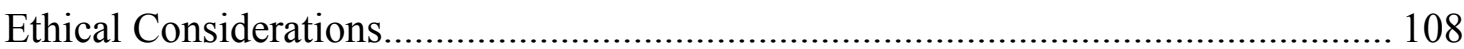

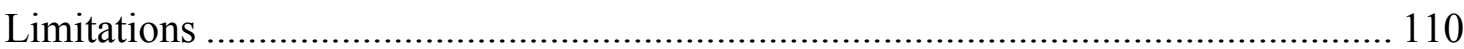

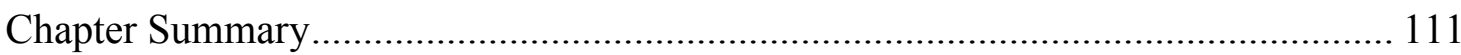

CHAPTER FOUR: FINDINGS ...........................................................................113

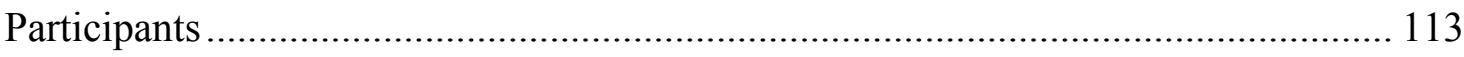

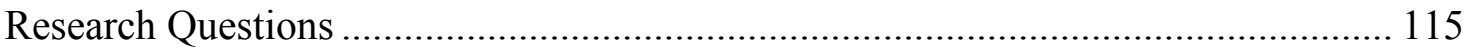

Student Leader Experiences Navigating Conflict and Controversy......................... 115

Student Leader Definitions of Conflict and Controversy..................................... 116

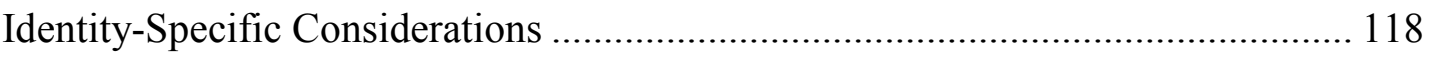

Impacts of Conflict and Controversy on Student Leaders ...................................... 122

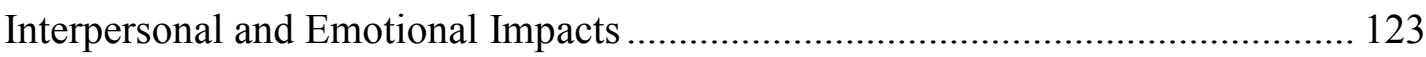

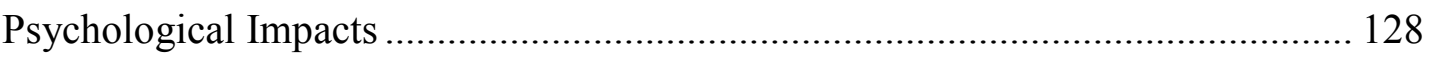




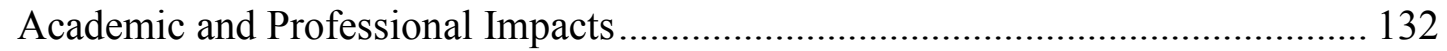

Navigating and Negotiating Conflict with Peers.................................................... 139

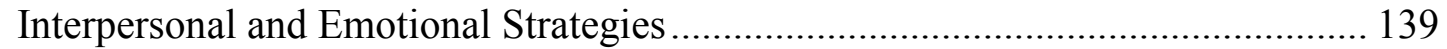

Psychological Strategy: Developing Resiliency................................................. 145

Academic and Professional Strategies.............................................................. 148

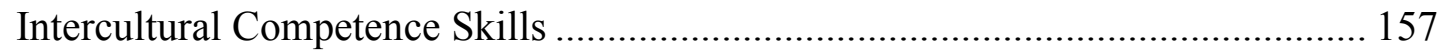

Motivators and Inhibitors in Times of Conflict and Controversy............................ 159

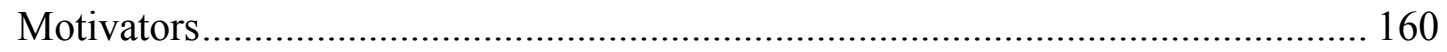

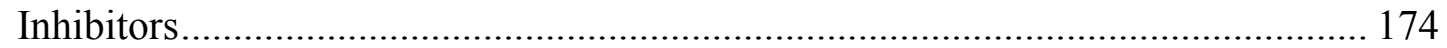

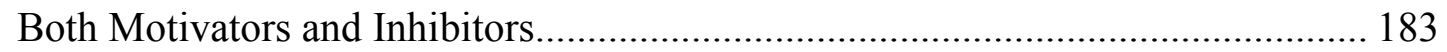

Socially Responsible Leadership Development.................................................... 191

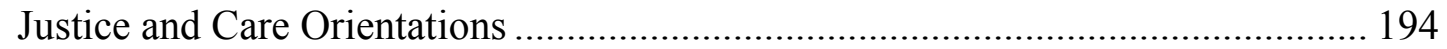

The Four Dimensions of SRL Development ..................................................... 195

Individual Theme: Lack of Confidence to Self-Efficacy ..................................... 201

Group Theme: From Individual Responsibility to Group Accountability .............. 205

Community Theme: From Individual Ego to Value of Shared Power ................... 210

Societal Theme: From Incivility to Empathy and Conflict Resolution/Dissolution 216

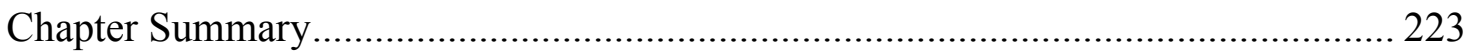

CHAPTER FIVE: IMPLICATIONS AND DISCUSSION ..................................226

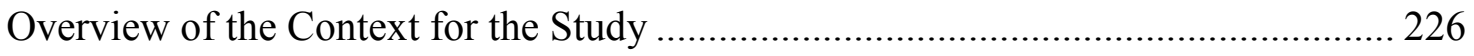

Purpose Statement and Research Questions....................................................... 227

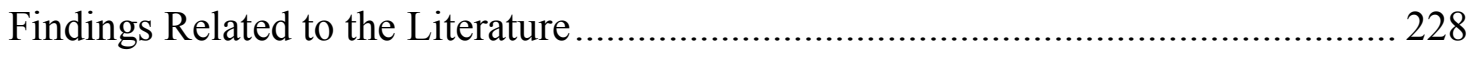

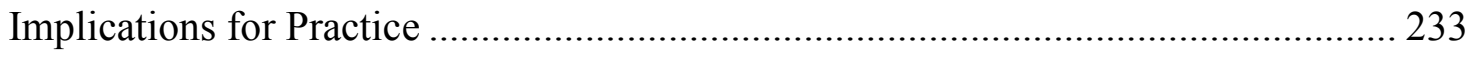

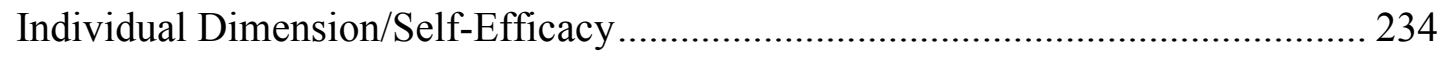

Group Dimension/Group Accountability ....................................................... 248

Community Dimension/Shared Power ........................................................... 255

Societal Dimension/Empathy and Conflict Resolution ...................................... 258

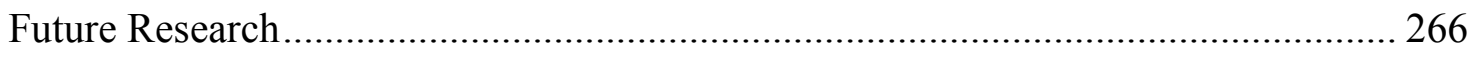

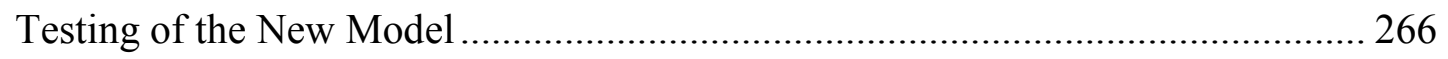

Different Student Types/Identities..................................................................... 267

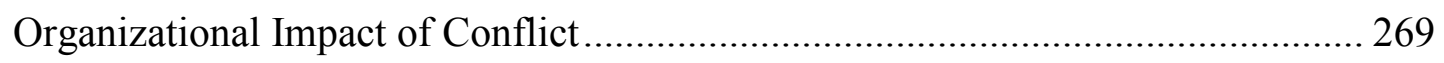

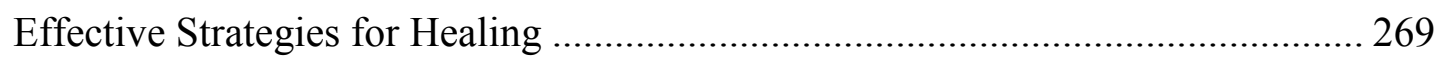

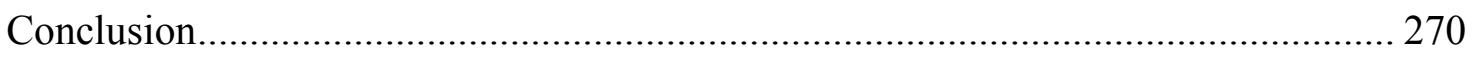




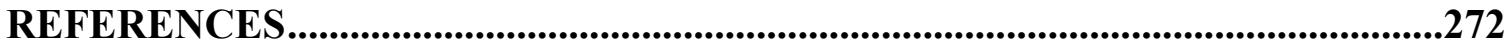

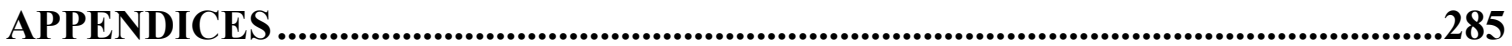

Appendix A: Table of Steps and Timelines for Study Design ................................. 286

Appendix B: Qualtrics Questionnaire for Participant Selection ............................... 287

Appendix C: Listserv Recruitment Email ................................................................ 292

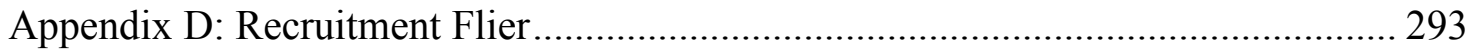

Appendix E: Follow-Up Email - Participants Who Met Criteria............................... 294

Appendix F: Follow-Up Email - Invitation to Participate ..................................... 295

Appendix G: Semi-Structured Interview Protocol ................................................. 296

Appendix H: Rubrics to Inform Protocol Questions............................................... 299

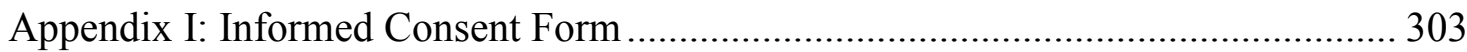

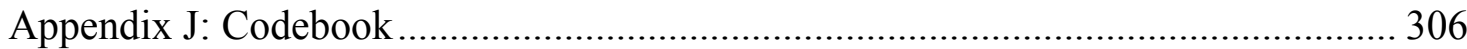

Appendix K: Trustworthiness Criteria, Strategies, and Actions .............................. 315 


\section{LIST OF TABLES}

Table 2.1. AAC\&U's Essential Learning Outcomes for a Liberal Education.... 20

Table 2.2. Descriptions of the SCM Core Values....................... 32

Table 2.3. 2016 CIRP Freshman Survey Weighted National Norms........... 43

Table 3.1. Sample Interview Questions, Purpose \& Correlated Constructs..... $\quad 88$

Table 4.1. Participant Table........................................... 115

Table 4.2. Four Dimensions of Socially Responsible Leadership............. 199

Table 5.1. Conflict Resolution Strategies for Advisors...................... 242 


\section{LIST OF FIGURES}

Figure 2.1. Relationship Between Values in the Social Change Model (SCM) of $\quad 30$

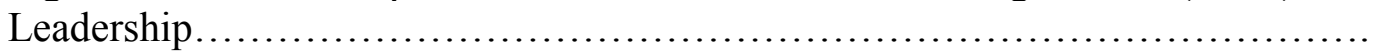

Figure 2.2. Practices with High Impact on the Development of SRL by Racial 35

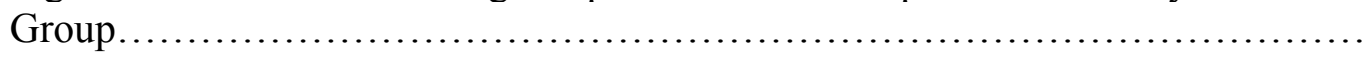

Figure 2.3. The Process Steps in the Model of Constructive Controversy......... 63

Figure 4.1. Interconnected Dimensions of the Childress Model of SRL........... 200 


\section{CHAPTER ONE: INTRODUCTION}

According to the Association of American Colleges and Universities' (AAC\&U) Liberal Education and America's Promise (LEAP) initiative, an excellent education should be focused on developing in students not only intellectual capacity, but also preparing critical thinkers for participation as citizens (Humphreys, 2009), and colleges have historically provided space for critical thinking and exploration of ideas (Pujol, 2016). In fact, higher education's role is to prepare graduates for the challenges of a fastchanging world by ensuring that our students graduate with a strong sense of ethics and integrity as well as personal and social responsibility (Humphreys, 2009). The idea of freedom of expression in particular is significant in the academy because "the free exchange of ideas remains the most powerful mechanism for change" (Bird et al., 2006, pp. 5-6). When considering higher education institutions as a place where learning occurs, learners must be exposed to all kinds of ideas to evaluate their own ideas in order to pursue truth. John Dewey believed the point of education to be the "intellectual, moral, and emotional growth of the individual and, consequently, the evolution of a democratic society" (Rodgers, 2002 p. 845). From this view, then, learning and democracy go handin-hand, and a key feature of learning is exposure to different ideas, reflection on those ideas, and integration and new ways of knowing that lead to growth in the learner. As institutional leaders, we know that the development of these skills happens both inside the classroom and in co-curricular settings. As institutions, how do we create environments that are sensitive to difference and at the same time, willing to confront differing ideas and create an environment of civil discourse? 
In today's diverse world with increasingly complex problems, a key task of higher education is to help students develop critical skills in perspective taking, problem solving, critical thinking, and collaboration. Barriers to achieving this end include the lack of engagement by White students in exploring their own identities and the related continued perpetuation of racism and White supremacy, which harm students of color. The cognitive dissonance and disorienting dilemmas that come from interpersonal conflictessentially, a difference in perspectives - can be powerful facilitators of learning and growth. However, little is known about how students make sense of and navigate conflict situations with peers on campus. Further, navigating different perspectives is a complex and necessary skill that is further complicated when students come from different viewpoints and social identities. Dialogue across diverse peers has been shown to be a promising practice in developing some of these skills sets, but more needs to be understood about how colleges and universities can foster conditions that promote this type of engagement.

Arguably, a group with which we have the most influence in this area are student leaders on college campuses, in part because of the opportunities that student leaders have to practice these skills sets in their student leader roles. Student leaders are those who engage in formal and informal leadership opportunities, including paraprofessional positions like a Resident Assistant, formalized leadership such as participating as an executive board member of a student organization or student government, or volunteer participation through general membership in a group or organization, or by serving in volunteer roles on campus. This chapter will contextualize the problem of managing 
controversy and difference of opinion in democratic co-curricular settings for student leaders by considering the negative impact of microaggressive campus climate on students with marginalized identities, the challenges with failing to engage students with dominant identities in meaningful perspective taking and exploration of their own identities, and the benefits of effective dialogic spaces and the role of liberal education environments to help students engage effectively across difference and come to see and value a pluralistic orientation.

\section{Description of the Problem}

Exposure to multiple points of view is one hallmark of learning; this ideal also seemingly comports with the desire of colleges to support students in freely expressing their points of view by exercising their First Amendment rights. However, in the context of today's college environments, we have observed the exercise of free speech in ways that can and have harmed marginalized students and the related increase in hate speech (Delgado \& Stefancic, 2004), a rise in hate groups (Sutton, 2019), and a marked rise in hate crimes against Muslim, South Asian, Middle Eastern, and Arab Americans- the highest since right after the events of $9 / 11$ - were identified in the two years after the election of Trump (Southern Poverty Law Center, 2018). Garcia and Johnston-Guerrero (2015), in a content analysis of racially biased incidents on college campuses that made the news, identified 205 incidents in a five-year period alone. Some very public examples include a University of Oregon law professor who wore blackface to a party (Svrluga, 2016); a Smith College student who was questioned by police while eating lunch after her presence in a common area was called in as suspicious by an employee of the college 
("Smith College employee," 2018); and a White nationalist rally in Charlottesville, Virginia in August 2017 that culminated in violence and death (Stolberg \& Rosenthal, 2017). Further, a poll conducted by the Pew Research Center on free speech attitudes across 38 countries has shown that, while globally there was a general support for free speech, Americans were more willing than other nations to support offensive or violent speech and to disfavor limitations to speech (Wike \& Simmons, 2015).

Today's college students are graduating underprepared with the skills sets needed to support meaningful change in the environment of our politically polarized, divisive society; for students to gain these skills, they must be willing to engage in perspectivetaking and be challenged by a different point of view (Thomas \& Brower, 2018).

According to Thomas and Brower (2018), "the goal for framing learning in this way is to challenge students' assumptions and open their minds to new and diverse perspectives, particularly on the most pressing moral, social, and political issues of our time" (p. 250). A major barrier to engagement and perspective-taking are a lack of support for White students to explore their own racial privilege, which means they are not able to situate or make meaning of their privilege in an unjust society, and the related resulting impacts of an unwelcoming campus climate to students of color and the continued perpetuation of racism and White supremacy.

\section{Goals of Liberal Education to Prepare Future Leaders}

The skill building that comes with engaging in discourse lays the groundwork for participating in an academic community as well as a democratic one. Developing critical thinking and reasoning skills allows students to evaluate their own points of view for 
potential bias and truth and effectively examine the claims of others (Colby \& Sullivan, 2009). When students have the opportunity to engage with diverse peers with different perspectives from their own, it supports their own learning and growth, even if it is at times an uncomfortable process. Content knowledge, or instruction specific to a field of study or profession, is important in college, but it is not enough.

There exists a clear connection between student leadership outcomes and liberal education goals. One challenge, however, is the disconnected nature of liberal education goals from what colleges are actually assessing in their students, a focus on developing student leadership skills (Cress et al., 2001) or intentionality in delivering on these outcomes (Association of American Colleges and Universities, 2002; Colby \& Sullivan, 2009). College is a critical time for students to explore and understand their own identities and define their sense of purpose (Colby \& Sullivan, 2009). A core goal of a liberal education is to turn out graduates prepared to exercise high-quality citizenship skills and demonstrate social responsibility, which in part means that colleges should be teaching skills that allow students to responsibly engage in the context and broader world about which they are learning (Colby \& Sullivan, 2009). The imperative of colleges is to prepare the next generation of leaders, but how to effectively do so given the complexities and challenges of our modern collegiate environments continues to pose challenges to educators.

\section{Benefits of Exposure to Diverse Environments}

The benefits of exposure to diverse perspectives and environments is well understood in the literature. For example, research has shown that White students that 
have engaged in programming around racial awareness have demonstrated development; similarly, White students that regularly participated in social justice conversations better understood their own unearned privileges and how to interrupt oppressive systems (Cabrera et al., 2016). According to Nadal et al. (2014), "there are numerous studies that describe the benefits associated with campus climates that facilitate cross-racial engagement and result in a number of educational, social, and personal gains for students during and after their college careers" (p. 470).

Students from across racial backgrounds - specifically, Black, Latino, White, and Asian students - all showed positive outcomes when their informal interactions with diverse peers was assessed (Hurtado, 2006). In terms of knowledge creation, Hurtado (2006) further hypothesizes that "diversity in the student body provides the kind of experience base and discontinuity needed to evince more active thinking processes among students, moving them from their own embedded worldviews to consider those of another" (p. 189). Further, the very presence of diverse students on campus reduces the incidents of targeted incidents relative to gender and race, and helps create a community where diverse members are valued (Vander Putten, 2001). Higher education does and should continue to have a vested interest in supporting the exposure of all students to different perspectives throughout their time in college, in order to promote opportunities for learning and growth while developing the skills they will need as citizen-leaders postgraduation. This also means that colleges must work actively to create and promote environments that fosters civility and democracy where multiple perspectives are represented. 


\section{Inhibitors of Development for White Students}

College is a critical time rich in experiences that facilitate student development, not only in terms of skill development, the ability to think more complexly, and in content knowledge, but also in students' understanding of their own identities and orientation in the broader world. For many White students, this may be the first time that they have confronted their own racial privilege and considered concepts like systemic racism. In order to fully be prepared to meaningfully participate in post-college society with a goal of racial justice, it is important that White students first recognize their own privileges and the existence of racial injustice. However, a common experience for White students is a lack of awareness or misunderstanding of racial inequalities, and institutional environments can play a role in insulating White students and perpetuating these perspectives (Cabrera, 2014; Jayakumar, 2015). Jayakumar (2015) describes a phenomenon in the literature called colorblindness that prevents White students from seeing racial inequities and even denying the existence of racism; this study will refer to this concept as race neutrality in order to avoid the ableist connotations of the word cited largely in the literature. DiAngelo (2018) describes this concept this way:

Whiteness rests upon a foundational premise: the definition of whites as the norm or standard for human, and people of color as a deviation from that norm. Whiteness is not acknowledged by white people, and the white reference point is assumed to be universal and is imposed on everyone. (p. 25)

According to Cabrera (2014), "white privilege allowed [study participants] to racially insulate, concurrently denying the power of racism in contemporary society" (p. 51). This, in turn, reinforces White supremacy through the concept of sincere fiction; in other words, "when whites do not realize the privileges conferred by their race, they can 
construe many of their social, political, and economic statuses as natural and their achievements as solely the products of individual merit" (Hikido \& Murray, 2016, p. 392).

In the discussion of safe dialogic spaces for students, Cabrera et al. (2016) persuasively argue that the concept of a safe space means different things to White students compared to students of color. For White students, this concept refers to the idea that they can be free from uncomfortable conversations, which is an unrealistic expectation in a higher education environment where we work to expose students to different perspectives and new ideas. Additionally, Cabrera et al. (2016) assert that "the demand, especially in cross-racial interactions, for White students to feel safe and comfortable frequently leads to micro- and macroaggressions being enacted upon Students of Color (Leonard \& Porter, 2010)" (p. 127). In other words, deferring to White students' sense of comfort in higher education environments is often done at the expense of students of color.

By shielding White students from engaging critically in perspective-taking and critical thinking, not only will they fail to develop the skills to engage in difficult conversations and problem solve post-college, but they also arguably miss out on developmental tasks necessary for their own racial identity development. Worse, by not creating intentional opportunities for students to critically examine their dominant identities and the intersectionality with others' perspectives, White students may not only miss the opportunity to identify oppression and work to dismantle it, but they may also perpetuate racism and White supremacy in college and post-graduation (Hikido \& 
Murray, 2016). According to Sensoy and DiAngelo (2017), "the way we make sense of our world... is often invisible to us. But we cannot address issues of critical social justice without first examining the maps we are using to identify the problem and conceptualize its solutions" (p. 28).

Students who are not able to engage in the confrontation of their own unearned privileges will fail to understand how racism is at play systemically because they cannot recognize it when it happens, and will likely continue to unknowingly perpetuate racist practices. Cabrera et al. (2016) describe this effect as "ontological expansiveness;" that is, a lack of awareness of their own unearned privilege that in turn entitles them by their race to participate in all aspects of campus life freely without fear of reprisal (p. 121). One of the challenges of ontological expansiveness is that when work is being done to achieve equitable environments and practices, those with dominant identities may feel that their own privileges are threatened - even though these privileges are unearned. By engaging in perspective taking, and supporting students to think critically about their own identities, we can help support their own development: "Cabrera (2012) argues that for White students to develop their racial selves, they must work through their Whiteness where being a racial-justice ally is a process engaged in as opposed to an end achieved (Helms, 1990)" (Cabrera et al., 2016, p. 129).

\section{Microaggressive Campus Climate and Harm to Students of Color}

Attending to civility and the support of effective dialogic practices are critical tasks for higher education, but microaggressive campus climates can impede this goal. Sue et al. (2007) describe microaggressions as "brief, everyday exchanges that send 
denigrating messages to people of color because they belong to a racial minority group" (p. 273). In addition to subtler attitudes, tone, words, and actions that can communicate that students of color are not welcome, some racist behavior shows up in more overt hate speech, sometimes operating under cloak of "free speech." According to Delgado and Stefancic (2004), research has shown that allowing for hateful speech can lead to lower grades and higher dropout rates for students of color, may impact application rates of faculty of color, and may perpetuate the problem of a chilly climate by reinforcing to the speaker that the behavior is permissible. The harms that come from chilly, microaggressive campus climates to students with marginalized identities-especially students of color - are well documented, and include emotional distress, an erosion of self-esteem, and a negative impact on their overall mental health (Nadal et al., 2014). "Often, Students of Color describe their collegiate raced space as unwelcoming, psychologically damaging, and not an ideal place to learn" (Feagin, Vera, \& Imani, 1996; Solorzano, Ceja, Yosso, 2000; Sue, 2010 as cited in Cabrera et al., 2016, p. 120). Further, research suggests that "microaggressions that occur in educational settings (i.e., by professors or other students) or work settings (i.e., by employers or coworkers) may particularly hurt individuals' self-worth" (Nadal et al., 2014, p. 468). In fact, multiple studies have shown the ubiquity of microaggressions in classroom environments and on campus (Garcia \& Johnston-Guerrero, 2015; Linley, 2018; Suárez-Orozco et al., 2015). Researchers have articulated the negative academic and health effects that are produced when students of color are the targets of microaggressions; exposure to this repeated behavior takes a toll on students of color that can negatively impact their ability to 
succeed as students (Cabrera et al., 2016; Nadal et al., 2014). In order to support students of color and students from other marginalized identities not only be able to persist at the institution but also do so while thriving academically, physically, and emotionally, college leaders must do the work of identifying and eradicating aspects that contribute to a chilly campus climate.

\section{Statement of the Problem}

A college's inability to effectively respond to issues of a hostile climate, conflict in perspectives, and preparation of students to engage effectively and see value in difference not only harms members of the collegiate community, but also potentially erodes societal trust in higher education institutions. Further, it can set up a college or university to fail in its mission to effectively prepare the next generation of citizens-our current students - for participation in democratic life and citizenship post college, including how to effectively manage conflict, how to seek to understand multiple perspectives, and appropriate limits to and the self-management of the exercise of freedoms. Research has shown that interactions with diverse peers in the first three years of college, regardless of other variables or influences, contributed to "significant gains in openness to diversity and challenge;" however, researchers were left concerned about the willingness and ability of today's students to engage in such interactions (Whitt et al., 2001, p. 195). Thomas and Brower (2018) argue:

Political learning... incudes an examination of power, systems, and structures, as well as the development of skills to effect systemic change: organizing, convening, advocating, and, most significantly, collaboratively creating better systems while working across differences of social identity, ideology, and lived experiences. (p. 250) 
Given this context, it is no surprise that an emerging challenge is creating civil learning environments where students with different perspectives and opinions can first be open to learning from one another, and then actually engage in discourse that allows them to learn from and with each other. This challenge is one that higher education cannot continue to ignore if they are to fulfill institutional missions to prepare students to participate as leaders in diverse society post-graduation. This is the call to action for today's higher education administrator and educator: in an environment that is increasingly diverse and divisive, how do we foster conditions where multiple perspectives can be shared in meaningful ways that contribute to knowledge creation in democratic learning environments? How do we create these opportunities for interactions in ways that they can be practiced and role modeled by student leaders?

\section{Purpose of the Study}

The impacts and experiences of students of color and students with other marginalized identities relative to campus climate have been well documented in the literature. Further, the research shows that engaging in dialogue across diverse peers supports a variety of positive outcomes for all students; however, less is understood about how students experience and navigate conflict and controversy, or about how college and universities can leverage these opportunities to facilitate skill building for all students. Understanding the behaviors, skills, and attitudes of diverse students who engage in productive conflict and controversy is a critical and necessary step in understanding how to facilitate environments where campuses are welcoming for all students and learning is enhanced because students can think critically and consider perspectives different from 
their own. Student leaders in particular have both more opportunities for interaction across difference in co-curricular environments, and also have a unique peer influence that could be a key in developing allyship and contributing to an overall more positive campus climate for all students.

Therefore, the purpose of this study is to understand the experience of undergraduate student leaders in navigating conflict and controversy, how they make meaning of those experiences, and if those experiences contributed to their learning and development in college. Specifically, this study will examine if and how student leaders navigate conflict and controversy in their undergraduate student roles, as well as how student leaders conceptualize or view conflict and controversy in the context of an increasingly diverse and polarized college campuses and societally. This study will also identify what internal and external factors allow for conflict to be leveraged as a transformative educational opportunity.

\section{Significance of the Study}

Having a better understanding of how student leaders conceptualize and enact civil discourse is critical to creating environments that foster the identity development of majority students who may have not yet in their lives had to critically examine their own unearned privilege — an important task in the development of perspective-taking.

Similarly, understanding how student leaders can help foster and role model democratic dialogue can be one way to reduce the well-documented harms to students who experience microaggressive campus environments, while facilitating diverse spaces conducive to positive growth and change for all students. Finally, an understanding of 
how student leaders can and do conceptualize their student leader roles is instructive in understanding how student leader positions foster the development of skills sets necessary to citizen-leaders that are the product of a liberal education. Examining how student leaders make sense of and navigate conflict — and the extent to which these experiences fostered their leadership development - may be instructive to identifying internal and external factors that institutions of higher education can use to help further facilitate liberal education goals and mitigate and interrupt negative campus climates.

\section{Chapter Summary}

Chapter 1 of this study serves as the introduction. In this section, there was an overview of the problem in the context of higher education; specifically, a college's inability to effectively respond to issues of a hostile climate, conflict in perspectives, and preparation of students to engage effectively and see value in difference both harms members of the collegiate community, and also prevents colleges from fulfilling their missions to effectively prepare the next generation of citizens - our current students - for participation in democratic life and citizenship post college. The problem included a discussion of who is impacted by the problem; the impacts on White students and students of color were particularly noted. The chapter concludes with an explication of the significance of the study to the field of education; in particular, the need to better understand how student leaders experience and navigate conflict.

\section{Organization of the Study}

The remainder of this study is organized into four additional chapters. Chapter 2 further explores what previous literature tells us about liberal education goals, student 
leadership, the concept of socially responsible leadership, and discusses the Social Change Model of Leadership, the theoretical framework used for this study. In Chapter 2, concepts of conflict and controversy, challenges of conflict, and growth opportunities from conflict are explored. Chapter 3 states the research questions, describes the methodology chosen in order to thoroughly investigate those questions, and provides a justification for the methodology chosen, including protocols the researcher followed to support the study's trustworthiness. Chapter 4 presents the findings of individual interviews with 12 student leaders at the study site and introduces a new model of socially responsible leadership based on this research. Chapter 5 discusses the implications of these findings for practice, recommendations as a result of this research, and opportunities for future research. 


\section{CHAPTER TWO: LITERATURE REVIEW}

Higher education has a key role to play in educating our increasingly diverse student populations (Astin, 2016; Humphreys, 2009); however, despite their self-belief that they are open to different perspectives, many students also expressed a lack of openness to having their own views challenged (Eagan et al., 2017), which poses difficulties for colleges attempting to educate the next generation of leaders. Further, highly diverse institutional contexts can pose additional difficulties for student learning and acquisition of socially responsible leadership skills (Riutta \& Teodorescu, 2014), all critical factors impacting student development across higher education today.

Following is a review of the literature discussing liberal education goals connected with democratic education and social change as well as a review of student leadership development outcomes, and connection of these outcomes to liberal education and democratic education goals. The concept of socially responsible leadership is explored, including the theory of the Social Change Model of Leadership (SCM), which serves as the guiding theory for this study. The constructs of conflict and controversy are reviewed, specifically how they are described in the literature; associated challenges of conflict and controversy; and potential opportunities for engaging effectively in conflict and controversy, including the advancement of skills such as critical thinking and perspective-taking, empathy and emotional intelligence, and a value for difference and different perspectives. Finally, a framework for understanding how to successfully navigate conflict to promote learning called constructive controversy is explicated in order to create the foundations for this study design. 
Following is a review of the context for college students today, including a review of widely accepted liberal education goals, student leadership outcomes, and the interconnectedness of both to advance the education of future citizen-leaders.

\section{Liberal Education Goals}

Colleges have long had the distinct and important responsibility to help develop the next generation of citizen-leaders for participation in a diverse, democratic society (Barnhardt et al., 2015; Dewey, 1916). In addition to supporting students'subjectspecific knowledge to prepare for future careers, colleges are also called upon to foster students' development as citizen-leaders, including developing skills sets around critical thinking, problem solving, collaboration, and perspective-taking. According to the Association of American Colleges and Universities (2020), "in the face of political and cultural polarization... liberal education can offer a collaborative model of problem solving that demonstrates the value of expertise applied in service to community" (p. 5). In The Student Personnel Point of View, the American Council on Education (1949) advocated for skill development through collegiate experiences, including

[acquisition of] an appreciation of cultural values, the ability to adapt to changing social conditions, motivation to seek and to create desirable social changes, emotional control to direct his activities, moral and ethical values for himself and for his community, standards and habits of personal physical well-being, and the ability to choose a vocation which makes maximum use of his talents and enables him to make appropriate contributions to his society. (p. 3)

According to Bowen (1997), educational goals for students are attended to not only through curricular, content-area knowledge, "but also all those influences upon students flowing from association with peers and faculty members and from the many and varied experiences of campus life" (p. 33). He goes on to categorize the goals of 
higher education across three domains: cognitive learning, affective development (that is, "enhancing their moral, religious, and emotional interests and sensibilities"), and practical competence (that is, "improving their performance in citizenship, work, family life, consumer choice, health, and other practical affairs") (Bowen, 1997, p. 39). According to a report issued by the Association of American Colleges and Universities (2002):

Throughout its history, the United States has asked much of higher education: to prepare leaders, train employees, provide the creative base for scientific and artistic discovery, transmit past culture, create new knowledge, redress the legacies of discrimination, and ensure continuation of democratic principles. The balance among these needs has shifted over time in response to many factors and will undoubtedly continue to do so. (p. iii)

Before the development and assertion of liberal education goals by the Association of American Colleges and Universities, Howard Bowen (1997) conceptualized goals for individual students as a synthesis of the literature on learning in higher education. He argued that education goals should be focused on education of the whole person through the interdependent dimensions of cognitive/intellectual development, affective skills, and practical competence. In the dimension of cognitive learning, Bowen (1997) categorized such skills as verbal and written communication; quantitative (mathematic) skills; "substantive knowledge" of "the cultural heritage of the West and some knowledge of other traditions," as well as in a few other selected fields of knowledge; rationality; intellectual tolerance; esthetic sensibility; creativeness; intellectual integrity; wisdom; and lifelong learning (pp. 55-56). He categorized under emotional and moral development skills sets of personal self-discovery, psychological well-being, human understanding, values and morals, religious interest, and "refinement of taste, conduct, and manner;" in 
the domain of practical competence, he categorized the following skills: "traits of value in practical affairs generally," citizenship, economic productivity, sound family life, fruitful leisure, and health (Bowen, 1997, pp. 56-58).

Liberal education goals include a specific set of skills institutions should be striving to cultivate in students. As a result of the Greater Expectations report (Association of American Colleges and Universities, 2002) and the Liberal Education and America's Promise (LEAP) initiative (Association of American Colleges and Universities, 2007), the AAC\&U restated classical educational ideals or domains that characterize an "excellent education," including intellectual development, "ethical and civic preparation," and "personal growth and self-direction" (Humphreys, 2009, p. 16). Further, the AAC\&U has laid out fundamental learning outcomes for students enrolled in college, including “inquiry and analysis, critical and creative thinking, teamwork and problem solving.... Civic knowledge and engagement, intercultural knowledge and competence," and "ethical reasoning and action," to name a few (Association of American Colleges and Universities, 2007; Humphreys, 2009). The AAC\&U also focused attention on the domain of personal and social responsibility through a set of skills called "Core Commitments;" specifically, they identified these dimensions as "developing a strong work ethic," "cultivating personal and academic integrity," "contributing to a larger community," "engaging diverse and competing perspectives as a resource for learning, citizenship, and work," and "developing ethical and moral reasoning" (see Table 2.1 for a full listing of the learning outcomes, from the Association 
of American Colleges and Universities, 2007, p. 3) (Association of American Colleges

and Universities, 2007; Colby \& Sullivan, 2009).

\section{Table 2.1}

The American Association of Colleges and Universities' Essential Learning Outcomes for

\section{a Liberal Education}

\section{THE ESSENTIAL LEARNING OUTCOMES challenges by gaining: humanities, histories, languages, and the arts and enduring \\ INTELLECTUAL AND PRACTICAL SKILLS, INCLUDING \\ - Inquiry and analysis \\ - Critical and creative thinking \\ - Written and oral communication \\ - Quantitative literacy \\ - Information literacy \\ - Teamwork and problem solving}

Beginning in school, and continuing at successively higher levels across their college studies, students should prepare for twenty-first-century

\section{KNOWLEDGE OF HUMAN CULTURES AND THE PHYSICAL AND NATURAL WORLD}

- Through study in the sciences and mathematics, social sciences,

Focused by engagement with big questions, both contemporary

Practiced extensively, across the curriculum, in the context of progressively more challenging problems, projects, and standards for performance

\section{PERSONAL AND SOCIAL RESPONSIBILITY, INCLUDING}

- Civic knowledge and engagement-local and global

- Intercultural knowledge and competence

- Ethical reasoning and action

- Foundations and skills for lifelong learning

Anchored through active involvement with diverse communities and real-world challenges

\section{INTEGRATIVE LEARNING, INCLUDING}

- Synthesis and advanced accomplishment across general and specialized studies

Demonstrated through the application of knowledge, skills, and responsibilities to new settings and complex problems

Note. From Association of American Colleges and Universities (AAC\&U) (2007), p. 3. 
Association of American Colleges and Universities (2007). College learning for the new global century: A report from the National Leadership Council for Liberal Education \& America's Promise. Washington, D.C.: AAC\&U.

In fact, many colleges codify a commitment to developing the leadership of their students in their institutional mission statements (Grunwell, 2015; Ouimet \& Pike, 2008). The presumption is that if liberal education goals are met, then college students will be prepared to collaboratively take on the significant challenges facing society and effectively enact social change (Manning, 2013). Rittel and Webber (1973), upon reflection of the upheaval of social change movements of the 1960s that included fights for civil rights and the anti-war movement, recognized that such collective action was indicative of a response to what they coined "wicked problems;" that is, those that "are ill-defined" and "rely upon elusive political judgment for resolution" (p. 160). Examples of such wicked problems include "global warming, religious and ethnic conflict, the maldistribution of wealth and opportunity, the decline of citizen interest and engagement in the political process, the increasing ineffectiveness of government, and the shift... from a national to a global economy" (Astin \& Astin, 2000, p. 1). Higher education institutions are called upon to develop both the content knowledge for students to succeed in the workforce, but also attitudes, behaviors, and skills that will serve them as civically engaged citizen-leaders prepared to participate in a democratic society.

Liberal education outcomes, democratic learning, and civic engagement and identity are overlapping and interconnected concepts that support the affective learning goals colleges and universities have for students. These principles are also closely linked with leadership education principles and goals for student leader education on college 
campuses. In her essay on the topic, Manning $\square$ Ouellette (2018) states: “As society continues to face challenges that require cross-disciplinary approaches, leadership education and democratic learning offer innovative approaches to addressing larger systemic problems" (p. 76). Following is a brief review of the importance of student leadership outcomes for higher education, a discussion of the definition of leadership, and the introduction of the concept of socially responsible leadership.

\section{Student Leadership Outcomes}

Student leadership development goals closely align with the expectations for a liberal and democratic education. According to Manning $\square$ Ouellette (2018), "Democratic engagement, an anticipated outcome of higher education, encompasses an array of skills and capacities that aligns well with leadership education.... Leadership education has long been associated with democratic education and the call to cultivate engaged citizens" (pp. 75-76). In a study reviewing elements in institutional mission statements, Morphew and Hartley (2006) identified that across doctoral-granting institutions, "civic duty/service" was one of three of the most common elements cited in mission statements at public/research-intensive and private/research-extensive, and "leadership" was one of the three most common elements cited in private/research-extensive mission statements, demonstrating both the importance and interconnectedness of these concepts in higher education. Further, there is a clear call for colleges to help facilitate the development of leadership skills in students. According to the Higher Education Research Institute (1996),

Co-curricular experiences not only support and augment the students' formal classroom and curricular experience, but can also create powerful learning 
opportunities for leadership development through collaborative group projects that serve the institution or community. These projects can be implemented through residential living, service learning, community work, and student organizations, or through groups created to meet the challenges of our present situations (task forces, ad hoc study groups, etc.). (p. 16)

This description suggests that co-curricular student leader experiences are important to fostering leadership skill development in college students. Student leadership programs, activities, and experiences on college campuses are vast and diverse, but share the goal of facilitating leadership skills in college students. In a formative, longitudinal study by Cress et al. (2001) on the development and learning outcomes of college students involved in leadership, they administered a survey that conceptualized the following measures as leadership outcomes:

Understanding of self; ability to set goals; interest in developing leadership in others; commitment to civic responsibility; sense of personal ethics; clarity of personal values; conflict resolution skills; decision-making abilities; ability to deal with complexity, uncertainty, and ambiguity; ability to plan and implement programs and activities; willingness to take risks; [and] understanding of leadership theories. (p. 17)

Findings from the study showed that students that participated in leadership programs in college had statistically significant gains in their understanding of theories of leadership and encouraging leadership in others; were "more likely to develop a sense of Civic Responsibility;" saw an increased "development of Multicultural Awareness and Community Orientation;" and were more likely to develop Leadership Skills, including ability to manage ambiguity and decision-making (Cress et al., 2001, p. 22). These gains held true regardless of gender or racial/ethnic identity (Cress et al., 2001). Further, Cress et al. (2001) also found that the activities that most facilitated this development included volunteering, interning, or working collaboratively in class. 
The following section will review the components that help define student leadership, and will review the theoretical framework of the Social Change Model of Leadership (SCM) that serves as the primary theoretical model of the study and which informs the working definition of socially responsible leadership, which is premised as the primary developmental outcome of a college graduate, encompassing liberal education goals and student leadership development goals.

\section{Definition of Leadership}

Leadership has been conceptualized many different ways over centuries, with more modern notions of leadership moving away from industrial hierarchical and maledominated conceptualizations of leadership as management, and acknowledging leadership instead as an interdependent, transformational process that is about more than individual goal attainment (Komives \& Wagner, 2009). The authors of the Social Change Model (SCM) of Leadership describe the qualities of leaders as not being necessarily positional, but as a collaborative and interdependent process based on shared values that promote positive social change (Higher Education Research Institute, 1996). Leadership activities include volunteerism or community service, peer mentoring, serving in an elected position, participating in student leadership trainings or workshops, among others (Cress et al., 2001). Leadership in college, then, could be conceptualized as a position, a process, and an outcome, depending on the context and the framework adopted. Any student could conceivably be a leader, and colleges provide optimal opportunities to help support and develop leadership skills sets in students. 
Several characteristics have been identified in the literature as being connected to student leadership development in college, and socially responsible leadership in particular - a functional outcome of the Social Change Model (SCM) of leadership, discussed later in this section-is grounded in concepts of positive social change and collaboration that directly aligns with democratic learning goals. As stated by Manning $\square$ Ouellette (2018) in her essay on democracy education and student leadership, "As society continues to face challenges that require cross-disciplinary approaches, leadership education and democratic learning offer innovative approaches to addressing larger systemic problems" (p. 76).

The research comports with calls to action that are as timeless as the field of student personnel itself. In a foundational document for the field of student affairs, the Student Personnel Point of View, states that a new goal of education is "for the application of creative imagination and trained intelligence to the solution of social problems and to the administration of public affairs" (American Council on Education, 1949, p. 1). Student affairs administrators are further called to develop via collegiate experiences the "ability to adapt to changing social conditions [and] motivation to seek and to create desirable social changes" (American Council on Education, 1949, p. 3). Given that student affairs professionals' main domains are in co-curricular and extracurricular contexts, a strategic method for fostering these skills sets in students include experiences like leadership opportunities, organizational and club membership, paraprofessional roles, and through participation in programs, events, and service. 
Given the important role that student leadership plays individually and collectively, there is a significant opportunity to leverage the role of peer leaders for positive change by understanding their experiences in supporting civil discourse.

Following is a more in-depth discussion of the concept of socially responsible leadership and the theoretical framework of the Social Change Model (SCM) of Leadership.

\section{Socially Responsible Leadership}

In this increasingly connected, global, and diverse information age, ideas of leadership have also changed to include shared-power notions of leadership, and a focus on leadership for the common good has become more prevalent. In early writings on this concept, Bryson and Crosby (1992) described mounting, confounding, and seemingly insurmountable problems and the role of leadership to respond to them, saying

...in order to marshal the legitimacy, power, authority, and knowledge required to tackle any major public issue, organizations and institutions must join forces in a 'shared-power' world... If public leaders are to accept the challenge to make the world better, they must find ways to think and act more effectively in sharedpower contexts. (p. 4)

The concept of socially responsible leadership brings together the ideas of working productively and collaboratively together with the shared end goal of supporting the common good, in part by attending to the root causes of problems in order to affect meaningful social change (Wagner, 2017). Wagner (2009) defines socially responsible leadership as "an approach to leadership that maintains a sense of responsibility for the welfare of others as the group goes about its business.... [it] means operating with an awareness of the ways in which the group's decisions and actions affect others" (p 33). Socially responsible leadership acknowledges that the issues facing society require a 
collective effort to resolve them, and that "working for social change and doing leadership both imply collaborative effort, or people working together toward shared goals" (Wagner, 2009, p. 34).

The importance of developing capacities for socially responsible leadership is evident, but not without challenges. Increasing diversity on campus and societally means a corresponding increase in the diverse perspectives, talents, and skills sets brought to bear on problems. This can both enhance a problem-solving process but also pose additional challenges as people learn how to work collaboratively with others who are different from them. Riutta and Teodorescu (2014) note: "One can anticipate that in a high diversity context the learning and demonstration of socially responsible leadership skills are more challenging.... This is because leading diverse groups often requires more complex communication and interpersonal skills than does leading homogenous groups" (p. 831). There is some evidence of how colleges can increase the capacity for socially responsible leadership in students. One way is to increase diversity course offerings. According to study findings by Barnhardt (2015), "diversity course requirements have a role in creating a campus context that is a place where socially responsible action and mobilization actually occurs" (p. 60). Further, in a different, mixed-methods study on college student acquisition of capacity for civic engagement, Barnhardt et al. (2015) found that students that perceived that their campuses advocated for and supported the goal of its students to become involved citizens had increased civic engagement commitments and capacities. The researchers promote the idea that students have the opportunity to use their experiences on campus as a means to apply learning about their 
social responsibility (Barnhardt et al., 2015), a useful tool to promote skill-building around civic engagement.

From the early conceptualizations of leadership for social change came a theoretical model known as the Social Change Model of Leadership (SCM) (Higher Education Research Institute, 1996). Under a grant from the Eisenhower Leadership Development program of the US Department of Education in 1993, the developers of the SCM out of the University of California, Los Angeles' Higher Education Research Institute began the work of creating "a model of leadership development for undergraduate college students" (Higher Education Research Institute, 1996, p. 10). Informed by the value of leadership for change for societal good, and premised on leadership studies that had as concepts shared power, collective action, qualities of emotional intelligence, and social justice, the SCM "explains and outlines in detail a 'leadership process' that maximizes the principles of equity, inclusion, and service” (Higher Education Research Institute, 1996, p. 12). Following is a more detailed review of the Social Change Model of Leadership and the Model's components.

\section{Social Change Model of Leadership}

Dugan (2015) describes the increasing imperative of colleges to intentionally foster leadership development of graduates who will go on to be citizen-leaders as a necessary educational outcome, rather than hoping for leadership development as a byproduct of education. The resulting increased research activity stemming from this imperative has led to the development of the concept of socially responsible leadership, which comes from a model of social change-focused leadership called the Social Change 
Model of Leadership (Higher Education Research Institute, 1996). According to Dugan (2015), the approach is "among the few... employed in education with clear definitional/theoretical foundations, empirically supported literature, and practical applications" (p. 24).

Wagner (2009) described the Social Change Model of Leadership as "an approach to leadership that is collaborative rather than coercive, civil and respectful rather than defensive, open to different perspectives rather than controlling and single-minded, and clear and consistent about values rather than hypocritical" (p. 33). The SCM "approaches leadership as a purposeful, collaborative, values-based process that results in positive social change" (Komives \& Wagner, 2009, p. xii). The SCM advocates specific skills, behaviors, and attitudes connected with leadership as a process with a goal of positive social change. The values (or attitudes) of the model include "equity, social justice, self-knowledge, personal empowerment, collaboration, citizenship, and service" (Higher Education Research Institute, 1996, p. 18). The model does this through seeking to develop two specific behaviors of students: self-knowledge, defined as “understanding of one's talents, values, and interests, especially as these relate to the student's capacity to provide effective leadership," and leadership competence, or "the capacity to mobilize oneself and others to serve and to work collaboratively" (Higher Education Research Institute, 1996, p. 19).

This framework examines leadership across seven dimensions called "the Seven C's" that are grouped in three clusters: individual values of Consciousness of Self, Congruence, and Commitment; group values of Collaboration, Common Purpose, 
and Controversy with Civility; and the societal/community value of Citizenship, all working to support the eventual goal of social Change (Higher Education Research Institute, 1996). These can also be translated as skills or capacities student leaders need to possess in order to demonstrate socially responsible leadership in order to advance social change. The model is concerned particularly with developing self-awareness and capacity for mobilization of a group to "facilitate positive social change" (Komives \& Wagner, 2009, p. xiii) (see Figure 2.1, from Owen, 2012, p. 5).

\section{Figure 2.1}

Relationship Between the Values of the Social Change Model (SCM) of Leadership

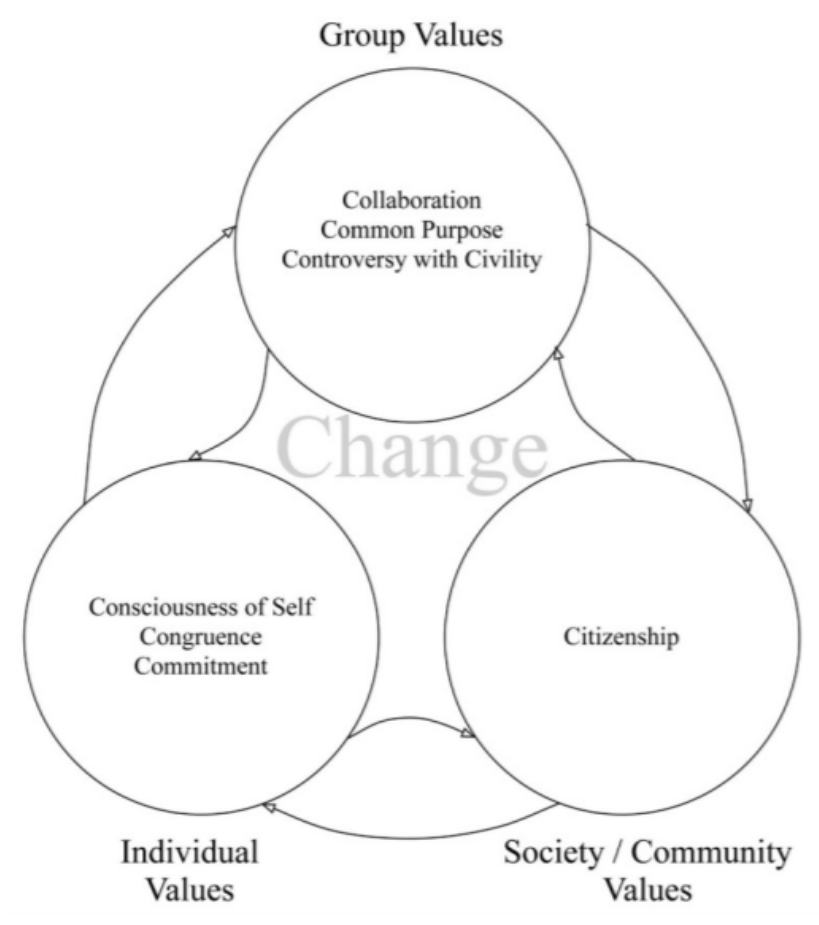

Note: From the Higher Education Research Institute (HERI) (1996). A social change model of leadership development. College Park, MD: National Clearinghouse for Leadership Programs. Adaptation of this model in this figure from Owen, J.E. (2012). Findings from the Multi-Institutional Study of Leadership institutional survey: A national report. College Park, MD: National Clearinghouse for Leadership Programs. 
The SCM is predicated on relationships as part of a collaborative process. In addition, growth and development is happening continuously across all of the values, because of the interactive nature of the values (Cilente Skendall, 2017). The assumption of the model is that "Growth in one value increases the capacity for growth in the others" (Cilente Skendall, 2017, p. 20). However, recent research indicates that the capacities at each level are sequential and follows a developmental pathway in which capacity in individual values supports development of capacity in group values, and capacity in group values supports the development of capacity of the society/community value (Dugan et al., 2013). Table 2.2 presents a description of each of the values as described by the (Higher Education Research Institute, 1996). 
Table 2.2

Descriptions of the Social Change Model of Leadership Development Core Values

\begin{tabular}{|c|c|}
\hline & The Critical Values of the Social Change Model \\
\hline INDIVIDUAL VALUES & \\
\hline Consciousness of Self & $\begin{array}{l}\text { Being self-aware of the beliefs, values, attitudes, and emotions that motivate you to } \\
\text { take action. Being mindful, or aware of your current emotional state, behavior, and } \\
\text { perceptual lenses. }\end{array}$ \\
\hline Congruence & $\begin{array}{l}\text { Acting in ways that are consistent with your values and beliefs. Thinking, Feeling, and } \\
\text { behaving with consistency, genuineness, authenticity, and honesty toward others. }\end{array}$ \\
\hline Commitment & $\begin{array}{l}\text { Having significant investment in an idea or person, both in terms of intensity and } \\
\text { duration. Having the energy to serve the group and its goals. Commitment originates } \\
\text { from within, but others can create an environment that supports an individual's } \\
\text { passions. }\end{array}$ \\
\hline GROUP VALUES & \\
\hline Collaboration & $\begin{array}{l}\text { Working with others in a common effort, sharing responsibility, authority, and } \\
\text { accountability. Multiplying group effectiveness by capitalizing on various perspectives } \\
\text { and talents, and on the power of diversity to generate creative solutions and actions. }\end{array}$ \\
\hline Common Purpose & $\begin{array}{l}\text { Having shared aims and values. Involving others in building a group's vision and } \\
\text { purpose. }\end{array}$ \\
\hline Controversy with Civility & $\begin{array}{l}\text { Recognizing two fundamental realities of any creative effort: 1) that differences in } \\
\text { viewpoint are inevitable, and 2) that such differences must be aired openly but with } \\
\text { civility. }\end{array}$ \\
\hline COMMUNITY VALUES & \\
\hline Citizenship & $\begin{array}{l}\text { Believing in a process whereby an individual and/or a group become responsibly } \\
\text { connected to the community and to society through some activity. Recognizing that } \\
\text { members of communities are not independent, but interdependent. Recognizing } \\
\text { individuals and groups have responsibility for the welfare of others. }\end{array}$ \\
\hline Since it is a key as & $\begin{array}{l}\text { mption of the SCM that the ultimate goal of leadership is positive social change, } \\
\text { "change" is considered to be at the "hub" of the model }\end{array}$ \\
\hline Change & $\begin{array}{l}\text { Believing in the importance of making a better world and a better society for oneself } \\
\text { and others. Believing that individuals, groups and communities have the ability to } \\
\text { work together to make that change. }\end{array}$ \\
\hline
\end{tabular}

(Adapted from Higher Education Research Institute, 1996, p. 21; Tyree, 1998, p. 176; and Astin, p. 6-7)

Note. These descriptions of the Social Change Model (SCM) of Leadership core values are based on work by the Higher Education Research Institute (HERI), (1996). A social change model of leadership development. College Park, MD: National Clearinghouse for Leadership Programs. Also, as noted, these are adapted by J.E. Owen (2012), p. 6.

The dimension of Society/Community includes the value of Citizenship, which

"acknowledges the interdependence of all who are involved in or affected by

[leadership activity] efforts" (Higher Education Research Institute, 1996, p. 23). The

dimension of Group includes the values of Collaboration, Common Purpose, and 
Controversy with Civility. The model frames group effectiveness in supporting social change relative to these values. In particular, the Higher Education Research Institute (1996) notes that the concept Controversy with Civility assumes that conflict is unavoidable, and that these differences must be managed civilly. Within the SCM, “civility implies respect for others, a willingness to hear each other's views, and the exercise of restraint in criticizing the views and actions of others" (Higher Education Research Institute, 1996, p. 23). Finally, the model assumes a need for effort at the Individual level across the values of Consciousness of Self, Congruence, and Commitment to promote leadership. Consciousness of Self, according to the model, "means being aware of the beliefs, values, attitudes, and emotions that motivate one to take action" (Higher Education Research Institute, 1996, p. 22). This concept has to do with self-awareness and reflection that are essential to working effectively with others and developing capacity for leadership (Komives \& Wagner, 2009), a concept closely aligned with student development, leadership development, and liberal education goals.

Research done using data from the Multi-Institutional Study of Leadership (MSL) has indicated that the individual values have a strong influence on group values, group values have an influence on societal values, but no relationship exists between individual and societal values directly (Dugan et al., 2013), further highlighting the importance of the group values and dynamic in advancing progress toward social change. Additionally, the same study found that "social perspectivetaking serves as a critical mediator of development between the individual and group 
domain" (Dugan et al., 2013, p. 28). The roles of both social perspective-taking and socio-cultural conversations in advancing socially responsible leadership skills align with concepts of constructivist approaches to development (discussed later in this chapter) as well as the importance and value of pluralistic orientations.

In a report issued reviewing Multi-Institutional Study of Leadership (MSL) data, a specific set of high-impact practices were identified as influencing the development of socially-responsible leadership in college students; the impact of these practices are dependent on the racial group of students, with socio-cultural conversations seeing a positive influence across every racial group surveyed (see Figure 2.2) (Dugan et al., 2013, p. 8). The authors define leadership as "grounded using the Social Change Model of Leadership and defined by the MSL as a values-based process in which people work collaboratively toward the purpose of creating positive social change" (Dugan et al., 2013, p. 6). A key finding advocated by these authors was that the delivery of the educational content — in other words, the "how" behind program delivery — was more critical for fostering leadership development than the "what"- the actual practices themselves (Dugan et al., 2013). Socio-cultural conversations with peers, mentoring relationships, community service, and memberships in off-campus organizations are the practices that have had the greatest influence on the development of socially responsible leadership across various demographics (Dugan et al., 2013). 


\section{Figure 2.2}

Practices with High Impact on the Development of SRL by Racial Group

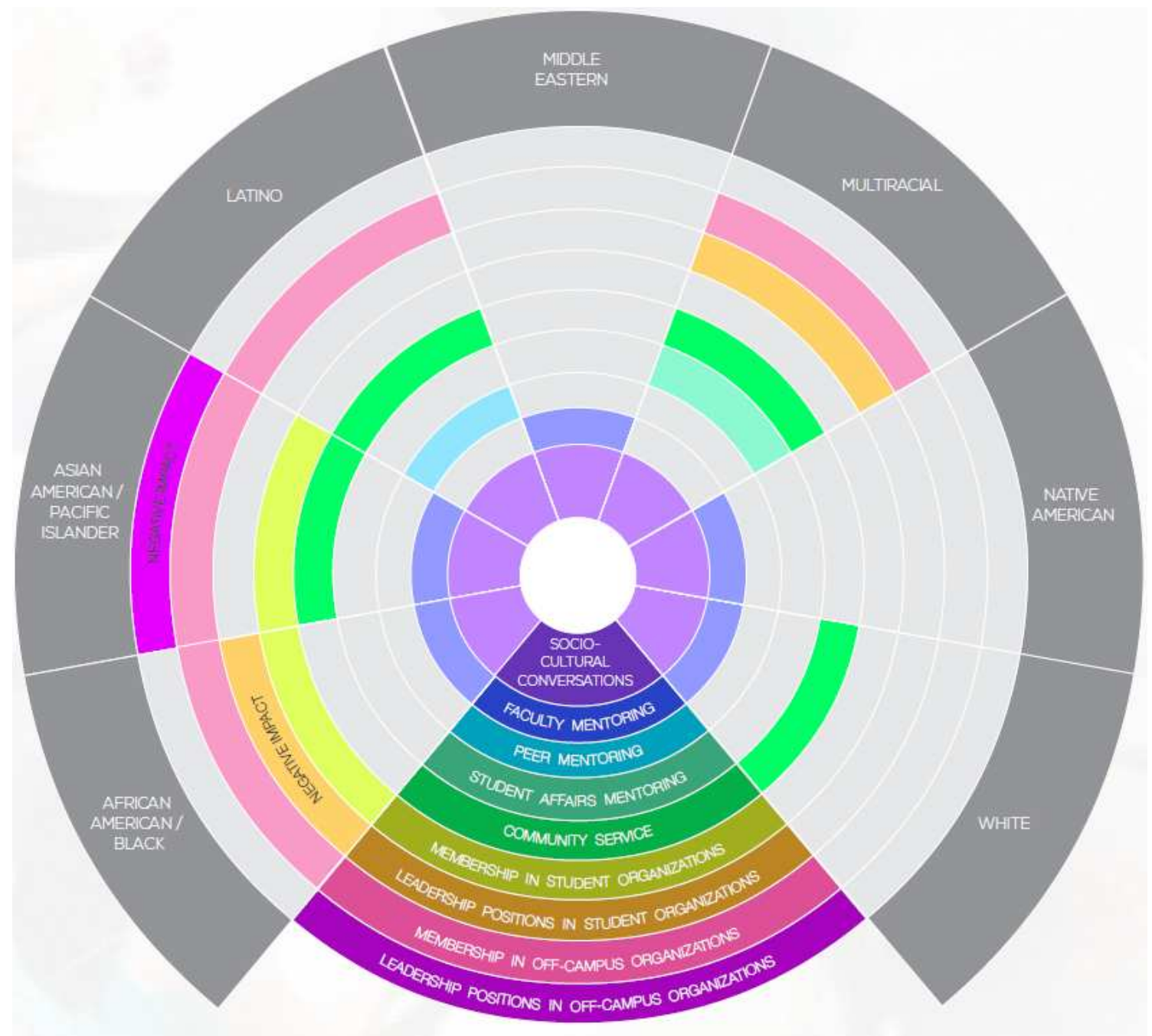

Note: Cited in Dugan, J.P., Kodama, C., Correia, B., \& Associates. (2013). MultiInstitutional Study of Leadership insight report: Leadership program delivery. College Park, MD: National Clearinghouse of Leadership Programs.

Dugan et al. (2013) also explored the extent to which leadership self-efficacy in college students was cultivated by high impact leadership practices. According to Dugan et al. (2013), "efficacy examines individuals' internal beliefs and assessments of their 
likelihood of success when engaging in a particular task. Leadership self-efficacy (LSE) extends this scholarship to the specific domains of the leader role and the process of leadership;" in other words, LSE represents the difference between if a student "could do something and whether they did do something” (p. 20). LSE mediates students' willingness to engage in leadership, and also "is a key predictor of gains in leadership capacity" (Dugan et al., 2013, p. 20). An important finding from the study was that growth in LSE was fostered for almost all demographic groups in two high impact leadership practices: positional leadership roles and socio-cultural conversations (Dugan et al., 2013). Given the clear demonstration of socio-cultural conversations and social perspective-taking on facilitating growth in student leadership (Dugan et al., 2013), these conversations and perspective-taking across diverse peers are experiences that should explored in order to leverage for student leadership development.

\section{Socially Responsible Leadership Scale}

Soon after the development of the Social Change Model of Leadership, an instrument was developed that was designed to measure socially responsible leadership across the SCM dimensions, called the Socially Responsible Leadership Scale (SRLS) (Tyree, 1998). The resulting tool had 104-items and was analyzed using statistical software, which hindered its widespread use until Dugan published two peer-reviewed studies that used an 103-item version of the SRLS in 2006; these studies were the first to indicate reliability of the instrument to other institutions in the United States (Dugan, 2015). 
Because of development and iterations of the Socially Responsible Leadership Scale (SRLS), much of the research on the development of socially responsible leadership in college students is quantitative; qualitative understandings of socially responsible leadership measures are less common in the literature, which creates a gap of contextual understanding of the lived experiences of student leaders on college campuses within this framework. However, the SCM also provides a useful frame for guiding qualitative exploration of the experiences of undergraduate student leaders navigating conflict. The values advanced in the model can be mapped to strategies and values that student leaders themselves describe having used to navigate difficult peerto-peer conflict situations, and informed a list of provisional or a priori codes to explore qualitative stories told by students via interviews (discussed in Chapter 3). Further, the SCM provides a theoretical grounding for the concept of socially responsible leadership, which aligns with liberal education goals.

Liberal education, democratic education, and student leadership are important goals for the preparation of students who will graduate and be asked to participate as citizen leaders, what some refer to as civic engagement. As our society becomes increasingly diverse, we have the opportunity to develop more creative, useful solutions for challenging societal issues by gleaning insight from diverse perspectives. However, this difference of perspectives can lead to conflict and controversy, and by avoiding conflict or by not managing it well, colleges run the risk of losing out on meaningful learning and development that difference can foster. Following is a brief review of what 
is meant by conflict and controversy, the challenges and growth opportunities of conflict, and one model of how students can successfully work through conflict.

\section{Conflict and Controversy}

In an age of extreme partisanship, political polarization, increasing diversity, and navigating the shift from an industrialized to a knowledge economy, there is evidence that student participation civically is declining, and students may be avoidant of conflict. A brief discussion of the elements of conflict and how conflict and controversy helps frame the role that conflict and controversy can have in advancing student learning and development.

\section{Definition of Conflict and Controversy}

At the heart of navigating difference of opinions are conflict of perspectives, lived experiences, and other factors that can make the task of group problem solving especially fraught with challenges. Interpersonal conflicts can take many different forms including argument, disagreeable communication, hostile episode, and pervasive tension (Solomon $\&$ Theiss, 2013); however, conflicts have in common three components: disagreement, interference (or the belief that someone is negatively impacting the interests of another person), and negative emotion (Barki \& Hartwick, 2004). The authors further describe escalation strategies in conflict scenarios, indicating that placing blame on the other party in a conflict can lead to escalation (Solomon \& Theiss, 2013). Within the Social Change Model (SCM) of Leadership, conflict is identified as having two opposing sides that require individuals to take a position, while controversy is identified as more of a dialogue or discourse around an idea, without a commitment to a position; in other words, 
conflict is about winning, and controversy is about perspective-taking to enhance a final outcome (Alvarez, 2009).

In their study on adolescent same-sex friendships and conflict, de Wied et al. (2007) found that using empathy was positively associated with problem-solving strategies of conflict resolution, and negatively linked to engagement in destructive conflict strategies, regardless of sex. In situations where differences of opinion escalate into conflict and blaming, uncivil interactions may be an outcome. In the SCM, civility is regarded as a value, an attitude, and a behavior, and is an essential component for creating a respectful environment that honors and seeks different perspectives (Alvarez, 2009).

While conflict is inevitable, there is little information about how students in college experience, make sense of, and navigate conflict, if at all. Further, while a popular assumption in higher education is that an opportunity of engaging in conflict and controversy facilitates learning and development, because of a lack of scholarship on conflict and college students, not much is understood about what internal and external factors help facilitate such learning and development. The primary goals of this study were to understand how students define, experience, and navigate conflict, and what factors in conflict situations facilitate their development, particularly of their socially responsible leadership skills. The next section explores more in depth the challenges that college students experience in navigating conflict and controversy on campus. 


\section{Challenges of Conflict and Controversy}

Conflict and controversy is inevitable on our complex, diverse college campuses, and if managed well, can help promote learning and development. However, several barriers exist that may lead to harms from conflict, or that may prevent students from engaging in conflict altogether. These challenges include a hostile climate experienced by diverse students on campus that may make them hesitant to share their perspectives, especially if different from the dominant perspective; students' insulation from different perspectives and their own self-belief that they are open to different points of view, even when that may not be the case; political polarity and divisiveness; and incivility in conflict interactions that may lead to conflict avoidance. Following is a more in-depth review of each of these challenges.

\section{Chilly Campus Climate}

Over the last half of the $20^{\text {th }}$ century and into the $21^{\text {st }}$ century, colleges have become increasingly diverse thanks to social, political, and policy efforts to increase access to higher education. Understanding how the climate of a campus is experienced by students is significant because if students perceive that campuses are supportive environments, there is a positive impact on student learning and social outcomes (Rankin \& Reason, 2005). This is important to consider given the data on polarization and interpolitical party friendships. If this polarization leads to self-segregation with others who are aligned ideologically, there is a potential for a worse climate for underrepresented students (as well as underrepresented faculty and staff) on campus. In the study conducted by Rankin and Reason (2005), climate was used to describe "the current 
perceptions and attitudes of faculty, staff, and students regarding issues of diversity on a campus" (p. 48). Cress (2008) describes campus climate as "the metaphorical temperature gauge by which we measure a welcoming and receptive, versus a cool and alienating learning environment" (p. 96).

Climate is key to understanding and creating communities on campus where students can have modeled for them and, in turn, practice their own skills in contributing to positive democratic communities in the future beyond the grounds of a college or university (Cress, 2008). In Rankin and Reason's (2005) study on how students on 10 different campuses perceived their campus climate based on a campus climate assessment instrument, they found that students of color perceived at greater rates than their White peers that their campus was hostile, disrespectful, and racist. In the same study, White students perceived that the campus climate was improving, whereas students of color perceived that not only was it not improving, but it was getting worse (Rankin \& Reason, 2005). In a review of the literature by Cress (2008), similar themes emerged for students from marginalized groups, in which experiencing discrimination was a consistent shared experience; these experiences, in turn, have the effect of undermining the learning communities we are trying to create and can be detrimental to the goals of discourse in co-constructed learning environments.

\section{Insulation and Students' Self-Perceptions of Their Own Openness to Difference}

Despite the increasing diversity of society and campuses - and thus the increasing opportunity to experience the myriad benefits associated with such diversity—structural factors mean that White students in particular insulate themselves from difference, and 
are subject to an "echo chamber" effect of sorts. Although many students are largely exposed to very homogenous points of view, students largely believe that they are accepting of others' perspectives. According to the 2016 HERI Freshman Survey findings, when looking at all baccalaureate institutions, $80.3 \%$ of students self-identified as either "a major strength" or "somewhat strong" their tolerance of others with different beliefs, with $77 \%$ of students affirming that they can see the world from someone else's perspective. However, there is quite a drop in students' self-perceptions when asked (using the same measures) their openness to having their own views challenged - only $64.8 \%$ of students felt this was a strength for them (Eagan et al., 2017, p. 40) (see Table 2.3). This is especially interesting when compared to a review of activities related to expression of opinion. In particular, when asked how frequently students "publicly communicated my opinion about a cause (e.g., blog, email, petition)," only $50.9 \%$ of students responded either frequently or occasionally (Eagan et al., 2017, p. 40). This data suggests that while students perceive that they are open to difference of views, they are less confident about expressing their own points of view, and are less open to challenges of their points of view. This is significant when we consider the liberal education goals of college and the types of environments that encourage discourse that we are trying to create. 
Table 2.3

2016 Cooperative Institutional Research Program (CIRP) Freshman Survey Weighted National Norms - All Respondents

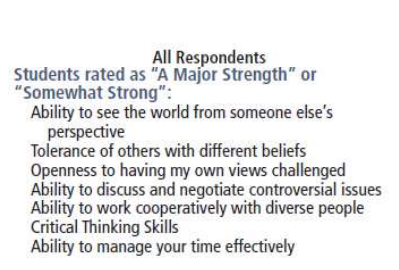

\begin{tabular}{|c|c|c|c|c|c|c|c|c|c|c|c|c|}
\hline \multirow{2}{*}{$\begin{array}{c}\text { All Bacc } \\
\text { Institutions }\end{array}$} & \multicolumn{2}{|c|}{$\begin{array}{c}\text { Baccalaureate } \\
\text { Institutions }\end{array}$} & \multicolumn{5}{|c|}{ 4-year Colleges } & \multicolumn{2}{|c|}{ Universities } & \multicolumn{3}{|c|}{$\begin{array}{l}\text { Black Colleges } \\
\text { and Universities }\end{array}$} \\
\hline & 4-yr Coll & Universities & $\begin{array}{l}\text { Public } \\
\end{array}$ & Private & Nonsec & Catholic & Oth Relig & $\begin{array}{l}\text { Public } \\
\end{array}$ & $\begin{array}{l}\text { Private } \\
\end{array}$ & All HBCU & Public & Private \\
\hline 77.0 & 73.9 & 80.3 & 73.6 & 74.3 & 75.3 & 75.3 & 72.7 & 80.0 & 81.4 & 69.6 & 66.6 & 74.8 \\
\hline 80.3 & & & 77.9 & & 78.9 & & & & & & & 74.5 \\
\hline 64.8 & 63.2 & 66.5 & 63.7 & 62.5 & 64.5 & 64.1 & 59 & 66. & 68 & 66 & 65 & 68.0 \\
\hline 71.1 & 68.4 & 74.0 & 69.2 & 67.5 & 69.0 & 68.5 & 65.4 & 73. & & 69. & & 73.5 \\
\hline 86.4 & 84.9 & 88.0 & 85.4 & 84.2 & 84.6 & 85.9 & 83.1 & 87. & & 82. & & 86.5 \\
\hline 76.8 & 72.5 & 81.2 & 72.6 & 72.5 & 73.2 & 74. & 70.7 & 80.9 & 82 & 73. & 70. & 77.4 \\
\hline 51.5 & 50.7 & 52.4 & 50.4 & 51.1 & 49.4 & 53.9 & 51.5 & 52.4 & 52.4 & 54.7 & 55.4 & 53.4 \\
\hline
\end{tabular}

Note. From Eagan, M.K., Stolzenberg, E.B., Zimmerman, H.B., Aragon, M.C., Whang Sayson, H., \& Rios-Aguilar, C. (2017). The American freshman: National norms fall 2016. Los Angeles: Higher Education Research Institute, UCLA.

\section{Political Polarization and Divisiveness}

According to the Higher Education Research Institute (HERI) 2016 Freshman

Survey data, the class that entered college during one of the most politically contentious election years to date are the most polarized of any incoming class in the history of the administration of the survey; specifically, the fewest number of students $(42.3 \%)$ since the survey was administered categorized their political viewpoints as "middle of the road," which means that more students than ever are pushed to either end of the political continuum (Eagan et al., 2017, p. 42).

This political polarization is reflective of a wider gap societally in the United States. According to a report by the Pew Research Center (2017), "the average partisan gap has increased from 15 percentage points to 36 points" between 1994 and 2017, and the largest gap of any demographic identity (including race, educational attainment, and religious attendance) was along party lines (p. 3). This gap is the largest it has been since 
the Pew Research Center began collecting this data in 1994 (Pew Research Center, 2017). Not only does there exist a widening gap among political party lines, but this polarization appears to be more contentious than in the past. According to the Pew Research Center (2017), "among members of both parties, the shares with very unfavorable opinions of the other party have more than doubled since 1994" (p. 65). Pew's research also has shown in the 2017 data that people tended to maintain close friendships with others in their same political party (Pew Research Center, 2017), decreasing exposure to other political (and perhaps ideological) perspectives.

This lack of political and ideological diversity may play out in perceptions of ineffective government and a lack of belief in government's ability to solve problems. Further, it appears that political divisiveness may play out in ways that cause students to want to disengage from political democratic conversations altogether. In Johnson and Ferguson's (2018) study on the role of political engagement of students' civic identities, they found that most of their participants believed that politics was "negative, divisive, nasty, offered little gratification, and ranged from a necessary evil to something that should be avoided altogether" (p. 518). In their foundational report Leadership Reconsidered: Engaging Higher Education in Social Change, Astin and Astin (2000) note: "in a democracy, of course, citizen disengagement from politics and governmental ineffectiveness not only go hand in hand, but also cripple our capacity to deal constructively with most of the other problems" (p. 2).

Incivility and Conflict Avoidance 
In their review of the education literature on the topic, Burke et al., (2014) defined student incivility as "discourteous or disruptive verbal and nonverbal student behaviors enacted toward others" (p. 161). If one judged solely by the media, they may believe that uncivil behavior is on the rise; and, certainly, the intractability of partisan politics is a framework for today's current state of United States democracy. The political polarization that exists today is undeniable (Eagan et al., 2017; Pew Research Center, 2016), and the perceived negativity surrounding politics is off-putting at best for some college students (Johnson \& Ferguson, 2018), both factors which may contribute to uncivil behaviors and an avoidance of discourse. However, even if it is unclear if uncivil behavior has actually increased (or if we are just more aware of such behavior thanks to media and other sources of information), there does appear to be an increased interest in and research focused on incivility behaviors on college campuses (Burke et al., 2014). Thompson (2014), in his discussion of reducing bias and promoting intergroup relations across diverse peers, indicated that "although the preponderance of evidence supports the positive impact of intergroup contact, negative outcomes, including prejudice, distrust, and conflict, can result from threatening contact situations" (p. 139).

It is a commonly held notion among many in the scholarly community that change is often predicated on conflict, in part because it "is thought to improve problem solving as individuals share information," although the research does not seem to support that claim (Knapp \& Daly, 2011, p. 426). According to Knapp and Daly (2011):

It is possible that the ineffectiveness of conflict for improving decision making and learning may result from inherent reactions to disagreement. De Dreu and Van Knippenberg (2005) found that when in conflict, individuals quickly take ownership of the positions and arguments they espouse and link them to their self- 
concepts. This linkage increases the likelihood of competitive communication, unfavorable impressions of each other, and attitudinal polarization. (p. 428)

Johnson (2015) asserts that "the issue... is not how to eliminate or prevent conflict, but rather how to make it productive or, at the very least, how to prevent it from being destructive" (p. 13). Freedom of expression is highly valued in higher education because of a fundamental belief in and commitment to the role of the exchange of ideas as a catalyst for advancement and change. Engaging in the exchange of ideas through dialogue is one way that college environments help to facilitate the development of critical thinking, problem solving, perspective taking, and participation in democracy of students. To understand the experiences of someone else means to contextualize and ground our own understanding and ways of knowing in the world, which can then be leveraged for positive action. According to Barnhardt et al. (2015):

The negotiated order of 'truth' that is pervasive in college settings is thus a democratizing force that is not simply a skill to enact but a collective spirit, a drive, a cultural value that is evident across all campus community members and their partners (Hartley and Saltmarsh 2011). Fox's (2012) qualitative study reveals the ways these processes work on one campus, where campus life situates students in recursive patterns of deliberation and action related to matters of both knowledge and power. She argues that it is the overall campus ethos or climate that drives students' civic inclinations and social change aspirations; and that the campuses most effective at cultivating citizenship are successful in conveying the expectation that students learn to intellectually and emotionally understand human suffering for the purpose of enacting 'their own visions of a fairer world' (Fox 2012, p. 205). (p. 623)

However, devolving into conflict may not be productive, especially if the outcomes include avoidance, micro- or macro-aggressions against underserved populations, or uncivil behavior. This information would suggest, then, that difference of opinion is 
inevitable but how we teach students to navigate it matters in order to promote positive outcomes.

In a study by Cress et al. (2001) on the educational and personal development outcomes for college students involved in leadership activities, the leadership program directors helping to design the supplemental questions to the survey identified conflict resolution skills as one of the key skill outcomes for students participating in leadership programs. Although conflict is an unavoidable part of life and conflict resolution skills and the ability to navigate controversy important skills sets to obtain, many students may actively avoid engagement in conflict and controversial situations. According to The National Task Force on Civic Learning and Democratic Engagement (2012), experiences in society today are "diminishing opportunities for civic alliances, and replacing what ought to be thoughtful deliberation about public issues with incivility and hyperpolarization" (p. 1).

Given the previously identified widening gap between political party alignment, it is unsurprising that avoiding conflict or finding conflict stressful may be an outcome of difference of opinion. In a Pew Research study, $50 \%$ of Republicans and $46 \%$ of Democrats viewed discussions about politics with those they disagreed with politically to be "stressful and frustrating" (Pew Research Center, 2016, para. 16-18). Several participants in a study on the role of political engagement in the civic identities of college students spoke specifically about conflict in politics as not gratifying and something to avoid (Johnson \& Ferguson, 2018). In Dugan's (2006) quantitative study of the connection between the Social Change Model of leadership development and the 
leadership development of college students, he found that, while students returned high scores relative to the SCM scales, the lowest of the measures were in controversy with civility and citizenship. He asserts that student affairs professionals should "engage students in dialogue more effectively around these topics" and poses the questions, "How are group experiences structured? Are students encouraged to engage in healthy conflict?" (Dugan, 2006, p. 341).

Difference of perspectives is an inherent part of society, and a college campus is no different. Exposure to different perspectives and co-creating meaning across peers is a meaningful learning and student development activity that can promote growth.

However, several inhibitors to conflict currently exist. When diverse students experience the campus climate as hostile, they may be disincentivized from engaging in conflict altogether, or harmed by conflict when they do engage. Further, many students believe they are more open to difference than they may actually be, indicating a lack of selfawareness and true appreciation of difference. Today's political climate of divisiveness and incivility may further contribute to conflict avoidance, all inhibiting the positive outcomes of engagement across different perspectives. Following is a review of the literature on the inherent opportunities associated with engagement in conflict and controversy, including student learning and development outcomes and the extensive and well-documented gains that come from peer-to-peer interaction. 


\section{Growth Opportunities of Conflict and Controversy}

Conflict and controversy fundamentally are about different perspectives on an

issue. This diversity of thought and point of view can lead to increased learning, development, and creativity in problem solving. Thompson (2014) argues that

people come to intrinsically value intellectual engagement as worth the effort it entails through engaging in the processes of inquiry and reasoned argument, and discovering form themselves that these processes are empowering and useful for problem solving, deciding among competing claims, and resolving conflicts. (pp. 56-57)

The gains from interacting with peers with a different perspective are particularly welldocumented in the literature (discussed later in this section). This idea is closely connected with the values of the Social Change Model of Leadership. According to Alvarez (2009), the SCM holds as a value the concept of controversy with civility, which fundamentally is about engaging in difference of opinions for the betterment of society: "By creating an environment in which various opinions are valued, a group can promote constructive discourse in order to negotiate a favorable outcome" (p. 271).

Inherent facets of the collegiate environment are student learning and student development opportunities, both formal and informal, and both in the classroom and out of the class. Factors that help facilitate the development and learning of students include co-created meaning making, reflection, perspective-taking, and interaction with others who have different perspectives. Following is a review of constructivism, knowledge and meaning-making, and the role, influence, and gains that come from interactions with peers.

\section{Student Learning}


Conflict and controversy are inevitable, and can provide powerful opportunities to promote student learning and development; this idea of learning from new information and different perspectives is the core of a constructivist approach to learning. Learning Reconsidered 2, in its exhortation to student affairs administrators to meaningfully respond to the call in Greater Expectations: A New Vision for Learning as a Nation Goes to College (Association of American Colleges and Universities, 2002) to deliver a meaningful liberal education for today's college students, challenges some classicallyheld assumptions about learning in higher education (Keeling et al., 2006). One of the critiques is of the historically positivist approach to learning, which assumes that there is a singular truth that can be known. Keeling et al. (2006) offer instead the foil of constructivism, and describe it as an epistemological and pedagogical frame that assumes that meaning emerges from inquiry, knowledge acquisition, and the relationships and conversations among people who learn... constructivism challenges positivism in a profound way by asserting that there is rarely a single truth about any situation although there may be a consensus about accurate information. (p. 4)

A related concept to co-constructed meaning making is that of discourse. Discourse is defined by the Oxford English Dictionary as "the process or faculty of reasoning; reasoned argument or thought" ("Discourse," 2017). At a time of critical identity development for students, "engaging diverse perspectives on issues that are important to them leads students to rethink their identities, their moral values, and other unquestioned assumptions toward the achievement of a more mature and thoughtfully examined identity" (Colby \& Sullivan, 2009, p. 27). Discourse is important, then, because of what Chang et al. (2005) refer to as the sociological imagination perspective 
that "one cannot know the world or oneself unless one is exposed to new and different experiences and ideas" (p. 11). This has been referred to in the literature as intellectually unsafe spaces (Callan, 2016). Related to this idea of exposure to different and sometimes uncomfortable ideas, Callan (2016) asserts:

Education worth having will encourage open-mindedness. To that extent, it must often take on an agonistic spirit as settled beliefs and values are subject to critique that some students will find distressing or exhilarating, or both at the same time. This is just to say that a good education requires teaching that makes students intellectually unsafe. (p. 65)

This concept is reflected in the Social Change Model of Leadership (SCM) group value of Controversy with Civility. In reflecting on this value, Alvarez (2009) states that "not letting people question the way things have always been done or refusing to acknowledge differing points of view diminishes the group and what it is able to accomplish" (pp. 264265).

The idea of discourse is significant to higher education learning environments, where the exchange of free ideas is valued and knowledge is often co-constructed. In fact, in their discussion of Justice Lewis Powell's opinion in the Regents of the University of California v. Bakke (1978) case, Chang et al. (2005) point out Powell's perspective that "the attainment of a diverse student body broadens the range of viewpoints collectively held by those students and subsequently allows an institution to provide an atmosphere that is "conducive to speculation, experiment and creation"" (p.11).

Burleson and Rack (2008) state that "in constructivism, communication is seen as an intentional, strategic activity in which people convey internal states to others in the effort to accomplish goals" (p. 55). In her text Teaching to Transgress, bell hooks (2017) 
describes the need to make space in classrooms specifically for multiple perspectives, stating that "making the classroom a democratic setting where everyone feels a responsibility to contribute is a central goal of transformative pedagogy" (p. 39). When curricular and co-curricular learning spaces are set up in this way, it allows for multiple perspectives and ways of making meaning. Conflict of perspectives is inevitable in such environments, and allows for the introduction of new information in order to further student understanding. This process also helps foster student development, including the acquisition of higher-order and more complex skills, discussed further in the following section.

\section{Student Development}

Development and growth refers to how individual learners make meaning, which involves increasing capacity to make meaning in more complex ways (Taylor, 2008). A critical part of the process involves some sort of dissonance, sometimes called challenge, that creates a conflict for the learner; "for progression or forward movement to occur, an individual must have a sense of dissonance and disequilibrium, which disrupts his or her current way of making meaning" (Taylor, 2008, p. 230). The educator who advanced the theory of challenge and support, Nevitt Sanford (1968), describes it this way: "it is only when old patterns of behavior are insufficient to reduce tension that a change will occur-hence the importance of challenge in the right degree" (p. 860).

This introduction of new ideas can be an uncomfortable and disorienting process for the learner. According to Baumgartner (2001), "whether planned or happenstance, new ideas may threaten students' worldviews" (p. 21). Similarly, Ettling (2006) describes 
her own experience in fostering dissonance and exposure to different ideas in a course she taught: "it was crystal clear that altering basic assumptions is fraught with fear and resistance even when the outcome may be a desired expansion of consciousness" (p. 59). Through the process of facing disorienting dilemmas, considering different perspectives, and incorporating new information, students necessarily develop in their skills sets around meaning making and capacity for understanding. From a student development lens, several skills sets are enhanced and developed, including critical thinking and perspective taking, adopting a pluralistic orientation, and the development of empathy and emotional intelligence. Following is a brief review of these skills as they relate to the developmental opportunities provided by conflict and controversy.

Critical Thinking and Perspective Taking. Thinking and critical reflection are important components of the learning process (Lindholm, 2007; Rodgers, 2002; Shushok, 2011). According to Rodgers (2002), "the process of reflection, Dewey claims (1916/1944), moves the learner from a disturbing state of perplexity (also referred to by him as disequilibrium) to a harmonious state of settled-ness (equilibrium)" (p. 850). This process of reflection and the role of disequilibrium mirrors what we know advances students in their developmental process in college. Student development refers to the process of positive growth and increased complexity in meaning-making that many learners experience in college; Evans et al. (1998) describe Nevitt Sanford's characterization of student development as a process "in which the individual becomes increasingly able to integrate and act on many different experiences and influences" (p. 4). Development and learning go hand-in-hand; Taylor (2008) “equate[s] learning with 
development because developmental capacities, such as the ability to mutually negotiate meaning with others, give rise to educational outcomes such as effective citizenship" (p. 216).

It has long been understood that exposure to different perspectives contributes to student learning and development. Research around the benefits of interacting across race are especially well documented. In a study done in 2004, researchers found that crossracial interactions promoted the intellectual and social skills as well as "civic interest" in students (Chang et al., 2004). The researchers attributed this in part to the effects of racism and segregation on different racial groups, which they theorized means that students that engage across race are more likely to encounter a perspective that they themselves had never experienced or considered before (Chang et al., 2004). Further, increased civic engagement in college students has been linked to their diversity experiences while in college (Bowman, 2011).

In their mixed-methods study of influences on students' civic commitments and capacities, Barnhardt et al. (2015) noted that college students tended to view peers' advocacy on campus as legitimate, but also expressed criticism when they perceived that peers would "'take stands, then will not listen to opposing views,' thus implicating activists' authenticity or fidelity to the philosophical ideals of freedom of expression" (p. 637). These students noted and legitimized their peers' perspectives on issues, and also named the importance of identifying your own stance on a subject (Barnhardt et al., 2015), suggesting the importance of the willingness to listen to other perspectives even while forming one's own. In the same study, faculty were identified by participants as 
"stewards for the classroom space" who "advocated by acting as arbiters of classroom respect....the learning space displayed public advocacy as a process with faculty demonstrating the ways in which alternative perspectives and evidence could be utilized to inform positions" (Barnhardt et al., 2015, p. 637). This would suggest that not only the act of perspective-taking, but also the manner of perspective-taking and engagement, matters when considering different points of view. Thompson (2014) describes perspective-taking as an aspect of empathy that involves "self-awareness" and "otherawareness" (p. 70). This shows up in the Social Change Model of Leadership value of Congruence, which calls leaders "to balance one's own values with the need to be inclusive of other people's perspectives and values" (Shalka, 2009, p. 351). Empathy and the concept of emotional intelligence are further discussed in the next section.

Empathy and Emotional Intelligence. One useful quality for navigating conflict that encompasses a variety of skills sets is that of emotional intelligence. Goleman (1998), in discussing skills sets necessary for leadership in the workplace, makes a distinction between rational intelligence, which one is born with, and emotional intelligence, which can be cultivated. He describes five dimensions of emotional intelligence: self-awareness, managing emotions, motivating others, showing empathy, and staying connected (Goleman, 1998), which align with affective skills sets colleges hope to develop in students. Unfortunately, the development of emotional intelligence has been on the decline in the United States, leading children to be "more impulsive, more disobedient, more angry, more lonely, more sad" (Goleman, 1998, p. 25). He advocates the development of these skills for effective workplaces and healthy 
organizations. From Goleman's (1998) perspective, emotional intelligence allows leaders to enhance what a group together to accomplish: "thinking positively, resolving conflicts, understanding relationships_-in short, skillfully connecting with others — is especially powerful in maximizing the potential of teams" (p. 24).

Empathy is an important component of emotional intelligence, and is connected within the core values of the Social Change Model of Leadership. With regards to the community value of Citizenship, necessary skills of leaders in realizing this value include empathy and multicultural citizenship (Bonnet, 2009). As Bonnet (2009) describes, "truly listening to others and understanding perspectives other than one's own are critical components to participating in a community.... It is often through the free discourse of ideas, including those that conflict, that communities seek shared solutions" (p. 165).

Pluralistic Orientation. A necessarily intertwined concept to support positive outcomes from conflicting points of view and working through controversy is that of pluralism; that is, an acknowledgement of and value for different types of people with different views and perspectives in the same society. The concept of pluralism connects closely with democratic and liberal education outcomes including inquiry and analysis, critical and creative thinking, teamwork and problem solving, intercultural knowledge and competence, and ethical reasoning and action. Mezirow (2003) talked about the value of exposure to different points of view through a transformative learning and critical discourse framework. Specifically, he states

When knowledge — beliefs, values, and judgments — is constructed through critical discourse - the synthesis of existing views and evidence-it is feasible to claim that, given current evidence or knowledge, some judgments or interpretations have greater validity than others. One may also reasonably contend 
that a given judgment is a supportable tentative conclusion on which to act until a new perspective, evidence, or argument is encountered and validated through critical-dialectical discourse. All conclusions remain open to the possibility of a future assessment by a larger, more diverse group. (Mezirow, 2003, p. 61) Soria et al. (2015), in their study on factors that promote integrative leadership

orientation in college students, found that outcomes related to perspective taking, teamwork, collaboration, and a pluralistic orientation may be enhanced by supporting and enhancing students' capacity "to work with others from diverse backgrounds and enhancing their ability to participate as active citizens for the benefit of the nation" ( $p$. 65). The necessity of pluralism is critical as society becomes more diverse and the problems we collectively face become more complex and require the ability to view a problem from multiple perspectives. As stated by Bowman (2011), “College students will ultimately work and live in an increasingly heterogenous society, so students who are exposed to diverse people and perspectives may be more motivated and prepared to participate fully in civic life" (p. 29). Pluralism is not just about a willingness to listen to diverse points of view, but also about seeing the value of those perspectives and actively seeking them out. The Social Change Model advances this idea through the group value of collaboration, in which diversity is a key component (England, 2009).

While conflict provides both an opportunity and potentially a barrier to learning, one demonstrated way to leverage the benefits of diverse perspectives is through peer interactions. Such interactions have been demonstrated to promote learning and development in meaningful ways. Following is a brief review of the gains from interacting with diverse peers. 


\section{Peer Interactions and Gains}

Research has shown the significant impact of other peers on students' learning and development (Astin, 1993; Dugan \& Komives, 2010; Strayhorn, 2008). Dugan (2012) indicated that "the theoretical assertion of the primacy of peer groups to student learning is corroborated by the vast amounts of empirical research that explored the topic (Astin, 1993b, 1996; Pascarella \& Terenzini, 1991, 2005)" (pp. 25-26). Students' selfreported increase in interpersonal skills was strongly associated with variables in which student-to-student interaction was present (Astin, 1993). In one study, "peer interactions had the strongest relationship with personal/social growth," and the researcher suggested that "administrators might pay attention to the various ways in which campus programs and services require students to engage their peers in meaningful discussion, debate, and service-related activities" (Strayhorn, 2008, pp. 9-10). Research has also shown that student leader peers have more access and legitimacy with other students than do nonstudents (Barnhardt et al., 2015). In fact, according to a study by Barnhardt et al. (2015):

Our initial codes revealed that students were most inclined to identify peers as the agents of campus public advocacy.... The quantitative and qualitative data aligned well; $43.4 \%$ of students surveyed viewed their peers as the most vocal advocates on campus in communicating the expectation that students need to be active and involved citizens. (p. 635)

The role of peer engagement and interaction in the development and learning of students is well documented. Studies have demonstrated that interacting with peers in meaningful dialogue increased students' civic commitments and skills (Barnhardt et al., 2015), increased students' development of socially responsible leadership capacities (Dugan \& Komives, 2010; Riutta \& Teodorescu, 2014), and that peer interactions in 
particular had the most significant impact on students' personal and social growth (Strayhorn, 2008). Dugan and Komives (2010) believe that one explanation for the enhancement of students' socially responsible leadership skills is that "these conversations may provide a platform for the development of listening skills, clarification of personal values and perspectives, and social perspective-taking” (p. 539). Barnhardt (2015) further suggests that "by engaging in or being exposed to peers' collective action, students can grapple with what it means to be a conscientious stakeholder, and how to express their common concerns about organizational and institutional accountability" (p. 61). Strayhorn (2008) exhorts practitioners to consider both opportunities to engage students in meaningful peer-to-peer dialogue, and also to consider the importance of cocurricular environments and involvement in fostering these types of interactions. This is critical when we consider what is known from the Multi-Institutional Study of Leadership (MSL) data on socio-cultural conversations, defined by the MSL as those that "consist of formal and informal dialogues with peers about differences (i.e., topics which elicit a wide range of perspectives) as well as interactions across differences (e.g., with people who have different backgrounds and beliefs than oneself)" (Dugan et al., 2013, p. 9). Socio-cultural conversations with peers was the one practice that influenced the capacity for socially responsible leadership across all demographic groups (Dugan et al., 2013), demonstrating the fundamental importance of peers to the development of socially responsible leadership.

Peer interactions generally and interacting with peers who were different from oneself specifically are both practices that are empirically supported. Leadership 
outcomes for students were best predicted by the variable of "engaging in conversations about difference" (Riutta \& Teodorescu, 2014, p. 831). Cross-racial peer interactions have been shown to promote educational outcomes for students (Chang et al., 2006). Dugan and Komives (2010), in their study of influences of higher education on the development of socially responsible leadership capacities, stated that "findings...suggest that peer conversations, not just interactions, across a wide array of differences... can contribute to gains in theoretically grounded measures of socially responsible leadership" (p.539). In fact, in their research, they found that socio-cultural conversations with peers was the strongest influencing factor for the development of these capacities in students (Dugan \& Komives, 2010). Further, research has demonstrated that cross-racial interactions have positive effects on racial-ethnic attitudes and values (Pascarella \& Terenzini, 2005).

The previous section reviewed what is known about both the challenges of conflict and also opportunities available with conflict, as well as a discussion of the power of peers in helping foster student development and learning. Given this context, considerations around how to engage in meaningful democratic discourse is useful in advancing ideas about how to help diverse individuals come together to solve society's problems in productive ways. How to engage effectively across difference is also an important question when considering how to support students. Following is one model that integrates theory, research, and practice and suggests a means by which students can engage meaningfully and productively across difference. 


\section{Model of Constructive Controversy}

One useful theoretical framework suggested to navigate conflict so as not to produce negative outcomes, but rather increase problem-solving tendencies, is that of constructive controversy. Johnson (2015) says that "constructive controversy exists when one person's ideas, information, conclusions, theories, and opinions are incompatible with those of another, and the two seek to reach an agreement that reflects their best reasoned judgment" (Johnson \& Johnson, 2007, in Johnson, 2015, p. 26). Johnson (2015) describes a myriad of outcomes that, when certain conditions are met, result from engaging in the process of constructive controversy, including "higher quality decision making and problem solving," "higher cognitive and moral reasoning," "more frequent and accurate perspective taking," "greater open-mindedness," "greater motivation to improve understanding," "greater commitment to process and outcomes," "higher selfesteem," and "more democratic values" (p. 107). Conditions that help contribute to these positive outcomes within the process of constructive controversy include a cooperative context and heterogeneity (or diverse perspectives) of the group (Johnson, 2015).

David Johnson (2015) provides a useful model for engaging in intellectual conflict that he refers to as constructive controversy. He describes the imperative to help citizens be able to effectively engage in constructive controversy this way:

On a societal level, in a democracy the ability of citizens to think critically is considered to be paramount. In addition, citizens need to evaluate arguments and counterarguments about the issues confronting their society, such as the desirability of genetically modified foods, the solutions to global warming, and whether to raise taxes to improve the infrastructure. Thus, at all levels of human interaction the competency to engage in constructive intellectual conflict is essential. (Johnson, 2015, p. 22) 
The key elements of constructive controversy involve both conflict and cooperation. The phenomenon of cooperation in particular has allowed humans to survive and flourish over centuries (Johnson, 2015). Among other mental health and positive relationship outcomes associated with cooperation, Johnson (2015) claims that it promotes a "greater effort to achieve," stating specifically:

Cooperation produces higher achievement and greater productivity than do competitive or individualistic efforts. This finding is so well confirmed by so much research that it stands as one of the strongest principles in psychology and education. The more conceptual the task, the more problem solving required, the more desirable higher-level reasoning and critical thinking, the more creativity required, and the greater the application required of what is being learned to the real world, the greater the superiority of cooperative over competitive and individualistic efforts. (p. 9)

Therefore, for conflict to be productive, cooperation must exist as part of the context (Johnson, 2015). In the SCM, one group value takes cooperation a step further to collaboration. The difference between cooperation and collaboration in the SCM has to do with unity around a common goal or purpose; rather than working cooperatively to achieve disparate individual goals, in a collaborative context, individuals would identify what their common goal is and then collaborate on strategies and interventions to reach it (England, 2009). The process of controversy is illustrated in Figure 2.3 (Johnson et al., 2000, p. 33). 
Figure 2.3

The Process Steps in Controversy

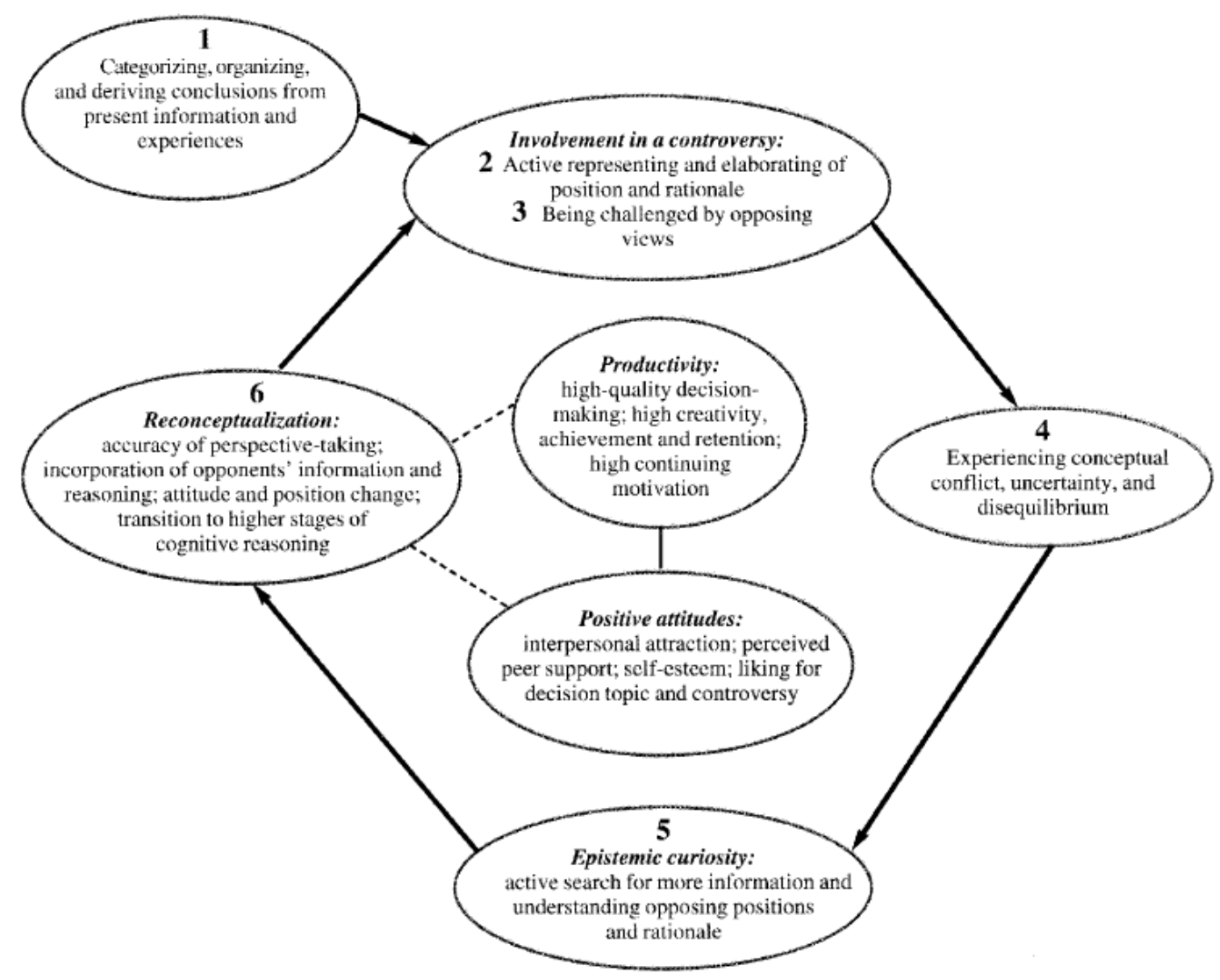

Note: From Johnson, D.W., Johnson, R.T., \& Smith, K.A. (2000). Constructive controversy: The educative power of intellectual conflict. Change, 32(1), 28.

At its heart, constructive controversy is a structured process of learning by advocating a position, listening to opposing points of view, and then using all of the information in order to arrive at a new understanding and make a determination about a resolution. Johnson (2015) describes the process through the following six steps (pp. 4381): 
1. Organizing information and deriving conclusions. In this instance, individuals "have an initial conclusion based on categorizing and organizing their current (but usually limited) information, experience, and perspective... Individuals tend to have a high degree of confidence in their initial conclusion (i.e., they freeze the epistemic process) (pp. 44-45).

2. Presenting and advocating positions. At this stage in the process, individuals present their positions while others present opposing positions. Two key concepts are at play: conversion, in which the individual is attempting to convince the other participants that their position is the superior choice among all of the alternatives and convert others to adopt that position; and reactance, in which the act of advocating or pressure causes someone to become more entrenched in their own point of view.

3. Being challenged by opposing views. In this stage, individuals advocating a particular position review the positions of others "in attempts to discern weaknesses and strengths.... [while being] aware that they need to learn the information being presented and understand the perspective of the other group members. Hearing opposing positions tends to unfreeze the epistemic process" (p. 51).

4. Experience of conceptual conflict, disequilibrium, and uncertainty. In this stage, the presentation of new information and different perspectives causes disequilibrium as the advocate for a position attempts to incorporate and understand the new information in light of their own positionality; this is described as cognitive or conceptual conflict and describes "the internal conflict that leads to growth in cognitive reasoning and learning" (p. 63).

5. Epistemic curiosity and perspective taking. After the introduction of a conceptual or cognitive conflict, an individual at this stage is spurred by epistemic curiosity to seek more information and opposing viewpoints about the issue.

6. Reconceptualization, synthesis, integration. At this final stage in this structured process, the goal is not necessarily to choose among the alternatives presented, but rather to synthesize information in order to "arrive at the best possible decision and find a position that all group members can commit themselves to implement" (p. 74). According to Johnson (2015), "students arrive at a synthesis by using higher-level thinking and reasoning processes, critically analyzing information, and using both deductive and inductive reasoning" (p. 80). 
This process model is a useful theoretical framework for understanding the steps used by students to engage meaningfully across difference and the extent to which they have used steps in this process, either structured or informally, to develop and deepen their own understanding and learning in a given conflict or controversy scenario.

A challenge of this model is that it only serves as an example of how to successfully engage in conflict, and does not account for contentious or negative conflict, or conflict avoidance, both which are possible outcomes when there are differences of perspectives. According to Alvarez (2009), within the SCM, Controversy with Civility can play out in three ways: trying to "maintain civility by avoiding controversy," “embracing controversy, but without civility," or the final and only appropriate strategy according to the model: "promote controversy with civility" (pp. 271-273). Using a combination of the Social Change Model of Leadership and the process of constructive controversy can provide insight into how students make sense of conflict and controversy in their leadership positions interacting with peers; what strategies they use to do so; to what extent do those experiences facilitate the development of their socially responsible leadership capacities; and what internal and external factors promote the positive resolution of conflict while also promoting learning and development.

\section{Chapter Summary}

Colleges are expected to develop the next generation of citizen-leaders to solve society's wicked problems through both curricular knowledge and the realization of broader liberal education goals. The context of college campuses and in society at large as evidenced in the media is that today's citizens are more politically polarized 
and unable to engage effectively across difference to solve the significant problems that society faces. However, the increasing diversity in society and on college campuses provide a valuable opportunity to promote creative thinking and enhanced decision making by utilizing and incorporating diverse perspectives. While engaging with diverse peers can help build pluralism, perspective-taking, and collaboration skills - both liberal education goals and student leadership development outcomesstudents can too easily avoid engaging with different perspectives, thereby limiting their exposure to different ideas, knowledge, and insight.

For colleges to realize their missions, it is imperative that they help support the development of socially responsible leaders, characterized as a process that promotes self-awareness, in which leaders value diverse perspectives, collaboration, inclusion, and respect, with the fundamental goal of fostering positive social change. The literature demonstrates a connection between students' leadership experiences and their civic engagement and social responsibility, and also clearly shows the benefits of a pluralistic orientation and engagement across diverse peers for a variety of gains. However, there is little known about how student leaders experience conflict and controversy, and how experiences with conflict and controversy have contributed to their learning and development. Most of the studies that have examined the concept of socially responsible leadership within the framework of the Social Change Model of Leadership are quantitative, so there is a lack of understanding of the actual lived experiences of students who have demonstrated socially responsible leadership. Further, little is understood about how college students experience and navigate conflict — if at all—and 
to what extent those experiences contribute to transformed perspectives and development of skills sets espoused in liberal education goals.

The aim of this qualitative study is to help fill in the gaps in the literature by exploring students' experiences navigating difference and conflict in order to better understand how student leaders experience conflict and controversy on college campuses; what strategies they use to navigate conflict and where they learned those strategies; to what extent experiences with conflict and controversy contributed to student learning and promoted the development of socially responsible leadership skills, attitudes, and behaviors; and what internal and external factors facilitated college student leaders successfully navigating conflict and controversy. 


\section{CHAPTER THREE: METHODOLOGY}

Chapter 3 outlines the method and design for this study. The chapter summarizes the problem of how many students graduate underprepared to engage in difficult conversations with someone who has a different perspective from themselves, as well as a lack of understanding of how college students make sense of and navigate conflict and controversy in their undergraduate journeys. This study used a qualitative approach and a basic qualitative study design to further explore undergraduate student leaders' experiences with conflict.

The chapter begins with a statement of the problem and introduces the theoretical frameworks informing the problem and approach to the study. The chapter then reviews a justification for the study method and design chosen, the research questions that are driving the design, and the goals of the study. Then follows a review of the study site, participants, and sampling method; data sources, justification, and collection strategies; and strategies for data analysis used. The researcher explicates her own positionality within the context of the study. The chapter concludes with a review of ethical considerations, a discussion of strategies to ensure trustworthiness, and a summary of the limitations of this study. Following is a brief review of the problem that is the impetus for this study.

\section{Statement of the Problem}

As campus populations continue to diversify, the challenges of effectively educating students across difference continues to confound colleges and universities. While many colleges share the goals of liberal education to help prepare the next 
generation of leaders to effectively deal with wicked problems (Rittel \& Webber, 1973), many campuses do not meaningfully build this into the curriculum or otherwise intentionally foster skill-building relative to communication, critical thinking, reflection, and considering different perspectives. Students who have not been exposed to or asked to consider perspectives different from their own may lack the experience and skills to effectively consider and incorporate diverse views, but given the increasing diversity of both college campuses and society broadly, these skills are critical for the development of effective citizen-leaders. Such work does often happen in cocurricular student experiences in more structured ways, such as student leadership roles, including student clubs and governance organizations, and paraprofessional roles such as being a Resident Assistant. If colleges and universities do not facilitate opportunities for students to develop these skills, they run the risk of graduating students who are unable to effectively address complex social issues post-graduation, and who may be harmed or cause harm (whether intentionally or unintentionally) during the time they do spend on campus.

\section{Theoretical Frameworks}

The Social Change Model (SCM) of Leadership (Higher Education Research Institute, 1996) and Constructive Controversy (Johnson, 2015) are the theoretical frameworks for this study. The SCM describes a set of seven core values, across three domains, that promote the development of socially responsible leadership. The individual values of the SCM are Consciousness of Self, Congruence, and Commitment. The group values are Collaboration, Common Purpose, and Controversy with Civility. The 
society/community value is Citizenship. All of these values are interconnected and work for the overall goal of positive social change.

The model of Constructive Controversy is a process that brings together research, theory, and practice to propose a six-step model of engaging in dialogue about different positions or stances on an issue in order to work toward integrating new information, informing one's own position, and working toward an eventual favorable outcome based on all of the available information. These models together allow for insight on how to positively promote change and growth while working through conflict and controversy scenarios.

\section{Research Methodology}

Qualitative methodology is well suited to the research questions and setting driving this study. Researchers using a qualitative approach are seeking to answer their research questions by understanding the lived experiences of the study participants, and then making sense of the data by coding the data and looking for common ideas and themes. Creswell and Creswell (2017) describe qualitative research as "exploring and understanding the meaning individuals or groups ascribe to a social or human problem" (p. 4). In a qualitative design, the researcher is the instrument for interpreting the data, reviews data from multiple sources, is particularly concerned with the meanings participants ascribe to their experiences, works to bring in multiple perspectives, and acknowledges that because the design is emergent, elements of the study design may change in order to be responsive to needs that arise as the context of the phenomenon being explored becomes more clear (Creswell \& Creswell, 2017). 
According to Merriam and Tisdell (2016), "qualitative research is based on the belief that knowledge is constructed by people in an ongoing fashion as they engage in and make meaning of an activity, experience, or phenomenon" (p. 23). Qualitative research contains within it several different types, including case studies, phenomenology, narrative inquiry, grounded theory, and ethnography (Creswell \& Creswell, 2017; Merriam \& Tisdell, 2016), each with a particular focus about how to understand a participants' experience. Qualitative research that does not follow one of the subtypes is described by Merriam and Tisdell (2016) as "a basic interpretive study," which they call a basic qualitative research (p. 23). Because qualitative research is concerned with how meanings are created out of experience, the uniting feature of a basic qualitative study is constructivism, and the main sources of data are interviews, observations, and document analysis (Merriam \& Tisdell, 2016).

A quantitative approach was not appropriate for this study, for a few reasons. Much of what is known about the development of socially responsible leadership is understood quantitatively already due to the development of an instrument - the Socially Responsible Leadership Scale (SRLS) — that measures socially responsible leadership characteristics (Tyree, 1998). Therefore, an existing gap in the literature prior to this study was understanding qualitatively the lived experiences of students using socially responsible leadership as a theoretical framework. Another reason a quantitative approach is ill-suited to this study is the nature of the research questions and what the researcher hoped to learn from the inquiry. Qualitative approaches are particularly suited to understand the nature of an experience, with the investigatory goals including 
“understanding, description, discovery, meaning, or hypothesis generating" (Merriam \& Tisdell, 2016, p. 20). Further, the questions about how student leaders experience and navigate conflict and controversy can only be understood by gathering information from participants about their experiences, and in order to interpret the data and make meaning from it, the researcher must serve as the instrument for data analysis. In a basic or descriptive qualitative study design, the researcher uses the words of participants to describe events in order to accurately reflect or describe phenomena (Sandelowski, 2000), such as student leader experiences with conflict. Findings from a qualitative study are "comprehensive, holistic, expansive, [and] richly descriptive" (Merriam \& Tisdell, 2016, p. 20), which allows this inquiry to provide new and previously missing insights into the lived experiences of student leaders as they navigate interpersonal conflict experiences. For these reasons, a qualitative approach was applied in this study.

\section{Purpose of the Study}

The purpose of this study is to understand the experience of undergraduate student leaders in navigating conflict and controversy, how they make meaning of those experiences, and if those experiences contributed to their learning and development in college. Specifically, this study examined if and how student leaders navigated conflict and controversy in their undergraduate student roles, and how student leaders conceptualized or viewed conflict and controversy in the context of an increasingly diverse and polarized college campuses and societally, in order to add to the overall understanding of how conflict impacts student development. 


\section{Research Questions}

Qualitative research questions should be focused on a specific concept, begin with what or how, and reflect an emerging design (Creswell \& Creswell, 2017). This study exploration of conflict has two primary research questions. They are:

1. How do undergraduate student leaders describe their experiences navigating conflict/controversy at a large, public institution in the Pacific Northwest?

2. In what ways does experience working through conflict/controversy at a large, public institution in the Pacific Northwest help facilitate the development of student leaders' socially responsible leadership skills?

Maxwell (2013) describes research questions as having features that are either general or particular, variance or process, and instrumental or realist. The first primary question is a particular, process, realist question because it is focused on a specific population, on exploring the process or experience of working through conflict, and in understanding student experience. The second primary question is a particular, instrumental, realist question; the difference is that the second question is interested in the degree to which (or to what extent) participation in conflict and controversy has facilitated key socially responsible leadership and liberal education goals (such as perspective taking, critical thinking, and problem solving) based on student leaders' perceptions and experiences.

\section{Research Design}

The design employed for this study was a basic qualitative design, which is most appropriate given the specific research questions regarding both how students conceptualize conflict and controversy, and also how they navigate the process and what 
meaning they make of their experiences. A basic qualitative study design allows the researcher to understand "(1) how people interpret their experiences, (2) how they construct their worlds, and (3) what meaning they attribute to their experiences" (Merriam \& Tisdell, 2016, p. 24).

The design and associated choices is fully developed in the following sections. Included in this discussion of the design are an explanation of undergraduate student leaders representing a maximum variety of participants from a subset group; a description of the study site in the Pacific Northwest; the primary source of data collection-semistructured interviews - and the strategies for collecting data from all sources; the plan for data analysis and related coding schemes; and an overview of strategies to maintain trustworthiness of the data and attend to ethical concerns within the study. For a table of steps and associated timelines in the basic qualitative study design, see Appendix A.

\section{Research Participants/ Population and Sampling Procedure}

In qualitative research, the data is collected based on a purposeful selection of the study site(s) and participants. Following is a brief description of the study site and justification for the study site, as well as a review of the participant population and sampling procedure to be used in the study.

\section{Study Site}

This study took place at a large, public, land-grant, research institution in the Pacific Northwest; for the purposes of this study, the site was assigned the pseudonym "Pacific Northwest University." The students at Pacific Northwest University come from all 50 states and over 100 countries. In the fall of 2018, enrollment was over 30,000 
students; $83.6 \%$ were undergraduate students and $14.4 \%$ were graduate students. Almost $58 \%$ of students enrolled were from within the state; approximately $42 \%$ were nonresident students, and $11.5 \%$ were international. U.S. minorities made up $24.8 \%$ of the student population; Hispanic and Asian were the most represented racial minorities, followed by two or more races. The smallest racial group representation were American Indian/Alaskan Native, Black, and Native Hawaiian/Pacific Islander students. Approximately $53 \%$ of the student population were male and almost $47 \%$ were female. The most popular majors for students were Engineering, Business, and Liberal Arts. As the state land grant institution, Pacific Northwest University does have branch campus sites as well as extension sites, but the population in the sample are all enrolled at the main campus, a required criteria for participation in this study.

Student leadership opportunities at PNWU span from paraprofessional roles to elected student leadership positions to involvement in clubs or organizations. Paraprofessional opportunities refer to those student leader positions that ask students to be in paid positions where they engage in leadership activities with their peers, and range from roles in residence life to cultural center student staff positions to orientation leaders. PNWU has 12 Panhellenic Council (PHC) chapters (women's housed organizations), 23 Interfraternity Council (IFC) chapters (men's housed organizations), six Unified Greek Council organizations (women's and men's culturally-based organizations, not housed), eight National Pan-Hellenic Council (“Divine Nine”) chapters (Historically Black Greek Letter Organizations), and four Collective Greek Council chapters (representing professional/academic or interest-based affiliation). PNWU also has over 400 student 
clubs and organizations that span from academic and professional, to cultural, governance, political and social action, recreation and sports, religious and spiritual, and volunteer and philanthropic groups.

The research site was chosen because the central concern - that colleges are not graduating students with the skills needed to work collaboratively to achieve democratic goals - implicate the unique missions of public institutions. Land grant universities are specifically charged in the development of an educated, productive citizenry, particularly for the benefit of the state. Understanding how these skills may be developed in student leaders at the study site offers a direct benefit to the institution of study, offering research and consequent feedback that can aid the institution in future efforts to achieve its liberal education and land grant aims. The study site also provided convenient access to the researcher to research participants because of previously developed relationships. Finally, the researcher's knowledge of the study site and resources available to students enrolled at the study site allowed for the researcher to provide specific and tailored resource referrals to student leader participants as needed, and in the case that participants experienced distress or concern at any stage of the study.

\section{Population}

Student leaders are a meaningful population to examine because development goals for student leaders - in particular, the concept of socially responsible leadershiprelate directly to liberal and democratic education goals. Student leaders also purposefully choose to dedicate time and energy to leadership activities, which means that they bring a particular experience working with peers that were invaluable for this 
study. Student leadership spaces and activities, which bring together diverse peers, also offered ample opportunity for students to experience conflict and controversy, necessary experiences to give life to the research questions that drove this study. It is possible that informal leadership opportunities - that is, those that did not involve an elected role, paraprofessional position, or student organization participation-may also provide opportunity for students to engage in transformative experiences facilitated by conflict and controversy. However, for this study, the sample was constrained to those who have experienced more formal leadership opportunities.

For this study, student leadership is defined as some form of formal leadership experience at Pacific Northwest University, either paraprofessional, an elected position, or through participation in an institutionally recognized student organization. In order to provide consistency and reduce the possibility of age or graduate-level course work as confounding constructs conceivably contributing to students' experiences with conflict and controversy, the study collected data from undergraduate student leaders in their junior to senior years of college. Undergraduate student leaders in their junior or senior years were selected because of their ability to uniquely provide meaningful data related to the constructs that were examined as a part of this study, due to their length of time and experience on campus, and likelihood of having navigated conflict and controversy. All participants were students enrolled at the main Pacific Northwest University campus.

\section{Sampling Procedure}

Purposeful sampling "is based on the assumption that the investigator wants to discover, understand, and gain insight and therefore must select a sample from which the 
most can be learned" (Merriam \& Tisdell, 2016, p. 96). Because the central construct of this study was conflict and the questions involve understanding how student leaders navigate conflict, a purposeful strategy was most appropriate. Seidman (2013) suggests a strategy of maximum variation sampling in order to select "participants who reflect the wide range in the larger population under study" (p. 56). The aim of the sampling procedure was to obtain a diverse range of experiences of undergraduate student leaders located on the main campus. Student leader opportunities at a large, public land grant are plentiful, and can range from participation in fraternity and sorority life leadership, student governance, paraprofessional roles in housing or cultural centers, participation in service-oriented or advocacy groups, and leadership in campus clubs and organizations. The goal was to create a study sample that is reflective of these diverse leadership opportunities in order to obtain a wider range of experiences to explore the phenomenon of navigating conflict.

In order to be qualified to participate in this study, participants were required to meet all of the following characteristics:

1. Enrolled at the main Pacific Northwest University campus,

2. undergraduate student with junior or senior standing,

3. has participated in some form of formal leadership experience, either paraprofessional, elected position, or through a student organization, and

4. has had some experience with conflict or controversy with a peer(s) while enrolled. 
This study did not examine specifically the impact that gender has on conflict and controversy experiences; however, the world is experienced differently based on gender. For this reason, the researcher strived for and achieved a sample that was equally representative of men and women, and inclusive (when possible) of individuals who do not identify in a gender binary. Similarly, the researcher strived for and achieved a variety of racial and ethnic identities represented, and worked intentionally to select participants across a variety of social, personal, and leadership identities which in turn provided a rich, complex set of perspectives for this study.

A questionnaire was used to gather demographic data about potential participants and to screen for participants that fit the study population parameters. Questionnaires for participants who were not interviewed were still considered for emergent and salient themes from the short answer data that was collected in the survey. The questionnaire was created using Portland State University's Qualtrics system and collected the following demographic information: name, year in school, age, major, gender identity, racial identity, international student status, disability status, student leadership experiences and any offices held, best contact information, a short answer question that asks students to describe a conflict in a student leadership position, a short answer question that asks students to describe a conflict in any undergraduate student experience, and a yes/no question asking students for permission for the researcher to reach out to them (see Appendix B). The questionnaire, in addition to identifying participants who fit the study parameters and that have a wide range of leadership experiences and demographic identities, was used to help prime participants to consider a conflict 
experience they may have experienced (versus asking a participant to think of such an example on the spot), and was used to build a participant table in the results chapter. The researcher serves in a mid-level professional role in one of the departments at Pacific Northwest University. To ensure ethics in data collection, the researcher also used the questionnaire sent out to potential participants to scan for and screen out paraprofessionals that work in the same department and with whom the researcher either knew very well or had a supervisory relationship.

Delimitations of this study are in how student leadership is conceptualized and defined for the purposes of sampling. Many students arguably have informal leadership opportunities that also provided opportunity for them to engage in experiences around conflict and dialogue with peers that may be transformative; however, the context of this study means that the sample was bounded by those who have experienced more formal leadership opportunities. The interview protocol and study questions were concerned with the experiences and the phenomenon of conflict and, because of the intellectual goal of understanding how student leaders make sense of the phenomenon, did not purposefully interrogate the role of identities in the ways they make sense of their experiences, although themes related to students' identities did emerge.

\section{Negotiating Access to Site and Participants}

In order to access participants, the researcher worked primarily with institutional gatekeepers; that is, those individuals who work directly with student leaders on the PNWU campus. The researcher sent individual invitations to professional staff at PNWU, some that she was acquainted with and some that she knew less well, and invited them to 
coffee or lunch to share her research topic and recruitment strategy, and to request their assistance in reaching out to student leaders. The meetings with gatekeepers focused primarily on the problem and context of the study, the research questions, the criteria participants had to meet to qualify, and the goal of the researcher to collect a wide and varied set of experiences across both student leader type and social identities such as race and gender.

The researcher invited interested gatekeepers to help with recruitment in at least one of the following ways: by forwarding an email on her behalf to their organization's listserv (see Appendix C), by shoulder-tapping individual student leaders who met the criteria and who they thought would be a good fit and encouraging them to complete the survey by sending them the recruitment email to them personally (see Appendix C), and by placing the researcher's recruitment flier in an area where student leaders in their organization congregate (see Appendix D). Altogether, the researcher met with 11 gatekeepers, who represented leadership areas that included student government, fraternity and sorority life, recreational sports, student leadership, cultural centers, civic engagement, orientation programs, student media, and residence life. All gatekeepers that the researcher met with agreed to some level of recruitment on her behalf. The email invitation that gatekeepers sent included a brief description of the study, an invitation to participate, and a link to a Qualtrics survey questionnaire collecting the following demographic information: name, year in school, age, major, gender identity, racial identity, disability status, student leadership experiences and any offices held, best contact information, two brief short answer questions that asks students to describe a 
conflict with a peer in a student leadership position and a conflict with a peer in any undergraduate student experience respectively, and a yes/no question asking students for permission for the researcher to reach out to them (see Appendix B).

Utilizing gatekeepers turned out to be a highly effective strategy for this study, for multiple reasons. First, the researcher did not need to do any additional recruitment, as the method outlined yielded the necessary number of participants for this study. Second, by meeting with gatekeepers directly, the researcher was able to explain the goals of the study in a clear way that allowed for gatekeepers to use their connections to directly encourage participants that were a good fit for this study. An important note for this aspect is that the researcher never confirmed back with any gatekeepers if or who someone they had suggested participate actually did so. This was to maintain the confidentiality of participants and create an environment where participants did not feel coerced to participate. Third, it was important for the credibility and reliability of the data that participants came into the interview setting already having in mind a conflict situation that they were prepared to discuss, allowing to maximize the time of the interview and yield thick, descriptive and useful data about their lived experiences. By describing the study purpose and aims to gatekeepers, who often were well aware of the conflicts occurring within their organizations, they were able to specifically pinpoint those who matched the need and encourage them to participate. (Additionally, an unexpected benefit was the number of gatekeepers who reaffirmed that the problem being studied was one that was very real for them in their day-to-day work with student leaders and who would therefore benefit from the results of this study.) Finally, the participant 
sample was very diverse, more so than what would be expected from the PWI environment where the study took place. The researcher attributes this to explaining to gatekeepers her goals of achieving maximum variation sampling, and of gatekeepers encouraging in particular student leaders from various racial identities to consider participating. This yielded rich data that was made stronger by a variety of themes that emerged despite very different leadership types, social identities, and lived experiences of the participants.

The researcher's goal was to use the information solicited in the questionnaire to obtain a diverse sample of leadership experiences and demographic identities; however, given the length of time between unique survey responses and the initial diversity of received surveys, the researcher began inviting participants immediately on a rolling basis to interview until an optimal number of participants was reached. Students who met the criteria for the study were contacted and informed that they met the criteria and were being considered for interviews, and were provided a copy of the informed consent form to familiarize themselves with the study parameters and what is being asked of them (Appendix E). Participants that were selected for interviews were sent a communication inviting them to set up a time and date to complete their interview with the researcher (see Appendix F).

\section{Participants}

The survey was open between August 27 and October 28, 2019. Of 32 survey responses, 12 participants were ultimately interviewed, 12 responses were not complete and therefore were not usable, one was not eligible due to age, two were eligible but 
responded after saturation was reached, and five were eligible but did not respond to invitations to be interviewed. Of the 12 students interviewed, six identified as female, five identified as male, and one participant identified as non-binary/third gender. Further, six identified as White and six identified as students of color, specifically Asian (2), Black (1), and Multiracial (3). The researcher believes in the importance of specific racial identity to the unique and salient lived experiences of the participants, and typically disagrees with collapsing racial categories into "students of color" because it obfuscates this identity and negates the importance of this lived experience. However, because of the context of a PWI and the risk of racial category being an identifying feature of participants whose identities are otherwise masked, the researcher chose to maximize protection of the participants by declining to attribute their specific racial identifications. The researcher also leaves out specific gender identities, majors, and ages of participants in order to further protect participants.

Most participants were involved in more than one leadership experience over their tenure at the institution and/or at the time of the study. Leadership experiences included participation in sorority and fraternity ("Greek") life, student governance, club and organization involvement, student media, and paraprofessional roles such as residence life or cultural centers. The participants ranged in age from 20 to 22 years of age at the time of the interview, and represented a diverse group of majors, including Business, English, Engineering, Math, Biology, and Art. 


\section{Instrumentation/Sources of Data and Collection Strategies}

Colleges, particularly those with a land grant, liberal education mission, purport the importance of developing affective skills in college students in order to prepare them for participation as citizen leaders in a diverse society. However, many institutions do not include the development of these skills sets-including perspective taking, collaboration, and critical thinking — within the curriculum, nor do they regularly assess for these skills. Research has shown that meaningful engagement with diverse peers helps to develop pluralistic attitudes in college students, and a variety of student leadership experiences are shown to facilitate the development of socially responsible leadership. Most of these studies are quantitative and use the Socially Responsible Leadership Scale (SLRS) (Tyree, 1998), creating a gap in understanding about how students perceive and experience their own learning and growth in their leadership positions. Further, virtually no studies exist exploring if and how students experience and navigate conflict, leaving a significant dearth of knowledge about how to optimize a common phenomenon - that of navigating conflict — and leverage the situation to help students develop critical skills and transformative mindsets. These questions are best suited to qualitative study, in individual settings in which the researcher seeks to understand the participant's own experience, in their own words. Given the research questions, goals of the study, and nature of what the researcher wishes to know, the most meaningful sources of data are individual interviews. 


\section{Source of Data: Interviews}

In a basic qualitative study, the researcher is intent on exploring individuals' lived experiences, with a particular focus on how participants make meaning of their experiences and "construct their worlds" (Merriam \& Tisdell, 2016, p. 24). In the case of understanding how undergraduate student leaders experience, navigate, and make meaning of conflict and controversy, gathering information directly from the sources by asking them about those experiences is the most direct way to collect data.

Interviewing - and participant storytelling — is particularly useful for understanding a participant's consciousness, as “individuals' consciousness gives access to the most complicated social and educational issues, because social and educational issues are abstractions based on the concrete experience of people" (Seidman, 2013, p. 7). Weiss (1995) further says that "interviewing gives us access to the observations of others. Through interviewing we can learn about places we have not been and could not go and about settings in which we have not lived" (p. 1). How undergraduate student leaders experience and navigate conflict, and to what end, can only be known and communicated by student leaders themselves. Given the study design (basic qualitative research), research questions, and theoretical frameworks, the researcher conducted in-depth interviews with undergraduate student leaders who have experienced conflict or controversy with a peer since being enrolled at Pacific Northwest University in order to understand how they have made sense of those experiences.

The advantages of interviewing are to obtain rich, detailed data; to bring together multiple points of view; to describe a process (such as navigating conflict); and to 
understand how participants are interpreting their experiences, to name a few (Weiss, 1995). In an effort to understand a particular phenomenon, the researcher used a semistructured interview approach. In a semi-structured approach, questions are grouped by theme or construct, with potential probes or follow up exploratory questions that could be asked based on how the participant responds. This allowed the researcher to follow trends and emerging leads that might not have otherwise been anticipated from the study participants, and also follow some points that were evidently salient to the participants, providing the most unbiased and non-leading approach to answering the research questions. Not all probes can be planned; it is the role of the researcher as instrument to understand when and how to follow what information the participant is providing as part of an emerging understanding of the topic that is yielding new insights, and when to guide the participant back within the parameters of the study if they are getting offcourse.

\section{Types and Sources of Questions}

The most useful interview questions are open-ended questions that allow a participant to share detailed, descriptive information (Merriam \& Tisdell, 2016). Patton (2002) describes several types of interview questions, including experience and behavior questions that explore the activities and actions a participant took, opinion and values questions that examine what someone thinks or believes about something, and feeling questions aimed at understanding how a participant felt or feels about their experience, among other types of questions. Additional types of questions include a grand tour questions, which allows the participant "to verbally take the interviewer through a place, 
a time period, a sequence of events or activities, or some group of people or objects," or presupposition questions, which allows the interviewer to frame an interview question as a strategy (Glesne, 2011, p. 108). Glesne (2011) identifies that the literature about the theoretical constructs or orientation to the study can also inform how questions are framed and asked.

In this study, the researcher asked questions about how students have experienced and navigated conflict, including how conflict showed up for student leaders, what their role was in responding to conflict, and what influence - if any_-peers had before, during, and after the process. Examples of some interview questions in the semi-structured protocol, the purpose and/or research questions addressed by the sample interview question, and the correlated categories and constructs are listed in Table 3.1.

\section{Table 3.1}

Sample Semi-Structured Interview Questions, Purpose, and Correlated Constructs

\begin{tabular}{|l|l|l|}
\hline Sample Interview Question & \multicolumn{1}{l|}{$\begin{array}{l}\text { Purpose/Research Question } \\
\text { Addressed }\end{array}$} & \multicolumn{1}{l|}{$\begin{array}{l}\text { Correlated Categories/ } \\
\text { Constructs }\end{array}$} \\
\hline Tell me about yourself. & $\begin{array}{l}\text { Collect basic demographic } \\
\text { information (name, social identities, } \\
\text { year in school, major, etc.); build } \\
\text { rapport }\end{array}$ & N/A \\
\hline $\begin{array}{l}\text { Tell me about your student } \\
\text { leadership experience. How } \\
\text { did you come to be in your } \\
\text { role? }\end{array}$ & $\begin{array}{l}\text { Understand how they make sense of } \\
\text { their own leadership experience and } \\
\text { journey; "grand tour" question; build } \\
\text { rapport }\end{array}$ & $\begin{array}{l}\text { Student leadership } \\
\text { Consciousness of Self }\end{array}$ \\
\hline $\begin{array}{l}\text { What have you been able to } \\
\text { accomplish in your student } \\
\text { leadership experience? }\end{array}$ & $\begin{array}{l}\text { Understand how they make sense of } \\
\text { their own leadership experience and } \\
\text { journey; build rapport; may inform } \\
\text { RQ 2: In what ways does conflict } \\
\text { facilitate SLR? }\end{array}$ & $\begin{array}{l}\text { Student leadership } \\
\text { Socially responsible } \\
\text { leadership } \\
\text { Leadership self-efficacy } \\
\text { (LSE) }\end{array}$ \\
\hline $\begin{array}{l}\text { How would you define or } \\
\text { describe conflict? } \\
\text { Controversy? }\end{array}$ & $\begin{array}{l}\text { RQ 1.a: How do student leaders } \\
\text { conceptualize or view } \\
\text { conflict/controversy? }\end{array}$ & $\begin{array}{l}\text { Conflict/controversy } \\
\text { Controversy with Civility }\end{array}$ \\
\hline
\end{tabular}




\begin{tabular}{|c|c|c|}
\hline $\begin{array}{l}\text { Can you remember an } \\
\text { experience you've had with } \\
\text { conflict or controversy with a } \\
\text { peer while in a leadership } \\
\text { role that you can describe in } \\
\text { detail for me? }\end{array}$ & $\begin{array}{l}\text { RQ 1: How do student leaders } \\
\text { describe their experiences navigating } \\
\text { conflict/controversy? }\end{array}$ & $\begin{array}{l}\text { Conflict/controversy } \\
\text { Controversy with Civility } \\
\text { Collaboration } \\
\text { Common Purpose } \\
\text { Peers/ peer interaction }\end{array}$ \\
\hline $\begin{array}{l}\text { Describe the steps you took } \\
\text { to work through it. }\end{array}$ & $\begin{array}{l}\text { RQ 1.b: What resources do student } \\
\text { leaders identify as being available to } \\
\text { them? } \\
\text { RQ 2.a and 2.b: What strategies do } \\
\text { student leaders use and where did } \\
\text { they learn those strategies? }\end{array}$ & $\begin{array}{l}\text { Conflict/controversy } \\
\text { Consciousness of Self } \\
\text { Controversy with Civility } \\
\text { Process } \\
\text { Strategies }\end{array}$ \\
\hline $\begin{array}{l}\text { What values guided how you } \\
\text { responded? }\end{array}$ & $\begin{array}{l}\text { RQ 1, RQ 1.a: How do student } \\
\text { leaders describe their experiences } \\
\text { navigating conflict, and how do they } \\
\text { define? } \\
\text { RQ 2: In what ways does conflict } \\
\text { facilitate SRL? }\end{array}$ & $\begin{array}{l}\text { Conflict/controversy } \\
\text { Consciousness of Self } \\
\text { Controversy with Civility }\end{array}$ \\
\hline $\begin{array}{l}\text { Did a peer or peers influence } \\
\text { or change your perspective in } \\
\text { the conflict/controversy? If } \\
\text { so, how? }\end{array}$ & $\begin{array}{l}\text { RQ 2: In what ways does conflict } \\
\text { facilitate SRL? }\end{array}$ & $\begin{array}{l}\text { Student leadership } \\
\text { Socially responsible } \\
\text { leadership } \\
\text { Peers/peer influence } \\
\text { Perspective-taking } \\
\text { Pluralism } \\
\text { Empathy } \\
\end{array}$ \\
\hline $\begin{array}{l}\text { Some people would say that } \\
\text { people who engage in } \\
\text { conflict/controversy are } \\
\text { close-minded or like drama. } \\
\text { What would you say to } \\
\text { them? }\end{array}$ & $\begin{array}{l}\text { RQ 2: In what ways does conflict } \\
\text { facilitate SRL? }\end{array}$ & $\begin{array}{l}\text { Student leadership } \\
\text { Socially responsible } \\
\text { leadership } \\
\text { Controversy with Civility } \\
\text { Attitudes/behaviors } \\
\text { Civility }\end{array}$ \\
\hline
\end{tabular}

In a semi-structured interview protocol that explores student leaders' experiences with conflict and controversy, a variety of question types previously described proved to be helpful. In particular, ordering questions from low-risk to higher-risk was warranted, as discussion about conflict had the potential to bring up feelings of embarrassment, anxiety, or frustration and could lead participants to be less willing to share information. Before asking any questions, spending a few minutes putting the participant at ease, explaining the study structure and process, and building rapport were of critical 
importance. Building rapport set the tone and allowed for a natural build-up to the higherrisk topic of navigating conflict.

For this study, the researcher asked open-ended questions in the areas of student leadership and socially responsible leadership, conflict and controversy, and experiences with conflict and controversy and strategies used (see Semi-Structured Interview Protocol, Appendix G). Within student leadership, the researcher asked questions such as "Tell me about your student leadership role(s)" and "How did you come to be in your role(s)?" These questions were meant to help identify the most salient leadership experiences for students, their sense of Consciousness of Self, and their reflections on their experiences within leadership roles. Examples of questions the researcher asked related to conflict and controversy were: "How would you describe or define conflict? Controversy?" and "Do you believe that the way you approach conflict is similar to how it was when you first started college?" These questions were designed to help answer the research question of this study about how student leaders define conflict and controversy. Finally, in an exploration of student leaders' direct experiences with conflict and controversy and strategies they have utilized, the researcher asked questions including “Can you remember an experience you've had with conflict or controversy with a peer while in a leadership role that you can describe in detail for me?" followed by specific questions of how they navigated that particular scenario (see Appendix G for full list of semi-structured interview protocol questions). The answers to these questions were analyzed to identify themes relative to the development and application of socially 
responsible leadership skills in conflict scenarios, the strategies student leaders employed in conflict situations, and how they made sense of those experiences.

\section{Interview Protocol and Parameters}

The researcher used a semi-structured interview protocol with potential follow up questions, or probes, to allow the interview to build upon what the participant is sharing while also keeping the content focused on the constructs the study is designed to explore (see Appendix G). The protocol questions related to conflict and controversy connected back to the Social Change Model (SCM) of Leadership individual value of Consciousness of Self, and the SCM group value of Controversy with Civility. The questions were informed in part by rubrics for each of these values that were developed for self-evaluation by student leaders, from the text Leadership for a Better World: Understanding the Social Change Model of Leadership Development text (Komives \& Wagner, 2017, p. 63, p. 168) (see rubrics, Appendix H). Because they are untested and subjective, the rubrics informed but did not dictate how questions were phrased.

Recognizing the limitations of her own White racial identity in terms of how the interview questions may be interpreted by participants of color, the researcher also shared the interview protocol with two colleagues of color, both with terminal degrees, to obtain their insights about how the protocol may be improved. Both advised that students may freely identify in the demographic portion of the interview. One advised that students may opt out of providing demographic information in certain categories (race, sexual orientation versus gender, or using ethnicity instead of race), which may delay the initial interview. The other advised that some students do not fit either a "domestic" or 
“international" student category, but may be considered permanent residents or other categorizations based on their nationality and relationship to their education in the United States, and to consider how to create a more open process for how students could selfdefine or identify.

Examples of skills assessed in the Consciousness of Self rubric include "selfawareness," "feedback," and "continual personal reflection" (Fournier \& Colasanto, as cited in Early \& Fincher, 2017, p. 63). Examples of skills related to Controversy with Civility within the rubric include "respect for and courtesy to others," "dialogue skills," and "awareness of worldviews" (Baruch \& Boyle, as cited in Alvarez, 2017, p. 168) (see rubrics, Appendix H). These two constructs in particular were more deeply examined for a few reasons. First, the construct of Controversy with Civility is situated directly in the research questions this study is exploring related to the inevitability of conflict and strategies for managing and leveraging these differences to promote positive social change. Second, data from the Mutli-Institutional Study of Leadership (MSL) suggests that, like other student development models would indicate, the development of capacity within each value follows a sequence of developmental readiness. Specifically, the development of individual values informs development of group values, and the development of group values informs the development of the societal value (Dugan et al., 2013). The goal of an in-depth examination of the value of Consciousness of Self was to allow for any potential insight into impacts of sequencing, developmental readiness, and level of development necessary to effectively develop capacity within the group value of Controversy with Civility. 
Interviews took place once per participant, and ranged between 90 and 120

minutes. Seidman (2013) suggests that 90-minute interviews are ideal, as 60-minutes may have participants more focused on time than on the interview responses, but two hours is a long time to ask someone to talk. Interviews between 60 to 90 minutes in length also allow for a faster turnaround of the interview transcripts in order to engage in ongoing data analysis without undue delay. Ultimately, the additional 30 minutes beyond Seidman's recommendation allowed for a review of the consent form with the participant, for rapport building, and for an opportunity to follow leads and probes a bit more in-depth, yielding new insights.

The researcher interviewed 12 participants, which allowed her to obtain maximum variety across types of student leaders. The interviews took place over a fiveweek time span between September and October 2019. The researcher was able to explore the planned topics in depth in the interview time allotted. Data analysis in the form of coding took place at the end of the data collection and transcription period (see section on Data Analysis), although the researcher did concurrently memo themes she observed emerging as interviews concluded. The researcher spent the first ten to twenty minutes of each interview reviewing in detail the informed consent procedure, explaining how the data would be securely managed, answering any questions the participant had, obtaining consent, and creating rapport. 


\section{Data Collection Procedure}

Following is a review of the procedure the researcher used to collect data for this study. Specifically, the plan to test the interview questions is reviewed, followed by a discussion of how the researcher recorded and securely stored the data.

\section{Testing the Study Questions}

Questions may appear clear, understandable, and well-designed to elicit information directly related to the constructs under study; however, how current undergraduate student leaders understand the meaning of the question may differ from the researcher's understanding. Further, until the questions were tested, it was unclear if they would elicit the richness and depth of data necessary for findings to emerge in the analysis phase. The length of time needed to obtain complete, in-depth answers to questions - and whether this amount of time can be encompassed within one interview or two- - was also unclear until the protocol questions were tested. Pilot-testing interview questions prior to data collection in order to identify if the questions are well-framed or if they need revision is a critical step to ensure the collection of rich, descriptive, useful data (Glesne, 2011; Maxwell, 2013; Merriam \& Tisdell, 2016).

Before conducting the first study interview, but after receiving IRB approval (see Appendices A and B), the researcher was able to conduct one pilot interview with a student who did not attend PNWU but otherwise met the study criteria. The pilot interview allowed for clarity in questions, in adding a question that asked students about the coalescence of their learning and experience with conflict on their leadership, and in developing a protocol wherein the researcher would assign pseudonyms rather than 
asking the participant to choose one. The pilot also demonstrated that a depth and richness of data could be obtained without needing more than one interview; therefore, the researcher planned for one interview with each participant. Given the emergent nature of a qualitative study, the precise wording of questions varied although the content and aims were the same, but piloting the questions ensured clarity and quality of the interview protocol from the outset.

\section{Recording and Securely Storing the Data}

Interviews were recorded using two methods: a handheld recorder and the student researcher's smart phone, an iPhone X. The iPhone was used primarily for data recording because of the quality of sound and the ability of the student researcher to immediately and securely upload the sound file post-interview to the student researcher's University Google Drive account. The institutional Google Drive is accessible via password and requires a dual authentication via Duo, providing an extra layer of security of the data. The information on the digital recorder was collected only as a back-up method, in the case where a technological issue may impact the primary mode of recording the interviews, and was stored in a locked safe in the student researcher's home. All data will be destroyed in accordance with data custodial procedures outlined by the IRB protocols of both oversight institutions post-dissertation defense, committee approval, and relevant publishing of the study findings; according to the Portland State University Office of Research Integrity, "Under the new regulations, [the researcher] may be requested to make your data publicly available.... once the data is de-identified, you can submit it for storage, and then delete it from your records. The general timeline for retention of records 
is five years" (E.Willis, personal communication, May 7, 2019). Interview recordings were saved with a naming convention that connected the recording to a student participant using their assigned pseudonym and the date of the interview.

\section{Ensuring Ethical Collection of the Data}

Fidelity in research fundamentally requires that the researcher goes to the lengths possible to protect participants from possible harms or risks of harm, and where those risks cannot be mitigated, to fully disclose the risks to participants so that they may make free and informed choices about whether or not to participate in the study at any phase. This ethical obligation begins with the recruitment of participants and the collection of data, and should be foregrounded in every decision the researcher makes throughout the duration of the study. Following is a brief review of the strategies utilized to ensure ethical collection of the data in this study.

\section{Ethical Recruitment of Participants and Informed Consent}

The very nature of the study constructs - experiences navigating conflict and controversy - expose participants to some risk of harm. For example, if participants describe engaging with conflict in a way that does not show them in a positive light, they may face reputational damage or lose credibility. Further, reflecting on conflict experiences could bring up feelings of stress, anxiety, anger, or shame. It is important for the researcher to be aware of these risks in an effort to safeguard against them. Seidman (2013) suggests that one of the best ways to prevent harm is to build an informed consent form from the ground-up, versus using a boilerplate example. This allows the researcher to create highly customized and specific language to fit this particular study and 
participants. According to Schram (2006), "gaining 'informed' consent is problematic if, as can be the case in qualitative fieldwork, researchers encounter previously unforeseen questions that lead to new directions for inquiry and different requests of study participants" (p. 54). Given this, the informed consent form not only needs to be tailored to the study and accessible to participants, but also should be worded in such a way that allows the participants to understand that the nature of the inquiry may shift given the emergent nature of qualitative design (see Appendix I for the Informed Consent form). The researcher worked with the supervising IRB to build a consent form that was tailored to the study and thorough enough to help address potential risks, but succinct enough that it was accessible and digestible for participants (Appendix I).

Offering an incentive for participation in the study can serve as both a way to recruit and also as a way to thank participants for their time. However, providing an incentive with a high value runs the risk of appearing to pay participants, and further, could impact their willingness to provide authentic and reliable information (for example, student participants who receive an expensive incentive may feel like they can only give a positive perspective of their experiences or may otherwise temper their responses to the researcher). Therefore, should an incentive be offered, it should be a token only in order to avoid these pitfalls. For this study, the researcher provided a $\$ 20$ gift card to Amazon at the conclusion of each participant's interview. One participant specifically asked if they would be required to accept the incentive, indicating that shopping online with Amazon did not align with their personal values. The researcher assured them that 
accepting the incentive was not a requirement, and the participant declined to receive the incentive.

\section{IRB Process}

This study involves understanding the lived experiences of undergraduate student leaders who have navigated conflict; therefore, no research activities can be undertaken without approval of the Institutional Review Board (IRB). Because the student researcher is a doctoral student at a different institution than the one where the data was collected, the researcher was required to submit IRB approval forms for both institutions and receive approval before proceeding with any participant recruitment or data collection. The student researcher completed IRB approval paperwork for both institutions. The student researcher obtained approval to conduct the research on August 21, 2019. Both institutions conferred and determined that the primary IRB overseeing this research would be at the site where the data was collected.

\section{Protecting the Identities of Participants}

In addition to the security measures listed for storing the data (see section "Recording and Securely Storing the Data"), it was critical to protect the identities of the participants involved. To the extent possible, the researcher did so by disguising the study site through use of a pseudonym, Pacific Northwest University ("PNWU”), and assigned pseudonyms to the participants. The only reference connecting a student participant's pseudonym to their actual identity was in a password-protected "key" document stored securely on the student researcher's Portland State University Google Drive. Given the uniqueness of certain student characteristics within particular student leader roles and 
organizations at a PWI, the researcher also adjusted demographic details as needed or obscured information in the table of participants in the Results chapter, or in some cases, left out key quotes from participants altogether in order to further disguise and protect their identities.

\section{Positionality}

According to Creswell and Creswell (2017), study design and research approach are informed by the researcher's philosophical assumptions and worldview. Because of the interpretive nature of qualitative research, researchers should identify their own past experiences and how those may shape the researcher's interpretations through a process referred to as reflexivity (Creswell \& Creswell, 2017). Identifying the biases the researcher brings to the study allows the researcher to guard against the risk of those biases influencing the outcomes of the study. Schram (2006) describes the importance of researchers that bring critical theoretical assumptions to their work to interrogate their own positionality and name their orientation to the problem under study:

The values of the researcher inevitably influence the inquiry as he or she foregrounds the judgment call that an injustice is holding back someone from something better. This places the particular demand upon researchers to make explicit how their own class status, ethnic or gender orientation, and power relationships relative to research participants affect what is investigated and how data are interpreted. (p. 46)

I approach this inquiry as a mid-30s, White woman with socioeconomic privilege with regards to class (middle class) and education. My career has been entirely in higher education, and I hold a strong belief about the transformative nature of higher education because of the exposure to different ideas, experiences, perspectives, and ways of viewing the world. As a student affairs practitioner, I view myself as an educator in a co- 
curricular environment and believe that out-of-class experiences contribute to student development, growth, and preparation for engaged citizenship. Further, my career has centered on student conduct in housing and residential education, which has inherent assumptions about the roles of reflection, cognitive dissonance, and lived experience in supporting the transformation and growth of students, as well as the role of a community of peers and peer mentors to help facilitate said growth.

All of these lenses and assumptions shaped the way I approached this study and the interpretations I brought to analysis as the instrument of the research. As an educator, I believe strongly in the power of cognitive dissonance and exposure to diverse perspectives to help facilitate student development and learning. Over the last fifteen years, my graduate and full-time experiences have led me to having hundreds of complex discussions with students about their behavior where I am essentially interviewing them to understand their thought processes, motivations, and reflections on their choices, and using probes to follow salient lines of discussion in order to promote student learning, all skills that certainly influenced my interviewing style and technique.

My positionality as staff in residential education also means that I believe in the power of community and diverse perspectives to help make meaning, and believe development moves from an inward-focused, black-and-white understanding of the world to a more complex, outward-focused orientation where one can hold multiple realities at once and be comfortable with ambiguity. These experiences allowed me to have nuanced and rich conversations with study participants while considering where they are developmentally. However, given my belief in the power of conflict for change, 
particularly when in community or in relationship with others, I needed to carefully consider information that does not comport with those beliefs that may have emerged during the study. This lens, if not considered throughout the data collection and analysis stages, could bias my perceptions in a way that impacts the fidelity of the study outcomes. I sought to address this by seeking to understand counternarratives, and through letting the voices of participants serve to shed light on the meaning making I made of the data.

\section{Data Analysis Procedures}

After interviews were complete, the researcher used Otter AI software to do a rough initial transcription of each interview. The researcher then went through each recording and transcript to correct mistakes and ensure meaning was captured accurately. The researcher began initially identifying insights and promising emerging leads as she transcribed interviews. After transcription was complete, the researcher uploaded transcripts into MAX-QDA, a data analysis software system that allows the researcher to securely store the transcript data and code the data electronically, and used the software to organize codes and retrieve code segments during coding and analysis.

The researcher reviewed each transcript and conducted a simultaneous provisional, or a priori, and open coding process (see Appendix $\mathrm{J}$ for the Codebook of all codes). Provisional code families included all six SCM values, Attitudes and Behaviors, Conflict, Controversy, Knowledge and Skills, Leadership Self Efficacy (LSE), Resources, Strategies, and Values and Beliefs. Open coding yielded additional codes and code families that emerged from the data. Specifically, salient open codes and code 
families included Career Goals, Societal Factors, Power, Mental Health, Social Justice, and Student Development.

Merriam and Tisdell (2016) assert that rigor is both a question of methods used and of the conclusions drawn. The second part of rigor-that of reaching sound conclusions - is another critical aspect that Merriam and Tisdell (2016) describe as "the process used to answer your research question(s)" (p. 202). Given this, the strategies the researcher used to ensure accurate conclusions involved reviewing full transcriptions of every interview, conducting a first round review of the transcripts as soon as they were ready to check for any "segments...that are responsive to [the] research questions" (Merriam \& Tisdell, 2016, p. 203) and then identifying anything that felt interesting and important (Seidman, 2013) by taking note of emerging themes, and writing researcher memos immediately after interview (Maxwell, 2013). The researcher also journaled insights at various time throughout transcript review.

The researcher used a coding and categorizing process that simultaneously used an exploratory method of provisional or a priori codes, and an affective method of values codes (Saldaña, 2016), in addition to open coding (see Codebook, Appendix J). Provisional or a priori codes are those that "can be developed from anticipated categories or types of responses/actions that may arise in the data yet to be collected" (Saldaña, 2016, p. 168) and are informed by the literature. Values codes examines and codes for the participants' values, attitudes, and beliefs, and may be included in a list of Provisional codes (Saldaña, 2016). For example, the researcher created a code family called "SRL" (Socially Responsible Leadership) wherein each SCM value was a specific code 
("Consciousness of Self," "Congruence," "Commitment," and so on). This category was fixed. However, other code families that were created had additional codes added during the coding process. For example, the code family "Conflict" included subfamilies of codes related to conflict style, conflict causes, and conflict characteristics, among other codes. Some transcript segments were coded with multiple codes.

The researcher also reviewed the transcripts as part of an open coding process, or what Saldaña (2016) refers to as Initial Coding, for any emerging codes that were not accounted for in the provisional and values coding process. This coding method is useful for allowing ideas and themes to emerge from the data that may not have been anticipated so that they can be further explored and compared across the data. The researcher nested these emergent codes by grouping them thematically to the extent possible. For example, some participants spoke to the importance of being exposed to a different point of view or trying something they had never done before as experiences they could point to that helped them grow. The researcher coded these segments as "Multiple truths or perspectives" and "Trying something new, out of comfort zone" respectively, and grouped them into a new code family she called "Student Development."

As part of the coding process, the researcher reviewed the data for connecting themes, what Maxwell (2013) refers to as a connecting strategy. This was important because the research questions driving the study were concerned in part with the interrelationship of conflict resolution to leadership and skill development, questions that cannot be answered through categorizing strategies alone. The researcher continued this process until saturation was reached and similar themes seemed to be arising from the 
data (Merriam \& Tisdell, 2016). The analysis process was iterative. In the initial data analysis process, as transcripts were reviewed, codes were added within nested code families as appropriate, and emerging themes were memoed in the researcher's journal. As part of this iterative process, the researcher categorized and recategorized the themes that emerged across the voices of diverse participants the analysis process, and then used the connecting strategy to understand how themes interrelated and intersected. From this process, a secondary round of analysis occurred, as the pervasive and recurring themes in the data illustrated both a process of development and growth that ultimately pointed to a model of socially responsible leadership, as well as structural elements that support this development in student leaders. These themes were reorganized into a model and updated definition of socially responsible leadership.

In the analysis phase, the researcher rigorously examined potential alternative explanations for the findings in order to maintain fidelity in the study within the context of the researcher's values and biases. Maxwell (2013) characterizes the "way[s] you might be wrong" as "validity threat" (p. 123), and Merriam and Tisdell (2016) identify one method of sussing out alternative explanations is through "negative or discrepant case analysis" (p. 249). This allows for comparison of alternative or contradictory information that also loans credibility to the results (Creswell \& Creswell, 2017). In the case of the data presented in Chapter 4, the findings reached were done so through a thoughtful examination of the participants' own words. 


\section{Trustworthiness}

In qualitative research, which is not concerned with the generalizability or "stability" of findings, validity and reliability are concepts that have a very specific meaning appropriate to the research method. Creswell and Creswell (2017) describe qualitative validity as referring "to the accuracy of the findings" and qualitative reliability as referring "to the idea that the researcher's approach is consistent across different researchers and among different projects" (p. 199). In qualitative research, validity may also be called credibility of findings or trustworthiness, and certain strategies of the researcher can strengthen the trustworthiness of the findings. The trustworthiness or credibility of findings in a qualitative study must be attended to throughout the study, beginning from the alignment of the research method, design, and questions, through the data collection and data analysis steps. Merriam and Tisdell (2016) characterize the components of rigor in a study as a consideration of the methods used and of the conclusions drawn. The previous sections of this chapter reviewed the justification for the selection of the research method and design and congruence with the research questions, which specifically answers questions about the methods used. Following is a discussion of the criteria used for obtaining trustworthiness as well as strategies employed to ensure trustworthiness of the data in both the data collection and analysis phases, which provides an answer for the second question of rigor: accuracy of the conclusions.

\section{Criteria for Trustworthiness}

Because of the constructivist nature inherent in a basic qualitative design approach, concepts such as validity are less applicable as criteria for the soundness of the 
data (Patton, 2002). Lincoln and Guba (1985) argue that instead of internal validity, external validity, reliability, and objectivity, a different set of criteria should be used; the corresponding parallel constructs are credibility, transferability, dependability, and confirmability. Following is a brief review of each of these criteria.

\section{Credibility}

Because no one reality or "truth" can be known from a constructivist lens, internal validity is not an appropriate measure. Credibility, on the other hand, occurs when the researcher has "represented those multiple constructions adequately," [emphasis in original] and in a way that rings true to participants in the study (Lincoln \& Guba, 1985, p. 296). Credibility exists when the researcher has adequately and accurately reflected the participants' experiences.

\section{Transferability}

Qualitative research is not generalizable; instead, transferability is the concept of focus. Transferability refers to the degree to which the learning or insights gained from one study transfers or "can be applied to similar contexts and settings" (Bloomberg \& Volpe, 2012, p. 31).

\section{Dependability}

Rather than reliability, qualitative researchers should seek to ensure their research is dependable. Dependability occurs when the researcher has thoroughly documented the process and methods used to reach their conclusions, so that those methods could be replicated or reviewed (Bloomberg \& Volpe, 2012).

\section{Confirmability}


Instead of the idea of objectivity, which Lincoln and Guba (1985) state puts the researcher and their objectivity at the center, confirmability looks instead at what the data themselves indicate. According to Bloomberg and Volpe (2012), "although qualitative researchers realize the futility of attempting to achieve objectivity, they must nevertheless be reflexive and illustrate how their data can be traced back to its origins (p. 126).

Following is a review of the strategies used to help meet these criteria for trustworthiness in this study.

\section{Strategies for Trustworthiness}

Various strategies to ensure trustworthiness were employed at different points of the study, in data collection, analysis, or both. For the purposes of this study, the researcher planned to use peer debriefing (Creswell \& Creswell, 2017) as well as transcript review (Seidman, 2013) in data collection and analysis in order to support trustworthiness. Following is a brief description of how the main strategies were employed for this study, and at what phase (see Appendix K for a visual representation of the study phases, strategies employed, and specific actions taken within each strategy).

\section{Peer Debriefing}

Peer debriefing is a strategy that allows someone besides the researcher to review the raw data and weigh in on if the data, in their view, corroborates the emerging findings identified by the researcher (Merriam \& Tisdell, 2016). Creswell and Creswell (2017) indicate that this practice is useful "so that the account will resonate with people other than the researcher," which "adds validity to an account" (p. 201). In addition to the support of the researcher's dissertation committee in performing this role, the researcher 
also processed emergent findings with her advisor (Miles et al., 2018) several times throughout the data analysis stage.

\section{Transcript Review}

Seidman (2013) offers a useful discussion about reviewing a transcript to support credibility of the data collected. He suggests that context such as "the syntax, the pauses, the groping for words..." can provide clues that "[the participant] is grappling seriously with the question" (Seidman, 2013, p. 28). He further offers that a review of the transcript can yield visual insight about the extent to which the researcher has allowed the participant to make sense of the question by not interrupting and allowing space for the participant to consider what was asked and formulate a response, allowing the thoughts expressed to be truly those of the participant (Seidman, 2013). The researcher conducted this process initially after the first interview transcription, and identified ways she could make even more space for participants to expand on their thoughts. The researcher reviewed subsequent transcripts for the context clues Seidman (2013) indicates, and in the transcription process, was able to identify words, phrases, pauses, and other behaviors that indicated the deep reflective and thought processes of participants. The researcher also journaled to reflect any insights and noteworthy signals that the participants' words were authentic and their own.

\section{Ethical Considerations}

Ethical considerations are of paramount importance and should be attended to thoughtfully through every phase of the study, from proposing the research, through the interaction with participants, and by following through with appropriate data retention 
and disposal procedures in accordance with Portland State University's data custodial guidelines at the conclusion of the dissertation research. Following is a non-exhaustive list of the ethical considerations that the researcher considered and attended to, with a discussion of steps the researcher took to ensure ethical obligations were met.

Given the nature of a qualitative study where interviews are the primary mode of data collection, some level of intrusion is inevitable. This risk means a clear informed consent form that lays out the risks and benefits to participants is essential, and it was imperative that participants did not feel coerced into participating but rather felt free to end their participation and revoke their consent at any time.

The nature of qualitative research, particularly with interviewing as the primary source of data collection, brings with it the risk of vulnerability and a deep sharing of personal or private experiences of the participants with the researcher. This risk was especially high in a case where undergraduate student leaders were sharing their experiences navigating conflict situations. One mechanism used to address this ethical concern was to maintain appropriate boundaries with the participant. The researcher disclosed her role as a staff member at the study site and therefore her limits to confidentiality and any other mandated reporting obligations under Clery, Title IX, and Mandatory Reporter state law, and to make referrals to appropriate campus resources should the student leader participants disclose feelings of distress or otherwise express that they require further support. This disclosure happened at several points in the process: in the participant Qualtrics survey (Appendix B), in the informed consent form 
(Appendix I), and at the beginning of each participant interview, prior to the student signing the informed consent form.

\section{Limitations}

Limitations refer to external factors "that restrict or contain the study's scope or may affect its outcome," while delimitations refer to those factors that the researcher puts in place in order to limit the study's scope (Bloomberg \& Volpe, 2012, p. 103). The choices in method and study design, chosen for the advantages they offer in terms of insight into student leader experiences with conflict, necessarily limit or otherwise obfuscate other opportunities in this research. Given that this study is qualitative, the most significant limitation is the lack of generalizability of the results; the boundedness of the participants, location, and time mean that the study is relevant in and to the context studied. The regional culture of "Northwest Nice" may have also impacted the results of this study; possibly, the same research done in another region of the country would have different outcomes or results because of regional differences. Well-documented procedures, however, may allow for a replication of this study at other sites.

Another potential limitation is the extent to which student leaders have engaged in conflict and so can meaningfully discuss those experiences, or their willingness to engage in a dialogue about those experiences — which are sensitive and could pose some risk - to a researcher that they do not know. Further, due to the researcher's staff role at the study site, it is possible that some student leaders purposefully screened or otherwise moderated their responses, although given the depth of their answers and reflection, does not seem to be the case. Finally, in a conflict scenario, there is necessarily more than one side, and yet 
the researcher was only able to get one perspective - that of the participant. The participant's perspective may be limited based on what they know, their own developmental level, or the level of reflection they have or have not done within the situation. Choosing juniors and seniors to interview helped mitigate this somewhat, and the researcher was surprised to find that student participants were often speaking of conflicts that were part of an interconnected web of student organizational relationships.

\section{Chapter Summary}

The purpose of the study is to understand how undergraduate student leaders navigate and make sense of interpersonal conflict experiences with peers. The main questions explored how undergraduate student leaders described their experiences navigating conflict/controversy, and in what ways experiences working through conflict/controversy helps to facilitate the development of student leaders' socially responsible leadership skills. Little is known about how undergraduate student leaders experience conflict and controversy, and most studies related to the development of socially responsible leadership skills are quantitative, leaving a gap in understanding the lived experiences of students. Given these questions, the research method is qualitative and the research design is a basic qualitative study. The participants are undergraduate student leaders holding formal leadership positions, either elected or paraprofessional, at Pacific Northwest University, a large, public, doctoral-granting institution in the Pacific Northwest. Data was collected from 12 participants with various social identities and leadership experiences using individual interviews that lasted between 90 and 120 minutes. Strategies for trustworthiness were used at both the data collection and data 
analysis phases and included triangulation of participant experiences, member checking, peer debriefing, transcript review, the use of rich, thick description, disclosure and reflection on researcher bias, and discrepant case analysis. Limitations include lack of generalizability of the results and the limits on time that can be spent with participants. Data was analyzed by reviewing interview transcripts, using MAX-QDA, through a simultaneous provisional, values, and open coding process, and then a review of those codes into themes.

Conflict is inevitable. With the challenges of conflict also come promising opportunities of transformative growth of students, the development of students' critical affective skills sets, and may ultimately contribute to students' preparedness as engaged citizens in post-college life. However, prior to this study, little was understood about the extent to which students or student leaders experience conflict and controversy, how they made sense of and navigated those experiences, and if those experiences actually facilitated the development of socially responsible leadership skills. This study was designed to explore with student leaders how they have experienced conflict with a peer in their student leadership roles. The goal of the study is to offer insights for college and university leadership about internal and external factors related to the positive resolution of conflict and the fostering of student development through conflict in order to design optimal learning environments for the next generation of citizen-leaders. 


\section{CHAPTER FOUR: FINDINGS}

In this chapter, the findings that emerged from conducting interviews with twelve college student leaders of junior or senior standing at the research site are presented. After summarizing participant characteristics and revisiting the research questions, the chapter begins by describing how student leaders described their experiences navigating conflict and controversy with peers, including how they defined the differences between conflict and controversy and how those perceptions differ based on identities of the participants. The chapter then describes findings related to how the student leaders were impacted by their experiences with conflict and controversy, followed by a review of what strategies student leaders used to navigate conflict and controversy. Next there is a discussion of the motivators and inhibitors for student leaders as they navigated conflict and controversy with peers; in other words, what factors supported conflict resolution and what factors inhibited conflict resolution for the participants in this study? The data coalesced into a definition of socially responsible leadership, and a model of how students developed socially responsible leadership skills, both of which are discussed at the end of the chapter.

\section{Participants}

Individual interviews were conducted with twelve student participants, whose ages ranged from 20 to 22 years old. All participants were of junior or senior standing and were currently enrolled at the research site at the time of the interviews. Student leadership roles included serving in student government, participation in sorority and fraternity life, participation within a range of student media, and serving in various 
paraprofessional roles, including in residence life, cultural centers, and other campus jobs. Several participants had leadership experience across multiple types and positions; the ones listed in the accompanying table are those that were most salient for the student leaders as they described conflict they had experienced with peers (see Table 4.1). Students also represented a variety of majors, including Business, English, Engineering, Art, Math, and Biology.

Demographically, six of the twelve participants were female, five of the twelve were male, and one student identified as nonbinary/third gender. Of the twelve participants, six were White and the other six identified as students of color, specifically: Asian (2), Black (1), and Multiracial (3), with one participant identifying as several races (Multiracial) in their questionnaire and as Native American but preferring the term Indigenous in the interview. The researcher values the importance and saliency of racial identity for meaning making and development for the participants, and believes that the racialized experience in the United States differs based on specific racial identities and individuals' lived experiences. Therefore, this researcher generally does not support the collapse of racial categories into "students of color," but rather prefers to name students' race based on how they self-identify. However, given that the racial disposition of the participant sample does not reflect the racial breakdown of students at the PWI research site, and in order to further protect the identities of individual participants at a PWI, racial categories of students who do not identify as White are not otherwise attributed to individual students in the participant table (see Table 4.1). 
Table 4.1

Participant Table: Pseudonyms, Leadership Type, Race, and Class Standing

\begin{tabular}{|l|l|l|l|}
\hline Pseudonym & Leadership Type & Race & $\begin{array}{l}\text { Class } \\
\text { Standing }\end{array}$ \\
\hline Erin & Greek Life & White & Junior \\
\hline Ryan & Greek Life & Student of Color & Junior \\
\hline James & Student Governance & Student of Color & Senior \\
\hline Jordan & Clubs and Orgs & White & Senior \\
\hline Mark & Student Governance & Student of Color & Senior \\
\hline Michael & Paraprofessional: Housing & White & Junior \\
\hline Abby & Student Media & White & Senior \\
\hline Abram & $\begin{array}{l}\text { Paraprofessional: Campus } \\
\text { Job }\end{array}$ & White & Junior \\
\hline Casey & Greek Life & Student of Color & Junior \\
\hline Elena & Student Governance & White & Junior \\
\hline Gia & $\begin{array}{l}\text { Paraprofessional: Cultural } \\
\text { Center } \\
\text { Student Governance }\end{array}$ & Student of Color & Senior \\
\hline Carmen & Student Media & & \\
\hline
\end{tabular}

\section{Research Questions}

This study exploration of student leaders and conflict has two research questions:

1. How do undergraduate student leaders describe their experiences navigating conflict/controversy at a large, public institution in the Pacific Northwest?

2. In what ways does experience working through conflict/controversy at a large, public institution in the Pacific Northwest help facilitate the development of student leaders' socially responsible leadership skills?

\section{Student Leader Experiences Navigating Conflict and Controversy}

In order to understand how student leaders developed socially responsible leadership skills by working through conflict with a peer, it is important to first understand how student leader participants make sense of conflict and controversy and 
how their identities impact the ways in which their identities impact their conceptualizations. Specifically, this conceptualization includes definitions, including an interpersonal versus group distinction in conflict, and any evident differences in these conceptualizations across identities.

\section{Student Leader Definitions of Conflict and Controversy}

In seeking to understand how college student leaders experience and navigate conflict and controversy with peers while in their student leader roles, of interest is an examination of how student leaders in the study defined or differentiated between conflict and controversy. The question was a tricky one to answer for some student leaders, who found it easier to describe attributes or give examples of each. Some common characteristics emerged among the participants as defining features of both conflict and controversy. The examination of the two terms with participants asked them to consider if conflict and controversy were different, and if so, in what ways. The question was purposefully comparative and the concepts were examined in relationship to each other. For some student leaders, both concepts felt very similar to each other; to others, they felt different but they found it difficult to articulate exactly how.

In the Social Change Model (SCM) of Leadership, conflict is defined as two opposing sides that requires someone to take a position. Controversy, on the other hand, is described as a perspective-taking exercise that involves dialogue or discourse around an idea without a commitment to a position one way or another (Alvarez, 2009). In this study, the most commonly expressed features of conflict were that it is interpersonal, or 
between individuals, and that it is defined by participants as negative, opposing sides.

James described it this way when discussing his conflict style:

It'd be easy if conflict was just one sided, right? If one person for no reason just did something, and it was offensive, and you were able to address it. That's really easy. But unfortunately, I don't think conflict really works like that. It's a lot more gray and muddled, and it tends to be mutual. It's like we're both doing something.

From James' perspective, conflict exists because of a difference or agitation between two different parties. Conflict is not a one-way proposition; the oppositional, interpersonal dynamic are defining features of conflict. The interpersonal nature of conflict was echoed by several of the participants in the study.

While student leader participants in this study conceptualized conflict in a similar way as the SCM, they did not necessarily share the same sentiments regarding controversy. In fact, the features connected to controversy that facilitate development and understanding in the Social Change Model were attributed by many student leader participants to positive or healthy conflict as opposed to controversy. Controversy, on the other hand, was viewed as more public or large-scale, and was defined as a difference of opinions or ideas that resulted in a polarized stance on an issue. Several participants articulated the belief that controversy can exist without conflict, or without leading to conflict. The key defining feature was the difference of opinion on a similar perspective, and that those opinions tend to be widely-held, often resulting in polarization. Abram described it this way: "I almost view [controversy] as a deviation in ethical value. Like... there's a controversy because a large amount of subset of people are viewing things one way and a large amount of people are viewing things another way." 
Overall, student leaders tended to view conflict as more interpersonal and tending to have a negative connotation, whereas controversy was seen more as factions or larger groups of people who are polarized around particular issues. Conflict tended to be viewed as more one-on-one or taking place among small groups, whereas controversy was viewed as more societal or broad. Most participants' views of conflict were that generally, conflict can lead to healthy and productive outcomes. Given that several student leaders expressed their belief that conflict is inevitable, the belief that conflict can be healthy and productive is important to understand and consider as college administrators work to support the development and growth of student leaders through conflict. This framework - that conflict is both inevitable and can lead to healthy outcomes - was the crux of how student leader participants experienced, navigated, and developed skills sets related to conflict and leadership. The implications of this finding for campus administrators will be discussed in more depth in Chapter 5.

\section{Identity-Specific Considerations}

Participants in this study were largely self-aware and were able to articulate their own social identities and the ways those impacted their leadership and their conflict styles and experiences. Gender was one factor that was salient for many of this study's student leader participants; in particular, the intersections of a racialized experience with gender was a common theme that emerged. In a discussion of her values of leading with her heart, Gia described a related challenge, sharing:

I guess the challenges are just... being dismissed as being emotional, especially as a woman of color. I guess that's pretty frustrating.... I'm always thinking, are they thinking I'm way too emotional because I'm a woman? Or especially when I'm having conversations with my male friends, and I'm upset or crying or whatever. 
Are they thinking, "oh my God, there she goes again, because she's a woman"? I don't know.

In addition to trying to navigate a situation that took her by surprise, one female participant expressed the additional layer of her identity that she was contending with when experiencing a confrontation with a male peer:

And he was very... I recognize it now as like, anxious, upset, uncomfortable, but I perceived at that time as aggression. Especially just because... I definitely recognize that I'm a small [race redacted] female. And so I definitely recognize that there's a difference in the way that especially male [peers] will talk to me versus my male student leader peers, which I don't appreciate. And that actually makes me just stand even firmer in whatever I've decided on, 'cause I just, [it] makes me really mad.

In navigating unexpected conflict that landed as aggressive, this student leader's racial and gender identities became very salient; in addition to managing the interpersonal conflict and finding strategies for resolution, she was also navigating issues of making sense of her own identity, role, authority, and climate of the organization, making an already difficult situation additionally challenging.

Gender was a salient lens for the White women in the study as well. Abby also spoke directly to the way gender identity plays out in groups. When describing skills that she thought were important for student leaders to have, she specifically named a gendered dynamic in who gets air time:

Knowing when to take space and make space. I think a lot of male-identifying student leaders have a problem with that. So thinking about how many comments have you made? And is there someone that is more... that has a more diverse perspective, that's going to say the same thing as you? Because if there is, you should probably shut up.

For Jordan, her gender was a very salient identity and a point of pride that guides her leadership experiences. She shared: 
Talking about how it guides me as a leader, maybe not necessarily as a core value, but being a woman is also I think, a really big factor.... I've learned in some spaces, I have to have a louder voice. I was... the first woman to be a president of [a student organization].... And that's a field that's very heavily dominated by men. And we went from having only two women on the board when I was [in a leader role] to like, five or six. And we doubled the size of the board and doubled the amount of women who were on the board, because I was very determined to have more voices. But also, I think that does mean that I'm very aware at some points of how I show up in spaces as a woman.... That's a driving force for me, I want to make a difference, and I want to make a change. And I want to do it as a woman.

Several male participants were also able to name the connectedness of their gendered identities to how they navigate student leadership spaces. Mark described experiences of being thoughtful of how he shows up in conflict situations as a male in particular, sharing:

So whenever I do have a conversation, or have a conflict... the only identity I really think about is me being a male, because that is something that I try to be mindful of. And whenever someone is, specifically a female- identifying individual is explaining something and I feel like they might have explained something wrong, I don't... I'm like, maybe I shouldn't just interrupt. Because my intention is not to be someone who is like, you're wrong.... My intention is more that the information that we're providing is accurate.... And so if I was interrupting, say a, a man or a male-identifying folk, I might be more comfortable in just straight up calling them out. Or not calling them out, but in a more direct fashion. But when I have a conflict with a female, and this is a person who maybe I'm not close with... I'm just more mindful of the words that I use. Or how I structure that. So maybe it's in a way that if the information was said, maybe I asked a follow up question that sort of makes them realize that maybe it was incorrect, or it's not like a direct like, "oh, you're wrong, and this is the correct information," but it's more of just like an indirect way of doing it.

James echoed the idea of paying attention to his gender identity, and also discussed the intersection of his gender and how he shows up in spaces with his racial identity. He shared:

I'm more mindful of how I take up space. I'm definitely a lot more mindful and conscious of how I take up space given my identity. It's like, I recognize that I'm a 
man. But I'm also a [named his racial identity] man. So if I were to go to a space with other men [with my same racial identity], I would feel comfortable talking, because that's a space that I can claim. What if I was the only man in maybe a more social justice-oriented conversation? I probably wouldn't take up as much room.... So one thing I learned is I'm more mindful of how I take up space. Especially in certain context and situations.

Interestingly, women seemed to identify their growth around the development of their own confidence by working through conflict experiences, whereas men cited their student leadership roles as being key facilitators of conflict skills development. Mark shared that his student leader experiences contributed to his ability to manage relationships with co-workers who are also friends, particularly when they are not completing job tasks related to their roles. Similarly, when asked to what he attributed his development of his conflict resolution skills, Michael expressed reflection on what it means to be a student leader, and identifying from other leaders what sets them apart as leaders. James recognized that while he has developed through his student leadership roles, his conflict resolution skills will continue to grow as he continues to navigate leadership experiences throughout his life.

The role that identity plays in peer-to-peer conflict is important for advisors to consider when coaching and supporting students, particularly as students are navigating multiple complex dynamics that may require validation and additional resources outside of conflict resolution strategies. Further, advisors should consider in these cases opportunities for validation but also empowerment, working with students to help them identify and process how they would like to proceed, versus taking the ability to resolve it on their own away from them. 


\section{Impacts of Conflict and Controversy on Student Leaders}

Beyond the ways that student leaders conceptualize conflict and controversy and describe their encounters with conflict, an additional important subset of themes were both the positive and negative impacts that conflict had on student leaders. According to a study by Johnson and Ferguson (2018) on the civic identities of college students and the role of political engagement in those identities, several participants found conflict in a political frame distasteful and as something to avoid. The current climate of political divisiveness (Eagan et al., 2017; Pew Research Center, 2016) may inhibit a willingness by college students to engage in conflict (Johnson \& Ferguson, 2018). Similarly, a chilly campus climate for students of color create environments of conflict that can and do undermine the learning environment for these students (Cress, 2008). Students in the HERI 2016 Freshman Survey reported a lower tolerance of having their own views challenged (Eagan et al., 2017), and according to a study by Pew, participants in the study were more likely to maintain close friendships with others who aligned with them politically (and, by extension, perhaps ideologically) (Pew Research Center, 2017). Relative to these insights from the literature, participants in this study spoke to experiences with incivility and being caught off-guard in conflict situations, challenges of climate, and fear of losing friends.

Opportunities for positive outcomes are also inherent within conflict situations. Specifically, a constructivist perspective assumes that knowledge and meaning are cocreated; from the perspective of Chang et al. (2005), this "sociological imagination" allows one to better understand self and the world because of exposure to other points of 
view. Related to student learning is the process of student development, or the idea that dissonance from new information and ideas allows one to grow and develop in their understanding of the world. Chang, Astin, and Kim (2004) found that cross-racial interactions promoted student intellectual and skill development as well as citizenship behaviors. The development of emotional intelligence (Goleman, 1998) is one potential outcome of working through conflict scenarios. Exercising empathy and multicultural citizenship are important skills in the process of discourse in community (Bonnet, 2009), and, emergent themes from this study also suggest that these are outcomes of participation in conflict as well.

In order to understand the big picture of how student leaders experience and navigate conflict with peers on campus, it's important to understand how they have been impacted by conflict and controversy with peers while in their leadership roles. This section will review the interpersonal and emotional impacts of conflict with peers on participants, as well as the psychological, academic, and professional impacts of conflict, both positive and negative.

\section{Interpersonal and Emotional Impacts}

The participants in this study described a myriad of emotional and interpersonal impacts of conflict. Two salient themes across many participants was being very concerned about losing friends or actually having friendships and relationships with others suffer as a result of the conflict they experienced; and, as student leaders made sense of what was important to them and what they value, experiencing role 
incongruence and cognitive dissonance relative to their values, which for many of them was the conflict.

\section{Impact on Interpersonal Relationships}

A commonly expressed theme across several participants in this study was a focus on their relationships with their peers and how experiences of conflict could or did threaten those relationships. Elena described her reluctance to assert her perspective in a conflict because she had relationships with peers who landed on both sides of a conflict, which ended up backfiring on her:

Having built relationships with all these different people that disagreed with each other... It was hard, because even though I felt like, once I was in the wrong, I felt like if I had expressed that too much, it would almost detrimental to our relationship. I think that things were just taken too far. And I just wanted to try to keep the peace, but in reality, it just ended up keeping this sense of controversy.

Abby shared a similar concern related to why she tries to avoid conflict, and was particularly unsettled by the idea of having peers who dislike her. She described not liking being passive aggressive, but believes passive aggressiveness has become a part of her conflict style in order to avoid experiencing malevolence from her peers, sharing "Being passive aggressive allows me to not have enemies." Abby acknowledged that she has become more confident and willing to stand up for herself, but also is uncomfortable with the idea of being out of positive relationship with her peers.

Abram described growing in his conflict style and emotional intelligence because of experiencing the consequence of losing friends. He shared:

Abram: And now I've definitely seen growth in being able to understand other people's perspective and I guess, being more empathetic.

Jill: Where do you think that came from? 
Abram: Losing friends because of conflicts that didn't need to happen, that was irrelevant, but it led to falling out.

Abram described the idea of the level of consequence from a conflict situation did not match the intensity or level of concern of the conflict itself, and this disorientation and loss of friendship changed how he engages in perspective taking in conflict situations now.

Several participants described losing friends or having damaged relationships as a result of conflict, and the isolating and stressful outcome connected to loss of relationships. Jordan described the damage to her relationships after a student leadership opportunity led to a change her living situation. She shared:

When I [took] the job... I lost my entire friend group. They were all really upset. My roommate was very upset that I was moving. Kind of isolated me from that. So I was feeling really alone and kind of lost.

James had a similar feeling of loss as a result of the conflict he experienced, sharing: “...From that I felt like I lost a lot of friends and... is just really stressful. And it just wasn't a good thing to do." Erin had a shared experience; her loss of friendship occurred after her position required that she hold her friend accountable within the organization. She shared:

I think the relationship that we had... was instantly strained. We just kind of fell out of... we really didn't talk anymore. I would check in with her every once in a while and just see how she was doing. She just really didn't want to talk. And when she did, she really was not happy, and she expressed that. So that was pretty tough.

Ryan similarly experienced the difficulty and fallout from holding a peer accountable, but also recognized the inevitability of his dilemma when he reviewed the options of how to move forward: 
Another option was to continue on as normal. Nothing will change, which reasonably was not an option at all, because our relationship at that time was compromised. He resented me a whole lot. But we cannot obviously work together, and it would not solve anything. He would not change. Things will not change.

Student leader participants in this study expressed a value and care for their peers and found belonging, inclusion, and purpose through their relationships; the alternatives many of them faced were stress, loneliness, and loss. The potential or actual outcome of loss of relationship was a very real negative impact for student participants in this study.

\section{Conflict Between Role and Beliefs}

One key emergent theme that developed was the widely-held belief of the importance to committing to values, and the conflict created when students were trying to reconcile their own conflicting values with their role expectations. In light of a student development process, key facilitators of committing to values among participants were perspective-taking, critical thinking, and reflection.

About half of the participants described the source of their conflict as a conflict between what their role required of them and how they really felt about the situation-a crisis of conscience and values. James described it as "there was that conflict of like, my role versus myself. Like, my role was kind of forced to do something that myself didn't do it." When asked what he would have done differently in the situation he described, he talked about how not standing up for his values led to a significant conflict and that he would do that piece differently if he could:

Next time I'm in a leadership position, I'm going to stand up for myself more, and not put myself in a situation quite like that one again. Because I've just learned that in life, you're going to run into people... who are going to put you in those situations. It's on you as to how you want to deal with that. You can't allow them 
to walk all over you. Or you can take the harder road, just substantially harder, and stick up for yourself. Make sure that you're doing something that's reflective of what you actually believe.

Similarly, Elena also faced difficulty managing the expectations of the role and organization with advocating for what she really believed. She described being stuck in not being able to express her real perspective on a matter in a way that would not endanger her position:

[The advisor] had kind of started to... That's when I noticed them kind of trying to sway me to kind of agree with their perspective. And I didn't agree. But I couldn't really express that. Especially because I knew that that could mean they would become biased against me, which would create issues further with my role.

Elena, when asked if anything about her leadership style had changed since experiencing the conflict she described, shared a similar sentiment as James - that she is more willing to be vulnerable and stand up for what she values:

I'll make myself vulnerable, I'll put myself in that position if I feel like it's the right thing to do. And I've kind of accepted that... where I put myself sometimes places me in drama and conflict, and that's something that [in] life, you have to deal with.

For these students, they recognized they had a set of expectations and a natural positionality due to their student leadership positions, and felt pressure to conform to those, but also struggled when their personal feelings and values were not aligned with what was expected of their roles. Part of this challenge may come from a natural developmental process of working out what is important to them, but also having lived experiences in their student leadership roles that pose disorienting dilemmas in terms of being forced to choose how to respond in difficult situations, and needing clarity of values in order to do so. 


\section{Psychological Impacts}

In addition to impacts related to interpersonal dynamics and role incongruence with personal values, many students described the stress of their experiences and the role of mental health in how they made sense of their own experiences and also as a consideration for them in how they acted to support their peers. Additionally, a few participants disclosed childhood trauma that have had an influence on the ways they approach conflict situations as emerging adults. Following is a discussion of the themes of mental health and trauma and the ways conflict impacted those psychological aspects, and vice versa.

\section{Mental Health Impacts}

Navigating mental health is an experience that several participants described from a very young age, and that they continued to navigate after coming to college. Several participants disclosed their own mental health diagnoses, including anxiety disorders and Obsessive Compulsive Disorder, and how those diagnoses have impacted the ways they navigate their leadership positions and life at college. Mental health was a salient concern for every participant, and awareness of both their own and others' mental health impacted how student leaders enacted their own leadership.

When asked about her core values, Elena named specifically mental health and her concerns about the mental and emotional wellbeing of her peers. When asked how what she values shows up in her leadership roles, she shared:

I think that when I go into these leadership roles, I feel like I'm not as focused on the specific small projects and things that we're doing as I am on how individuals are doing, if that makes sense. If I go into a meeting, I'm not just thinking about 
the agenda, I'm thinking about how is everyone doing? But then it's like, that can be off-topic, quote, unquote, but I don't think it actually is.

Casey expressed a similar concern about how peers are experiencing meetings and managing mental health concerns, sharing:

I guess another thing that is not always considered, but is pretty big to me, is considering other people's needs emotionally, whether it's like delivering feedback, or just being at a decent volume during meetings, because a lot of people require different things for whatever traumas they may have, or sensitivities to light and sound and things like that. It's very irregular for neurotypical people to think about things like that.

In her student leadership role, Carmen was also specifically concerned about student leaders who reported to her, with a particular focus on their mental health and attentiveness to their mental health concerns: "And now I've been able to help [other student leaders], because I noticed something about them... I saw the signs of anxiety that... weren't noticed by someone else, and was able to step in and help them from spiraling." She also shares her orientation to mental health concerns in general and the ways she strives to create an inclusive environment: "I always try to have empathy and understand where people are at emotionally, and not make them feel anxious or unwanted or unsafe."

Abram described a similar experience of the desire of a safe environment connected to his student leadership position. He expressed the way that his organization's site serves as a defacto non-clinical mental health support as an outlet to student peers who have experienced some significant trauma and mental health concerns. He shared:

There's two students... this is like kind of like a lot, because I don't get emotional. But these two students hit a chord with me. One of them was actually not even a student, he went to [another institution], weirdly enough. Ran cross country track there, and graduated a year before me. Moved back home because he has cancer. I 
think he may have passed away, I don't know for sure. But the escape was the [center] for him... As soon as I talked to him for months - I didn't even know he was sick, he confided that in me - that made me come to work and realize that [this place] is an escape for people just like running is an escape for me... I mean, he's choosing that. He's going to spend his time [here], when he doesn't know how many days he's gonna have left, because that makes him feel good inside. That hit hard, that really hit hard for me. And then the other one is a student actually.... He struggles with a huge amount of anxiety and identity issues. He's diagnosed and all that. And if he didn't have [this center], he wouldn't have the escape from his anxiety.... He also has mentioned that he doesn't feel like comfortable being him in a lot of situations and a lot of places on campus. But when he [comes here], he's able to just be him. And, that was another situation where I was like, all right, my ethical values of people having their escape, being able to be themselves, feeling full, of the feelings that I get from other things is something that I can provide here.

Ryan expressed his own experiences feeling overwhelmed in high school because he was a high achiever with many commitments, and wanting to provide support for peers who are also feeling overwhelmed. When asked how he has enacted his core values in his leadership, he shared:

Talking to others, letting them know you're struggling, I think is a big one, [and] when to ask for help. I place a lot of trust, a lot of responsibility in my members and my co-workers to do those things.... but I also want them to be able to come to me when they're in over their head, [or] they don't know how to do something. There's no need to fake it 'til you make it if you're struggling. Let me know, because I'm going to let you know, my parents know, my professors know if I'm having a hard time and I just want that same kind of transparency from everyone.

Ryan was very interested in supporting his peers when they are overwhelmed and also recognized that he is unable to be helpful if they do not communicate with him what is going on. James also described the satisfaction he feels from supporting peers who are having a hard time personally. When asked about what he's been able to accomplish in his student leadership role, he shared pride in being there for his peers in difficult times, saying: 
A lot of people would come to me in a personal life crisis type thing. So I would find myself helping someone out when they had just broken up with their partner or when they were going through something traumatic or something like that. So that's honestly a lot more meaningful to me than being like, we've provided funding to this or [our other student organization activities].

\section{Trauma Impacts}

Some participants also disclosed childhood experiences with trauma and the way that those traumas, including interpersonal relationship violence and substance abuse, has influenced how they approach leadership and engage with their peers. In two instances, student leaders described childhood trauma as having an impact on their conflict resolution styles. One student leader described witnessing domestic violence when they were very small, and described intervening in that situation. That participant went on to describe their conflict approach as "taking it on with full force," and later describes their growth in their conflict style around taking a more reflective and measured approach.

They described their increased sensitivity when they perceived a female may be experiencing harm, sharing:

...I was definitely a lot more sensitive to people who are young screaming, specifically girls... When I heard females yelling and screaming, I was out of my room within five or 10 seconds, and hunting it down as fast as possible. And then confronting that situation as soon as possible. So I was on the edge for a little while there, which I didn't really think of until just now, but I was.

Another student leader described growing up in a household with an alcoholic father; in that scenario, the participant experienced neglect and feelings of anger. Their conflict style developed as a result of needing to find a way to communicate their needs to their parents and find "middle ground" with them. Related to their experiences growing up, they try to pragmatically identify a resolution to a conflict situation. If they are unable to 
do so, they process with someone close to them in order to "make peace" with their situation. In both of these instances, the trauma that student leaders experienced as youth impacted their own style and strategies to manage conflict as they navigated their student leader roles.

\section{Academic and Professional Impacts}

Given that all enrolled students are making progress towards a degree, and many if not most of them are also seeking a degree in part to prepare for their careers, there were also necessarily academic and professional impacts of navigating leadership and conflict with peers for the participants in this study. Specifically, a few of the participants had the isolating experience of not being able to process the experience of conflict with others because of the confidentiality and/or professional and ethical demands of their student leadership roles. Many college student participants in this study expressed the growth in their own professional skills sets as a result of both conflict and their student leader experiences; several participants also described their experiences in their student leader roles as being meaningful experiences to help prepare them for professional settings post-college. Some participants also described immersing themselves in their academics as a way of managing the stress of conflict situations they experienced with their peers; in those instances, academics helped serve a distraction for some of what they were experiencing. Following is a review of the academic and professional impacts of leadership and conflict navigation on the participants in this study. 


\section{Inability to Process the Conflict With Others}

An unexpected theme that emerged from the data was the inability of participants to process or discuss the conflicts they were experiencing with other people. This was often due to the confidential or sensitive nature of the conflict, and the ethics and responsibilities of their roles. Erin described the role of a peer who she leaned on because she was limited in what and with whom she could share the specifics and stress of her conflict. She shared:

Erin: And [my peer and I] work really closely together, and that's a really special thing that I've never had before. But she supported me when others, like other friends of mine, literally couldn't...

Jill: Because of the role?

Erin: Because of the role, because of just the position, of everything.

Erin's sense of professionalism and privacy with regards to the situation she described meant that she felt uncomfortable debriefing the specifics of the conflict itself with the researcher, even after the conflict had resolved. Erin felt the stress of the conflict but was also isolated and limited in her ability to process what she was experiencing with someone else.

James shared a similar experience. His conflict was observed by many and created controversy when the public nature of the conflict led to others taking sides. He expressed that he looked for opportunities to appropriately hear and address concerns while balancing the confidentiality of his peer. Carmen also described the isolating experience of not being able to process what was going on; at the same time, her own internal confidence provided a sense of peace and validation about the decisions she made. She shared: 
I feel like [my name] is attached to this role. And then also, I'd want to talk about it after [a situation] too, but I just felt like it would be inappropriate. I can handle it on my own. I felt confident handling it before and I felt confident that I'd handle it after. I was pleased how it went. But I felt like I wasn't in a situation where I needed that support. I sometimes do need help problem solving with my peers, but I felt like, since I'd handled this, it would be equivalent to gossip and inappropriate, both before and after, to discuss this very personal airing of grievances and discussion with someone who wasn't involved. Like it just felt weird. So, I did not discuss the contents of the conversation.

Carmen was concerned with the ethics of her role and the extent to which processing or problem solving with others could be seen as gossip. Because of this, Carmen ultimately navigated controversial or difficult situations largely by trusting her own internal decision making and keeping concerns to herself.

When asked if she had processed or sought help from anyone as she navigated the conflict situation she experienced, Elena shared: "Yeah, honestly, my mom. I wanted somebody not involved, who wouldn't go sharing the information.... But, it was just about seeking support..." From Elena's perspective, she had to be very specific about when and how she chose to seek help in order to balance getting support with someone who would not violate her confidence and trust. In the end, for Elena, that individual ended up being a family member. Michael similarly described not being able to really process with others due to the limits of his role, sharing:

After talking to this person, and then filling out the reports and whatnot, completing that, it was... it was reflection, and I kind of wished that I had relied more on my peers to reflect with, but unfortunately, I didn't think or feel like I could have all the way. And so I didn't.

Michael expresses a sentiment and frustration that was a professional and role impact for many student leaders: the conflicts they were navigating took an emotional and mental toll on them, and yet in order to maintain the confidentiality and privacy of their peers 
and the integrity of their roles, they were very limited in where and how they could process, who they could trust, and, because of this dynamic, often navigated the conflict solely on their own.

\section{Preparation for Professional Roles}

One important theme of this study was the professional development of student leaders thanks to the levels of responsibility afforded them within their student leadership roles. Some student leaders described gaining insight into their career goals post-college thanks to their lived experiences in their student leader roles. For example, Carmen shared:

... Something that I regret a lot is that I don't [push] myself to the very highest position that I can achieve. Maybe because I'm afraid once I get there, I'll be average. Or that it will be too much and I'll be stuck in it. I was like, well, I know that I don't want to do a management position now in my career just because of my experiences. I don't like all the hidden agendas that you have to deal with. But I was like, well, if I do this now, then it's one year, I can do my best to make sure those agendas aren't here and make sure that I solve these problems that I see. And at the same time, I can push myself to achieve this highest level of something I've been working at for a long time, and just experience that, and then I won't feel regret later about not having tried, or not having had this particular experience, or having let go the good that I thought I could do for this particular organization and cause.

Carmen also described her experience in a fast-paced, highly-visible, high-pressure student leadership role, attributing a significant portion of her professional growth to her leadership experience:

Even though it is high pressure, it's made me grow up a lot more and mature more quickly and gain a - the last [student leader in my role] called it a 5000 foot view to me - much faster than any of my classes would have taught me or even like a regular job somewhere. Because I work in a research lab during the summers, but this particular job has just been so intensive and I've been given so much responsibility beyond I think what your average college student has that I've just 
come away with so many skills that I didn't really expect to have but that I'm sure will help me.

Elena also described using her student leader experiences to help develop her academic and professional interests; in addition to community and public speaking experience, she also shared that she gained "work experience that I wouldn't have had otherwise." Elena ended up changing from one leadership position to another position within a different organization. When asked what that was like, she said:

It's been lovely.... I mean, I can basically - my job description is much more loose there than it was in [my other student leadership role]. It's kind of open to interpretation of the student themselves. And that's been really lovely because I can do things [which] kind of fit [my future career goals] even.... She'll let me take on my own projects. And I basically coordinate events. But the nice thing is that I can also use things that I learned in [my previous student leadership role], like coordinating meetings, running meetings, writing agendas, collaborating with multiple student organizations.

Abram had the opportunity to help interview and hire peers into his student organization, which he found to be invaluable for his own professional development:

We had 100 plus applicants and we interviewed 20 plus people, so doing the interview experience was huge for me. Not only for the interpersonal communication aspect of it and seeing that, but also for my future as well, seeing how I should be interviewing, how I should be presenting myself in an interview.

Abram also sought participation in the student fee process because he saw it as a way to set himself apart on his resume from others when it came time to apply for jobs:

...I knew I wanted to be on a board of something, not just for my academic interests or personal interest, but also because I know that's what I need for a career, is being a part of things that are going to deviate me and separate me from everyone else. And so I was asked by my [supervisor] if I'd be interested in that. 
Michael's student leadership experience helped provide fulfillment related to career goals he had. When asked why he chose to participate in the leadership roles he was in, Michael shared:

It is kind of a natural role for me to play. I've always kind of wanted that extra little boost. I thought I was going to join the military for a little bit there. And then I didn't. To try to fill that fill that hole, I guess, I feel [I] sometimes filled with the leadership-type role, really.

For Michael, student leadership positions helped fill a void that was left when his plans to join the military did not pan out. When asked to further elaborate on the gap left from not joining the military and what specifically he felt like was missing, he shared:

A duty to help others. Kind of that military perspective... I'm doing what other people aren't for the greater good. Now, I've noticed that being in a student leadership role, working my butt off goes further than a simple position like a painter or, I mean, just other jobs. And just people's attitudes, I mean, being in that student leadership position, I'm used to - my mom was a single mom for a little while there, and so I was instilled at a very young age that hard work will pay off, and that it's the key to success... Being in that leadership role, and working as hard as you can, shows other people that you can do it, that it is possible. And yeah, kind of leading by example.

\section{Role of Coursework and Academics}

In addition to the impact of leadership experiences for professional preparation, a few participants mentioned the impact of their leadership experiences on coursework and vice versa. Gia described gaining confidence in student leadership positions that would have changed the classes she had signed up for earlier in her collegiate career: "I remember signing up for my classes. My freshman year, I took interpersonal communication instead of public speaking because I was so scared. But now, I think that'd be different. I don't know." Jordan discussed the role academics played in planting 
the seeds of understanding for social justice frameworks. She described a class where students from various social identities served on panels, sharing:

We were asked questions [on the panel], and everybody served on at least one panel, and it was very powerful. And I think that was a very big turning point as well, because that was at the tail end of my freshman year, when I was looking for more leadership experiences. And at the time, I was kind of ignorant in that I was like, Oh, this is stupid. Racism isn't a thing, because that's the ideology that I grew up with. But in retrospect, even those little seeds of doubt about those were super powerful, because then when I did move into more trainings on social justice, it's like, oh, yeah, I remember hearing about that. Oh, yeah, I remember when this one student talked about how he was profiled.

Student participants were able to ascribe their development to the intersections between their leadership experiences and skills gained as well as their academics, an important theme when considering how to best scaffold and support the development of student leaders in college.

Several participants specifically mentioned the role of academics as they navigated the stress of conflict. Jordan described utilizing academic coaching as a means to figure out balance in the midst of the stress she was experiencing, sharing:

I had done an academic coaching appointment to kind of talk about what does this look like? And how do we manage that? And how do I manage my time really well, because I was very stressed because I'm trying to help and work in this position, while also trying to run for [another position].... And then, also, how do I maintain some self-care and stay on top of school?.... But I definitely did academic coaching and leaned on people who I trusted to be other resources.

Elena used her academics as a distraction, or a place to dedicate her psychological and emotional energy during conflict. She shared: "I just like focused on other things. I think at that point is when I started focusing more on school, than the work aspect. So in a way my professors were helping, but not in a direct way." 
Both the demands of student leadership positions and the stress of conflict with peers contributed to academic and professional impacts for students. For many participants, they could point to the development of their maturity and readiness for professional careers thanks to their lived experiences in their student leader roles. Overall, student leaders in conflict situations encountered a myriad of interpersonal, emotional, psychological, and academic and professional impacts due to their experiences navigating conflict and controversy. The next section will review the strategies they adapted to help them navigate these experiences with their peers.

\section{Navigating and Negotiating Conflict with Peers}

The previous section described the interpersonal, emotional, psychological, and academic/professional impacts of conflict on college student leaders. The impacts of conflict and controversy had both positive and negative outcomes for college students. This section explores what emerged from the data as the methods college student leaders used to navigate conflicts with peers, including the interpersonal and emotional strategies, psychological strategies, academic and professional skills, and intercultural competence skills.

\section{Interpersonal and Emotional Strategies}

Two key interpersonal and emotional strategies developed from student leaders: developing and using emotional intelligence skills, particularly in taking a measured and civil approach to conflict with peers, and the ability to engage in difficult conversations in an effort to help preserve peer relationships in student leadership group environments. The following sections review both of these themes. 


\section{Demonstrating Emotional Intelligence by Taking a Measured Approach}

Generally, student leaders viewed conflict favorably and as an opportunity for growth. Erin shared:

I think learning that conflict can actually be a really good thing is something that I never kind of opened my mind to before. I now kind of view conflict in a different way. And I definitely feel like I'm more comfortable with that discomfort, if that makes sense.

James agreed, and had this to say regarding conflict: "I actually wouldn't define it as being a bad thing. You can have healthy conflicts. Like if two people have the same ending goal, for example, but want to implement different strategies to achieve that ending goal." Jordan described her experiences with conflict as positive as well, because it challenged expectations and resulted in a change that needed to happen:

I think the conflict was important. I think it was important to have the discussions we had. I think that it raised questions about the processes and about the way that our constitution was structured that would not have happened otherwise. So I'm hesitant to say that I would change much because I think good did come with it.

Goleman (1998) describes the five dimensions of emotional intelligence as selfawareness, managing emotions, motivating others, showing empathy, and staying connected. Most of the student leader participants demonstrated most if not all of these skills, and described ways that working through conflict and with peers who are different has cultivated their emotional intelligence. In terms of strategies that reflect emotional intelligence, striving for civility and taking a measured approach (or managing emotions), showing empathy, and perspective-taking were the most commonly used. James describes how he maintain composure in conflict situations. Specifically, he describes better understanding others' perspectives and responding in a measured way: 
I'll literally never get mad. Because I just understand where people are coming from now. There's just no reason to get mad at somebody you don't know and waste that on them. So I think my freshman year... I probably wouldn't have cared if somebody was being rude to me to return that same energy or level of rudeness to them. But I would never do that now. Even if somebody came at me with a hothead. It wouldn't make sense for me to feed into that, or make them more mad.

Mark and Michael both describe needing to stay level-headed in order to operate in a leadership capacity. Mark described it this way: "In the context of being a successful student leader on campus.... I think the ability to get along with the folks that you're going to be working with, I think that's a huge factor." Michael names managing emotions as a specific skill he has learned in his leadership:

When someone strikes one of [my core values], sometimes it can be difficult to take a step back. However, with my experience, I've been able to do that.... I mean, especially in that student leadership position, because there's really not an acceptable time which you can think with emotion and act with emotion. You can think with emotion, sure. But then you have to have that reflective time or else. I mean, then you're not really being that leader that you're supposed to be. So in my experience, I've been able to keep my cool, even though sometimes different perspectives or different opinions struck those core values.

Carmen agrees with this perspective. She describes growth in her conflict approach and gaining confidence through experiences with conflict:

Because I wasn't really practicing going into conflicts before when I was younger, I didn't ever really have that experience, that knowledge that it could turn out good, and that I could actually step into those situations confidently. And even if the other person is going to get upset, that if I stay calm, and I know what I'm talking about, and I am thinking about their feelings, that usually it just gets resolved.

Elena also believes that taking a measured approach is an important student leadership skill. She shared: "Definitely being able to communicate in ways that aren't degrading... Communicate on an equal level with everyone.” 
Jordan also described how she manages emotions differently now, and, like

James, connects her growth to perspective taking of others. She shares:

Handling my emotions is a big one. If I compared the two years that [I] have been on [this leadership committee], the first year, I took things very personally when conflict arose, and when things didn't go the way I expected. And it had more of an impact on me and my emotional toll. And then I learned how to kind of separate my emotions and let myself know that I can feel how I feel, but also know that they're probably not out there trying to get me, they're doing it because of their own reasons. And so even though things went way haywire the second year, too, I was able to handle my emotions a little bit more.

A common thread among all of these participants is a desire to take a civil and measured approach in order to show care for and consideration of others' feelings, and to consider where they are coming from — in other words, empathetic behavior. When asked about what skills are important for student leaders to possess, Casey summed it up this way:

Kind of being practical with your emotions and how your first instinct reaction is to things. If it makes you upset, you kind of not first off, go and express that in a big explosive way that is most easy for you to. You need to be able to be practical and I guess, tone those things down - not hide them away and not express them, because emotions are important to understanding each other, but consider other people as well, how you might affect them.

The common theme of considering others' feelings showed up in one of the most commonly-used strategies among participants: that of perspective-taking. Every single student leader participant described perspective-taking as a strategy they adopted; this isn't surprising considering their concern for taking a measured approach with their peers and considering their peers' feelings. When describing her conflict style, Carmen shared this internal process she follows: "And how much of your viewpoint can I understand, so that I can reconcile my decisions as much as I can and see if I truly did something 
wrong." Elena describes a similar approach, connected to her value of empathy, of using perspective-taking as a strategy to work out where she stands on a particular issue:

I guess it goes with empathy of imagining myself in each person's shoes that were involved, and how I would have done things, and if I would have done them differently. And that was kind of what helped me come to a conclusion of where I was in this situation.

Abram similarly tried to put himself in his peers' shoes while navigating conflict with them. He shared:

So for that conflict in particular, I think the main value was being understanding. I really tried to understand where they were coming from. They were done with college, basically, they were over this job. They wanted to be done. And so understanding that I'm not going to change the behavior, but I can change that it doesn't have to be like they feel personally attacked by me kind of thing, or I feel personally attacked by them because they're not doing their job. And it can be more of me understanding that that's probably unfortunately how it's going to be, and them understanding that I'm not going to be lenient all the sudden because there was conflict.

Mark took a similar approach when navigating conflict with his peer. His peer had an emotional reaction and he sought to try to understand their perspective:

When I went to this conflict, I wanted to know where they were coming from. And so I definitely used empathy in the sense that I was trying to understand what was the reason behind their emotions? And that if I could sort of put myself in their place, that would be the best - not the best, but like, it would be a good place to be. And I would be better understanding of the situation.

Several other participants described similar approaches, often couching perspective taking as empathizing by seeking to understand their peers' points of view. This ability imagine a lived experience that was different than their own and consider the impacts of that lived experience are hallmark features of student development and the development of emotional intelligence.

Ability to Engage in Difficult Conversations 
In addition to taking a measured, civil approach to interacting with peers and striving to understand another person's perspective, many participants described the growth of both their capacity and willingness to engage in conflict with others through conflict. James described the ability to engage in conflict as one key way his leadership capacity grew, sharing:

In terms of what I learned about leadership, I feel like I have a better ability to lead now. And it's just because I've been through a lot of stressful situations to where I feel more equipped to handle them.... I do feel more comfortable handling conflict and kind of walking into the flame, so to speak, just like when there's something really tense or a hard conversation that needs to be had, I feel more comfortable doing that now.

Mark shared a similar sentiment. When asked if he believes his approach to conflict has changed since starting college, he shared:

I don't think the structure has changed much, but maybe my confidence and my ability to have that conversation has changed... And the language that I use... like I mentioned, the feelings and expressing those... has become a little bit easier for me.

Abby described her willingness to engage in difficult conversations as one area of growth in her leadership. When asked if she thinks her leadership has changed at all as a result of her experience with the conflict she described, she shared:

I think so. I think I've gotten a lot more open to confrontation through that. I'm very willing to have uncomfortable conversations rather than run from them. And I think that helps me to be a better leader because I'm less fearful of causing conflict and coming in contact with it. I'm kind of just very accepting, like, Oh, okay.

Carmen and Gia both described a similar shift in mindset, a willingness and ability to embrace difficult conversations that did not exist before. Carmen described one area of growth the following way: "Having tough conversations. Like I used to be very 
non-confrontational, but now I guess I don't even see them as confrontations anymore, which kind of removes the barrier a lot." Gia was also more comfortable engaging in difficult conversations. The conflict Gia described was still ongoing. When asked what next steps she thought she would take, she shared: "I'll probably bring it up... just because like I said, I'm working on being more confrontational, in healthy ways. So I'll probably open that conversation even though I'm not good at it."

Increased confidence due to having lived experiences with and developing skills around conflict was a commonly expressed interpersonal theme and area of development for many of the student leader participants in this study. In addition to a willingness and ability to engage in difficult conversations, another way conflict resolution facilitated the development of socially responsible leadership was by helping student participants develop resiliency skills. The next section reviews the development of resiliency as described by student leaders at the research site.

\section{Psychological Strategy: Developing Resiliency}

A common strategy that student leaders described was developing resiliency; that is, the mental and emotional fortitude to recover from setbacks and forge ahead. While the practice of developing resiliency skills was fairly common, the participants in this study described a range of specific resiliency strategies they utilized.

Erin described the value of her leadership experience and the ability to take criticism better. She shared: "I developed like a thicker skin a little bit. I need to stop being so sensitive." When describing what skills she believes are important for student leaders to possess, Abby named resilience specifically: “Also just resilience, like not 
letting things bog you down, or else you won't get anything done." She also described a strategy of stress management in which she both compartmentalizes stress but also works to prioritize her tasks to help reduce feelings of stress. When asked what she feels like she knows now that she did not know before her student leadership experience, she expressed:

Just basically like dealing with things not going your way and basically not holding on to that too much. Just taking it one day at a time and being like, what can I do better this day? And identifying what things really stressed me out and figuring out a way to tackle those...

When describing how she has grown in her own leadership skills, Carmen described developing confidence and the role of self-belief in increasing her capacity for resiliency:

And then [in the past] I wouldn't be able to respond [to conflict] because I'd be too distraught. But now I do have more confidence that when I have a problem, it's legitimate and that I can handle something without getting super offended when they don't respond the way I want them to right away.

Jordan shared a similar perspective and described the specific role resiliency has played in her life, and connected her resilience to her own self-belief in her capabilities, saying: "I've realized that I can trust myself, and I'm a resilient person." Jordan further describes her ability to have a positive outlook:

So things... fall through for a reason, because then it opens up more doors, and it makes you think, and so I try to stay very positive, because it allows me to see what's the next door that's going to open. Just because this one closed, doesn't that mean that there's not another door soon that's going to be even better.

From Jordan's perspective, staying positive means staying future-focused and constantly aware of the next potential opportunity, which may also be described as having a hopeful outlook. 
James described how resiliency played out in his experience, describing the manner in which he developed capacity. He shared:

And I reclaimed my happiness.... And then earlier, you had asked what was something I learned?... It's like I kind of mentioned, that I learned what my limits are in terms of stress. I feel like my limits kind of expanded when I realized that one thing is, you can just focus on those who actually care about you.

James' illustration of the role of resiliency in helping create margin and expand capacity is a useful metaphor for how to address the stress of leadership and conflict. James also described a specific strategy that worked for him, in particular focusing in and giving energy to his relationships. He said:

What I realized, I think was really important. It's something that I'll keep with me forever, and it's this: it's that there are people who will want the worst for you. Who will want for you to feel bad, who will want for you to go through stress. But there are also a lot of people in our lives who want the best for us, who genuinely think positively about us, who care for us, who will be there for us in a time of crisis. And when conflict occurs, we focus way too much on that first group of people who just don't like us, and we feel like the world is against us, but that's never going to be the case. You'll always, no matter what you go through, will have people who support you and who love you, who like you, who genuinely want the best for you... that's there. It's just hard to see sometimes. So I stopped focusing so much on those who were being rude to me, and then instead shifted all of my focus and intention... and attention into my friends from back home.

James, Carmen, and Jordan all expressed a value in themselves and their own ability and worthiness that contributed to their overall ability to be resilient. In other words, selfesteem and a belief that one has value appears to be a protective factor against stress and helps develop and build capacity for resilience.

Related to this theme of self-care and worthiness, Gia described the toll that justice work can take: 
I guess especially in [justice work], having a strong will I found is key to the work we do. Because we have some people come in and they just say the most ignorant things and without knowing, which like isn't really their fault. Well, maybe it is. And so I guess you can't just let that one experience or two or three experiences break you down where you're not wanting to do the work anymore.

Gia also named the importance of recognizing when you have reached capacity to help develop sustainability in leadership efforts and resilience to see commitments through. She shared:

And I guess learning that I can't always be at my $100 \%$ all the time. It's okay to admit that, hey, I need a break right now, or I don't have space for this conversation, was also something I learned about myself, which I think is a big accomplishment, especially leading with your heart. It gives you a lot of space to let others in. But not to put yourself at the forefront sometimes.

Resiliency was a common strategy that student leader participants used to manage the mental health impacts and stress of their experiences and conflicts. Resiliency stemmed from a sense of self-belief, worthiness, and a recognition that self-care is important. For some student leaders, resiliency came from building capacity and margin; for others, it came from a place of confidence. Advisors would do well to help coach student leaders on how to pay attention to this dynamic and notice what works for them in terms of capacity building and developing personalized resiliency strategies.

\section{Academic and Professional Strategies}

Participants in this study described a series of academic and professional skills and strategies that they developed and utilized as they navigated both the demands of their student leadership positions and the stress of navigating conflict with their peers. Specifically, student leaders described a common set of professional skills they developed, which included critical thinking and understanding when to take 
responsibility for their actions. An additional salient theme across nearly every participant was the way in which they tried to navigate and preserve interpersonal relationships with peers within a professional setting - specifically, by attempting to create a personal versus professional distinction.

\section{Developing Professional Skills Sets}

Student leader participants in this study spoke about the growth in their professional skills sets thanks to their experiences navigating conflict, and also to their student leadership roles overall. The growth of these skills sets not only were developed through their experiences with conflict, but also served them as strategies as they navigated conflict. The most commonly described skills that student leaders developed were critical thinking and reflection, taking responsibility for their actions, and professional skills around public speaking and meeting management.

Critical Thinking. Critical thinking, often connected to the process of reflection, was a commonly named skill that student leaders used when navigating conflict situations. The most frequent ways critical thinking played a role was in developing strategies for resolution (or problem solving) and in deeply reflecting on a situation. Jordan described the specific role of critical thinking for problem solving:

With critical thinking, I think that was a big one, too. That's what helps with problem solving. That's what helps with innovation. That's what helps with finding solutions or new avenues to go down. And that's what we had to do, we had to come up with something... [that had] never happened before. And this was different than the year before. So I definitely think that that critical thinking and trying to figure out those solutions, trying to plan, trying to come up with ways to present information in a new way, trying to come up with a new strategy. 
Michael also described the role of critical thinking to help address and find resolutions to problems. He shared:

I would say that during my leadership experiences... that I was able to think more critically. And that is definitely a useful skill, as well as problem solving, that type of stuff. It's when you're in a room full of other student leaders, and you're given a question... Like if, for instance, in a conference [or] in some type of development experience, when you're in a room and you're asked to solve a specific problem, or even just to talk about a specific problem, let alone solve it, you get to hear about what everyone's bringing to the table first - what everyone's bringing the table like, perspective, sure, more like ideas to solve the problem.

Ryan also described how he used critical thinking strategies with his advisors to help problem solve the conflict he was navigating. He described brainstorming with advisors as a tool to help in a time when he lacked strategies and experience to navigate conflict. Gia had similar sentiments about the role critical thinking played in problem solving in the conflict she navigated; from her perspective, describing reaching a resolution with her peer required critical thinking to brainstorm strategies to address the solution of "separating our personal and work life" from her peer.

In addition to the role of critical thinking for problem solving, several participants also describe the role of critical thinking and reflection to make up their own mind about a situation. When asked by an advisor if she needed help addressing a conflict situation, Carmen declined the offer, saying:

I want to handle this on my own. I feel confident that I can handle this on my own, because I believe so strongly in what I did, and I feel confident that I've thought through the situation enough that I can be transparent and explain where I think that I was wrong, where I could compromise, and where I could explain what I did with enough reasonable justification, because I thought about it so much. 
She describes this deep reflection process as confidence building, sharing: "And I feel like I trust my decisions a lot now, because I've seen the way I've been able to prevent problems because I thought deeply about something and how it would affect people." The critical thinking aspect was enacted when she considered the potential impacts on others and then worked to solve the problem or conflict while keeping the potential impact in mind.

Elena described how she used critical thinking to weigh multiple perspectives and then draw her own conclusions about what she believed about a situation. She shared:

Elena: ...it's just a lot of meeting with people person-to-person, I'm talking to them, listening to them, hearing their side out. And sometimes it would be both sides. But then I would have my own biases as well. And then at the end, sometimes I would come to a conclusion of like how I felt, and sometimes I would be wrong and I would change my mind, which, I don't know, kind of sometimes led to more conflict because I think it came across as distrusting. Jill: Like, oh, we thought you were with us, but now you're against us type of a thing, when really you were swayed by additional information or perspectives? Elena: Yeah, exactly.

Erin and James both described the role of critical thinking to confirm and affirm the best next step for them to take. Erin described it this way:

Critical thinking really drove kind of my role in the conflict. Because basically, with something like this, when I had a friend who was going through this, I really just had to take the emotion out of it and just say, this is the right thing to do.

Erin was responsible for supporting an accountability process with a peer who was also a friend. This dilemma required her to navigate the balance of her responsibility within her role and her relationship with her peer - two opposing sides. She used critical thinking to reaffirm her role responsibility in order to move forward with the accountability process. 
Critical thinking for problem solving and the role of reflection in critical thinking were two common strategies student leaders used as they navigated conflict situations.

Taking Responsibility. Another common strategy used by student leaders in conflict situations was that of taking responsibility for their part or role in the conflict. This was shared as both a philosophical orientation to their student leader roles as well as a specific step or strategy they used in a conflict resolution process. In terms of an orientation to the work, one student leader described it this way:

We have to make sure that [our student organization is] really up to the standard that people deserve. And that means owning up to mistakes. I'm soon probably going to have to [report out about] here are why I made the choices we made. Here are some of the choices that I regret making. And I own up to that.

Abram described a similar philosophy, noting that apologizing is the first step but that getting forgiveness often takes time. He shared: "I'm the quickest person to turn around and be like, I messed up, I'm sorry now, but at the same time... it takes time. You have to prove it sometimes to people." Ryan also described the amount of time it can take to work through conflict. In the situation he described, the apology, processing, and healing came long after the initial conflict. He shared:

And then fast forward to the end of the term towards summer. We definitely had a heart to heart. And I apologized for the way things were handled, how he may have felt, or felt he was treated. [I] communicated that was not my intention at all, even though that was the impact.

Abby and Michael both acknowledged the potential difficulty in apologizing and the ways in which someone may be oblivious to their own wrongdoing at times. When asked about skills that are important for student leaders to possess, Abby shared:

... And also learning when to apologize if you really mess up. Because sometimes that just helps. You can just be like, you're right. I'm sorry. Just admitting that 
you've done something wrong. I think people have a very hard time doing that, if you have an ego.

Michael also described an experience of missing information when making a decision, saying:

If I go through the whole process and make my decision, I own it. So I'm confident, got it, this is the right thing to do. And then the person goes, Well, what about this and then, "oh, crap, okay. You're right. I'm sorry." And so that part is definitely kind of important.... When you follow through with your decision, to be able to pick up [extra information and say], "Oh, wait, I was wrong." Accountability.

Several student leader participants described apologizing and taking ownership as the first step on a pathway to conflict resolution and healing. Erin shared:

If they have a problem with something that I'm doing, I kind of just try... and say this was not intentional. I'm so sorry, that that was the impact on you. And I really do try and dig deep and say, I deeply apologize that that hurt you. And kind of try and go from there.

Gia shared this perspective. When asked what strategies she used to resolve the conflict she described, she shared: "I think... we both recognized our wrongdoings, and then we just went on from there to... I guess rebuilding."

Overall, most student leaders identified apologizing and taking responsibility, when appropriate, as a strategy and skill they developed by working through conflict with others. Taking responsibility was a demonstration of emotional maturity and an ability to reflect on another person's perspective, and also demonstrates an internal locus of control where the participant had a belief in their own role and ability to positively impact the outcome of the conflict situations in which they found themselves.

\section{Personal Versus Professional Distinction}


One major strategy or coping mechanism students often used to try to help manage and navigate relationships with peers was by making a personal versus professional distinction. The major theme or strategy that emerged was a "personal versus professional" distinction when navigating relationships and conflict with peers within a student leadership/ work setting. Many student leaders identified that, although they may have personal relationships or friendships with those they were experiencing conflict with, they would address conflict as a workplace or job performance perspective versus as an interpersonal relationship issue. The strategy of naming for peers the conflict and that it is a separate concern from the friendship or friendly relationship that they had with a peer was a common one. This is unsurprising, given that another strong concurrent theme was that of a loss of or strain on friendship as a result of conflict. Mark described navigating a conflict with a friend in his leadership capacity, and struggling to balance his responsibility to give feedback while maintaining the relationship:

I was like, so can you explain what's happening, because I am very lost, and if I don't know what's happening... I want to solve this, I want to help you out. I don't want [us to not] get along, and we still are working.... I want us to be in a good relationship. And even if that relationship is just a professional good relationship, I'm comfortable with that.

Most of the participants articulated that some conflicts they have experienced placed a strain on their friendships, if not ending them altogether. In fact, student leaders who avoided conflict tended to do so in an effort to preserve their relationships with their peers. Elena described the tension of having relationships within her organization with people who were in disagreement with one another, and the challenge of exhibiting her 
point of view at the potential cost to those relationships. Abby also expressed a deep aversion to being in conflict with others and developing "enemies." According to Abby,

I don't think there's anyone that hates me, which I think is great. I think having enemies is terrifying, because I know friends that have people that hate them, and that is literally the worst. I could not live with myself.... If I do get in a fight, I'll probably apologize the next day.

Ryan described one of the strategies he attempted to adopt when addressing a peer's nonperformance in their leadership role. He shared: "Looking to understand where he's coming from at first, but then looking to correct those behaviors, communicating, this wasn't personal, this was strictly about the job was crucial." Ryan also explicitly stated to his peer the separation of the personal from the professional: "We said, hey, going forward, none of the things we say are going to be personal or a fault against you or your character. They're strictly going to be professional as if this was some sort of performance review."

This perspective was echoed by Gia. In Gia's case, her conflict came from a peer micromanaging her performance, and an added challenge was the personal relationship she had with this person. She felt caught off guard and uncomfortable when her peer addressed the conflict with her in her work environment, and felt a lack of value in her friendship when her peer did not honor her wish to discuss their concerns outside of a work environment:

I told him that I was frustrated that he did schedule this during work hours, and like I said, I'm an emotional person. So I was like, I don't want to leave this room, emotional and having all my co-workers being like, Oh my God [name redacted], are you okay? And he said, "Well, if we don't schedule it, and then it won't happen." And I told him, that's the difference between him and I... I would make him a priority. 
As a result of this peer-to-peer conflict, Gia and her friend made a conscious effort to separate out their work life from their personal friendship, including communicating about work tasks using a separate messaging system versus using text messaging. Another student leader, Jordan, shared that the experience of being in a student leader role provided some natural distance in a conflict situation, compared to those relationships like family or close friends. In her case, she was more likely to engage in conflict with a peer within a student leadership position because of the distance her leadership position afforded, but engaged in conflict with those she was closer to with more reluctance. Mark expressed another perspective on this same scenario; specifically, he shared the challenge of addressing a peer who is not performing in their role and, in instances where they are also a friend, the inevitable challenge of work concerns impacting personal relationships. Gia shared a similar sentiment with a friend who was also in similar leadership roles to her: "Through the last year and a half, we became really close... But that comes along with like a lot of messy stuff too. Especially when you're bringing it to the workplace."

Other student leaders described their separation of their feelings and friendship from a shared work environment, and the ability to compartmentalize and balance work tensions with personal relationships. James described it this way:

Things will get really tense at work between me and someone I work with. And even if I like kind of hate them in the moment, to be honest, I'll still invite them to do something after work to show that we can leave our differences aside at our job, and still have a friendship that's separate from the work we do.

Abby, on the other hand, expressed specifically not trying to have interpersonal relationships with individuals she supervises in her peer leadership role in an effort to 
avoid challenging interpersonal dynamics, but also acknowledged that doing so was difficult because of her desire to relate to her peers. Abram also spoke to his responsibility to maintain an appropriate professional appearance at work because he represents his organization as a peer leader, stating: "I think a leader has to separate certain personal things from who they work with, to best present themselves in the position. Because I don't want to be viewed as incompetent or unequipped to do the job." In this instance, it was important to keep too much of his personal life from showing up in his peer leader environment, in order to keep an appropriate separation and represent his work environment well.

When asked if they would have done anything in the conflict scenario differently, Mark expressed that he would have used the strategy of separating "the individual from the idea" and, in providing feedback to a peer who they were also friends with, letting their peer know that they were speaking with their peer strictly about their work and not trying to impact their friendship, which he saw as separate and different. Abby expressed the belief that maintaining a professional setting allows for conflict to be resolved in a more appropriate manner: "You know, it's a very professional setting. We have to keep it professional or else, I don't want to be there if it's not. Or else it just turns into a hissy fight."

\section{Intercultural Competence Skills}

A common attitude among all of the participants was the value of diverse perspectives and the strategy of perspective-taking. When asked about the impact of peers who are different from him on his experience, Ryan shared the following: 
I think it's made me challenge myself to be more mindful, to not just say what's on my mind and to really think about the people in the room, and the people outside of the room even, what my words that maybe I don't even think about, how they can affect others. So being aware.

Within an interpersonal and intercultural context, exposure to diverse peer perspectives was a powerful facilitator of student development. A theme that was expressed from a few participants was the exposure to diverse peers and different perspectives that helped facilitate their own conflict skills development. Abram specifically cited his growth in how he's been able to understand others' perspectives and grow in his empathy skills. Ryan expressed a similar sentiment. When asked what he attributes to his growth, he shared that it is the diversity of the institution specifically that has exposed him to difference in new ways:

[This institution is] not as diverse as one might think, or even one as a university employee might claim even. But still, being around so many different students, faculty members and everybody here that comes from different places geographically, comes from different places culturally, different home life scenarios, has really opened my eyes because, yes, I care about all my friends and I care about the people I interact with. So, yes, like I should listen and understand where they're coming from. And when there's a problem, I should take that into account understand that, hey, their circumstances probably lead them to believe in something, to do a certain action, to say something, and knowing that, hey, that difference is okay and that's something that shouldn't just be tolerated, but accepted.

Ryan was able to appreciate difference and different perspectives, which also means that he does not outright dismiss someone who disagrees with him, but instead approaches situations from a place of empathy and perspective-taking. This also left Ryan more open to what a peer with a different perspective may have to say. This perspective that it is important to recognize that we do not know what someone else is going through was one that came up commonly among participants in this study. 
Elena eloquently sums up the perspective and value of different perspectives. She expressed a strong value of allyship and support as a person with some privileged identities, and developed this perspective as a result of her relationships with diverse peers. Elena shared this perspective on what she believes contributed to her development and growth:

Part of it is that in college, I've made more friends who aren't like me, and who come from different backgrounds.... I think it's having those relationships with people from other backgrounds and feeling deep connection to them in a way that I need to be a better ally to them. And I've always, in the back of my mind, I've always felt like, Oh, I need to be good ally, but now it's like, this is my personal relationships that I need to be there for. And a lot of times it is related to marginalized communities, a lot of conflict in college and student leadership roles, especially.

The results of this study show that student leaders not only developed a recognition that others see the world differently, confidence to navigate conflict, and specific conflict-resolution skills, but also shared that working through conflict facilitated this development. Specifically, student development facilitators were having experience and practice working through conflict, which in turn built their confidence; participating in student leadership experiences; experiencing disorienting dilemmas with negative or stressful outcomes; and interacting with peers who were diverse and different from themselves. The next section will address in more detail what supported student leaders or inhibited student leaders in their ability to navigate and successfully resolve conflict.

\section{Motivators and Inhibitors in Times of Conflict and Controversy}

Conflict often brings with it stress, discomfort, and disequilibrium, as noted in the section on the impacts of conflict on student leader participants. Given a review of how student leaders make sense of conflict, the ways conflict impacts them, and the strategies 
they have used to navigate conflict, a natural next question are what are the aspects of the student leaders experiences that motivate or inhibit their ability to navigate conflict? In some cases, the factors that motivated or sustained some students in some situations inhibited the successful resolution of conflict in others. Following is a review of the motivators or sustaining elements for students in times of conflict, inhibitors or those factors that interrupted students' successful resolution of conflict, and a discussion of how organizational factors and the role of advisor were both a motivator and an inhibitor depending on the situation.

\section{Motivators}

Motivators are those factors that fueled students or sustained them in difficult times of conflict, allowing them to successfully navigate difficult situations, commit to the organization and other students despite stressful circumstances, and see conflict through. Following is a discussion of the salient themes that emerged around motivators, including sense of belonging and commitment, a value of love and kindness for others, peer accountability and support, and the role of societal events.

\section{Belonging and Commitment}

Commitment is described as an investment, in both intensity and duration, to a group and a goal to see the goal realized (Higher Education Research Institute, 1996). The key themes that emerged from this area were students' commitment to their organizations, even in the midst of very challenging circumstances, and the role that sense of belonging played in helping students make a commitment to an organizational home on campus. 
This value was the least discussed of all of the SCM values. When the idea of Commitment as a value was brought up by participants, it tended to be in the context of not giving up on people or on their roles, even when things became very difficult within their student leader context. An additional theme that emerged related to the value of Commitment were two drivers that seemed to help student leaders weather difficult situations within their organizations: a passion for positive change through their leadership role and a desire to be a difference-maker, and having a sense of belonging and inclusion to the organization or group.

Abram described persistence as one of his core values, and described how he enacted that value when working through the conflict he experienced. He shared:

I am persistent as hell, like that is definitely a value. I don't give up on things. And so just not giving up on it. It almost became like a game to me, like how can I trick them into doing work? I remember one time I put a bunch of stuff in boxes that didn't need to be in boxes, because that-- it needed to be put away anyway, and I taped them shut and I set them on the counter. And I said, I have to go, you need to open all these boxes and put them away. And they were like, huge. So they had to, because otherwise they couldn't put their laptop there.

Abram's value around not giving up meant that when his peers were not performing their tasks of putting items away while at the desk, he thought creatively about how to get them to do so, versus just giving up and doing it himself. James also described his own commitment to his organization, and shared his perspective about considering quitting but deciding not to:

So I didn't give up.... I got really close to quitting [my position].... There was actually a department on campus that extended me an offer without me applying.... I didn't give up even though it was very tempting to, because I could've just like dropped the hammer, just been like I give up, this is awful. So that was one core value. That's probably the most relevant thing. It's like... almost like wanting so badly to quit and like fantasizing about quitting, but just knowing 
that like, bigger picture, I would regret doing that. Twenty years down the line, I wouldn't be like, Oh, that's so awesome that I quit.... No, I'm going to be a lot more fulfilled in my life if I stick with it, and just push through no matter how hard it is.

James was able to consider his value around commitment, and although he expressed being under a tremendous amount of stress due to the highly visible conflict he was involved in, ultimately was able to consider the long-term impacts and potential regrets, and decided to stay the course, even despite his difficult situation, and with another viable option offered to him.

Jordan framed her value around commitment as loyalty, and described quitting as the "easy" thing to do. She described an alignment with the vision of the organization as one of the contributing factors of her loyalty:

I'm not someone who wants to give up, which is part of my determination, perseverance. But I think that also plays back to loyalty. If you're not loyal, then it's going to be easy to dip when things get hard. And I've gone through some really hard-- in terms of like, there's been times where I really want to give up, when we're working with [the student organization] a 30 hour week on zero pay and zero compensation. While we're also trying to be students, and have other obligations. Because we did have a week like that. And it's so easy to want to quit. But if you're loyal to the organization and to the vision, that's what pulled us through.

Abby also shared that a core value is commitment, and identified her sense of commitment as spending time on things that are actually important to her: "Not giving up on things that I'm passionate about... delegating my time and energy to things that I'm passionate about and like ditching the rest."

Several participants also articulated that their commitment was driven by their passion for the subject and a desire to influence a positive change. According to one participant: 
When you ask someone why they like [this creative medium], they're going to say self-expression every single time until you actually do work with it. Then you see how it amplifies diverse voices, how you can lead college media, how you can ask thought provoking questions, and the power that it has. And that's why personally I've stuck around....They tell us not to say that [our organization] is fun. Because if you say it's fun, you get people with extrinsic motivation. And if you say that it's empowering to be your own boss and you're creating media for students, by students, you get intrinsic motivation. And then you get people that stay. During midterms, during finals. You got people that come back after conflict through conflict.

James expressed similar sentiments about how passion drives his level of commitment to the work, even despite the stress:

I realized for myself, that I must be passionate about this, if, after all that, I still want to do it. It makes no sense. If after all that I didn't quit. If after all that I still think about it every day. I still think about future leadership positions I want to pursue. I must be passionate about it. I didn't realize it, but I think I love it a lot. And I especially loved it when things go well. Like when we have some sort of win, that's just such a great feeling.

Ryan agreed with this perspective, and talked about how motivated he was when he saw

the positive outcomes of his leadership on the group, sharing:

And so then [it] really unlocked my passion for the for the group, for fraternity. It showed me all the positive ways I was affecting all these all these people besides myself and how leading them didn't mean I was just scheduling meetings, or telling them to go to this event or whatever. And then that at the end of the day, I could sit back and just watch a room full of guys, you know, be happy and knowing that I played a part in facilitating that... that was awesome. And that's why I keep doing it every day.

Another participant also described the role that passion and desire to make a positive change made in their decision to participate in student media, despite the high-stress, deadline-driven, highly visible nature of the organization, expressing the following:

I'd been encouraged to step up. And I noticed a lot of problems... [and I] was like, well, if I come in already knowing them, then maybe I can fix some of the culture problems that we have.... maybe I can make this better, because I also very strongly believe... I guess part of the reason too that I joined in freshman year 
was that was right after the election. So I could have taken an editing job somewhere else, in the Writing Center, but right after the election, I was super frustrated with a lot of the polarized and biased media that I'd seen. And so I was like, well, I could make sure that doesn't happen here, then that would be ideal, even if I can't do anything about it on a larger scale.

Elena described her experience after a close friend of hers within the student organization quit amid a significant conflict situation, and her own struggle with the decision to continue on with the group or not. She shared:

After my peer mentor left the job, I was still in the position I was in. Which was probably the most difficult time because I wanted to continue the role for other students, but I wanted to stand in solidarity with her leaving, but I just didn'tthen it wouldn't actually be helpful to anyone, because then we would have a lacking diversity team.

In the experiences of these student leaders, their commitment was often connected to the congruence of their values to the position, and the desire to see a positive change strengthened their commitment, even when the circumstances they found themselves in became very difficult. Further, several participants described their strong connection and sense of belonging to an organization - a sense of loyalty to the organization - as one that allowed them to stay committed, even in difficult times.

Every student leader participant described growth in their development through their student leadership experiences, and many of them identified that the organizations of their student leadership roles provided them a home on campus and a place where they felt they belonged, and in turn to which they made a commitment of their time and energy. Sense of belonging as connected to a student leader's willingness to engage and stay committed to the group and its goals, despite turbulent circumstances, was one 
salient theme from this study. Carmen described the pull of relationship as a key factor to her staying committed to her role within student media. She shared specifically:

But at the same time, [the student media group] was like a little community. Yes, there was my dorm on campus, but that was also a place different than clubs. Like, well, I belong here, and I'm helpful here. And then so I would kind of [make] friends with the people there. And so it's probably the reason why I've stuck around. Because I didn't-I don't want to do [media] really at all. But I like being there. I like the environment, and I believe in the mission too.

Again, this is illustrative of how Congruence connects with student leaders' sense of Commitment. Not only did Carmen find a community and sense of belonging within the organization, but the mission resonated with her in a way that aligned with her own values. Abby shared a similar sense of being where she belonged when she joined student media. She shared:

On the first meeting, we went over the mission statement and talked about why everyone's in the room and what they're passionate about. And the results from that were really helpful for me to see that I'm exactly where I should be, because I'm able to make an impact.

Ryan described his strong sense of belonging to his fraternity, alignment with his core

values, and the impact that had on his sense of Commitment to the group:

Doing so much work, I was giving figuratively blood, sweat and tears. I was really caring about the organization, the people, chapter, really working hard. And so to me, [the fraternity] was definitely not just another club, just another extracurricular, not just a resume builder, it's so much more than that. The brotherhood, all those core values we stand for.

Erin expressed similar sentiments in terms of participation in sorority life. She played a role in recruitment for sorority in her student leadership role, and described the sense of belonging that came from her participation in her sorority:

What I tell a lot of people who are interested in sorority specifically is [that] getting involved in a leadership position makes [this institution], which can be 
really overwhelming, seem a lot smaller, and just a lot more connected. And it's just great to be a part of something that kind of feels like... like a home. Being part of council is kind of like a second family.

A strong emergent intrinsic factor was when student leaders felt connectedness to the organization and their roles, they were more strongly committed to their organizations. Student leaders' abilities to commit to the organization and their role was often connected to their level and sense of belonging, in part because of the support they received from the group. The opposite was also true. Casey described the experience of feeling unheard, thus wanting to disengage from projects and the group:

If I am feeling unheard or unsupported, [I] clam up and not participate. So if in a team, I start being insecure about my position there, I can stop contributing and try to dip from the project. I'm kind of in the middle of that right now with the newsletter... [there was communication from the team] that [the newsletter] was only my perspective.... And so, because it seemed too much my vision, I think that's how they put it, I stepped back this year, and I do nothing to contribute to the vision of the newsletter. So all I do is take the content and put it into the email program. I don't do any editing. And I get asked if I saw anything, if I edited anything, how I feel about it. And I said, Oh, I don't know. I just put it in there. I don't know. So I kind of... that's a special situation, I guess because the sense of belonging came from the direct communication by the team members that I was doing too much. And then I took upon myself to say it I don't belong here because of that. I've been stepping back and stepping away and it's not fun anymore. So I'm thinking about stepping away from my team altogether.

Casey is struggling with feelings of not having a place due to not feeling like there is not an opportunity to contribute to the group and not feeling a sense of connection or belonging. This counternarrative that emerged from the participants' stories is an important one for administrators and organizational supervisors and advisors to consider.

\section{Value of Love and Kindness for Others}

One of the most enduring themes that emerged in this study was the deep care, love, and connection that the student leader participants had for their peers. This value 
around love and kindness showed up not only in how student leader participants talked about their values, but also in the strategies they adapted to try to address conflict situations, and the ways they enacted their leadership for positive social change, considering the needs of those within the group. The value of love and kindness is probably the most single salient theme of the entire study, a thread that connects all of the Social Change Model values.

In his discussion of the conflict he experienced, James described the tremendous stress he experienced due to the public nature of his conflict and the dissonance of his personal values with what his role demanded of him. However, he was able to name a positive outcome of the conflict, even though it ended in a broken relationship with a peer. He shared:

This is kind of weird, but [the conflict] also showed me my capacity to love which is really weird. But it's like in the midst of drama, I didn't hate people. So, I think that was that was really big. It showed me my capacity to still care for other people, regardless of what I speculated their opinion was on me.

Jordan had a shared perspective about her desire to love others even when she's been hurt by them, because of her core value of love. She shared:

Love is a big one. I'm a very loving person, I want to have those deep relationships with people. I want to see the good things [in] people; it's hard. Because the older you get, I'm realizing the more cynical you get. I've had past experiences that I've had people who've done things and that have hurt me, but I still want to love.

Elena spoke at length about her focus and care for others. When asked about her core values, Elena said the following: "I just care about individual people, like each individual person and how they're doing in a more deep way." She also processed her experience this way: 
I think that I value people over organizations a lot. I remember a specific example if that would help. There was an organization that wanted us to speak on their behalf for budgetary purposes, but it kind of turned into manipulating students a little bit. And so I realized that although I cared about the things organization did, I cared more about the positive impact that it had on students. But then when that was going on, it was like, now you're putting this organization above the students, which is the whole purpose is not to do that. And so I realize that you have to kind of draw a line of where, like, I guess you've just have to remember where you're coming from too and not get caught up in this whole, "I have to protect this" thing that's not as concrete or as important as students and people.

Several participants used the term "kindness" to self-describe their values and approach. Erin described herself as "very kind" and as someone who wants to get to know others; Abby also named "kindness" when asked what her values were. Carmen described how her core value of kindness has impacted her leadership roles, specifically in terms of not making negative assumptions if her peers are not meeting expectations, but rather trying to understand what may be driving or motivating the behavior, and assuming that students are doing their best. She shared:

Kindness. Because I try to be aware of, when someone isn't doing something, I don't ever assume that they're just lazy. I'm like, Well, are you dealing with anxiety? Are you safe? Are you not doing [this meeting] because you're afraid of this person? Like I didn't prepare you well enough? It's more of a how can we achieve this goal together.

Ryan had a similar orientation. When asked what values guided how he responded in the conflict scenario he described, he shared:

I guess kindness too. I wasn't trying to be mean and it really was hurtful. It really was surprising to see [my peer] react this way. To question, wait, am I being a dictator? Am I doing things wrong? Am I expecting too much even? So really question the way I was doing things. But I wanted him and I wanted all my members to understand where I was coming from. All I wanted to do is facilitate their success, our success. 
Ryan, similar to Carmen, enacted his value of kindness by trying to understand where his peers were coming from and interrogating his own behavior in order to understand the impact it may have been having on his peer, or to otherwise understand the motivation or reaction of his peer. This aligned with his declaration of two core values for him: love and kindness. He said:

Along with that, love for others or kindness. Family has been a big part of my life.... And that's been big, knowing that I've always been accepted and wanted for who I am. And so looking to accept others for who they are, but also love them for who they are. Be kind.... Because really, like the world would be so much better off we treated each other... like we wanted to be treated. You know, if we were just nice to people, if we were friendly.

Casey shared the perspective that it is important to consider other folks' experiences when working with them in student leadership situations, and was specifically interested in helping people feel valued: "Recognizing that, you know, going back to the ability to recognize people and appreciate them and make them feel heard."

When asked about his core values, Abram also specifically named kindness. He described his approach to working with his peers; his perspective was aligned with many other participants in this study in his belief that other students are doing their best:

Just being understanding. I guess, not the word compassion, but just being understanding that everyone has their own stuff going on and everyone's doing their best... Everyone's always doing their best and you're just there to - as a leader, I feel like I'm there to support them through their job and not tell them what to do.

Michael conceptualized this idea of care for others as well. He named the specific lack of kindness he has seen and a desire to see a different world where people were nicer to each other: "Just really being a good human. I mean, there's a lot of not that. And like I said, it would be nice if everyone was just nice to each other. But that's not how it is." 
This theme was incredible prevalent and showed up in an indelible way throughout all of the participants' interviews. It is an exciting finding to see the extent to which student leaders often have a deep and abiding love, care, and concern for their peers, because that value lays the groundwork for action and allyship to work through difficult circumstances for a more just future and world. Institutions should continue to seek ways to foster this attitude and belief, and provide opportunities for skill development that bridge this attitude to action in meaningful ways.

\section{Societal Events}

Societal factors came up in multiple interviews, and ranged from social justice considerations to truth and bias in media to politics. The idea of what is salient to a student at any given time and the opportunities they had for reflection were emergent themes that impacted how students made sense of disorienting dilemmas as they navigated their leadership and conflict experiences with their peers.

The experiences students have on campus are necessarily influenced and impacted by what is happening in the world. An awareness and concern for these issues, as well as an acknowledgement that societal factors impact the experiences of student leaders on campus is important for college administrations to consider. Students in this study discussed the impact of politics, the Presidential election, and perceived bias in media, for example. One participant shared this about their experience with and commitment to student media:

What I want to do in this job is make sure that truth is available and... it's not sensationalized. It's not yellow journalism. It's true, because news is pretty much a framework for reality. I think it's just so important. It really scares me what's happening with our administration, like, decrying the news and villainizing the 
news, and like, "Oh, yeah, the media sucks" is just such a common thing to say these days. And that's really troubling to me. So I feel like we have a responsibility to start local, and build that trust so that people trust the news they're being given, because news is there to inform and help people make informed decisions and be a watchdog for power. I feel all of those responsibilities very strongly every time we publish an issue, or take on a problem in the community and write about it.

Not only can societal factors impact student motivation to become involved, but it is a framework through which students begin working out their values and developing their leadership capacities for change_citizenship behavior. Providing opportunities to dialogue about what is happening politically, allow students to make informed decisions and be exposed to different perspectives, and giving them opportunities to try out citizenship behavior by participating in student leadership roles is an important role colleges and universities play. Besides politics, other societal factors could impact a students' experience, including legislation that may impact an identity they hold, the job outlook upon graduation, or major national or international traumatic events. Campuses must be aware of and responsive to these larger events and how they are impacting students and student leaders.

Campus administrators should also seek to understand what is salient for students on their campus. From this study, key drivers for students included the desire to maintain their friendships and support networks; the role of social media in navigating conflict scenarios; and the impact of local controversies, both on campus and within the community. In particular, the role of social media came up in various interviews, in particular the role of social media in broadcasting issues or interpersonal conflicts, in 
ways that changed when and how student leaders in the study managed and responded to conflicts. One participant shared:

Somebody [posted about the conflict] on [a social media page] and that... has over 30,000 people. So in the comments, people are just arguing back and forth. It was horrible. It was so bad. People were saying such mean things to one another. And I didn't know about it, because I barely checked social media at that time.... It was on there for a day. So in one day, in social media terms... Yeah, a lot can happen just like that.

Not only was this participant managing the stress of the interpersonal conflict, but they also saw it broadcast widely because of the power of social media, adding an additional layer of stress. In certain types of conflict situations, developing student leaders may be managing multiple dynamics: the conflict itself, but also community perceptions regarding the situation. This dynamic is one that campuses should be aware of is part of the reality for student leaders, and have strategies to help students navigate these realities.

Campuses have an opportunity to support students in reflecting on this behavior as it is happening, in order to make meaning and develop knowledge, skills, and attitudes that will best serve them in those situations. In fact, within this study, the single biggest facilitator of student development for students was reflection. Erin had this to say about her experience:

I look back on it. I've never been proud of how I acted in conflict. And I'm pretty proud of how I acted during that conflict. Because I think, for whatever reason, I kind of just... like a switch flipped. And I was just like, this is a real-life problem that people deal with, this is preparation for workplace conflicts, or whatever else. And it's real life, and we're going to deal with it.

For Erin, making sense of her experience, reflecting on and considering what went well and what that means for her as she continues to full adulthood was an important part of meaning-making. 
Michael also described experiences of using reflection in order to understand where others are coming from. He shared:

When I was better able to not act on emotion, but really understand and be able to communicate, I mean not only to other people, but to myself. What it is that I'm thinking, why I'm thinking it, why this person or whoever, whatever is happening is triggering reactions. And then lots of reflection.... I don't know, reflection was actually kind of the way that I got out of the hole that I had dug myself in high school. So that's kind of a skill that I thought was important during that time. But moving on to a leadership position, I was better able to understand how my use of reflection... it was a tool, specifically [for] relationship building.

James described how he was continuing to still reflect on and work through his experience, even over half a year later, and processing the pain the experience held for him. He shared:

[The conflict] just blew up. It was just horrible. It was really stressful. It took a lot of time to get over that. In fact this happened [last year] and I'm still working through today. I still think about it a lot. I just process things slow, so it'll take me a year to get over it or move on. I'm over it, but to move on from it completely, it'll take probably take a really long time.

James' experience is a salient reminder of the negative impacts of conflict situations. A significant finding connected across multiple student leaders' experiences, including how they enact their leadership, what they value, and how they have navigated conflict, is love and care for their peers and a desire to be in relationship with others. In addition, conflict was often an isolating experience for many student leaders; several shared that they did not feel like they were able to process their conflict experiences because they were unable to talk about what they were experiencing, due to confidentiality, ethics, and other reasons. 


\section{Inhibitors}

Inhibitors were those factors that impacted a participant's ability or willingness to engage in or work successfully through conflict. These factors impeded the successful resolution of conflict for students. The major inhibitors that emerged for participants in this research included being caught off-guard in conflict situations and campus budget climate and racial climate at a PWI. Following is a review of these themes.

\section{Being Caught Off-Guard}

A common experience expressed by participants in this study was being caught off-guard in a conflict situation, which generally resulted in one of two outcomes: wanting to avoid conflict altogether, or struggling with how to respond in a situation when they had not had time to process and consider the information brought to them by a peer.

Erin described her lack of confidence of addressing conflict situations, and how that is compounded when she does not see conflict coming: "I don't deal with conflict very well. I kind of shy away from it. Okay, if I'm 100\% honest, I just really have a hard time saying kind of how I feel, and especially when I'm caught off guard.”

Both Jordan and Mark described not knowing how to respond in conflict situations where they felt caught off-guard. Jordan described a situation where she was running for an elected position and, as part of a public question and answer process, was asked to respond to a one-sided question regarding her previous experience advocating for a particular side. Jordan was frustrated that the question was asked in such a way that did not allow her to fully respond to the complex and nuanced nature of the issue, which 
was contentious and had many sides. She shared: "I was very, very frustrated. I felt blindsided by that question, I felt like it was meant to pick and choose. And it was meant to throw a stab at me." Mark expressed engaging in a challenging conversation with a peer about their performance, and the difficulty of being caught off-guard when his peer became upset in the meeting. He had this to say:

But when we were having our second conversation, she started crying.... during that time, I was lost for words. And I was just like, what is happening? What did I do? Because I like to get along with people, I was like, shit, I don't know why you're crying. And I don't understand what's happening and [it] made me feel really bad.

Other student leaders described feeling "ambushed" in conflict situations with peers, which left them trying to navigate situations without very much time to prepare. For Gia, the conflict occurred when a peer introduced the conflict during a meeting they had while at work: "Because I felt kind of ambushed that he wanted to talk about that when I thought we were just talking about work stuff. So I was kind of taken aback." Carmen had a similar experience. While at work, an angry peer approached her with another peer and expressed anger and frustration, which took Carmen by surprise. She shared:

I don't remember how the conversation went exactly. But we were standing in the middle of the [room] where everyone else works. And he was like, hey, I think it's really unreasonable that you are requiring this. I can't do this. I'm really busy. I can't get this done in time. I've been trying, I think It's ridiculous. And then his friend piped in... I don't really remember the extent 'cause I was pretty taken aback. I don't think anyone had ever confronted me like that in a job before, it was pretty early on.

Ryan described a conflict situation where another peer leader was underperforming in his job. Ryan's approach was to make a personal versus professional distinction, and 
although he attempted to create an environment and an approach of caring, his peer responded poorly. Ryan shared:

He took [the feedback] pretty terribly. He definitely saw it as an attack against him. He thought we're kind of ganging up on him, bullying him, wanted to force him out of the organization even because we wanted things our way.... And so he reacted very emotionally, very negatively, ended up storming out on us.... Which is a pretty disappointing kind of outcome of that first conversation, because the whole time we're emphasizing this is not about you, we're not trying to attack you. We're not trying to bring you down. This is really what's going on. This is what's been happening with the group and what your role has been in it.

When reflecting on the lead-up to that conversation, a few elements of the conversation may have contributed to Ryan's peer's poor reaction to bringing up valid concerns about non-performance. Specifically, the conversation began with a check in of how his peer was doing. After that initial introduction, both Ryan and another peer leader that he invited into the conversation began to address the performance concerns. It is possible that the peer's poor reaction may have come from being caught off-guard, particularly if these two peer leaders did not do enough to seek the non-performing peer's perspective. Because the rest of the conversation after getting his perspective on how things were going was them pointing out what was problematic about his performance, but perhaps not providing another opportunity for the peer to non-defensively provide his perspective on the situation, it is possible that this peer felt caught off-guard, or in Ryan's words, "attacked," even though the intention was to provide support and have a realistic conversation about his peer's ability to perform his role. Considering these examples, it is important for advisors and supervisors to have a conversation about how to set up feedback conversations in order to help others not feel blindsided.

\section{Campus Climate: Budget}


The financial realities at the study site proved to have an impact on climate, in part because of the belief that the way money was allocated reflects what is important to the institution. The ways that budget impacted student leaders' experiences was an emergent theme of the study. Specifically, a common source of conflict was disagreements about how money should be allocated as part of a student fee funding process. Part of the conflict seemed to arise from the positioning of the funding process as a "zero sum" game, which meant that those organizations that were viewed as valuable and important — priorities — were funded or were awarded more funding. While the surface issue was about how money would be spent, the underlying issue was around power dynamics and what was being communicated about what was important to the institution and to students at the institution, particularly between organizations that do equity and inclusion work versus those who do not have that as a foundational part of their mission. Gia, a student leader of color who works for a cultural center on campus, described the process this way:

I know they're my peers in the Student Government, but it felt like they were holding a higher role because they had the say in our budget. And I'm sure like my co-workers at [student organization redacted] could agree that we were just like, begging instead of asking.

Another student leader, Jordan, expressed frustration with attitudes of scarcity within the process. From Jordan's perspective, all of the initiatives being presented in a student fee process were important, and the difficulty for her came from a place of providing funding for opportunities that benefit students across multiple identities and values, and to consider the long-term impacts of these decisions on the student population. 
Gia also described how students of color in her peer group perceived the process

this way:

Last year we were fighting for our budget.... And so we attended a budget meeting every week it feels like.... And it felt like we had to explain why diversity and cultural engagement work is important to this campus, especially at a PWI. And with that, we would have to share our experiences. And so we always joke at the [organization where she works]. We're always like, Oh yeah, we totally like prostituted our traumas for money. I guess after all that we all felt just burnt out after, especially like balancing school and then other jobs along with that.

Gia describes both logistical concerns - allocating budget for diversity organizations to be able to do their work - but also the additional labor and emotional energy of convincing peers in a position of power about the value of their organization's efforts.

This perspective was echoed by another participant of color who served in a student government role that was deciding fees. He described the effort he made to listen to those students while recognizing his own positionality in an effort to equalize the power dynamics associated with the budget climate:

So we were trying to figure out student fees for the year, and there was a lot of conflict, because students felt like we were allocating a lot of money towards Athletics, and not enough money towards [diversity organizations].... So I emailed students who gave testimony because I was friends with some of them. And I asked to go to one of their staff meetings, just by myself. And since I had heard top leadership members saying that they... that these people didn't have the facts, and that they disagreed with the student testimony... since I heard them say that I intentionally didn't bring them with me when I went into their space. So instead of going there, trying to teach them or persuade them that someone is right or someone is wrong, I instead took more of a listening approach. And I think that was a more effective way to handle that situation given that circumstance. So I was mindful if I took up space in that situation... because I heard stories of people in top leadership going to student clubs and organizations, and then just like invalidating or saying that's wrong. So it was something that I just realized over time, could really like offensive and ineffective. 
Scarcity of resources also put pressure on students to be doing work normally tasked to professionals, which created tension and added levels of stress. At least one participant also spoke to how budget impacted their student leadership position, requiring them to take on the work that traditionally would be allocated to a professional staff member, and the related challenges of that situation. Abram described frustration of the nonperformance of peers he was in a pseudo-supervision role for. When asked about the role he plays in a performance evaluation process, he expressed that he technically is not allowed to provide performance feedback because he's not supposed to be overseeing students, but the budget situation means that the organization cannot afford another professional staff member to do that role. He goes on to express the professional value he finds given his increased responsibility, despite the challenges and limits to how he can perform the role.

\section{Campus Climate: Racial}

Many student leaders expressed a desire to make a change for a better world and to make a positive impact. Several also spoke to both specific interpersonal conflicts but also how some of those conflicts were reflections of broader organizational and campus climate concerns. Campus climate had not only to do with resource scarcity and specific support for students of color and other underrepresented student populations, but also the culture and overall health of student organizations. Some participants specifically pointed out concerns for the health of their student organization or the campus, but also lacked skills or resources to address those. 
Data from questionnaires collected to determine the study participants included descriptions of classroom and student leader conflict experiences from both selected participants and others who were not selected or were non-responders after the survey stage. The questionnaire asked two brief short answer questions (see Appendix B): "Please briefly describe (in 1-3 sentences) an example of a conflict you have had with a peer while in a student leadership position at [the study site]," and "Please briefly describe (in 1-3 sentences) an example of a conflict you have had with a peer in any undergraduate student experience at [the study site]." From 20 completed surveys with usable data, five respondents described experiences of racism in classroom and student leadership experiences. Racist classroom encounters included being subjected to racist comments from group members on class assignments, being excluded from participation in laboratory assignments from White peers, and experiencing passive aggressive examples of peers unwilling to help them or otherwise partner or work with them in class because of their race. Leadership examples of racism included having a peer within their leadership context comment on their features and make a racist comment, and having a White peer silence peers of color in shared leadership spaces. This further illustrates the prevalence of campus racial climate on the student experience in and out of the classroom at the study site.

Several participants identified problematic campus and organizational climates that have stoked tensions that have led to conflicts. In addition to the budgetary considerations discussed previously, racial tensions and the climate for students from traditionally underrepresented identities was shared by several participants. One 
participant mentioned the context of campus media and the importance of not shying away from controversial stories: "And things that are really happening now. And not just event coverage of the school but taking on-- like, there are some racial tensions here." Gia expressed frustration about having to advocate for and explain to peers about the importance of diversity work at a Predominantly White Institution (PWI). One participant described the challenges of lack of racial diversity in their academic college, and that they instead have sought opportunities outside of class to engage with diverse people:

Although my classes have not been as diverse as in other colleges, the opportunities that I've put myself into tend to give me a reach for a broader range of people... A lot of people tend to transfer out of the College... because they feel it's not diverse enough so they'll switch to [another major] or something.

As a White student, Jordan also named this dynamic. She shared an experience of hearing about a peer who, during a presentation, described the chilly climate for students of color:

And she had brought up that there's a negative space when you bring in students of color into a predominately White field. Like they're coming into Congress, which is predominantly White, and asking them to unpack and relive and represent aggressions or racism that they've gone through, really negative experiences. And that's not a healthy environment. I was like, I didn't think about it that way. I'm really glad somebody brought [it] up that way.

Another White female participant, Abby, talked about a subgroup of her student organization whose responsibility was providing leadership for diversity initiatives. She described an interaction where, after breakout sessions among the subcommittees, the diversity team came back together and acknowledged to the broader organization that there were no White students on the diversity subgroup, only students of color. She shared: 
And they said, they went off and talked in their huddle. And then they came back and said, there wasn't any White people on our team. Like, why do White people think that they can't be on our team? We need you. And I agree with that.

She went on to describe her struggle with finding ways to support diversity initiatives without feeling like she was taking space. Understanding how to enact her role as an ally and student leader within the group was something she was still grappling with. The experience she shared from her racially diverse peers further illustrates the challenges that students of color experience navigating the research site.

One participant shared their own struggles of navigating their racial and religious identities, and picking and choosing when and how to share identities they hold that are not immediately visible. They expressed:

My race in the United States is a marginalized group of underrepresented folk. My religion is definitely something that I leave out when explaining who I am.... I am a Muslim and I'm proud about it. But it's a subtle identity for me, because it's something that in the current climate, I don't put out there to everyone and everybody. So that's I guess a survival mechanism that I use.

This participant identified the need to obscure identities that they are proud of as a protective factor, given the climate for people of color and non-Christians in the United States.

Elena, another White female participant, described the development of her ally identity because of her relationships with peers of color and her concern for how they were experiencing campus. Even after the conflict that she described had abated, she felt the issues still were not resolved, and felt a pull to take some meaningful action to support her peers. In general, nearly every participant of color described the chilly campus climate, and the White female participants all described a value around diversity 
and a desire to be an ally, although they demonstrated varying levels of skill in developing allyship.

\section{Both Motivators and Inhibitors}

Several participants described organizational contexts, including how positions were set up and the role of advisors, as both sustaining and impeding the conflict resolution process. In general, positions that were set up without a lot of balance contributed to students' stress and diminished their capacity. Further, advisors were often cited as supportive and motivating, but advisors also inhibited student leaders' abilities to successfully navigate conflict, particularly in cases where they were unwilling to hold other students accountable, when they were perceived to be pushing their own agenda, or when they showed a lack of care or otherwise disregarded the students they were meant to be supporting. Following is a review of organizational structures that served as both an inhibitor and motivator in conflict situations.

\section{Positional Set Up}

Some salient points that emerged from the data in this area are the need to create sustainable student leader positions and the support of advisors to do so. Mental health impacts and feeling extreme amounts of pressure and stress were commonly shared sentiments of student leaders, particularly for those who were in highly visible or widelyimpactful roles, such as student governance executive teams or student media. Student leaders in this study tended to express a strong level of responsibility for others and connectedness in their roles, which put extra pressure on them as they navigated (sometimes with underdeveloped skills sets) challenging conflict situations. 
One participant found much of their time consumed by their student leader responsibilities, which often led to not being able to get enough sleep in a week. They shared: "There were weeks where I get like three hours of sleep per night. It was disgusting. That was way too much." When speaking about their responsibilities and the amount of work and pressure, they also had this to say:

I think I should have been given far less responsibilities.... There's absolutely no reason for a student to sit on several advisory boards-because that itself takes up several hours per week, have periodic meetings with administrators, and try to liaise as much information as they can from a campus of 30,000 individuals.... It's a ridiculous amount of work... And then the worst part about it is that you're paid 20 hours a week, and it's just offensive. It's like, if I worked 20 hours in a week, it'd be like a week off, you know?

Between this participant's role in student leadership, school, and the conflict they experienced, their sense of stress was immense; they described it this way:

I had never been under that much pressure before, that much stress. But I was able to get through it and everything done. So I think the first thing that I learned is what my boundaries are and how much I can handle pressure-wise and workloadwise.

This participant discovered their capacity because of the pressure they experienced in a highly visible position that required them to balance multiple priorities, and the conflict they experienced added another layer of extreme stress.

Another participant expressed similar sentiments. Their position brings with it an additional layer of pressure, both because of the visibility of the position and the impact that student media can have on other students. When asked about skills they thought were important for student leaders to possess, they shared:

Ability to stay calm under pressure, and that doesn't mean not being stressed. I mean, it's hard to say because I say recognizing what's happening isn't like a catastrophe, like, also at the same time, there's weight to what I do at least, 
because if we report a story wrong, that could ruin someone's life. And so that's something you've got to think about before you publish.

Given these participants' experiences, advisors of students who are in fast-paced, highpressure environments, or in positions that are visible and upon which lots of other student leaders depend, should consider how position descriptions are worded, how the hierarchy of the organization distributes workload more easily, coach and support students in how to set boundaries, and set up opportunities for frequent check ins or an open door of support for students to process what they are experiencing in the role.

Several other participants expressed that a common experience for them was balancing their student leadership responsibilities with everything else, and experiencing difficulty compartmentalizing or turning off their student leadership responsibilities. Elena expressed a desire to better balance all of her responsibilities, sharing: "I mean, my job is really important to me. And school is too, but I think that like they could be on like an equal level. But I usually let work kind of take over." Gia also described the toll that her student leadership position took on her, as her and her peers advocated for resources for the equity and inclusion work they were doing. In Gia's experience, her student leadership experience required both physical and time-intensive effort, but also emotional labor that left her feeling emotionally exhausted.

Jordan described trying to balance multiple responsibilities, including wanting to give up at one point because of how much time, effort, and stress her student leadership role required of her. Mark emphasized the challenge of compartmentalizing and separating out work and school, especially when student leadership obligations and conflicts from leadership roles added stress that was hard to turn off: 
And then just the fact that you try to separate work from your school life, but these kind of things don't get separated as easy as emails do. So that made that feeling carry into my school, and-- going to my education and impacting that was also... was hard to deal with.

One interesting finding of this study was the impact of interpersonal conflict for student leaders on the broader group. Conflict between individuals often led to controversy within groups, in part because the interpersonal conflict often signaled a wider-spread organizational cultural problem or systemic issue. While student leaders in this study differentiated between conflict and controversy as interpersonal versus public or large scale, when speaking of conflict impacts on a group dynamic, several of them described the polarizing effect of controversy in those scenarios. In other words, when interpersonal conflicts impacted a group dynamic and peers began to take sides, the result was polarizing controversy. Erin spoke to this in a situation within her sorority:

I remember there was a lot of controversy in my sorority over something like really, really, really stupid, really stupid. And I just remember... it was the littlest thing, but it made people just so polarized... it was one of the most polarizing things for my sorority so far that I've been a part of.

Similarly, another participant spoke of a conflict that became a larger controversy on social media, saying:

A lot of people liked [the social media post]. A lot of people disliked it, a lot of people like laughed, and like.... it was just like, a lot. And just to be part of that was just really shitty. And then now I'm going to have to like go to class, right? .... Another thing that was really hard was that people who I disagree with ideologically are really agreeing with the [post]. And I was like, why am I lumped in with these people? That sucks.

Elena echoed this perspective and described seeing an entrenchment around a particular perspective occurring within groups she was a part of. Perhaps the most concerning issue 
she raised within a group conflict scenario is the unwillingness of individuals to adjust their stance once they had taken a side:

I would say... people choose a side, kind of. It seems like it's almost like human nature to just choose a side whenever there's any sort of controversy or conflict. Like we just automatically [go], Okay, which side do I agree with? And then people stick with that a lot, no matter what the conflict, or what the reasoning is, I feel like they just all of a sudden, they'll back that no matter what.

Student leaders in this study often were speaking about different perspectives that were part of a broader organizational controversy, suggesting that conflicts are actually a part of an interconnected web of relationships that have a resonant impact across the group, both on individual relationships and on group dynamics, culture, and functioning.

\section{The Role of Advisors}

The role advisors played was an important theme for participants in this study, and their experiences differed depending on the context. Some student leaders found their advisors to be very helpful, while some identified advisors as not very supportive, even when they were sometimes well-meaning. Some participants describe very positive experiences with advisors, who helped recruit them into their roles and otherwise encouraged and supported them. Following is a review of sub-themes related to the role of advisors.

Building Confidence. Erin described how an advisor helped build her confidence as she came into her position later than the rest of her peers, sharing: "[my advisor] was just super supportive of me... definitely someone that I felt like I could just talk to openly and share with her how I was feeling without judgment or anything." Similarly, the encouragement and support of the advisor helped to build Jordan's confidence, and also 
allowed her the opportunity to get better connected with a community she was newly a part of on campus.

Gia described the types of support that her advisors in both of her leadership roles offered to her:

I guess my boss at the [cultural center] really helped provide resources for us to build that confidence I believe. And same with my bosses at [my student leadership organization]. They laid out all the resources that would be helpful to me so that I could be successful. So yeah, I guess that helps build the confidence because then I could seek out those resources or if I had questions about them, then I could go to those people.

Advisors had a key role to play in building up the confidence of the student leaders within their organizations, reinforcing when they were doing things well and their belief in them and their abilities, which in turn was a motivating factor for student leaders.

Supporting Problem-Solving. Advisors also served as sounding boards and supported problem solving in the conflict situations that several of the participants shared. James described how an advisor was a critical source of support when he was under immense pressure from the conflict he was experiencing. The advisor took him to lunch listened to him when he was stressed. Ryan also described the role of an advisor in helping him brainstorm possibilities and outcomes for pathways forward in a conflict situation he was experiencing. He said: "So [my] advisor, on the whiteboard, we sat there for probably an hour and a half, but we listed out all the different possibilities we could do, pros and cons for each one." Ryan's advisor took time to think through possibilities and served as a sounding board for Ryan to identify best next steps in the conflict he was navigating. Carmen described her advisor providing perspective prior to meeting with a disgruntled fellow student, saying: 
And I went to her and was like, What if he asked this?.... Can you give me a fresh perspective on it? And she kind of gave her opinion of the situation that really helped me reconcile, like, well, like, I could have done it better, but I didn't completely botch it, like I was thinking.

Carmen's advisor's support offered another way to think about the issue and also built Carmen's confidence in her own decision making up to that point.

The supportive role that advisors played when navigating conflict was echoed by other participants. Gia shared: "My advisor at [my student organization], she's really helped me navigate the conflict and think of ways to take care of myself and move forward." In Michael's situation, his instinct was to directly confront the conflict situation, but his supervisor told him not to in order to not escalate the situation and cause harm to others in the process. Because of his positive relationship with his advisor, he took her advice and was able to take a more measured approach. He shared:

I was told by my supervisor not to do that. I think that could have been because I had a very strong relationship with my supervisor last year. And so I was able to trust her when they said not to do that. Because I felt like that my supervisor knew me well enough.

Lack of Support. Several participants also experienced difficulty and lack of support from their advisors, which negatively impacted their student leadership experiences. Elena describes the influential role of mentors in helping students process and work out what they believe. She shared:

I think in some ways they can help a student navigate where they're at with something or how they feel about a situation. But then I think there's always that bias that bleeds through. And that has a big impact on the student's thought process. I mean, I would catch myself in that situation of talking with somebody who was advising me. And I would realize that they were pushing me one way, where I was like, I'm not trying to be either side of this, but I think that you're just unintentionally-- I didn't say that, but it felt like an unintentional push to what 
they were thinking.

From Elena's perspective, she felt that advisors overstepped their roles when they seemed to be encouraging students to think about an issue in a particular way or influence their thinking one way or the other, as opposed to serving as a sounding board or way to help students work out what they believe based on their own values. Elena also described the critical role of advisors to supporting student leaders, and her observations of the loss of support felt by students when those relationships were damaged. She described it this way:

It seemed like mentors had a really big impact on students in those roles, and where they were kind of at and then... but when those relationships become damaged, that creates a lot more conflict, because then it's like, they become lost in who to go to.

James agrees that the relationship advisors has with student leaders - and recognizing the importance of the relationships student leaders have with one another-can influence the culture of an organization, or at least negatively impact interpersonal relationships. He shared:

A lot of people, especially advisors.... a lot of times may not value student to student connection as much as they should. And if it's not prioritized, it will probably lead to more conflict.... I think an advisor should strive to be more relational than transactional. I think that's a start.

Jordan described the hurt that came from working hard in an organization and feeling like the advisor was not supportive and that student leaders were not a priority for the advisor, even when the organization was a priority for student leaders. She shared:

I decided not to come back, because it was just a tough relationship between myself and the advisor. She told us the previous year, we were one of her lowest priorities. She would take credit for the good things that we did. And then blame us for the bad things. She never told us thank you, or you're doing a good job. She 
consistently treated us like we were either non-existent or not worth her time. And that was tough for me. So I decided I wasn't gonna come back to my senior year.

Abram got along well with his advisors, but found them ultimately to be unhelpful because they were unwilling to hold other students accountable, and Abram's position did not allow him to carry out an accountability process. From Abram's perspective, the advisors provided too much support and not enough challenge around performance expectations for his peers, which put him in a difficult situation because he was left to try to figure out how to accomplish tasks that were not getting done. While the advisors were well-intentioned, it had a negative impact on Abram's experience in student leadership, leading to more conflict for him.

These themes have significant implications for advisors. Advisors should understand how the roles of student leader positions put pressure on student leaders, depending on how the position description is worded, the responsibilities assigned to their roles, the context in which they are performing their roles, and the set up of the organization overall. Further, it is important that advisors recognize the high level of impact and influence they have over student leaders, and try to not unduly influence student leader outcomes, but rather facilitate and guide the efforts of student leaders within the group.

\section{Socially Responsible Leadership Development}

The data from this study has illustrated student leader development and growth as they navigated conflict in leadership contexts. The juniors and seniors in this study all exhibited an appreciation for peers and growth in their own leadership, emotional intelligence, and development due to their experiences navigating conflict with peers. 
Student leaders not only became more confident in their values, but also demonstrated a value for diverse perspectives and a desire to work towards bettering themselves, their student groups, their campuses, and, in some cases, the world. This combination of attitudes and behaviors and skills developed through the process of working through conflict fostered student leader growth in their socially responsible leadership skills, including aspects of intercultural and connective leadership. These findings point to a contemporary understanding and model of socially responsible leadership development across four dimensions. Following is a discussion of the skills and attitudes that developed for participants and that signaled their growth as a result of conflict in leadership contexts, the balance and negotiation of justice and care approaches, and a review of the socially responsible leadership development of students across four dimensions: individual, group, community, and societal.

Bennett and Bennett (2001), in their report on developing intercultural sensitivity, describes the intersection of behavior with attitudes, and asserts that "...knowledge, attitude, and behavior must work together for development to occur" (p. 7). They state:

The mindset refers to one's awareness of operating in a cultural context. This usually entails some conscious knowledge of one's own culture (cultural selfawareness), some frameworks for creating useful cultural contrasts (e.g., communication styles, cultural values), and a clear understanding about how to use cultural generalizations without stereotyping. The mindset (or better, "heartset") also includes the maintenance of attitudes such as curiosity and tolerance of ambiguity that act as motivators for seeking out cultural differences. (p. 6-7)

What Bennett and Bennett describe is the importance of a complex set of skills and attitudes intersecting to allow individuals to navigate diverse situations in interculturally competent ways; these are at the center of an intercultural leadership approach. Related to 
this idea of intercultural leadership is Lipman-Blumen's (2017) idea of connective leadership. According to Lipman-Blumen,

Inevitably, hyperconnected individuals and groups, scattered around the world, reflect diverging, frequently incompatible, agendas. These inescapable contradictions serve up a steaming recipe for conflict. Connective leaders, however, with their powerful behavior repertoire, undergirded by ethics, and emotional intelligence (Schreiner, 2016), offer a formidable response to even the most serious global problems. (p. 171)

These two approaches bring together both a value and appreciation for difference

and the skills of an emotionally intelligent individual. Several participants exhibited these qualities and perspectives. James echoed this appreciation for difference and a recognition that others have important and valuable lived experiences. He shared:

There are people who hold identities that are vastly different from mine, whose lives I can't really understand. And so the only way I can begin to empathize or learn about what they go through, is by reading, and through talking with them. And I'll still never understand what another person goes through who isn't me, but I can still make an attempt to be an ally.

Similarly, Jordan described the importance of this heartset and emotionally intelligent approach. She shared:

[Student media] was actually very integral to who I was able to become as a leader. Because I had no one ever challenge anything that I believed, ever. I came from a community where confirmation bias, everybody believes the same thing you believe, has the same background that you do, looks the same way that you do. So there was no challenge there of perspective. So when you join media, you have to learn how to take somebody else's perspective and not only listen, but write from their story, and be able to tell their story in a way that shines the light about who they are. And so I learned a lot, I think, inadvertently and semi consciously that year about identities, and learning all these things that I never heard about before.

This idea of working across diverse perspectives and developing and harnessing diverse perspectives and skills sets to sensitively navigate areas of disagreement and seek 
opportunities for successful collaboration for the common good is the central goal of the Social Change Model of Leadership. Student leaders in this study exhibited both citizenship-focused behaviors and skills that are at the heart of a democratic society.

\section{Justice and Care Orientations}

The central emergent theme of this study was the melding of students' values of love and kindness for others and their desire to be in relationship with their peers with their desire to work in concert and accountability with others towards a shared goal that gives forward motion to positive change, holding themselves, their peers, and ultimately society at large accountable for achieving this vision.

This blend of an ethic of care (evidenced by their desire to be in relationship with others, their common core value of love and kindness, and their expressed desire for a better world) and an ethic of justice (gaining confidence in their own abilities and solidification of what they value, a concern for sharing power across a group in order to achieve a common goal and ultimately work for a more just world) were ultimately both balanced and navigated in their own understanding and enactment of socially responsible leadership (see Figure 4.1). Carol Gilligan (1995) famously made the distinction between a justice and care orientation in her response to Lawrence Kohlberg's scholarship on moral development that had a solely justice orientation. She states:

From a justice perspective, the self as moral agent stands as a figure against a ground of social relationships, judging the conflicting claims of self and others against a standard of equality or equal respect.... From a care perspective, the relationship becomes the figure, defining self and others. Within the context of relationship, the self as a moral agent perceives and responds to the perception of need. The shift in moral perspective is manifest by a change in the moral question from "What is just?" to "How to respond?" (34-35). 
Participants in this study realized their desire for a better world through a commitment to their values and beliefs about what is right, their moral compass, held together in truth with their commitment to love and show kindness for others. Both of these elements were necessary to realize and enact citizenship behaviors — change for a better world.

"Change" in this instance implies positive directional movement, made possible through a clarification and commitment to values. This played out for participants in their own self-awareness, the growth of their leadership capacity (leadership self-efficacy), and their commitment to organizations and roles with which their values aligned and in which they believed in the purpose, mission, and goals: the justice perspective. "Better world" implies a desire to make a hospitable future with positive outcomes for all, evidenced in this study through the ways participants strived to maintain relationships, the myriad of ways they showed care and empathy for their peers, the development of their emotional intelligence, and the strategies they used to navigate conflict: the care perspective. Socially responsible leadership for these student leaders required both aspects to develop and exist simultaneously, in compliment, rather than conflict, with each other.

\section{The Four Dimensions of SRL Development}

Student leader participants in this study give us a contemporary understanding and definition of socially responsible leadership, as evidenced in the following four interconnected themes (see Table 4.2):

1. Individual Dimension/Self-Efficacy: moving from a lack of confidence toward leadership self-efficacy. 
2. Group Dimension/Group Accountability: moving from individual responsibility to group accountability.

3. Community Dimension/Shared Power: moving from individual ego to shared power and empowerment.

4. Societal Dimension/Empathy and Conflict Resolution: moving from incivility and disequilibrium to empathy and successful conflict resolution/dissolution.

The data from this study led to a new definition and model of socially responsible leadership (SRL). The new definition of SRL is: Socially responsible leadership promotes the common good through the interculturally-adept negotiation of justice and care and cognitive and affective competencies that moderate controversy and foster capacity building. This contemporary model and definition are particularly compelling because the themes emerged and coalesced across a diverse group of participants who had a wide vary of lived experiences across race, gender, leadership experiences, and major/area of study.

This definition offers an updated perspective of socially responsible leadership in a few ways. First, it describes SRL as a developmental process that leads to capacity building that empowers collective problem-solving. Secondly, it involves the navigation and constant balance of values (or justice framework) and relationships (or a care framework). This balance is achieved through a complex set of cognitive and affective skills sets, including emotional intelligence, empathy, perspective taking, and critical 
thinking, that are developed through leadership and conflict, and are applied within the context of a given situation.

Within the Social Change Model of Leadership (SCM), seven values, commonly called the "seven C's," work across three dimensions to facilitate the development of socially responsible leadership for social change. The individual values of the model include Consciousness of Self, Congruence, and Commitment; the group values include Collaboration, Common Purpose, and Controversy with Civility; and finally, the societal value of Citizenship (Higher Education Research Institute, 1996). Elements of these values can be seen throughout these four dimensions of socially responsible leadership outlined in this new definition and description of socially responsible leadership.

Within the individual dimension, Consciousness of Self and Commitment are indicated through students' growth in their self-belief in their own leadership abilities (Leadership Self Efficacy), and their solidification and commitment to what they value. Within the group dimension, the individual values of Commitment and Congruence are evident in the participants' alignment of their personal values with the organizations and roles with which they choose to affiliate. Further, evidence of the group values of Controversy with Civility is apparent in student leaders' motivations and desires to have their peers enact the mission of the organization and successfully fulfill their roles.

The group value of Common Purpose and the societal value of Citizenship are enacted in the community dimension of a desire for shared power and empowerment of others. The societal value of Citizenship is also evidenced in the societal dimension, as both a process of socially responsible leadership and an outcome or product of the 
socially responsible leadership process. In this updated reflection of the process of socially responsible leadership, self-efficacy, purpose, collaboration, and conflict resolution are key principles interwoven throughout the SCM values that help foster development for student leaders.

From this new framework, principles of justice previously mentioned (that is, student leaders' steadfastness in their principles and values, sense of purpose, and performance and exercise of their leadership) are blended with principles of care (that is, a deep, unwavering love, concern, and commitment for others, and a focus and value on relationships with peers) in an ongoing, contextualized, constant negotiation and enactment of socially responsible leadership to advance the common good and strive for a better world (see Table 4.2). 
Table 4.2

Four Dimensions of Socially Responsible Leadership

\begin{tabular}{|l|l|l|l|}
\hline Dimension & Development & Description & \multicolumn{2}{|l|}{ Orientation } \\
Self-Efficacy & $\begin{array}{l}\text { From Lack of } \\
\text { Confidence to Self- } \\
\text { Efficacy }\end{array}$ & $\begin{array}{l}\text { Velief in own ability and } \\
\text { solidification of one's own } \\
\text { values }\end{array}$ & Justice \\
\hline $\begin{array}{l}\text { Group/ } \\
\text { Group }\end{array}$ & $\begin{array}{l}\text { From Individual } \\
\text { Responsibility to Group } \\
\text { Accountability }\end{array}$ & $\begin{array}{l}\text { Belief in the mission, } \\
\text { values, and goals of the } \\
\text { group leads to commitment } \\
\text { to the group and shared } \\
\text { purpose }\end{array}$ & Justice \\
\hline $\begin{array}{l}\text { Community/ } \\
\text { Shared Power }\end{array}$ & $\begin{array}{l}\text { From Ego to Shared } \\
\text { Power }\end{array}$ & $\begin{array}{l}\text { Exposure to other } \\
\text { perspectives leads to a } \\
\text { desire to share power and a } \\
\text { focus on common good }\end{array}$ & Care \\
\hline $\begin{array}{l}\text { Societal/ } \\
\text { Empathy and } \\
\text { Conflict } \\
\text { Resolution }\end{array}$ & $\begin{array}{l}\text { From Incivility and } \\
\text { Disequilibrium to } \\
\text { Empathy and Conflict } \\
\text { Resolution/Dissolution }\end{array}$ & $\begin{array}{l}\text { Experience with incivility } \\
\text { and conflict leads to } \\
\text { increased emotional } \\
\text { intelligence and democratic } \\
\text { participation }\end{array}$ & $\begin{array}{l}\text { Care and } \\
\text { Justice }\end{array}$ \\
\hline
\end{tabular}

The remainder of this chapter will review these four emerging themes of how student leader participants' knowledge, skills, and approaches have changed and developed into a nuanced and dynamic enactment of socially responsible leadership (see Figure 4.1). 
Figure 4.1.

Interconnected Dimensions of the Childress Model of Socially Responsible Leadership

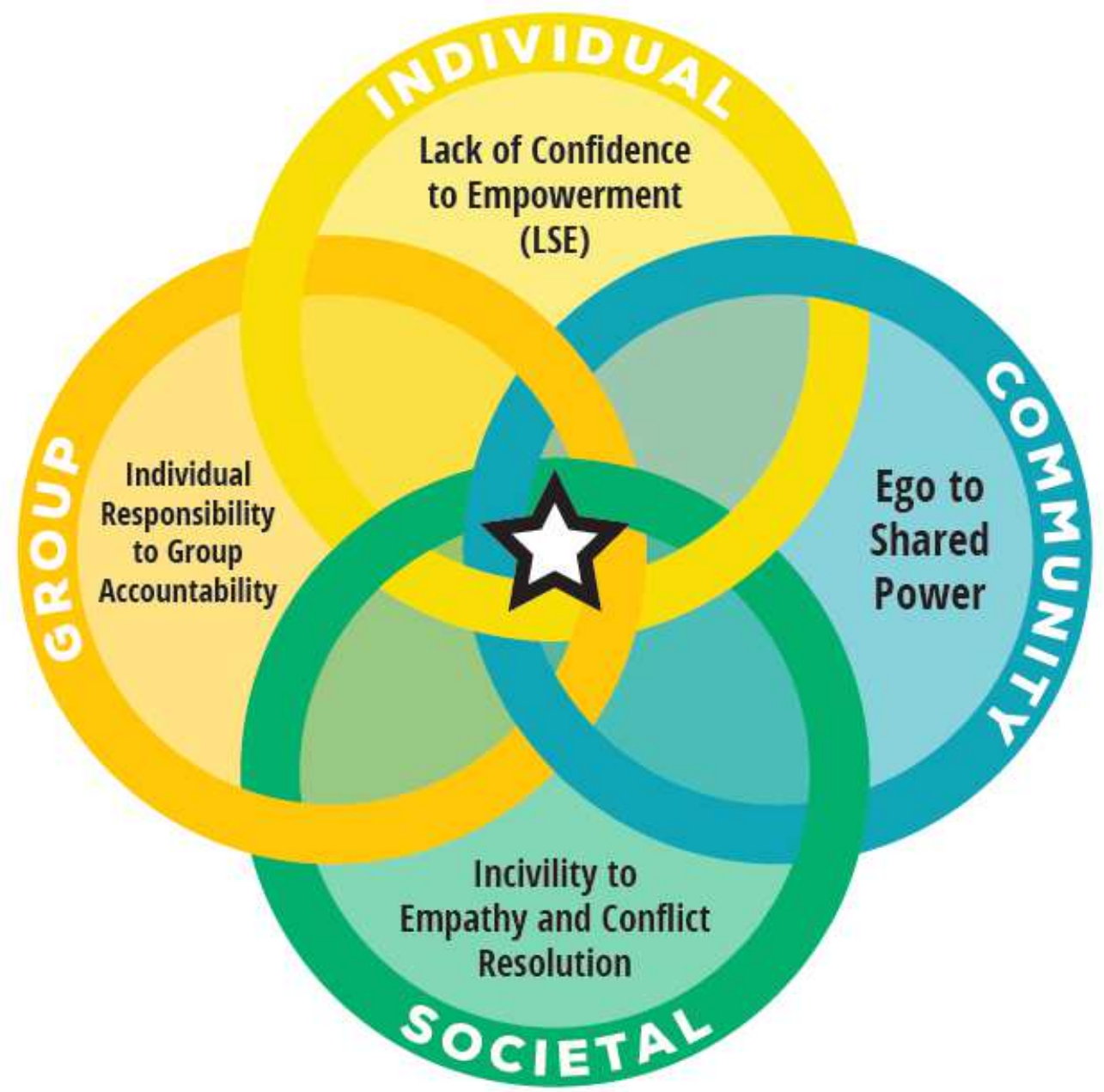

\section{今 SOCIALLY RESPONSIBLE LEADERSHIP}

Socially responsible leadership promotes the common good through the interculturally-adept negotiation of justice and care and cognitive and affective competencies that moderate controversy and foster capacity-building.

Justice $\bigcirc$ Justice $\bigcirc$ Care $\bigcirc$ Care \& Justice 


\section{Individual Theme: Lack of Confidence to Self-Efficacy}

For the purposes of this study, Consciousness of Self was described as awareness of one's own values, attitudes, beliefs, and emotions (Cilente Skendall, 2017) and the ways those impact action for leadership for change. Consciousness of Self was the most frequently coded SCM value. Every participant was able to self-identify and reflect in multiple ways on how their own identities connected to the exercise and application of their leadership. One aspect of self-awareness is leadership self-efficacy (LSE). Leadership self-efficacy refers to one's internal beliefs about their ability to successfully complete a task. According to Dugan et al. (2013), LSE plays a role in the extent to which a student is willing to engage in leadership activities, and "is a key predictor of gains in leadership capacity" (p. 20). Bandura (2012), known for his scholarship on selfefficacy, describes the phenomenon this way:

To be an agent is to exert intentional influence over one's functioning and the course of events by one's actions.... In this triadic codetermination, human functioning is a product of the interplay of intrapersonal influences, the behavior individuals engage in, and the environmental forces that impinge upon them... Because intrapersonal influences, in which self-efficacy is a constituent, are part of the determining conditions in this dynamic interplay, people have a hand in shaping events and the course their lives take. (p. 11)

Gaining confidence in their leadership abilities through validation from peers and advisors was a common facilitating factor of developing student leaders' leadership selfefficacy (LSE). Related experience that helped to develop LSE were empowerment in their roles and gaining experience and levels of comfort. These factors helped move student leaders from lack of confidence to empowerment and self-belief in their own abilities. 


\section{Self-Growth as an Accomplishment}

Some student leaders identified accomplishments as the growth they have seen in themselves and their abilities to lead, even in difficult circumstances. Gia said, "I also think learning more about myself as an accomplishment." She recognized that understanding of herself and what that means for her was a meaningful developmental step. Relatedly, Abby shared: “Oh, what I have been able to accomplish? I think just like self-growth honestly, like developing as a person." Michael also described one of his accomplishments as his own personal development within his leadership role. He had this to say:

I would say a lot of professional development, kind of personal development, as well.... Accomplishment-wise, I'm able to present myself better, and understand the importance of that....There's a time and a place. And I've been able to better understand the time in the place.

\section{Experiences That Fostered Leadership Self-Efficacy}

Student leaders in this study were able to articulate conditions that helped to facilitate the development of their leadership self-efficacy. Specifically, participants' leadership self-efficacy was fostered through validation of their performance by their peers and advisors, and through the experience of taking risks and trying something that had not tried before. Following is a more in-depth review of both of these strategies.

Validation from Peers and Advisors. When probed about what led to student leaders' confidence that they could achieve the accomplishments they listed, validation from advisors and peers was a resounding theme. Carmen shared:

Part of it, I think definitely would be like about receiving validation from the older student leaders and from the advisors. Like, "Hey, that was a tough 
situation. You handled it well," or "Yeah, your gut was right" or, "Hey, I saw you like, made [this choice], I would have done that too." That's super important.

She additionally shared the role experience played in building her confidence: "So just like having more confidence in myself that I've built through experience and through affirmation and support system."

Gia described feeling a low sense of LSE when new to her role, but seeing it grow over time. When asked what built her confidence, Gia shared: "I guess validation from my peers and my advisors. They would tell me that I'm doing good work. So I'm like, hey, we'll keep doing stuff like this."

Elena echoed the role of trying things out and gaining experience, along with support of others, particularly peers. When asked what contributed to her confidence, she shared: "Definitely words of encouragement. Peers building off of each other and our strengths, and a lot of collaboration. And then just the experience of, I guess, people kind of just throw you in." Jordan agreed that validation from both peers and her mentor were significant, and described validation as helping her "feel seen and like I was doing good things."

Taking Risks and Trying Something New. For some of the participants, the ability to take risks and try things out, and feeling safe to do so, also allowed them to have an increase in their leadership self-efficacy and develop their awareness and skills as student leaders. Abram talked about having a safe environment to take risks. When asked what factors helped him accomplish the things he was able to do in his leadership role, he shared: "Not being worried about failure. My bosses are so supportive and understanding that if I have something going on my life that's personal, I can come to 
them about that, and they'll be understanding." Abby expressed a similar perspective, and recognizing when and how she should take responsibility and when she is not responsible for things was also freeing for her to try out new things. She shared, "I think just like understanding that not everything is my fault. I think that really helps me to take risks."

Validation from peers and advisors both were significant facilitators of student leaders' self-efficacy. Advisors should consider how they are fostering peer-to-peer support, and also how they are proactively encouraging student leaders to take risks and try out new experiences within their student leader roles.

\section{Self-Efficacy and the Connection to Group Agency and Effectiveness}

Ultimately, there is evidence from the literature that achieving self-efficacy is part of a process that allows individuals to work collectively towards a common purpose or goal, understanding that people have varying levels of control over the conditions within which they are navigating, which Bandura (2012) describes as "proxy agency" (p. 12). He describes it this way:

People exercise their influence through different forms of agency rooted in corresponding types of efficacy beliefs.... People do not live their lives in social isolation. Many of the things they seek are achievable only by working together. In the exercise of collective agency, they pool their knowledge, skills, and resources and act in concert to shape their future. To do so they have to achieve unity of effort for common purpose within diverse self-interests and distribute and coordinate subfunctions across individuals of differing competencies. The more heavily group performance depends on the interdependent effort, the greater the contribution of collective efficacy to group productivity (Stajkovic, Lee, \& Nyberg, 2009). (p. 12)

The role leadership self-efficacy plays helps individuals contribute in concert with others to activate group agency and influence. In the process of constructive controversy put forth by Johnson (2015), important elements were cooperation as well as conflict, and 
cooperation contributed to overall higher productivity compared to competitive approaches. This connects with the second theme that emerged from this research, the group theme of participants moving from their individual responsibility towards accountability of the group to help achieve the group's purpose and goals.

\section{Group Theme: From Individual Responsibility to Group Accountability}

Socially responsible leadership depends upon effective democratic participation across a group of individuals with different backgrounds, skills sets, identities, and perspectives. The self-belief of individuals and the ways they contribute and interact with others in the realization of the group's purpose was one dimension through which participants in this study saw growth in their socially responsible leadership skills. Movement in this dimension began with a solidification and commitment to their values, and alignment with particular groups and roles based on those values, and then using their agency and position to motivate the group towards that common goal or purpose. Following is a review of the related subthemes of the group dimension, beginning with a discussion of individual commitment to their values and beliefs.

\section{Solidification and Commitment to Values}

This idea of self-belief related to ability to accomplish leadership tasks - a demonstrable product of leadership — connects directly with a student's awareness of their own beliefs, emotions, and values and how those impact their leadership. For example, Carmen shared this about her own internal belief in accomplishing tasks within her role: 
I believe that I deserve to be in a space. That in times of pressure, I am the person that I would want to have next to me. I'm calm, focused on like problem solving and next steps, but at the same time, still compassionate.

Despite the stress of navigating conflict with peers, a common salient theme for student leaders was the importance of holding fast to values and holding others accountable for their behavior. This was expressed commonly across student leaders and was conceptualized as a true enactment of values as opposed to simply espousing values without action. In fact, for some student leaders, individual responsibility led to feeling compelled to act, and an expectation that the group as a whole is accountable.

A commonly expressed attitude from participants was their commitment to their values. Ryan described one of his gains from his participation student leadership as a willingness to stand up for his beliefs: "To stand up for my values, what I believe in, to go against groupthink, and what other presidents might say is how we do. To be more independent, definitely.”

When asked about her attitudes on conflict, Jordan talked about nuanced differences between standing your ground versus being close-minded:

And because I believe that the conflict is productive, and that is not drama, in terms of closed-mindedness. I think that that's a misconception. I think that there's a difference between being close-minded and... standing firm your beliefs like I talked about. I held firm to those values, because I believe in those values. But also, I did hear these other people's ideas, who did think that we needed to have compromise. So I think what people see is closed-mindedness is simply just people having beliefs.

Jordan articulates an important difference between commitment to one's values and close-mindedness: the process of reflection on what you believe and why you believe it, and what others believe and why they hold those beliefs. This aligns with another 
frequent theme among participants, that of perspective-taking. The belief that holding to values is a matter of critically thinking and committing to a set of beliefs was also shared by Abby, who shared: "It's also probably helpful to have some conflict because then if you have no conflict, there's probably no one in the room that is willing to stand up for their opinion."

Jordan and Abby expressed similar sentiments, that conflict allows for clarity of values and a commitment to values allows one to move more productively through conflict, in an effort to compare beliefs and work through conflict with those who hold different perspectives. Michael also spoke to the importance of critical thinking and understanding what your values are in order to guide decision making:

Having a good understanding of my own values is helpful when making those decisions, because, of course, as human, I don't think I'm wrong $100 \%$ of the time, I think I'm wrong sometimes. But I don't like to be wrong. And so I like to think that my way of thinking is right, it is a good way to think and so relying heavily on my own morals and values, then when it comes to thinking critically, it becomes easier as well.

Abram believed similarly. He described a shift in his leadership style as one that is more thoughtful, considered, and reflective before responding in a situation, and that process includes an internal check of his own personal values applied to the situation. In these situations, student leaders expressed reflecting on their own values and, through a process of critical thinking, and using their values as a measure, arriving at a decision or opinion.

Jordan described how the values she grew up with do not seem to comport with the behaviors of those same people, and the struggles she is feeling with her own religious identity because of this lack of congruence; her experiences in student leadership trainings and being exposed to different perspectives on campus have also 
facilitated this growing realization for her. This process of understanding and committing to values, and behaving in a way consistent with those values was echoed by many of the student leader participants, possibly because of their advanced development as juniors and seniors at the institution and their lived experiences have allowed them to process and work out what they believe for themselves.

\section{Source of Conflict: Motivating Peers to Achieve Group Goals}

The most common source of conflict that student leaders described was conflict that arose while student leaders trying to get peers to perform the expectations of their student leadership positions and the resulting conflict from trying to hold them accountable. Abram struggled to understand how he could impact a positive change and motivate his peers to complete their work. He processed the experience with another peer, who changed his perspective about his level of efficacy in the situation:

And [my peer] basically... in a way they explained like, that's just kind of how it is right now. It's not supposed to be but that's kind of how it is. And that made my perspective change of like, this isn't something that I can fix. Because... that was my first thought is, I'm going to fix this, I'm going to change their behavior. And I kept getting... in a little argument kind of thing. Like, "no I don't really need to be doing that. You don't really need me telling me what to do" kind of thing.... And so... talking to her about it made me realize the issue was something that wasn't necessarily going to change, but I could find a way to make it not as bad.

Abram expressed frustration in the conflict because he was responsible for holding peers accountable, but lacked authority and strategies to do so. James described a similar difficulty and seeking support from a campus administrator about how to navigate holding a peer and friend accountable. The advice James received about being kind and in relationship with his peer comported with many student leaders' desires to share power, maintain relationship, and achieve shared goals; however, he struggled to be able 
to accomplish these tasks despite his friendship relationship with his peer. This

experience was shared across many of the study's participants.

A consistent source of conflict for several of the participants was how to hold peers accountable for non-performance or for not meeting expectations, and also for how to support peers effectively. Several student leader participants described their focus on and desire to support their peers, and the ways that they did so. When asked if there was anything about his leadership style that has changed since he has experienced conflict, Abram shared:

Yeah. Not only like setting things up for success on the front end and realizing that that like the most important thing to do as a manager is having the systems in place for the students to succeed or the employees to succeed. That leadership perspective has changed. I think I used to view like, a problem happens and then you resolve it, but you can like problem solve ahead of time in advance. Foresight, I guess the foresight.

\section{Fostering Peers' Success}

Another theme that emerged was the desire of student leaders to create environments where their peers could use their experiences in their student leadership roles to develop and grow; a common sentiment was the desire to foster peers' success. Abram shared about his desire to set up the organization so that it supports student career goals and aspirations:

I don't know if this is a core value but like the appreciation for people's talents and gifts.... And you have to appreciate them for that because that's special. That makes them special.... Whether that's like, in an artistic form, or even someone that's really good at math, you have to be appreciative of people's talents and gifts... We have two people who want to be doctors that are working there. And that's amazing, we need to encourage that, we need to figure out ways that [this organization] can help them towards that. That may not sound like a natural step, but there are ways. Like, they can do a study on people's happiness before entering and after exiting [the space], stuff like that. 
Carmen echoes the experience of wanting her peers to succeed. She described wanting to provide a positive educational experience for her peers. She shared: "I feel a responsibility to make sure everyone is like, getting the educational experience they deserve from working there, and like feeling welcome, like I did."

Student leaders struggled at times with holding their peers accountable and how to navigate that conflict, which was a common experience. However, student leaders also desired to make the work experience and organizational cultural a positive one, including finding ways to support their peers' development and goals beyond their roles. Advisors and institutions should identify ways to continue to channel this motivation and energy, and support student leaders in strategies to effectively support their peers.

Movement in this theme was connected to alignment of one's values and beliefs with where and how they affiliated and channeled their energy; that is, what roles and organizations they joined and the level of congruence and belonging they had within those groups. Student leaders then spent time trying to foster and develop the skills of their peers and to motivate individual members to help accomplish group goals, in an attempt to foster a sense of accountability for the purpose of the group. In the next section, a related theme was working with, around, and through power structures and seeking opportunities to reduce hierarchy and barriers to create a collectivist sense of shared power to work towards achieving common goals.

\section{Community Theme: From Individual Ego to Value of Shared Power}

Student leader participants spoke about the value of collaboration commonly in terms of power structures and sharing power with their peers. Nearly every participant 
spoke to the role of power within the organization and how power dynamics influence leadership. This included a desire to give up or share power with others to help achieve a common goal. Related to this was a theme of setting aside one's own ego and considering the common good.

\section{The Challenge of Hierarchy}

James expressed the challenge of navigating conflict with someone who was at a different level in the hierarchy from him, and the additional challenges of navigating conflict that the power imbalance posed. He shared:

So one reason why there is conflict there is because there's hierarchy.... It didn't really make sense that hierarchy would be there to that extreme. There's kind of tension as it was, because whenever we were to pursue disciplinary action, it wouldn't be as equals, it would be like shooting down, which I really didn't like doing. That was like an awful feeling.

He also expressed trying to take action to purposefully compensate for power imbalances in his student leadership role, including attending other student groups without fellow student organization members in order to avoid a significant power differential.

Similarly, Jordan expressed concerns about power and described her experiences feeling like peers were wielding unnecessary power that was invalidating to the work she and her peers had done on a committee, and the sense of frustration that came from that. Her advocacy meant that others understood her desire for shared leadership and authority, and the role power imbalances could play in invalidating the work of many peers working cooperatively together. She also discussed her own perspective of leadership, and her disinclination to buy into power structures of leadership:

I want to stray from using the definition of a leader, because leader means power. And it means that you're the one who's in charge. And I don't want it to feel like 
I'm a leader, this is me, I'm doing this. I'm simply someone in the position who's helping... who's in the act of leading, and also helping find others who lead... [in my student organization], the student leaders rotate through every year, because they don't want people to get stagnant and stuck in that position. They want other people to get the opportunity to grow and learn from those experiences. So that's my goal is to find other people who lead and who can do really well in my position, other positions, other organizations.

Mark also described looking for opportunities to dismantle structural systems of power in order to share power with his peers. He disliked hierarchy and tried to get buy in from his peers by reducing hierarchy where he could. He shared:

When I was doing that leadership role, like, I tried to keep it a pretty horizontal leadership structure. I didn't try to impose a huge, hierarchical, like, I'm your boss kind of structure.... And I was literally just like, for some specific tasks, I need to be like the approval point. But other than that, you have all the autonomy in the world to do what you want. And I think that because [me and my leadership liaison]... sort of set that tone earlier on, that allowed for like, in terms of conflict, not to have that hierarchical structure that, oh, because he's the leadership liaison, he will have the final say, or like it, because he's higher on that list, that he's right. So that was avoided because of that kind of structure that we implemented earlier on.

Through striving to have a flat organization where peers felt empowered and in which they shared authority, Mark believes he avoided conflict situations.

Abram described having authority over desk staff, who he struggled to motivate to carry out their responsibilities. From his perspective, part of the challenge was the hierarchy, as his peers had only ever known him in a supervisory role. He compares that to the previous peer supervisor, who had been their co-worker before being promoted into a supervisory role. He shared:

She actually was front desk staff with them and then was hired into that role. So they were like, equals, and then they worked, you know? So the all the new staff, they've only viewed me as a person that is in charge, like, I'm not like, in charge. Yeah. Like, if I'm at a party and I run into one of them. Like, they'll be like this. My boss, like, this is my manager, blah, blah, blah. And I'm like, yeah, that's 
funny.... So yeah, they-- she was viewed as an equal. I think that helped a lot. It's hard to be new and be viewed as equal.

Abram felt distance because of his supervisory position, and struggled to bridge the power gap that would allow him to connect with his peers in a different way and create buy-in for them to perform in their student leadership positions.

\section{Setting Aside Ego}

Setting aside one's ego to best facilitate the group as a leader was another commonly expressed value of several of the participants in this study. Ryan spoke to this when he shared important skills for leaders to possess:

Just because you are in an elected position, or are a leader doesn't mean you're the most knowledgeable in the room, doesn't mean you have the most supreme authority. You can always learn from others.... And so not to kind of power trip and get in over your head over that I think is crucial.

Abby also described the importance of setting aside one's ego to effectively support peers and their role in the organization, sharing: "But it's not really about me... [my leadership position is] a very behind the scenes type of role. And that's why you can't be in it for fame and glory."

\section{Shared Power for a Democratic Process}

Jordan's perspective is future-oriented as she has sought opportunities to develop peers to be the next leaders or facilitators of the group in an effort to share power and authority with others. She expressed this sentiment and recognized that adopting a shared leadership perspective sometimes means that everyone supports the final decision after a robust and participatory decision-making process, even if there are parts they disagree with. She shared: 
I'm also relying on the people who we did have [on the committee]. It was a big deal to me that the committee decided to rally around the budget that we said, even though there are people who didn't agree with it, they voted. But then we-when it came up about whether or not we should vote, people weren't like, Oh, I voted no, during our presentation, so I'm not voting no. They're like, No, we set this as a group, we're going to believe in the purpose of what we did and we'll vote yes. So I think that trust was a big deal too.

Carmen shared many of her peers' distaste for having and holding power, saying:

I have never felt the need to... be in power, be in charge. Like I don't, I don't even really like that. If I had to pick, I think I would say I dislike it.... Like I don't really like to force. I mean, I will. But I don't like to like force things on people.

Carmen's perspective is similar to the other participants; that is, trying to get participation and buy-in from peers due to force is ineffective and does not feel natural or comfortable. She also shared about how she works to set aside her ego, saying: "My ego isn't in this position. I mean, of course it is, to some extent. I want it to do well, and I feel guilt for collective failures. But I'm not in it for the power." Casey shared Carmen's and other participants' perspectives about leadership and a desire for shared power. Casey viewed power negatively and desired a model of leadership that was more focused in facilitating the group as opposed to making unilateral decisions, sharing:

I guess because this is in the forefront of my consciousness at the moment is the ability to hear those that you are quote unquote leading. Because you're not doing it for you. And it's very easy to, you know, go on a power trip if you're in a leadership position. I tend to think of leadership positions more as... those people are more coordinators and facilitators rather than being in control of everything. So being-- I think being able to be open minded and facilitate... lead rather than control and dominate, I think. Yeah.

Overall, student leader participants were very aware of and named power structures, and also how hierarchy and power created conflict and roadblocks to accomplishing shared goals, including preventing buy-in and disempowering their peers 
in their organizations. Several participants actively worked against this dynamic, even if they had positional leadership, through looking for ways to create a flatter organization, purposefully setting their ego aside, and looking for opportunities to empower their peers in their roles. Within this dimension, students started from a place of self-centeredness and their own ego and individual power to a perspective of reducing hierarchy and looking for opportunities for collaboration and partnership to share power with peers. This shift often came from a realization that hierarchy creates barriers to accomplishing shared goals and a distaste for power structures.

Advisors should consider how organizations are structured and where opportunities are given for shared power. For example, one student organization at the research site specifically only allows students to hold particular positional leadership roles for one year in order to cycle student leaders through and create a culture where new students are consistently being groomed to step up into leadership roles and prevent unnecessary hierarchy. These student leaders were resistant to power structures and tended to find them ineffective in allowing them to carry out their student leadership roles effectively.

Through developing leadership self-efficacy, developing congruence of values through affiliation and belonging to groups, and working with peers to hold the group accountable to the purpose and to do so in a way that eliminated barriers that were created due to power dynamics, student leader participants showed development and growth in their socially responsible leadership skills. These themes emerged as a product of conflict resolution as they sought to achieve these goals. Ultimately, student leaders 
were able to work across a societal dimension of disorder and incivility to empathy and conflict resolution, both a process and product of conflict and controversy with peers.

\section{Societal Theme: From Incivility to Empathy and Conflict Resolution/Dissolution}

Nearly every participant (ten of twelve) described that their conflict styles changed during the course of their collegiate career. The changes can be broadly categorized across three themes: a recognition that others see the world differently, a willingness and increased confidence to engage in conflict, and developed skills for how to address others in conflict situations.

\section{Recognition That Others See the World Differently}

Michael expressed that early in his college career, he would be very vocal if he felt something was wrong and display an emotional response; one of the ways he grew was in considering what others' perspectives were and incorporating that information into what he already believed or knew to be true about the world. He also shared his growing realization that he may not have all the answers:

A little bit of time passed after that, and I realized, I'm just gonna keep my mouth shut. Because no one wants to hear us anyway. And they're wrong. And I'm right. And that's that. Well, no, as I experienced more college, "crap, that's actually not how it is. I'm not always right." Right. That's, that's kind of rebellious teenager coming back in like, "I am right." And I'm not. And that kind of sort of developed, like, Okay, well, how is this person right? Or why is this person saying this thing?

Abram also described his recognition that others may have a different response to conflict situations than him. He described specifically growing in his level of compassion for others and "ability to recognize that other people are more sensitive than [him]."

\section{Willingness and Increased Confidence to Engage in Conflict}


Some student leaders appeared more willing to engage in difficult conversations with others as a result of their experience and growth through a conflict process. Increased skill in this area appeared to build their confidence in being able to manage these situations and, in fact, allowed difficult conversations to become less of a big deal, the more confidence they gained. According to Carmen, "I used to be very nonconfrontational. But now I guess I like... I don't even see them as confrontations anymore, which kind of removes the barrier a lot. Like I lean into those tough conversations now, which has been helpful."

Erin described being "more comfortable with [the] discomfort" of conflict since starting college. Mark shared this sentiment, describing an increase in his own confidence as well as having access to language to help have difficult conversations. Gia expressed that she was very shy and non-confrontational coming into college, but her experience through her leadership roles have changed how she approaches conflict. Elena similarly described herself as conflict-avoidant when starting college, and realized a change in her willingness to engage in difficult conversations with others:

I think I was much more of an avoider before. And now it's harder for me to avoid it. To avoid handling it even, just because, I have this like, I feel like this moral obligation to do something about things.

\section{Advanced Conflict Management Skills and Strategies}

Beyond a recognition that others have different lived experiences and an increased willingness to engage in conflict, participants described the development of more advanced skills sets related to conflict management. Ryan believes that how he addresses conflict is fundamentally the same, but that he has learned strategies to enhance 
his style. One hallmark of student development is an ability to recognize and acknowledge the experiences of others separate from oneself. Ryan illustrates this growth:

I'd say definitely like, gotten a lot more patient. I've listened to understand, something I definitely didn't do before. It was-- is mostly about me, but now it's definitely about both parties, about others. Knowing where they're coming from like I said, like more patient, more understanding, more empathy I think is the big one.

Abby also expressed growth in her approach. Compared to some of her peers, she expressed moving from previously having a "softer" approach to being able to better communicate her perspective and position.

A few participants expressed developing self-confidence in their own ability to work though conflict, and also a realization that even though conflict can be difficult, it can have positive outcomes and therefore not as daunting as they first believed. In fact, Erin specifically named the value-add of conflict:

I think conflict can signal that something needs to change. And I know, in my personal experience with like, a few conflicts that I was just really down about, and have made me reevaluate my own behavior and like, take a look in and be like, Oh, my gosh, like, I did not realize I was doing that. And I really need to, like, work to be better.... Um, I think, maybe just learning more about conflict, I think the more I learned about it, and the more I kind of just understood what it was at its core, I think helped me a lot to, to kind of see the bigger picture a little bit.

Erin's growth came through reflection, after receiving new information and having to evaluate the meaning and how it shaped who she wanted to be in her own identity formation.

Part of Carmen's growth in conflict situations was a willingness and confidence to engage, in part because of her belief through lived experience that the consequences will 
not necessarily be dire. Abby shared a similar sentiment. She described learning about conflict resolution through observing others and empathizing. She also named that having a set of conflict resolution skills has built her confidence level: "But I think being more open to the possibility of conflict is because I know that I have a lot of tools to deal with it and like nothing can really hurt me in that way. Like, nothing's that bad." For these participants, there was comfort in knowing that, while uncomfortable, conflict can-and often does - have positive outcomes, and having experience and strategies to navigate those situations led them to feel more equipped.

A counternarrative to the perspective that conflict does not necessarily need to result in negative outcomes was presented by a few of the participants who described disorienting dilemmas related to their conflict experiences. While James acknowledged growing through conflict in his student leader roles, he also expressed feeling caught "literally in the middle of two extremely polarized sides." He goes on to share:

And that was really hard for me to reconcile those, that was the single hardest thing I had to deal with last year, was when they were like.... in short, right, because it's a long story. There were two parties that were intensely against one another. And then I saw where both sides were coming from, even though I thought the person who quit was in the right.

Similarly, Abram expressed the challenges that he has experienced through conflict experiences. When asked where his empathy for others came from, he shared the disorienting dilemma of losing friendships as a result of conflicts - a tangible, negative outcome that increased his capacity for perspective-taking and empathy.

\section{Desire to Make a Positive Change}


Another significant theme that emerged from the participants in this study, connected with their value of love and kindness and concerned for the well-being of their peers, was their desire to make a positive difference in the world and considering the ways that they could help influence that positive change - in other words, how to enact Citizenship behaviors. For many of them, this started at a local level, within their student leadership roles. Jordan described her desire to make a positive impact without needing credit for it. She shared:

I love legacies, I love projects and making those differences.... And that's what matters to me. That's what makes impact. Nobody has to know it was me. Nobody has to know that it was what I did... it was lots of people, it was lots of discussion, it was lots of growth.

Carmen described feeling frustrated with how things were playing out on a national scale and wanting to make a local difference. Erin described her desire to impact her peers as well, sharing:

And then eventually, when I joined my sorority, I got two leadership positions which, um are not a ton of responsibility, but still enough to keep me kind of involved and, you know, feeling.... I don't know, just feeling like I can like actually influence things that are going on.

Similar to Carmen and Erin, Gia became involved because she thought her efforts could contribute to positive change: "So I'd attend a lot of a lot of meetings there and I thought there could be change, and I thought my voice could help so I think that's why I got involved." Gia also described the motivation she had to make a positive change and get involved in social justice work on campus, which in her case was her mother:

I guess what made me excited was... so my mom grew up on a reservation down south in California. And she never really had the chance to voice her experience. And her experience is very different from mine because I didn't grow up on a reservation. I guess she inspired me to fight for what I believe in because she 
never had the chance to. And just seeing problems in the community that are always occurring with little to no change. It's also inspiring.

Similarly to their peers, Casey got involved in student leadership because they saw an opportunity to make a positive difference for students, particularly because their own experience was negative, sharing:

I saw some flyers [for a peer advisor job] and I think I saw an email or something and one of my friends in my chemistry lab was talking about it.... So [my onboarding experience was] a bit different, but I had a poor experience. I wanted to make it better for students.

Elena described her motivation to participate in student leadership experiences; she also named being excited about the possibility of making a positive impact for other students. When describing what she knows now from her experience in student leadership that she did not know previously, she shared:

And also like the impact you can have on students and I don't think that people realize it. Like the impact that you have in these roles on large groups of students. But in other ways, it also seems like you can get so caught up in it, but you don't realize that students aren't paying attention to some of the stuff we're like doing or some of these students don't even know what [our student organization] is. It's kind of this funny line of, you feel like you're doing a lot or you feel like you're not, when it could be either way.

From Elena's perspective, the student organization she was a part of had the ability to make a significant positive impact on students — often without them even realizing the efforts their peers were making on their behalf.

Abram described his goal of wanting to make the center where he worked the best it could be. In his streamlining of the front desk manual, he added in on the to-do list an item where other student leaders could contribute their ideas of how to improve the work of the organization. He shared: 
I put in the front desk manual. The last thing on your to do list is how can I make the [this organization] better? And if there's nothing to do, like figure something out, write something out for me and I'll read it and I'll like, you know, take that into account.

Abby shared the satisfaction she got from her role because she was able to make a positive change. She shared: "I'm able to make an impact. And that's something that's rare, to be able to impact $30,40 \ldots$ actually 500 people because of these [events]... Like that is not normal. So that's been a really amazing experience." Similarly, when asked what he has accomplished, Michael shared pride in helping others and helping them have a positive experience, saying:

I think I've been able to make a difference in people's lives. I think that's something I have accomplished. And although I don't always let myself understand that, I've heard that from others, people who I trust, people who are close. And so, hearing it from them, it's been like, okay, maybe I am helping a little bit.

Ryan described the desire to impact positive change through leadership, and saw it as a shared vision and goal across many other student leaders at the research site:

Being a leader interacting with other leaders in the local community... and seeing that, hey, these are people here at [the university] with me, across the country, that they care about so much more than just partying and drinking, that they want to make a positive change through their philanthropies, through their service work, but also in their behavior, their policies, the way they treat others, the basics like that. So that's been really empowering.

Nearly every participant in this study spoke to being motivated by a desire to make a positive change. This is an exciting finding for colleges and universities who are developing the next generation of leaders within a democratic society. Many student leaders are interested in channeling their love and kindness through others in active ways that contribute to meaningful change. Knowing that this is the case, colleges can help 
create meaningful engagement opportunities, both formal and informal, via student leadership, classroom, service learning, allyship and justice, and other avenues, to help students explore avenues for actions and opportunities to effect positive change on campus and within their communities, developing citizenship behaviors and attitudes that they can take with them into the world after graduation.

\section{Chapter Summary}

This chapter began with an exposition of how student leaders define and differentiate conflict and controversy, and the ways that their identities impact their conceptualizations and navigation of conflict and controversy. Following that review was a discussion of the interpersonal/emotional, psychological, and academic and professional impacts of conflict on student leaders. These included student leaders being concerned about maintaining relationships with their peers and the conflict of their roles with their personal values (interpersonal/emotional), how stress and trauma impact their approaches and orientation to conflict (psychological), the ways they felt stifled and unable to process the conflict (professional/academic), the role of coursework and academics on how they made meaning in conflict situations (professional academic), and the professional growth that was fostered thanks to the experience of navigating conflict and controversy (professional/academic).

A review of themes related to the strategies that student leader participants used to navigate conflict and controversy was also discussed. These included the interpersonal/emotional strategies of developing and applying emotional intelligence by using a measured approach in conflict scenarios, and developing the ability and 
willingness to engage in difficult conversations; the psychological strategy of developing resilience; the academic and professional strategies of developing professional skills sets—-specifically, critical thinking and taking responsibility for wrongdoing — and the strategy of making a personal versus professional distinction in the effort to preserve relationships; and intercultural competence skills around valuing diversity and engaging in perspective-taking.

Following a discussion of strategies, a review of the motivators and inhibitors of student leaders' willingness to engage in conflict was examined. Among the motivators for participants were feelings of belonging that resulted in commitment to the group, a universal value of love and kindness for others, and the saliency of societal events. Inhibitors were being caught off-guard and unprepared in conflict situations, campus climate relative to budget, and campus racial climate. Finally, some factors operated as both motivators or inhibitors of conflict, depending on the features and operationalization of those factors; specifically, the ways that the student leadership position and the organizations were set up, and the role advisors took when working with student leaders.

This research demonstrates that conflict and controversy helps to facilitate the growth of socially responsible leadership skills. The development of socially responsible leadership is a multi-faceted process that occurred in this study across four dimensions for student leader participants: individually with the development of leadership selfefficacy; within the group by moving from individual responsibility to group accountability; within the community dimension through movement from individual ego to a desire for shared power; and through the societal dimension through moving from 
disorder and incivility to empathy and conflict resolution/dissolution. These factors worked together in a constant negotiation of student leaders balancing their values and responsibilities - an ethic of justice perspective - with the navigation of relationships with their peers - an ethic of care perspective. These factors were constantly balanced and negotiated as part of a developmental process in which student leaders became empowered, self-aware, aligned with their organizations, developing relationships, learning how to effectively support and influence their peers, and ultimately striving for a better world.

Chapter 5 will discuss the implications and applications of these findings more indepth, and include considerations of future research in the area of college student leaders and conflict negotiation and resolution. 


\section{CHAPTER FIVE: IMPLICATIONS AND DISCUSSION}

This chapter presents a summary of the significant findings of this study. It begins with a contextualization of the research by reviewing the problem in practice, the purpose of the research and the research questions that guided the inquiry. This chapter will then review the major findings from the data--a new definition and description of how college student leaders develop socially responsible leadership in the midst of conflict and controversy with their peers. Following that is a discussion of the implications for practice, with specific insights for college administrators, advisors, and faculty. The chapter concludes with recommendations for future research.

\section{Overview of the Context for the Study}

In today's world of complex, "wicked" problems with unclear solutions (Rittel \& Webber, 1973), institutions of higher education are tasked with preparing future citizen leaders with both content knowledge relevant to their fields, and also a myriad of complex cognitive, social, and emotional skills to work with others who have different skills and backgrounds to work democratically to find solutions for these problems. At the same time, college populations are becoming increasingly diverse across a variety of social identities, levels of preparation for college, and backgrounds, resulting in a hostile climate for many students of color, conflict of different perspectives, and posing risks to the development of socially responsible leadership skills in college students. According to the Association of American Colleges and Universities (2020),

Democracy is not self-sustaining; rather, it depends on the sustained engagement of a free people who are united in their commitment to the fundamental principles it is intended to preserve and advance - justice, liberty, human dignity, equality of persons. The task of an education allied to democracy is not simply to help 
students gain knowledge and skills, but in so doing also to form the habits of heart and mind that liberate them and that equip them for, and dispose them to, civic involvement and the creation of a more just and inclusive society. (p. 4)

The challenge for colleges is that they are tasked with creating civil learning environments that allow for discourse and successful conflict resolution in order to allow students to learn and develop, all within the context of this environment, in a setting that is often under-resourced.

The challenges of campus climate to students from various racial backgrounds and other marginalized identities are well-documented in the literature (Cabrera et al., 2016; Delgado \& Stefancic, 2004; Garcia \& Johnston-Guerrero, 2015; Linley, 2018; Nadal et al., 2014; Suárez-Orozco et al., 2015; Sue et al., 2007). Similarly, the benefits of exposure to diverse peers and multiple perspectives is also well known (Cabrera et al., 2016; Nadal et al., 2014; Saenz et al., 2007; Vander Putten, 2001). Shapiro and Stefkovich (2016) assert that "in the $21^{\text {st }}$ century, as society becomes even more demographically diverse, educational administrators will, more than ever, need to be able to develop, foster, and lead tolerant and democratic schools" (p. 4). However, the literature is mostly silent on how students experience conflict of perspectives or controversial situations with their peers who are different from them, or the ways that colleges can utilize these moments to enhance the development of all college students.

\section{Purpose Statement and Research Questions}

Given the increased racial diversity and other marginalized identities on college campuses and resulting climate challenges, in addition to increased polarization that increases tensions and conflict, a significant gap in our understanding is how students 
experience these conflicts, including they ways they make sense of conflict and controversy; the skills, strategies, and resources they utilize to address conflicts; and the extent to which experience in those situations facilitates their citizenship and socially responsible leadership skills. Understanding that conflict is not only pervasive but also inevitable, this knowledge gap is critical to fill in order for colleges to better understand the ways in which they can leverage and facilitate both co-curricular and curricular learning environments that promote learning, understanding, and development in the face of conflict. In particular, student leaders are a group of students who have more opportunities for exposure and participation with peers who are different from themselves, and are situated to influence their peers in ways unique from other peer relationships in college, which may be critical to contributing to a more positive campus climate for all students and set the stage for gains in knowledge and skills, and overall growth in their personal development.

Therefore, the research questions investigated in this study were:

1. How do undergraduate student leaders describe their experiences navigating conflict/controversy at a large, public institution in the Pacific Northwest?

2. In what ways does experience working through conflict/controversy at a large, public institution in the Pacific Northwest help facilitate the development of student leaders' socially responsible leadership skills?

\section{Findings Related to the Literature}

According to the data, student leaders in this study developed socially responsible leadership through demonstrated growth through the process of conflict 
resolution/dissolution, evidenced across four areas: self-efficacy (individual domain), group accountability (group domain), shared power (community domain), and conflict resolution and empathy (societal domain). The participants in this study demonstrated through their stories a new understanding and definition of socially responsible leadership, characterized by increasingly developmentally complex growth across four levels; these levels and the directional movement are:

1. Individual Dimension/Self-Efficacy: moving from a lack of confidence toward leadership self-efficacy.

2. Group Dimension/Group Accountability: moving from individual responsibility to group accountability.

3. Community Dimension/Shared Power: moving from individual ego to shared power.

4. Societal Dimension/Empathy and Conflict Resolution: moving from incivility and disequilibrium to empathy and conflict resolution/dissolution.

Based on the data, socially responsible leadership is redefined as a process that promotes the common good through the interculturally-adept negotiation of justice and care and cognitive and affective competencies that moderate controversy and foster capacity building.

The four domains of SRL development in the new model aligned and were enacted in ways that were congruent with ethic of justice and an ethic of care approaches, or in the case of the societal dimension, both. Ethic of justice is a framework associated with Lawrence Kohlberg (1976), who proposed a theory of moral development in which 
individuals sequentially progress across six stages which are likewise grouped across three levels. At the highest stage in Kohlberg's framework, an ethic of justice emerges in accordance to what is considered "right," specifically, he says that "principles are universal principles of justice: the equality of human rights and respect for the dignity of human beings as individual persons" (Kohlberg, 1976, p. 35). Carol Gilligan (1993) famously refuted this perspective and, based from her own research, introduced the concept of ethic of care, which incorporated a feminine perspective that was absent in Kohlberg's original research. Gilligan (1995) instead describes a care perspective, which emerged from her research interviewing women, as being oriented around a relationship with someone else, where "the self as a moral agent perceives and responds to the perception of need" (p. 35). From her research, a care orientation requires consideration of the situation to determine how to most appropriately respond (Gilligan, 1995).

In this study, student leaders navigated and applied both principles. They were justice oriented in how they made sense of the world, how they identified and committed to values, and how they identified organizations to join because of their alignment with their values. They were care oriented in their willingness to commit to their organizations even when things became difficult, in their desire to share power and realize the goals of the group with others, and in their overarching desire to prioritize and preserve their relationships with their peers and to enact leadership because they believed it would make a positive change. In short, as student leaders developed and grew through the process of conflict resolution and dissolution, they constantly negotiated, balanced, and prioritized both justice and care; both orientations were critical in how they 
conceptualized and made sense of conflict situations and identified, committed to, and espoused their values and used them as a guide for what they believed was right, and how they enacted their values in the context of being in relationship with others. The fundamental overarching principle for most participants was care and kindness for others, and that care showed up in through the way they enacted their leadership and navigated conflict and controversy.

For participants in this study, different dimensions of the model were emphasized at different times and were impacted by different contexts; these dimensions were not enacted equally and did not remain static, but they did overlap and work together to allow students to develop and enact socially responsible leadership. Conflict and controversy were processes that allowed students to work out what was important to them (their values), negotiate expectations and relationships with their peers, become more empowered in their ability to exhibit leadership, and develop increasingly developmentally complex strategies to successfully navigate future conflict. What a student leader was balancing and their level of capacity at any given time, the level of support they had within a conflict, their levels of stress, sociopolitical and campus climate and issues, classes they were taking, what their peer relationships looked like, and time from event to resolution and beyond were all factors that helped these dimensions have a stronger or lesser influence at any given time. Further, identity of participantstheir orientation to the world and to campus, their lived experiences, and the ways their identities intersect with their leadership roles, contexts, and conflicts - also were an important factor for how students developed and grew through conflict resolution. For 
campuses interested in supporting all students from a social justice framework, individualized approaches to support students based on complex intersecting identities and within the context of campus climate are critical.

Within an individual context, saliency of disorienting dilemmas and how student leaders were making sense of new information often was an influencing factor. Within the group dimension, interpersonal relationships - both on a peer-to-peer and at a group level—created or alleviated tension that impacted student leaders' development and growth. From a community perspective, structural elements impacted student leader participants' orientations to power, including the pressures of hierarchy, the desire to accomplish goals alongside peers, and inefficiencies in achieving these goals within existing power structures and, in some cases, with a lack of structural supports. Finally, campus climate had a significant role in the growth and development of participants at a societal level, and the pressures related to climate were often activators for growth through the presentation of conflict and challenge and the necessity of resolving those challenges.

Across every dimension in this model of socially responsible leadership, the inherent and inevitable challenge for student participants is that of conflict and striving for conflict resolution or dissolution. The implications for this challenge is that colleges have an opportunity to facilitate environments and support students in ways that allow them to successfully navigate and grow from these inevitabilities; the alternative is that students may become stuck, stagnated, or in the worst cases, experience harm related to the conflict. Many student participants in this study expressed the belief that conflict is 
inevitable but also that it is productive and can be healthy. Understanding the impacts and opportunities for growth inherent in conflict allows colleges to use effective strategies to respond and best support students and their organizations, and in turn positively impact the overall climate on campus. These results require energy, time, effort and thoughtful attention to the situation and context at hand, and successful modeling within Student Affairs organizations. Also important to consider is the timeliness of the intervention. Disorienting dilemmas and conflict situations in this study were salient based both on time since the conflict but also level of impact or disorientation. However, the goal of colleges is to help students make progress toward degree completion and ultimately to graduate. Like our students, the moment of conflict disorientation eventually moves on, and without intentional and structured support, the opportunity for development and growth is also lost. Several structural supports and strategies emerged from this data as productive in conflict situations that advisors and colleges can adopt to best facilitate environments that support student development and growth. These strategies are discussed in depth in the following section.

\section{Implications for Practice}

Conflict and controversy are inherent and inevitable across every organization; however, the data from this study show some clear ways that colleges, organizations within colleges, and faculty and staff advisors can help students effectively navigate conflict situations, use conflict and controversy as a measure of health of their organizations and design appropriate interventions, diffuse conflict altogether, or otherwise enhance the positive aspects of conflict and minimize the negative impacts of 
conflict. According to Giacomini and Schrage (2009), the concept of conflict culture "speaks to the unique lens or story an individual brings to the table in a dispute and the ways in which this surfaces or influences his or her engagement in a conflict” (p. 15). They advise that such conflict cultures are varied and unique to students based on their identities, cultures, and lived experiences, and state that "this is further complicated by the likelihood that personal circumstances, peer group, and identity development during the college years often cause a student to adjust his or her approach to conflict over time" (Giacomini \& Schrage, 2009, p. 16). Following are implications for practitioners and institutions as students progress through various dimensions of this new model of socially responsible leadership.

\section{Individual Dimension/Self-Efficacy}

Student leaders in this study developed leadership self-efficacy through validation and empowerment from their peers and advisors, from taking risks and trying something new, and by working through disorienting situations including conflict. Movement or growth through this dimension was from a place of uncertainty and low self-efficacy to a place of empowerment. Advisors can help support growth through this dimension through both helping student leaders develop strategies for individual support and conflict resolution, and also through implementing protective factors for students' mental health. Following is a more in-depth review of these recommendations.

\section{Strategies for Individual Support and Conflict Resolution}

Students believe that conflict is inevitable but also that it is productive and can be healthy. Given this belief, advisors should be aware of and actively managing conflict 
situations for both the powerful developmental opportunity afforded in these situations, and to help it resolve conflict in productive, healing ways rather than in damaging and harmful ways. Following is a discussion of these conflict resolution strategies; Table 5.1 outlines some questions or statements that advisors can use when working with student leaders connected to each of these areas.

Consider the Role Identity Plays and Coach Accordingly. Several students in this study, particularly students from racial backgrounds that were not White, as well as women, felt acutely the impact of their identities as they navigated complex dynamics with their peers. This sense of chilly campus climate is consistent with the experiences of other students of color at Predominantly White Institutions (PWIs) (Allen, 1992; Johnson et al., 2014; Yosso et al., 2009). According to a study by Johnson et al., (2014), for example, students that experienced racism on campus, either directly or indirectly tended to have lower persistence and a lower commitment to the institution. In another study of Latinx students at elite PWIs, the researchers found that experiences of navigating microaggressive campus environments led to a high level of stress and diminished their sense of belonging to the institution (Yosso et al., 2009). In a comprehensive quantitative study $(\mathrm{n}=8,490)$ of campus climate across institutions at a national level, Cress (2008) identified that women had a higher likelihood of perceiving a negative campus climate than men, with the highest reported feelings of negative campus climate by African American/Black students, and then Puerto Rican Americans, Asian-American/Asians, Chicano/Mexican Americans, and American Indians. This study, along with previous 
research, undergirds the saliency of students navigating their collegiate experiences through the lenses of their identities.

Further, conflict is necessarily a result of new information or a different perspective, which may pose a disorienting dilemma for a student as they consider the new information, identify how that does or does not fit with what they already believe or know, and incorporate that new information as part of a growth process. Processing and reflecting to make meaning and move forward in healing and productive outcomes is a critical component of navigating conflict, however, so advisors should be especially attenuated to carving out space and showing caretaking in terms of helping student leaders reflect on their experiences and make meaning of conflict situations. College administrators and advisors should expect that students are in a process of taking in new perspectives and knowledge and refining their own core beliefs as they experience this new information. Advisors and other support staff can foster a process to proactively help students consider what is important to them. Further, these professional staff members can be present as a sounding board when student leaders are working out challenges of their roles with what they believe, and act as a safe space and sounding board for students to process these experiences and identify for themselves the best ways to move forward, versus putting pressure on them to behave in a certain way.

Providing opportunities, time, and structure/guidance for students to critically reflect on their experiences and develop critical consciousness is an important finding of this study. How students necessarily developed skills to allow them to navigate conflict situations is important for staff and administrators to understand and support. Ideally, 
advisors are using trainings, one-on-one meetings, ongoing professional development opportunities, program and activities debriefs, and other opportunities to help students explore their identities and their values before conflict situations even occur, both as the group is forming and throughout the cycle of the group. This pre-work allows for reflective space and sets up student leaders with more confidence and skills when difficult situations such as peer-to-peer conflict arises.

In instances where advisors are supporting students through conflict situations, a proactive and supportive approach is useful. Advisors coaching student leaders should ask them: What are they thinking about what is going on? For many students in this study, the conflict they experienced was the incongruence of what their positions called them to do with their personal values. Knowing this, ask student leaders: how does this situation resonate with them on a values-level? How are their identities impacted or showing up in these situations? Further, it is important that White advisors in particular consider their own identities when working to support students who hold different social identities. Depending on the context and situation, it may be necessary or advisable for advisors to help link students with other advisors or mentors who share their social identities to better process their lived experiences. These are opportunities for values clarification, commitment, and to support identity exploration.

Use Both Validation and Empowerment. In addition to using conflict as an opportunity for identity development and values exploration, it is also an opportunity for empowerment for the student relative to their own capacity and ability to effectively resolve conflict. Advisors have the opportunity to serve as facilitators in the process and 
as sounding boards for student leaders who are processing their experiences. Several student leaders in this study expressed challenges around not being able to talk about the conflicts they were experiencing with anyone in order to maintain the integrity of their roles. Not having an outlet to debrief can be an isolating and stressful experience; advisors can help relieve some of that stress simply by talking with student leaders and helping them problem solve and work out steps towards resolution, while being careful to stay focused on the dynamics of the situation and not take on a therapeutic role.

Further, students often have the most context and understanding of dynamics with their peers and the student organizations they are working with and can share that expertise as part of a strategizing session about how to move through a conflict scenario. Doing so could help reduce the stress of conflict for student leaders, help them feel confident that they have a considered approach that they took time to reflect on, and help prevent escalation in the form of retaliation, broken relationships, or the commutation of conflict into controversy as factions form within the group. Staff working with students can advise student leaders with fledgling conflict resolution skills on strategies to support successful navigation of conflict. For example, strategies may include letting someone know the nature of the conversation when scheduling the meeting ('I'm concerned about your lack of follow through and would like to schedule a time to sit down and talk about what's going on"), introducing the concern in a meeting in a calm manner and then asking open-ended, non-judgmental or leading questions inviting the other person to share about their lived experiences and validate those, and/or invite ideas from the other person about how to work toward a resolution that is satisfying to all parties involved. In 
the case where the conflict is non-performance, this could also include creating a set of shared expectations and strategies (agreeing to communicate in advance if they would not be able to meet a deadline, for example), or connecting students to relevant campus resources to support students who are navigating challenges around non-performance. This is where an advisor can be particularly helpful, assuming they have a greater knowledge of and connection to a diverse set of campus resources than perhaps other peer leaders. Further, advisors can work with student leaders to discuss how to frame non-performance conversations, and can also role play those conversations with peer leaders in order to help build their confidence and further develop their skills in having nuanced, challenging conversations situated from a caring perspective.

Additionally, advisors are often situated uniquely in a position of trust with students; advisors should try to avoid taking sides when possible in conflict situations or exerting undue influence in how a situation is resolved. Instead, advisors should be asking: how would student leaders like to proceed? Not only is it disempowering to remove the opportunity to allow students to resolve conflict on their own, but it can also break trust and lead to more conflict, which was the case for some of the participants in this study.

Build Capacity for Perspective-Taking and Empathy. One of the main developmental arcs for students in this study was moving from experiences of disorientation and incivility to empathy and emotional intelligence, which resulted in more effective conflict navigation and resolution. According to Thompson (2014):

To be responsive to the societal needs of the twenty-first century, higher education must prepare students to constructively engage ethnic, pollical, and 
religious differences. To accomplish this task, colleges and universities must provide an undergraduate experience that enables students to develop a personal epistemology that includes a commitment to evaluative thinking and their capacities for perspective taking, empathy, and an integrated identity that includes a sense of agency for engaging differences. (p. 127)

Two common strategies that were utilized by participants were perspective-taking and empathy, which helped expand student leaders' understandings of different points of view, identify gaps in a shared leadership approach, and work more effectively toward resolution by dismantling feelings of defensiveness. For many participants, these skills did not come naturally but were the product of values clarification and experience. Several participants discussed conflict experiences that had just occurred or were very recent and they were still working through; these came up because they were the most accessible and salient for them at the time of the study. Administrators and advisors can take a lesson from this. Disorienting dilemmas or other periods of cognitive dissonance is a great opportunity for development and growth for students, and having an opportunity to work through, reflect, and making meaning of those experiences in a timely and meaningful way is one strategy that advisors or other campus administrators can use to proactively support student development.

The experience of interpersonal conflict with peers in student leader roles was very common; this was expressed across the participants of this study as well as gatekeepers who work closely with campus leaders. Taking advantage of those disorienting moments, when experiences are still salient and accessible to students, is one powerful way that administrators can support students on their journey to become more socially responsible leaders. Conflict and controversy are a natural and inevitable part of 
a democratic society and being in relationship with others, but with the right advising, they can illuminate possibilities and signal change instead of resulting in harm and loss of relationship. Advisors have the ability to foster these skills and attitudes by how they work with college student leaders, including asking developmentally-appropriate questions that encourage them to step into someone else's shoes, and to name together strategies that allow for empathy to be demonstrated in the resolution of difficult conflict situations.

Support Relationship Maintenance with Their Peers. A prominent theme in this study was the importance of peers in helping student leaders feel validated, supported, and like they belong, and the importance and significance that students put on those relationships. Additionally, the actual and perceived impacts of potentially losing those relationships was a critical concern for many students. Therefore, it is important for advisors to help students consider measured approaches that balance the need of the organization with the ability to maintain relationships with peers. Some key themes that emerged from this were that conflict did not usually go as well when someone was caught off-guard, and that sense of belonging was a protective factor in terms of longevity and commitment to an organization, even when the circumstances were very difficult. Advisors can leverage this understanding by setting up environments from the beginning that foster a team atmosphere and a sense of belonging, and by helping student leaders set up challenging conversations in advance. The extent to which everyone is offered meaningful opportunities to participate in and contribute to the organization, and a place where multiple perspectives are welcomed, allows for students to feel like they 
belong, are included, and have something to offer to the group, which in turn can increase their overall sense of commitment to the organization. Administrators can continue to support all students in a self-exploration of what is important to them, and also help them identify ways that they can make small positive impacts through their participation and involvement within student organizations and student leadership roles. Administrators should consider the ways that framing organizations as values-led allows students to make a stronger commitment, even in difficult circumstances, and helps to make space for everyone in the group.

\section{Table 5.1}

\section{Conflict Resolution Strategies for Advisors and Related Questions/Statements}

\begin{tabular}{|c|c|}
\hline Strategy & Related Questions/ Statements for Advisors \\
\hline $\begin{array}{l}\text { Consider the role of } \\
\text { identity and values } \\
\text { formation }\end{array}$ & $\begin{array}{l}\text { - What's your take on what's going on? } \\
\text { - How are you feeling about this situation? } \\
\text { - What impact is it having on you? Why do you think that is? } \\
\text { - What's most important to you in this situation? } \\
\text { - Is there anything that's been shared that is changing your perspective } \\
\text { on this situation? }\end{array}$ \\
\hline $\begin{array}{l}\text { Validate students' } \\
\text { experiences and } \\
\text { perspectives }\end{array}$ & $\begin{array}{l}\text { - That sounds really difficult and I'm sorry you're having that experience. } \\
\text { - I am glad you felt comfortable to share your perspective with me. } \\
\text { - } \quad \text { I appreciate your thoughtful approach in this matter. } \\
\text { - What would be most helpful from me as your advisor in this situation? }\end{array}$ \\
\hline $\begin{array}{l}\text { Empower students } \\
\text { in the conflict } \\
\text { resolution process }\end{array}$ & $\begin{array}{l}\text { - What ideas do you have for how to approach this/ how would you like } \\
\text { to proceed? } \\
\text { Where do you feel confident? What are areas that you are less } \\
\text { confident and how can I support related to those areas? } \\
\text { - I like your idea about X. Do you want to outline a set of talking points } \\
\text { together? } \\
\text { - Can I help you role play the conversation? } \\
\text { I think you can really use your X skills in this way. }\end{array}$ \\
\hline $\begin{array}{l}\text { Build capacity for } \\
\text { perspective taking } \\
\text { and empathy }\end{array}$ & $\begin{array}{l}\text { - How do you think X may be feeling in this situation? Why do you think } \\
\text { they feel that way? } \\
\text { - How does your peer like to be approached in situations like these? } \\
\text { How would you like to be approached? } \\
\text { Given what X has shared with you, what if anything might you consider } \\
\text { doing differently? Or, how does the new perspective X provided impact } \\
\text { what you're thinking in this situation? }\end{array}$ \\
\hline
\end{tabular}




\begin{tabular}{|l|l|}
\hline $\begin{array}{l}\text { Support } \\
\text { relationship } \\
\text { maintenance }\end{array}$ & $\begin{array}{l}\text { Let's brainstorm how you can communicate with X in advance of the } \\
\text { meeting about what concerns you'd like to discuss and see what they } \\
\text { need to feel prepared for that meeting. }\end{array}$ \\
- Is there anything that you think you need to take responsibility for in \\
this discussion? If so, what is it and how will you name that in your \\
conversation? \\
- Is there any context you think we should consider for your peer as we \\
plan for the timing and logistics of this conversation? \\
In what ways can we help X feel like they belong in our organization \\
and can meaningfully contribute? If we don't know the answer, how \\
can we use our meeting to try to better understand that aspect?
\end{tabular}

\section{Mental Health Support}

The role of mental health and trauma was a salient finding in this study; every single participant described mental health concerns, either for themselves or concerns for their peers. It is not a surprise that mental health concerns are front of mind for college students, as it is a high priority issue for colleges as well, particularly for staff within student affairs divisions. According to Kruger (2019),

The expanding role of student affairs in supporting the health, safety, and wellbeing of students is the most immediate and widely documented challenge.... As any student affairs professional will express, this increase in mental health issues not only directly affects clinical providers on campus, but it impacts every campus function. (p. viii)

Further, several participants described the stress and pressures that their student leader roles and the navigation of conflict put on them, and some discussed how childhood trauma impacted the way they navigate conflict as adults.

This theme has significant implications for colleges and universities. It is important that administrators understand that childhood experiences with trauma are common (Dube et al., 2001) and impact the mental health of students coming to campus. U.S. undergraduates have seen a significant increase in presenting mental health issues and concerns in the last decade (Duffy et al., 2019). Additionally, mental health is not the 
taboo topic it once was. Stigma around seeking mental health support has significantly reduced for many college-aged students, with institutions nationwide seeing increasingly high utilization rates of their counseling centers (Xiao et al., 2017). Further, many students are coming to campus already diagnosed with mental health concerns and with years of experience managing those concerns. Institutions should consider the prevalence of mental health and how they set up positions and organizations to best support the mental health of students. The value of care and love for peers came through in this study from participants in terms of how student leaders are trying to positively influence conditions for their peers' mental health. Institutions should for look for opportunities to partner and support student leaders in that effort, become and enact trauma-informed practices (discussed more in Chapter 5), and reduce barriers for students with trauma or mental health concerns to navigating the institution.

Advisors centering the importance of mental health and introducing specific ways to minimize challenging mental health impacts is an important approach to support students moving from uncertainty to empowerment. Gaining confidence through validation and developing strategies for resiliency in difficult situations supports the progression of students within the individual dimension and is protective of their mental health. Mental health concerns are part of a common student vernacular for many college students, and several of the study participants were concerned about how they enacted their leadership to help support their peers' mental health, including finding ways to better support the positions and reduce stress for specific roles. 
Research from the Adverse Childhood Experiences Study (ACES) has demonstrated the ubiquitous nature of trauma in adults (Dube et al., 2001), which includes emerging adults coming to or already enrolled in college (Frazier et al., 2009). Additional stress from conflict with peers may compound the impacts of mental health concerns or give rise to new concerns; this stress may be compounded when students are not able to debrief or otherwise process their experiences with conflict. Given this, advisors should consider how to help connect students to useful resources, or how to proactively engage student leaders who are navigating conflict in meaningful discussion about their experiences and act as a sounding board and a means to help students debrief, process the stress and emotion of a situation, experience validation for how they are working through a situation, and ultimately have a safe space in which to reflect upon and make meaning of their experiences in a healthy way. At the same time, it is important that advisors are careful to not enter into a therapeutic relationship with students and to not address mental health concerns that they are not trained to appropriately manage and that is not an established part of their role. Advisors should also recognize that student leaders may feel stuck or unable to seek this support on their own, and find ways to carve out spaces that allow for student leaders to use these spaces within the confines and ethical limits of their roles. Advisors should become knowledgeable if they are not already about the signs of significant mental distress and monitor for these signs in students and link them to mental health professionals on campus when necessary and appropriate. In the most emergent circumstances, advisors should be prepared to walk students to on-campus mental health support. 
Given the prevalence of trauma experiences, institutions should identify traumainformed care (TIC) strategies to partner with student leaders on efforts to help reduce the negative mental health impacts for students and ways to build capacity and resiliency skills. Further, institutions should look for opportunities to reduce barriers for students with trauma or mental health to be able to navigate the institution successfully. The idea of a trauma-informed approach is relatively recent in higher education circles, and has been more commonly adapted in K-12, social work, counseling, and medical contexts, but has promising applications for removing barriers and increasing participation of all students across various collegiate contexts. In their article on how to implement TIC principles in educational environments, Carello and Butler (2015) suggest behavioral characteristics that instructors should pay attention to that would also be useful for advisors to consider. Specifically, they share:

Some instructor behavior (even inadvertent) may be activating for students. One way to diminish this risk is to avoid engaging in minimizing or being dismissive of student concerns, or permitting threats, ridicule, or displays of power, impatience, or even disappointment. Using neutral language and a strengths-based perspective in communication... can also address this risk. (Carello \& Butler, 2015, p. 271)

Further understanding trauma and seeking resources to better implement TIC approaches should become part of the framework of higher education institutions, and advisors should actively seek to better understand how trauma is defined, the ways it shows up, and how to integrate TIC approaches in their advising and supervision.

Beyond trauma, several student leaders expressed concern about their own feelings of anxiety, stress, and burnout, often connected to the responsibilities of their student leader positions and an inequal distribution of responsibilities throughout the 
organization. Advisors can support student leaders who are experiencing stress in their roles by structuring the positions to have clear role responsibilities that are realistic for full-time students, coaching student leaders on how to plan ahead and delegate work based on the roles within the organization, and check in with them regularly to ensure they have the skills and resources to effectively carry out their duties, or help connect them to resources or empower them as needed to reduce unnecessary and unhealthy stress.

Individual components of moving from low confidence to empowerment and high leadership self-efficacy is facilitated when advisors coach students relative to their identity development and what that means for both their leadership and conflict resolution; when they proactively work to both validate and empower student leaders; when they help build capacity for empathy and perspective-taking, and when they help support peer relationship maintenance. Further, colleges can help facilitate positive movement through conscientiousness of mental health needs and supports, including instituting trauma-informed approaches to teaching, leading, and advising, by supporting the sustainability of student leadership positions to avoid excessive stress and burnout, and by appropriately connecting students to mental health professionals on campus as needed. Enacting these supports allows for students to successfully reconcile cognitive dissonance that comes from disorienting dilemmas and builds their confidence to problem solve and move towards empowerment. Following is a brief review of Group supports that can help students and organizations move from individual responsibility to group accountability. 


\section{Group Dimension/Group Accountability}

In addition to working with student leaders on an individual level, advisors also have an opportunity at the group and organizational level to provide support.

Development across the group dimension included moving from individual responsibility to group accountability. This was a point of contention for several of the study participants, as they were in roles to hold peers accountable, but often lacked effective strategies and structural supports to do so. Helping student leaders develop conflict resolution strategies was addressed in the previous section and enacting these also help support student movement towards successful group accountability.

The role of change on a college campus environment is something that Kezar

(2018) has written extensively about, saying:

Rethinking structures and support for students from different backgrounds is an area in which campuses have made some advances....Part of the concern is that higher education institutions have not worked in partnership with K-12 systems to align standards helped teacher educators in being successful in supporting diverse students, created environments that support college-going within high schools, or examined campus transition processes. Furthermore, higher education tends to add on single programs or services to help students, rather than fundamentally rethinking the structures and culture to support new students. While there are complexities to this issue because students are also responsible for their success, this remains a major challenge for higher education. (p. 10)

In addition to individual strategies for conflict resolution, then, colleges must also consider the structural elements in place to serve students, and for student organizations, these may exist at the organizational level. Several points emerged from the data that suggest opportunities for simple process, procedure, and other structural supports that help provide clarity for role expectations, preparation for the role, shared expectations and clear accountability processes, and opportunities for feedback. Enacting these 
structural components support students in the empowerment they get from their advisors, their peers, their experiences, and the authority of their roles, and allow them to work collaboratively to realize the goals of the group. Following is a more in-depth review of these elements and the ways advisors can address these components proactively and alongside student leaders within the organizations the oversee.

How organizations are set up is connected to how student positions are set up and made an impact for the experiences of student leaders. Participants in this study spoke to several organizational aspects, including training, constitution and by-laws, and setting expectations as a group. Giving student leaders tools and structure (and empowerment/authority) to address conflict (constitution and bylaws, training, group expectation setting, goal setting, evaluation processes). Several student leader participants discussed that the conflicts they experienced opened their eyes about organizational structures and ways to avoid conflict in the future because of how the organization was set up. Structures of the student organizations themselves, including training, expectations setting, constitutional considerations, and opportunities for formal evaluation were often missing or lacking in cases where conflict escalated, which in turn negatively impacted the organizational climate. These pieces also allowed for students to hold themselves and the group accountable for what they purport is their mission, values, and goals.

\section{Designing Student Leader Training for Maximum Effectiveness}

Student leader training was often identified as the source of beginning knowledge for students relative to social justice concepts, including their first exposure to different 
beliefs and identities. For several participants, student leader training laid the groundwork for understanding that difference exists, appreciating different perspectives, and celebrating and creating a culture of inclusion, allyship, and advocacy. Student leader training is a developmental process that plants the seeds for later reflection, awareness and growth around appreciation for others. In this study, every participant expressed a deep care for their peers and most identified love and kindness as guiding values. This is a great starting point for having socially just conversations and trainings. Effective trainings not only expose student leaders to perspectives different than their own, but affords them an opportunity to more deeply examine their own identities, values, and beliefs, and make meaning of the contrasts and similarities in their lived experiences with those of their peers.

In addition to social justice concepts and identity exploration, for some participants, training also parlayed content relative to their leadership areas (for example, bias training in the case of student media) with social justice concepts, ethical principles, and skill building relative to their particular field. This helped the training be salient and immediately applicable for student leaders. A resource that may be helpful in designing student leader training is one written for college faculty and instructors entitled Learning Assessment Techniques: A Handbookfor College Faculty (Barkley \& Major, 2015). This text is set up to help instructors utilize a diverse set of activities, called "LATs" (Learning Assessment Techniques) to assess student learning. It also offers a comprehensive list of classroom activities across large groups to small groups that allows someone designing training or workshops to adapt activities based on the size and needs of the group. 
Every student leader training will have unique contexts and needs. Advisors should consider, both through their own knowledge and expertise and also by working with seasoned student leaders, what skills are most critical to help build foundations for in training. In particular, skills that would be helpful to develop based on this research include strategies for conflict resolution, especially empathy, perspective taking, and how to give and receive feedback; developing a culture of kindness and care (sometimes referred to as civility), which could be integrated as ground rules that members contribute to or frame about how they want to be together; developing strategies of how to work effectively together, including through coalition-building, cooperative exercises/activities, and shared goal-setting to help build common values and vision and congruence for the group's purpose; and taking time for students to have clarity and understanding around their roles and the roles of others within their organizations. Further, in broader areas where multiple student leaders and organizations would benefit from similar exposure to skills and content area knowledge, the staff responsible for student leader development may consider what it looks like to create a shared "student leader training syllabus" with connected lesson plans on things such as identity exploration, meeting management, effective dialogue, campus resources, and more.

\section{Setting Up the Organization's Structure and Processes for Success}

Another commonly discussed aspect of group life was the structure and logistics of the organization to help create clarity and process in advance of challenging situations. These included clarity in by-laws and constitutions, manuals with written organizational procedures, clearly articulated and outlined evaluation processes, grievance procedures, 
written processes for non-performance, and a clear pathway for decision-making in contentious situations.

With regards to constitutions and by-laws, one participant described working proactively to develop their relatively new student organization's bylaws and create clarity in situations that had caused conflict; a specific gap was specifically conflict of interest that was created when individuals were able to hold multiple leadership roles. Further, they were writing into the bylaws a code of conduct for how members should behave, focusing on professionalism and respect for others. Further, this participant is using the bylaws to clearly outline the different positions and role expectations of each to create more clarity for members. Expectations of the role and creating those to be helpful and realistic was something a few other participants described. One participant named the unequal amount of work across several individuals in the organization and the way unnecessary hierarchy created an artificially high work load. Another participant described the immense stress in some of the positions that she oversaw, and working to re-write the position descriptions and expectations to help distribute work in a more equitable and appropriate way. Advisors usually have institutional memory as well as the skills and positionality to help student leaders make these adjustments as needed. They should look for opportunities to work alongside student leaders and empower them to make needed adjustments within their organizations for the health of the organization and its members.

Another student leader expressed that his significant accomplishment was making a usable and accessible desk manual for staff. He identified the value of streamlining a 
very complex work environment and providing efficiency and order to something that had previously been chaotic and confusing for staff. In addition to creating guidance for how to complete the tasks necessary for his paraprofessional peers, he also described intentionality of creating the "groundwork" across training as a cohort, setting expectations, and creating structure that leads to a healthier and more productive work environment than in previous years. Advisors can come alongside student leaders to help create these structures and resources if they do not already exist, strategize how to create and deliver expectations, and identify ways to codify those expectations, whether within position descriptions, signed agreements, training, constitutions, or other documents.

\section{Create Evaluative Frameworks}

Grievance and non-performance processes also came up as a theme from participants. Specifically, the most common source of conflict was holding peers accountable for completing work. In some cases, this challenge was structural, because of the peer-to-peer nature of a supervisory line and institutional policies that prohibited peers from conducting evaluations. In this particular instance, because the student leader was not empowered to be able to give feedback, the ability to hold students accountable fell to the advisor, although the day-to-day peer supervision was his responsibility. In instances like these, advisors or supervisors of record should have written evaluations and a clearly articulated evaluation process, criteria, and timeline that are shared with student leaders from their first day in the role. Further, those evaluations should be timely, should provide examples from those peers who are expected to hold their peers accountable, developmental in nature, and anything written should not come as a surprise for the 
student being evaluated. Recognizing when avoiding a performance conversation puts more stress and challenge on other members is important, and advisors/supervisors must recognize when they are positioned to alleviate that unnecessary stress and take actions appropriate to their role.

Part of a feedback cycle is giving and receiving information in one-on-one advising meetings. It is important for advisors to also consider how they are supporting student leaders in terms of balance, including having candid conversations about how much student leaders are taking on. If advisors are privy to conflict situations that student leaders are experiencing, checking in around that and offering support may also be helpful. This could include brainstorming potential strategies for resolution, serving as a sounding board, asking the student leader what they need or want to have happen next, referring and connecting student leaders to resources, or identifying a way to help develop skills for students to navigate conflict scenarios, including role playing having a difficult conversation.

Through the implementation of structural supports at the organization level, including giving thoughtful attention to the design and implementation of student leader training, ensuring the organization's structures and processes are clear and well-defined, and creating intentional models for feedback and grievance processes, advisors can help student leaders move from having an individualized sense of responsibility to a shared group accountability for achieving their goals, in part because those expectations are made clear, they participated in the creation of them, and they have clear tools and guidelines to address the issue when goals are not being met. 


\section{Community Dimension/Shared Power}

Student leaders in this study found it challenging to navigate very hierarchical structures and generally disliked the idea of positional leadership as a source of power and control. Growth across this dimension was seen when students moved from a sense of individual ego to a desire for shared power across their organizations. They espoused a value of sharing power with their peers and seeking opportunities for shared decision making or allowing space for multiple voices to participate. Participants who had moved from a place of individual ego to a desire for shared power often had critically considered their own identities and the unearned privilege their dominant identities may have afforded them. Relatedly, they also had been exposed to peers who had different lived experiences than them based on their traditionally oppressed identities, and sought ways to account for those experiences in their organizations, empower their peers, and create positive organizational cultures. Advisors can assist in the shift from individual ego to a desire for shared power through helping students individually explore their identities and introduce them to concepts of social justice, and through helping develop strategies to engage in difficult conversations with empathy, emotional intelligence, and bravely confronting necessary issues, which connect to socially responsible leadership pedagogies relative to creating transformational change for a better, more just global future. Following is a more in-depth review of this strategy.

\section{Building Identity Exploration and Social Justice into the Curriculum}

A few of the participants described the way that their student leadership training experiences helped plant the seeds towards increased understanding and perspective- 
taking across difference, or vice-versa. Some participants described social justice skillbuilding within the context of their student leader training only, and were silent about the role that their academic curriculum played. However, several participants and nonparticipants of color in the survey data described in very plain language their experiences with racism and micro- or macroaggressions within their classroom environment. Given that most college students are enrolled at the institution in order to make progress toward degree completion, and given that student leader settings are opportunities to develop professional skills sets and adapt curricular learning into a co-curricular environment, colleges should ensure that concepts around perspective-taking, collaboration, social justice and identity exploration are embedded across the curriculum. According to Museus and Lepeau (2020):

The growth of neoliberalism within US society has contributed to what we understand as an urgency for civic (re)awakening, which can be facilitated by institutions refocusing their missions on democratic education. Institutional leaders can engage campuses across the community in the process of (re)envisioning their mission to be more socially just, in order to maximize buy-in and investment in the mission across their campuses. Leaders who live out such missions on their campuses must support faculty and staff in embedding social justice throughout the curricula, programs, and activities at their institutions. (p. 219)

The integrated nature of these concepts across the curricular and co-curricular environment plants the seeds of understanding that can be nourished across multiple institutional settings, create a more welcoming campus climate, and encourage democratic participation in the development of citizenship behavior in students.

\section{Civility, Emotional Intelligence, and Tone Policing}


In the Social Change Model, one of the group variables that demonstrates socially responsible leadership is that of controversy with civility (Higher Education Research Institute, 1996). Social justice activists and scholars have problematized the idea of civility as another way that a dominant group invalidates the experiences of marginalized identities and otherwise silences or suppresses the very real and legitimate experiences of individuals who are not afforded privilege; civility understood in this context is sometimes called tone policing. Museus et al. (2017), in their creation of the Social Action, Leadership, and Transformation (SALT) model as critically-centered response to the original SCM, refers to this value instead as controversy with courage, saying:

[Controversy with Courage] recognizes that, while some level of civility is important, calls for civility can also be used to avoid difficult conversations, vilify those confronting oppression, and inhibit progress toward justice. Thus, social justice leadership requires individuals to engage controversy courageously by embracing discomfort, acknowledging privilege and oppression, and contributing to conversations about significant social problems (Callahan, 2011; Singleton \& Hays, 2008). (p. 6)

It is important to recognize the multifaceted layers of the term civilityparticularly in the desire to help achieve a vision of a more just and better world—and also indicate how civility is differently understood within the context of this study. In this study, civility, as operationalized by the researcher and described by participants, had to do with taking a measured approach through utilizing emotional intelligence skills sets including empathy and perspective-taking; the participants who developed and utilized emotional intelligence skills described both the disorienting impact of experiencing uncivil conflict, and also their desire to not escalate or harm their peers when addressing their concerns. 
This distinction is critical for consideration of administrators at colleges and universities in order to support effective and meaningful conflict resolution strategies. Tone policing can have the effect of silencing, creating an unwelcome space for dialogue, privileging some voices over others, and ultimately creating an inherently undemocratic process on campus. However, developing emotional intelligence skills, creating space for all to share their relevant experiences, and seeking to learn from those experiences and find effective pathways forward are the hallmark of a democratic process that incorporates all voices, and promotes an environment that not only welcomes, but also encourages and facilitates shared power. Administrators, faculty, and advisors should be clear about the difference, and design dialogues and conflict resolution processes with the articulated goals of inclusion, healing, and positive outcomes for all in mind, and then align practices with those goals. This is critically important, because by taking these actions, colleges help support the movement of students from a focus on their own ego and contributions to distributing power more broadly across the group. Doing so creates the space for student organizations to function from a model of shared power, where all members are valued and are able to meaningfully contribute. The findings from this study also showed that creating opportunities to contribute and participate in meaningful ways led to a sense of connectedness and belonging to the group overall, important factors for both shared power and also connection and retention to the institution.

\section{Societal Dimension/Empathy and Conflict Resolution}

Within this dimension, development or progress occurred when student leaders moved from a lack of emotional intelligence and lack of strategies to manage or engage 
in conflict to demonstrating empathy, perspective-taking, and not only a willingness to participate in difficult conversations with peers, but also effective strategies to do so. The previous sections addressed ways that advisors and institutions can facilitate the development of conflict resolution strategies and emotional intelligence skill development on an individual level, which helps support movement from incivility to empathy. Advisors can also help support through two overarching and broad ways: through facilitation a positive organizational climate by effectively managing group controversy, and in the process modelling a socially just organization that works through conflict in democratic ways; and through appropriately managing the pressures of institutional politics and alleviating some of that pressure on individual students and student groups. Following is a brief review of these strategies.

\section{Understanding Climate and Managing Group Controversy}

An important finding from this study was that unfettered individual/interpersonal conflicts had the potential to become group controversies if not well-managed and factions within the group developed. Further, these controversies often developed as a result of the negative campus climate for students within the organization. For PWIs in particular, this is an important construct for campuses to identify, and they must seek to understand what the attitudes are on their campuses and how those are impacting the experience for students from a variety of different social identities and cultural backgrounds as part of a socially just framework. A useful definition of social justice is offered by Museus and Lepeau (2020) in their article on the culture of neoliberalism in higher education; they describe social justice as "efforts to resist systemic forms of 
oppression and cultivate a more equitable world—one that centers democracy as a primary core value and in which everyone has equal opportunity to thrive regardless of their backgrounds and situations" (p. 210). This idea that social justice is inclusive of full democratic participation for the benefit of all in society dovetails with understandings of citizenship, an outcome of socially responsible leadership.

Social justice issues were highlighted in complex institutional conversations at the study site related to budgets and campus racial climate. Given enrollment dips nationwide and the divestment in public higher education by many state entities, as well as the reality of the long-term impacts on budgets of the 2019-2020 global pandemic, a culture of scarcity and difficult decisions is a reality for most higher education institutions. Campus administrators and leadership should be aware that the impacts are felt by students as well and consider ways to have healthy and values-based conversations and decisions around budgets, bring student leaders along in the process and allow them opportunities to participate in a democratic space regarding how money is allocated, and provide transparency when making budgetary decisions that considers the needs of a broad, diverse group of stakeholders. Further, campus administrators should be attenuated to the experience of racially diverse students at their campuses and recognize that they will experience the campus differently than their White peers at a PWI. Attention should also be given to supporting White students in their racial identity development, and also providing strategies and skills around how to be an effective ally with their peers that are racially diverse. 
While it is important for advisors to support and empower student leaders to help problem solve and address their own conflicts, it is the advisor's responsibility to pay attention to and respond to problematic cultural elements or other organizational or climate dynamics that are impacting the student experience. In particular, advisors should pay attention to interpersonal and group relationship dynamics, and work with student leaders to identify strategies to address interpersonal conflicts, while also recognizing when those conflicts may start to impact the organization more broadly and therefore require a response from a professional staff level. Failure to do so may contribute to a negative campus organizational climate that becomes much more difficult to remedy as time goes on.

Interpersonal challenges within the group may be more easily addressed if group goal setting and group expectations are established from the beginning of the group's time together and are revisited from time to time. Unfortunately, group controversy may be a sign of more problematic climate concerns, especially around identity clashes and resulting harms. In these instances, advisors should seek to gather information about what is happening and the impact it is having across diverse perspectives of the group, and then use the context to help guide a problem-solving effort, including bringing in outside resources as appropriate to help remediate in a conflict and provide productive pathways forward.

\section{Responding Instead of Reacting to Institutional Politics}

According to Manning (2013), "knowledge about colleges and universities as political organizations assists administrators, faculty, and students to achieve their goals 
in an environment containing conflict, interest groups, and divergent points of view" (p. 68). The political environment of higher education and associated conflicts, power plays, and tensions was one that advisors had the ability to influence in terms of supporting student leaders within the framework of this study. In fact, one of the most influential factors in this study overall was the role advisors played. Advisors supported the development of student leaders, encouraged them to join organizations, helped them to problem solve, and through validation supported the development of their leadership selfefficacy. For some participants, their advisors also served as mentors, or as mentors for their peers. According to a quantitative study on the impact of mentors on college student leadership outcomes, socially responsible leadership appeared to be positively impacted when a mentorship orientation was focused on a psychosocial perspective, including psychosocial tasks such as developing autonomy, managing emotions, developing interdependence, and developing sense of purpose (Chickering \& Reisser, 1993), in addition to using a leadership empowerment approach (Campbell et al., 2012).

Abram, when describing how his leadership has shifted since his experience with the conflict he described, shared:

[I went] from someone that would react to someone that would respond. And what I mean by that is like, when I... responded, it's something that I've thought through, I've taken consideration, I viewed the perspective, I've subconsciously looked at my personal values through my understanding, all those things, and then I respond to the issue. Where I used to... an issue would happen. And then I'd be like, "you're being dumb," or "you did this, like why could you do that?" The contrast there, I think that's huge in my leadership style.

Abram's distinction of reacting to a situation from a place of judgment, versus responding to a situation in a way that is considered, values-led, and reflective, is a useful 
framework for advisors, faculty, and administrators alike to consider. Although advisors served as a meaningful resource and source of support in this study, several participants also described the challenges that were posed from advising relationships. Specifically, advisors had the potential to damage trust and relationships with student leaders by not appropriately managing conflict situations, even in cases where they were wellintentioned. Another potential for harm that occurred for some participants was when their advisor showed lack of care, did not remain impartial, or seemed to take sides or otherwise pressure students into behaving or believing in a particular way. In some cases, this broke trust; in others, taking sides or attempting to influence damaged relationships and ran the risk of severing a student's meaningful connection to faculty or staff at the institution.

Because advisors do not operate in a vacuum, and often are navigating their own conflicts, controversies, and challenges related to their identities and lived experiences while attempting to execute the functions and expectations of an advisor, they must also recognize that these recommendations are often easier said than done. To that end, advisors, administrators, and others working with student leaders on campus would benefit from recognizing the messiness inherent in conflict resolution processes, their own need to identify trusted mentors and supporters to navigate these situations, and the importance of being transparent and honest with students (as professionally appropriate) about partnering with students to problem solve, rather than being set up to have all of the answers. 
Further, given what was presented by participants in this study, it is advisable for advisors to be cautious to not to take sides or giving the appearance of partiality. Museus and Lepeau (2020) provide this context in regard to campus unrest and pressure:

Institutional leaders who experience campus unrest often focus their reaction and energies on how to regulate, temper, or suppress faculty and student activism before it "goes viral."... Alternatively, however, some leaders view such resistance as a fundamental democratic process and interpret protestors' actions as applying the pressure that can creates [sic] opportunities for change and allow leaders to more effectively enact a social justice agenda. Leaders who welcome resistance from the ground can inform alumni and other stakeholders of these pressures and explain how the changes they are making align with the mission for democratic education and a better world. (p. 220)

The potential negative impact to college students of playing sides in campus politics means that campus advisors, leadership, and administrators should respond thoughtfully to institutional political dynamics that may be at work to pressure students and organizations in a particular direction. Instead of reacting and imposing a perspective on students, campuses should consider a values-led response that makes space for-and role models - what a true democratic process looks like, involving students and inviting them to share their perspective, rather than attempting to influence their perspective. For advisors in particular, in some instances, this may mean shielding students from political happenings. At other times, it may be appropriate to help students understand the pressures that come from concern at the community level such as in town/gown relationships; with institutional budgets; legislatively, particularly for public institutions; and with faculty/staff, institutional governance board(s), or even other peers on campus. These are educational moments that help students prepare for what democratic participation will continue to look like when they are in their jobs, communities, and 
schools post-college, and provide them opportunities to practice those skills and gain understanding prior to the end of their time at the institution.

The findings of this study demonstrate that students developed socially responsible leadership skills through growth across four major dimensions: individually, by moving from uncertainty to empowerment; on a group level, by moving from individual responsibility to group accountability; on an organizational level through moving from individual ego to shared power in their organizations; and finally, on a broader societal level by moving from incivility and disorientation to successful conflict resolution and dissolution . Experiences in leadership overall as well as experiences navigating conflict and controversy with peers while in their student leader roles both contributed to students' development and growth across these dimensions.

Further, student leaders enacted leadership across these dimensions in a way that balanced an ethic of justice - including committing to a set of personal values, aligning actions with those values, and holding themselves and others accountable to seeing those realized - with an ethic of care, which centered love, kindness, empathy, and relationship with others at the core of both how they engaged with their peers through conflict and also why they did so. Colleges and universities should be aware that student leaders are enacting citizenship and demonstrating socially responsible leadership through this constant negotiation, and utilize the strategies provided as well as the justice and care framework to best support student leaders who are learning how to successfully navigate conflict with peers, and should likewise seek to model this for student leaders as a lived 
example of how to address conflict in socially just, critically caring and student-focused ways.

\section{Future Research}

There is a dearth of literature on the experiences of college students navigating conflict with their peers, and none on how conflict and controversy help facilitate the development of students' socially responsible leadership skills. The information gleaned from the participants in this study not only gives a rich and deep insight into the inevitability and challenges of conflict for college student leaders, but also provides a useful framework for how students develop through that process and the way they make sense of conflict in a new model of socially responsible leadership. In addition to the understanding that was gleaned from the participants in this study, the data also raises a number of additional questions and areas for future study and exploration. Following is a brief review of areas ripe for further study.

\section{Testing of the New Model}

The findings that emerged from this study are promising for how to structure student leadership experiences as well as how to leverage conflict and controversy within organizations to help support the democratic and socially responsible leadership skills of all students. Future research should test both the concepts identified in this new model of socially responsible leadership and the suggested strategies across different institution types and sizes, while also considering the impact of individual student identities and types of student leadership positions. 
To that end, replication of this qualitative research at other institutions, both similar and dissimilar to the institutional type, mission, region, and demographics of this study site, can further help colleges understand the extent and magnitude of conflict and controversy on campus, how students are making sense of those experiences and navigating them, and how those experiences are shaping and influencing students on campus.

Further, the experiences of the participants in this study afford us a new understanding and conceptualization of socially responsible leadership and the ways that college student leaders develop, balance, and enact citizenship behaviors in pursuit of a better world, balancing concepts of justice (their values) and care (their relationships). Our understanding of how today's college students are developing socially responsible leadership capacities would benefit from quantitative testing of the principles identified in this new model across a larger group of college student leaders and a general college student population.

\section{Different Student Types/Identities}

This study was done specifically within the boundedness of college student leaders, defined as those students in elected positions, appointed positions, paraprofessional roles, Greek Life, and/or who were otherwise involved in student clubs and organizations. However, what is not known is if some or all of these same themes hold true for students who do not participate in defined leadership roles. Given the useful insights provided from the data in this study, higher education broadly would benefit from understanding how conflict and controversy is experienced by all students, and the 
extent to which such experiences facilitate development regardless of student leader identity or affiliation. Further, because of the limitations of the participant requirements for this study, it is unclear how this process might impact non-traditional aged students, online learners, and students at other institutional types and sizes.

A commonly expressed attitude among the participants in this study was the desire to affect positive change, and the action of joining leadership opportunities in order to make a difference as an enactment of that value. These experiences, in turn, allowed student leaders to grow and develop, both by gaining professional skills and also in developing a sense of leadership self-efficacy. Given that this study was focused on the experiences of college juniors and seniors, who tend to be more developmentally advanced, what is unclear is what experiences foster an attitude to affect positive change. Do college student leaders come to college with this attitude, or does it develop in college? And if that orientation does develop in college, what environmental aspects help to foster a citizenship-oriented belief? Is it intrinsically motivated, extrinsically fostered, or both? Future research in this area is useful to identify the extent to which colleges can foster this orientation and attitude in its students.

Another outcome of this study is that student leaders were strongly committed to care and shared power and the idea of dismantling inequitable power structures, which is largely inconsistent with current sociopolitical frameworks, economic frameworks, and education frameworks within a U.S. context. The reasons for this are unclear from this study, but may be explained by cohort generational characteristics. One potential area for future research would be an exploration of generational differences to orientations of 
power, and what might that mean for the future of democratic participation at all levels within American society, including politics.

\section{Organizational Impact of Conflict}

Within the context of a college student leader experience was necessarily the context of the group or organizational impact; however, the extent to which interpersonal conflict impacts the culture of a group was not the central focus of this study. The initial data from participants, including the (unknowing) web of connectedness of interpersonal conflicts across multiple student leader experiences, suggests that this is an area with a high level of potential impact for individual students and groups of students. Understanding the extent to which interpersonal conflicts impacts group culture, functioning, and campus climate could be a fruitful and useful additional area of study.

\section{Effective Strategies for Healing}

Finally, participants in this study spoke at length about experiences with conflict with peers, including the stress, moments of disequilibrium, strategies and resources used, and areas where they self-identified growth. One area that was largely silent for nearly every participant were any strategies or resources used for healing and the role, if any, of forgiveness in conflict resolution and dissolution. Additionally, a potential limitation of this study was the self-selection out of student leaders who have experienced significant harm from conflict and who did not choose to engage in further conversation about their lived experience because of those negative impacts. Given the strong orientation of student leader participants to love and kindness for others, their deep and abiding concern for maintaining relationships and realizing a better world, research in 
this particular area would be insightful about how colleges can further support healthy democratic participation for all students, and allow space for students to productively move forward from difficult or harmful conflict scenarios.

\section{Conclusion}

This study has illuminated a new model of socially responsible leadership in which student leader participants constantly negotiated an orientation to justice connected to the espousement of their values and beliefs, and an orientation to care as they enacted those values in their service to their organizations and in relationship with their peers. They did this through the individual task of developing leadership self-efficacy, including empowerment rooted in their values; through a group dimension of aligning with and holding organizations accountable for their goals, mission, and purpose; through a community level of seeking to share power to achieve these outcomes; and through a societal dimension of moving from chaos and incivility to empathy and conflict resolution. Further, this study illuminated several promising strategies for how to leverage an inevitable experience — conflict and controversy — as a vehicle for values exploration and clarification, identity development, group enhancement, and a useful measure of the campus climate. This story of development through conflict emerged out of the voices and lived experiences of participants who had a wide variety of identities, including racial, gender, leadership experience, and academic major.

Conflict is an inevitable part of a peer-to-peer collegiate context, as well as a democratic context that pervades the citizenship experiences of post-college life. Student leaders in this study navigated conflict simultaneously through a values-based justice lens 
as well as through a relationship-centered care lens; both were inextricably intertwined and were constantly enacted as a means to effectively resolve conflict. The outcomes of conflict can be either harmful to students and organizations, or can lead to positive and productive growth, particularly in instances where it signals necessary change. Given this inevitability, colleges must enact appropriate strategies and campus supports for conflict resolution and dissolution that are intentional and consistent, rather than adapting a laissez-faire approach. By taking a proactive approach, colleges have the ability to harness the power of conflict and controversy to make positive change for all on campus, to help students learn and grow through the process, and ultimately to help realize a critical liberal education goal: the development of future citizen-leaders, ready for democratic participation to collaboratively solve problems in a dynamic, complex world. 


\section{REFERENCES}

Allen, W. (1992). The color of success: African-American college student outcomes at predominantly White and historically Black public colleges and universities. Harvard Educational Review, 62(1), 26-45. https://doi.org/10.17763/haer.62.1.wv5627665007v701

Alvarez, C. (2009). Controversy with civility. In S. Komives \& W. E. Wagner (Eds.), Leadership for a better world: Understanding the Social Change Model of Leadership Development (pp. 263-292). John Wiley \& Sons.

Alvarez, C. (2017). Controversy with civility. In Leadership for a better world: Understanding the social change model of leadership development (Second edition, pp. 149-170). Jossey-Bass.

American Council on Education. (1949). Student personnel point of view. https://www.naspa.org/images/uploads/main/Student_Personnel_Point_of_View_ 1949.pdf

Association of American Colleges and Universities. (2002). Greater expectations: A new vision for learning as a nation goes to college (pp. 1-60).

https://www.aacu.org/sites/default/files/files/publications/GreaterExpectations.pdf

Association of American Colleges and Universities. (2007). College learning for the new global century: A report from the National Leadership Council for Liberal Education \& America's Promise. AAC\&U.

Association of American Colleges and Universities. (2020). What liberal education looks like: What it is, who it's for, and where it happens (pp. 1-32). https://portal.criticalimpact.com/user/25043/image/whatlibedlookslike.pdf

Astin, A. W. (1993). What matters in college? Liberal Education, 79(4), 4.

Astin, A. W. (2016). Are you smart enough?: How colleges' obsession with smartness shortchanges students. Stylus Publishing, LLC.

Astin, A. W., \& Astin, H. S. (2000). Leadership reconsidered: Engaging higher education in social change. https://eric.ed.gov/?id=ED444437

Bandura, A. (2012). On the functional properties of perceived self-efficacy revisited. Journal of Management, 38(1), 9-44. https://doi.org/10.1177/0149206311410606

Barki, H., \& Hartwick, J. (2004). Conceptualizing the construct of interpersonal conflict. 
International Journal of Conflict Management, 15(3), 216-244. https://doi.org/10.1108/eb022913

Barkley, E. F., \& Major, C. H. (2015). Learning assessment techniques: A handbook for college faculty. John Wiley \& Sons.

Barnhardt, C. L. (2015). Campus educational contexts and civic participation: Organizational links to collective action to collective action. The Journal of Higher Education, 86(1), 38-70. https://doi.org/10.1080/00221546.2015.11777356

Barnhardt, C., Sheets, J., \& Pasquesi, K. (2015). You expect what? Students' perceptions as resources in acquiring commitments and capacities for civic engagement. Research in Higher Education, 56(6), 622-644. https://doi.org/10.1007/s11162014-9361-8

Baumgartner, L. M. (2001). An update on transformational learning. New Directions for Adult and Continuing Education, 2001(89), 15-24. https://doi.org/10.1002/ace.4

Bennett, J. M., \& Bennett, M. J. (2001). Developing intercultural sensitivity: An integrative approach to global and domestic diversity (pp. 1-44). The Diversity Collegium.

Bird, L. E., Mackin, M. B., \& Schuster, S. K. (2006). The First Amendment on campus: A handbook for college and university administrators. NASPA - Student Affairs Administrators in Higher Education.

Bloomberg, L. D., \& Volpe, M. (2012). Completing your qualitative dissertation: a road map from beginning to end (2nd ed.). SAGE Publications.

Bonnet, J. (2009). Citizenship. In S. Komives \& W. E. Wagner (Eds.), Leadership for a better world: Understanding the Social Change Model of Leadership Development (pp. 149-189). John Wiley \& Sons.

Bowen, H. R. (1997). Investment in learning: The individual and social value of American higher education. JHU Press.

Bowman, N. A. (2011). Promoting participation in a diverse democracy: A meta-analysis of college diversity experiences and civic engagement. Review of Educational Research, 81(1), 29-68. JSTOR.

Bryson, J. M. J. M., \& Crosby, B. C. (1992). Leadership for the common good: Tackling public problems in a shared-power world (1st ed.). Jossey-Bass Publishers. 
Burke, L. A., Karl, K., Peluchette, J., \& Evans, W. R. (2014). Student incivility: A domain review. Journal of Management Education, 38(2), 160-191.

Burleson, B. R., \& Rack, J. J. (2008). Constructivism theory: Explaining individual differences in communication skill. In L. A. Baxter \& D. O. Braithewaite (Eds.), Engaging theories in interpersonal communication: Multiple perspectives. SAGE Publications. https://doi.org/10.4135/9781483329529

Cabrera, N. L. (2014). Exposing Whiteness in higher education: White male college students minimizing racism, claiming victimization, and recreating White supremacy. Race Ethnicity and Education, 17(1), 30-55.

https://doi.org/10.1080/13613324.2012.725040

Cabrera, N. L., Watson, J. S., \& Franklin, J. D. (2016). Racial arrested development: A critical Whiteness analysis of the campus ecology. Journal of College Student Development, 57(2), 119-134. https://doi.org/10.1353/csd.2016.0014

Callan, E. (2016). Education in safe and unsafe spaces. Philosophical Inquiry in Education, 24(1), 64-78.

Campbell, C. M., Smith, M., Dugan, J. P., \& Komives, S. R. (2012). Mentors and college student leadership outcomes: The importance of position and process. The Review of Higher Education, 35(4), 595-625. https://doi.org/10.1353/rhe.2012.0037

Carello, J., \& Butler, L. D. (2015). Practicing what we teach: Trauma-informed educational practice. Journal of Teaching in Social Work, 35(3), 262-278. https://doi.org/10.1080/08841233.2015.1030059

Chang, M. J., Astin, A. W., \& Kim, D. (2004). Cross-racial interaction among undergraduates: Some consequences, causes, and patterns. Research in Higher Education, 45(5), 529-553.

Chang, M. J., Chang, J. C., \& Ledesma, M. C. (2005). Beyond magical thinking: Doing the real work of diversifying our institutions. About Campus, 10(2), 9-16. https://doi.org/10.1002/abc.124

Chang, M. J., Denson, N., Sáenz, V., \& Misa, K. (2006). The educational benefits of sustaining cross-racial interaction among undergraduates. Journal of Higher Education, 77(3), 430-455. https://doi.org/10.1353/jhe.2006.0018

Chickering, A. W., \& Reisser, L. (1993). Education and identity (2nd ed.). Jossey-Bass Inc.

Cilente Skendall, K. (2017). An overview of the Social Change Model of Leadership 
Development. In Leadership for a better world: Understanding the social change model of leadership development (Second edition, pp. 17-40). Jossey-Bass.

Colby, A., \& Sullivan, W. M. (2009). Strengthening the foundations of students' excellence, integrity, and social contribution. Liberal Education, 95(1), 22-29.

Cress, C. M. (2008). Creating inclusive learning communities: The role of studentfaculty relationships in mitigating negative campus climate. Learning Inquiry, 2(2), 95-111. https://doi.org/10.1007/s11519-008-0028-2

Cress, C. M., Astin, H. S., Zimmerman-Oster, K., \& Burkhardt, J. C. (2001). Developmental outcomes of college students' involvement in leadership activities. Journal of College Student Development, 42(1), 15-27.

Creswell, J. W., \& Creswell, J. D. (2017). Research design: Qualitative, quantitative, and mixed methods approaches. SAGE Publications.

de Wied, M., Branje, S. J. T., \& Meeus, W. H. J. (2007). Empathy and conflict resolution in friendship relations among adolescents. Aggressive Behavior, 33(1), 48-55. https://doi.org/10.1002/ab.20166

Delgado, R., \& Stefancic, J. (2004). Understanding words that wound. Westview Press.

Dewey, J. (1916). Democracy and education (Later Printing edition). Free Press.

DiAngelo, R. J. (2018). White fragility: Why it's so hard for White people to talk about racism. Beacon Press.

Discourse. Def. 1. (2017). In Oxford English dictionary online. www.oed.com/view/Entry/53985

Dube, S. R., Anda, R. F., Felitti, V. J., Chapman, D. P., Williamson, D. F., \& Giles, W. H. (2001). Childhood abuse, household dysfunction, and the risk of attempted suicide throughout the life span: Findings from the adverse childhood experiences study. JAMA, 286(24), 3089-3096. https://doi.org/10.1001/jama.286.24.3089

Duffy, M. E., Twenge, J. M., \& Joiner, T. E. (2019). Trends in mood and anxiety symptoms and suicide-related outcomes among U.S. undergraduates, 2007-2018: Evidence from two national surveys. Journal of Adolescent Health, 65(5), 590598. https://doi.org/10.1016/j.jadohealth.2019.04.033

Dugan, J. P. (2006). Involvement and leadership: A descriptive analysis of socially responsible leadership. Journal of College Student Development, 47(3), 335-343. https://doi.org/10.1353/csd.2006.0028 
Dugan, J. P. (2012). Students' involvement in group experiences and connections to leadership development. New Directions for Institutional Research, 2011(S1), 17-32. https://doi.org/10.1002/ir.414

Dugan, J. P. (2015). The measurement of socially responsible leadership: Considerations in establishing psychometric rigor. ECPS - Educational, Cultural and Psychological Studies, 12, 23-42. https://doi.org/10.7358/ecps-2015-012-duga

Dugan, J. P., Kodama, C., Correia, B., \& Associates. (2013). Multi-Institutional Study of Leadership insight report: Leadership program delivery (pp. 1-36). National Clearinghouse for Leadership Programs. https://www.leadershipstudy.net/s/201402-06-mls-full-report-optimized.pdf

Dugan, J. P., \& Komives, S. R. (2010). Influences on college students' capacities for socially responsible leadership. Journal of College Student Development, 51(5), 525-549. https://doi.org/https://doi.org/10.1353/csd.2010.0009

Eagan, K., Bara Stolzenberg, E., Zimmerman, H., Aragon, M., Whang Sayson, H., \& Rios-Aguilar, C. (2017). The American freshman: National norms fall 2016. 188.

Early, S., \& Fincher, J. (2017). Consciousness of self. In Leadership for a better world: Understanding the Social Change Model of Leadership Development (Second edition, pp. 43-65). Jossey-Bass.

England, J. (2009). Collaboration. In S. Komives \& W. E. Wagner (Eds.), Leadership for a better world: Understanding the Social Change Model of Leadership Development (pp. 195-235). John Wiley \& Sons.

Ettling, D. (2006). Ethical demands of transformative learning. New Directions for Adult and Continuing Education, 2006(109), 59-67. https://doi.org/10.1002/ace.208

Evans, N. J., Forney, D. S., Guido, F. M., Patton, L. D., \& Renn, K. A. (2009). Student development in college: Theory, research, and practice. Jossey-Bass.

Frazier, P., Anders, S., Perera, S., Tennen, H., Tashiro, T., Park, C., \& Tomich, P. (2009). Traumatic events among undergraduate students: Prevalence and associated symptoms. Journal of Counseling Psychology, 56(3), 450-460. https://doi.org/http://dx.doi.org.proxy.lib.pdx.edu/10.1037/a0016412

Garcia, G. A., \& Johnston-Guerrero, M. P. (2015). Challenging the utility of a racial microaggressions framework through a systematic review of racially biased incidents on campus. Journal of Critical Scholarship on Higher Education and Student Affairs, 2(1), 4. 
Giacomini, N. G., \& Schrage, J. M. (2009). Building community in the currrent campus climate. In J. M. Schrage \& N. G. Giacomini (Eds.), Reframing campus conflict: Student conduct practice through a social justice lens (pp. 7-21). Stylus Publishing, LLC.

Gilligan, C. (1993). In a different voice: Psychological theory and women's development. Harvard University Press.

Gilligan, C. (1995). Moral orientation and moral development. In Justice and care: Essential readings in feminist ethics (pp. 31-46). Routledge.

Glesne, C. (2011). Making words fly: Developing understanding through interviewing. In Becoming qualitative researchers: An introduction (pp. 101-137). Allyn \& Bacon.

Goleman, D. (1998). The emotional intelligence of leaders. Leader to Leader, 1998(10), 20-26. https://doi.org/10.1002/lt1.40619981008

Grunwell, S. G. (2015). Leading our world forward: An examination of student leadership development. Journal of Leadership Education, 14(2), 82-99. https://doi.org/10.12806/V14/I2/R6

Higher Education Research Institute, H. E. R. I. (1996). A Social Change Model of Leadership Development. National Clearinghouse for Leadership Programs.

Hikido, A., \& Murray, S. B. (2016). Whitened rainbows: How White college students protect Whiteness through diversity discourses. Race Ethnicity and Education, 19(2), 389-411. https://doi.org/10.1080/13613324.2015.1025736

hooks, bell. (2017). Teaching to transgress : Education as the practice of freedom. Routledge.

Humphreys, D. (2009). College outcomes for work, life, and citizenship: Can we really do it all? Liberal Education, 95(1), 14-21.

Hurtado, S. (2006). Linking diversity with the educational and civic missions of higher education. The Review of Higher Education, 30(2), 185-196.

https://doi.org/10.1353/rhe.2006.0070

Jayakumar, U. M. (2015). The shaping of postcollege colorblind orientation among Whites: Residential segregation and campus diversity experiences. Harvard Educational Review, 85(4), 609-645. https://doi.org/10.17763/00178055.85.4.609 
Johnson, D. R., Wasserman, T. H., Yildirim, N., \& Yonai, B. A. (2014). Examining the effects of stress and campus climate on the persistence of students of color and White students: an application of bean and eaton's psychological model of retention. Research in Higher Education, 55(1), 75-100.

https://doi.org/10.1007/s11162-013-9304-9

Johnson, D. W. (2015). Constructive controversy: Theory, research, practice. Cambridge University Press.

Johnson, D. W., Johnson, R. T., \& Smith, K. A. (2000). Constructive controversy: The educative power of intellectual conflict. Change, 32(1), 28.

https://doi.org/10.1080/00091380009602706

Johnson, M. R., \& Ferguson, M. (2018). The role of political engagement in college students' civic identity: Longitudinal findings from recent graduates. Journal of College Student Development, 59(5), 511-527.

https://doi.org/10.1353/csd.2018.0050

Keeling, R. P., American College Personnel Association, \& National Association of Student Personnel Administrators U. S. (2006). Learning reconsidered 2: Implementing a campus-wide focus on the student experience. ACPA, NASPA.

Kezar, A. J. (2018). How colleges change: Understanding, leading, and enacting change (2nd Edition.). Routledge.

Knapp, M. L., \& Daly, J. A. (2011). The SAGE handbook of interpersonal communication. SAGE Publications.

Kohlberg, L. (1976). Moral stages and moralization. Moral Development and Behavior, 31-53.

Komives, S. R., \& Wagner, W. E. (Eds.). (2017). Leadership for a better world: Understanding the Social Change Model of Leadership Development (Second edition). Jossey-Bass.

Komives, S., \& Wagner, W. E. (2009). Leadership for a better world: Understanding the Social Change Model of Leadership Development. John Wiley \& Sons.

Kruger, K. (2019). Foreward. In K. L. Treadwell \& M. R. O’Grady (Eds.), Crisis, compassion, and resiliency in student affairs: Using triage practices to foster well-being (pp. vii-xi). NASPA - Student Affairs Administrators in Higher Education. 
Lincoln, Y. S., \& Guba, E. G. (1985). Naturalistic inquiry. SAGE Publications.

Lindholm, J. A. (2007). Spirituality in the academy: Reintegrating our lives and the lives of our students. About Campus, 12(4), 10-17. https://doi.org/10.1002/abc.218

Linley, J. L. (2018). Racism here, racism there, racism everywhere: The racial realities of minoritized peer socialization agents at a historically White institution. Journal of College Student Development, 59(1), 21-36. https://doi.org/10.1353/csd.2018.0002

Lipman-Blumen, J. (2017). Connective leadership in an interdependent and diverse world. Roeper Review, 39(3), 170-173. https://doi.org/10.1080/02783193.2017.1318994

Manning, K. (2013). Organizational theory in higher education. Taylor and Francis.

Manning $\square$ Ouellette, A. (2018). Fostering the unification of academic leadership outcomes through democracy education. Journal of Leadership Studies, 12(2), 75-78. https://doi.org/10.1002/j1s.21583

Maxwell, J. A. (2013). Qualitative research design: An interactive approach. SAGE Publications.

Merriam, S. B., \& Tisdell, E. J. (2016). Qualitative research: A guide to design and implementation. John Wiley \& Sons.

Mezirow, J. (2003). Transformative learning as discourse. Journal of Transformative Education, 1(1), 58-63. https://doi.org/10.1177/1541344603252172

Miles, M. B., Huberman, A. M., \& Saldaña, J. (2018). Qualitative data analysis: A methods sourcebook. SAGE Publications.

Morphew, C. C., \& Hartley, M. (2006). Mission statements: A thematic analysis of rhetoric across institutional type. The Journal of Higher Education, 77(3), 456471. https://doi.org/10.1353/jhe.2006.0025

Museus, S. D., \& Lepeau, L. A. (2020). Navigating neoliberal organizational cultures: Implications for higher education leaders advancing social justice agendas. In A. Kezar \& J. Posselt (Eds.), Higher education administration for social justice and equity: Critical perspectives for leadership (pp. 209-224). Routledge.

Museus, S., Lee, N., Calhoun, K., Sánchez-Parkinson, L., \& Ting, M. (2017). The social 
action, leadership, and transformation (SALT) model. National Center for Institutional Diversity and National Institute for Transformation and Equity. Retrieved from: Https://Lsa. Umich. Edu/Content/Dam/NcidAssets/Nciddocuments/Museus\% 20et\% 20al, 20.

Nadal, K. L., Wong, Y., Griffin, K. E., Davidoff, K., \& Sriken, J. (2014). The adverse impact of racial microaggressions on college students' self-esteem. Journal of College Student Development, 55(5), 461-474.

https://doi.org/10.1353/csd.2014.0051

Ouimet, J. A., \& Pike, G. R. (2008). Rising to the challenge: Developing a survey of workplace skills, civic engagement, and global awareness. New Directions for Institutional Research, 2008(S1), 71-82. https://doi.org/10.1002/ir.263

Owen, J. E. (2012). Findings from the Multi-Institutional Study of Leadership institutional survey: A national report (pp. 1-29). National Clearinghouse for Leadership Programs.

Pascarella, E. T., \& Terenzini, P. T. (2005). How college affects students (2nd edition.). Jossey-Bass.

Patton, M. Q. (2002). Qualitative research and evaluation methods (3 ed.). SAGE Publications.

Pew Research Center. (2016, June 22). Partisanship and political animosity in 2016: Partisan environments, views of political conversations and disagreements. http://www.people-press.org/2016/06/22/3-partisan-environments-views-ofpolitical-conversations-and-disagreements/

Pew Research Center. (2017). The partisan divide on political values grows even wider (p. 107).

Pujol, J. (2016). The United States safe space campus controversy and the paradox of freedom of speech. Church, Communication and Culture, 1(1), 240-254. https://doi.org/10.1080/23753234.2016.1234124

Rankin, S. R., \& Reason, R. D. (2005). Differing perceptions: How students of color and White students perceive campus climate for underrepresented groups. Journal of College Student Development, 46(1), 43-61. https://doi.org/10.1353/csd.2005.0008

Rittel, H. W. J., \& Webber, M. M. (1973). Dilemmas in a general theory of planning. Policy Sciences, 4(2), 155-169. https://doi.org/10.1007/BF01405730 
Riutta, S., \& Teodorescu, D. (2014). Leadership development on a diverse campus. Journal of College Student Development, 55(8), 830-836. https://doi.org/10.1353/csd.2014.0082

Rodgers, C. (2002). Defining reflection: Another look at John Dewey and reflective thinking. Teachers College Record, 104(4), 842-66.

Saenz, V. B., Ngai, H. N., \& Hurtado, S. (2007). Factors influencing positive interactions across race for African American, Asian American, Latino, and White college students. Research in Higher Education, 48(1), 1-38. https://doi.org/10.1007/s11162-006-9026-3

Saldaña, J. (2016). The coding manual for qualitative researchers. SAGE Publications.

Sandelowski, M. (2000). Whatever happened to qualitative description? Research in Nursing \& Health, 23(4), 334-340.

Sanford, N. (1968). Education for individual development. American Journal of Orthopsychiatry, 38(5), 858-868.

https://doi.org/http://dx.doi.org.proxy.lib.pdx.edu/10.1111/j.19390025.1968.tb00604.x

Schram, T. H. (2006). Conceptualizing and proposing qualitative research (2nd ed.). Pearson Merrill Prentice Hall.

Seidman, I. (2013). Interviewing as qualitative research: A guide for researchers in education and the social sciences (4th ed.). Teachers College Press.

Sensoy, O., \& DiAngelo, R. (2017). Is everyone really equal?: An introduction to key concepts in social justice education (2nd ed.). Teachers College Press.

Shalka, T. (2009). Congruence. In S. Komives \& W. E. Wagner (Eds.), Leadership for a better world: Understanding the Social Change Model of Leadership Development (pp. 335-364). John Wiley \& Sons.

Shapiro, J. P., \& Stefkovich, J. A. (2005). Ethical leadership and decision making in education: Applying theoretical perspectives to complex dilemmas. Lawrence Erlbaum Associates, Inc.

Shushok, F. (2011). Spiritual and moral friendships: How campuses can encourage a search for meaning and purpose. Journal of College and Character, 12(4). https://doi.org/10.2202/1940-1639.1822

Smith College employee who called police said black student looked "out of place." 
(2018, August 3). CBS News.

Solomon, D., \& Theiss, J. (2013). Interpersonal communication: Putting theory into practice. Routledge. https://doi.org/10.4324/9780203147832

Soria, K., Snyder, S., \& Reinhard, A. P. (2015). Strengthening college students' integrative leadership orientation by building a foundation for civic engagement and multicultural competence. Journal of Leadership Education, 14(1), 55-71.

Southern Poverty Law Center. (2018, March 1). Report: Rise in hate violence tied to 2016 presidential election. Southern Poverty Law Center. https://www.splcenter.org/hatewatch/2018/03/01/report-rise-hate-violence-tied2016-presidential-election

Stolberg, S. G., \& Rosenthal, B. M. (2017, August 12). Man charged after White nationalist rally in Charlottesville ends in deadly violence. The New York Times.

Strayhorn, T. L. (2008). How college students' engagement affects personal and social learning outcomes. Journal of College and Character, 10(2), 1-16. https://doi.org/10.2202/1940-1639.1071

Suárez-Orozco, C., Casanova, S., Martin, M., Katsiaficas, D., Cuellar, V., Smith, N. A., $\&$ Dias, S. I. (2015). Toxic rain in class: Classroom interpersonal microaggressions. Educational Researcher, 44(3), 151-160. https://doi.org/10.3102/0013189X15580314

Sue, D. W., Capodilup, C. M., Torino, G. C., Bucceri, J. M., Holder, A. M. B., Nadal, K. L., \& Esquilin, M. (2007). Racial microaggressions in everyday life: Implications for clinical practice. American Psychologist, 62(4), 271-286. https://doi.org/10.1037/0003-066X.62.4.271

Sutton, H. (2019). Hate groups increase 30 percent in four years. Campus Security Report, 15(12), 9-9. https://doi.org/10.1002/casr.30499

Svrluga, S. (2016, November 3). Law professor placed on leave after wearing blackface to a party. The Washington Post.

Taylor, K. B. (2008). Mapping the intricacies of young adults' developmental journey from socially prescribed to internally defined identities, relationships, and beliefs. Journal of College Student Development, 49(3), 215-234. https://doi.org/10.1353/csd.0.0005

The National Task Force on Civic Learning and Democratic Engagement. (2012). A 
crucible moment: College learning and democracy's future. Association of American Colleges and Universities. https://www.aacu.org/crucible

Thomas, N., \& Brower, M. (2018). Conceptualizing and assessing campus climates for political learning and engagement in democracy. Journal of College and Character, 19(4), 247-263. https://doi.org/10.1080/2194587X.2018.1517651

Thompson, R. J. T. (2014). Beyond reason and tolerance: The purpose and practice of higher education. Oxford University Press.

Tyree, T. M. (1998). Designing an instrument to measure socially responsible leadership using the Social Change Model of Leadership Development [Ph.D., University of Maryland, College Park]. https://search-proquestcom.proxy.lib.pdx.edu/pqdtglobal/docview/304428452/abstract/9829F2FEECD54 $\mathrm{BFAPQ} / 1$

Vander Putten, J. (2001). Bringing social class to the diversity challenge. About Campus, $6(5), 14-19$.

Wagner, W. (2009). What is social change? In S. Komives \& W. E. Wagner (Eds.), Leadership for a better world: Understanding the Social Change Model of Leadership Development (pp. 7-41). John Wiley \& Sons.

Wagner, W. (2017). Examining social change. In Leadership for a better world: Understanding the Social Change Model of Leadership Development (Second edition, pp. 233-260). Jossey-Bass.

Weiss, R. S. (1995). Learning from strangers: The art and method of qualitative interview studies. Simon and Schuster.

Whitt, E. J., Edison, M. I., Pascarella, E. T., Terenzini, P. T., \& Nora, A. (2001). Influences on students' openness to diversity and challenge in the second and third years of college. The Journal of Higher Education, 72(2), 172-204. https://doi.org/10.1080/00221546.2001.11778877

Wike, R., \& Simmons, K. (2015). Global support for principle of free expression, but opposition to some forms of speech. Pew Research Center, 18.

Xiao, H., Carney, D. M., Youn, S. J., Janis, R. A., Castonguay, L. G., Hayes, J. A., \& Locke, B. D. (2017). Are we in crisis? National mental health and treatment trends in college counseling centers. Psychological Services, 14(4), 407. https://doi.org/10.1037/ser0000130

Yosso, T., Smith, W., Ceja, M., \& Solórzano, D. (2009). Critical race theory, racial 
microaggressions, and campus racial climate for Latina/o undergraduates.

Harvard Educational Review, 79(4), 659-691.

https://doi.org/10.17763/haer.79.4.m6867014157m7071 
APPENDICES 
Appendix A: Table of Steps and Timelines for Study Design

\begin{tabular}{|c|c|c|}
\hline Research Phase & Steps & Timeline \\
\hline \multirow[t]{2}{*}{ IRB Approval } & $\begin{array}{l}\text { Post-committee approval, } \\
\text { submit IRB form and } \\
\text { deferment forms }\end{array}$ & June - July 2019 \\
\hline & Obtain IRB approval & August 21, 2019 \\
\hline \multirow[t]{3}{*}{ Pilot Questions } & $\begin{array}{l}\text { Recruit two non-PNWU } \\
\text { students for pilot interviews }\end{array}$ & June 2019 \\
\hline & $\begin{array}{l}\text { Conduct and transcribe pilot } \\
\text { interviews }\end{array}$ & \multirow[t]{2}{*}{ August 2019} \\
\hline & $\begin{array}{l}\text { Adjust semi-structured } \\
\text { interview protocol as } \\
\text { needed: rephrase questions, } \\
\text { add or delete questions, } \\
\text { and/or split questions into } \\
\text { two interviews }\end{array}$ & \\
\hline \multirow[t]{3}{*}{ Recruitment } & $\begin{array}{l}\text { Email by gatekeepers to } \\
\text { listservs }\end{array}$ & \multirow[t]{3}{*}{$\begin{array}{l}\text { September-October } \\
2019\end{array}$} \\
\hline & $\begin{array}{l}\text { Fliers posted in free speech } \\
\text { areas }\end{array}$ & \\
\hline & $\begin{array}{l}\text { Participants selected and } \\
\text { notified }\end{array}$ & \\
\hline \multirow[t]{3}{*}{ Data Collection } & Set up interviews (8-12) & $\begin{array}{l}\text { September - October } \\
2019\end{array}$ \\
\hline & Conduct interviews & \multirow{2}{*}{$\begin{array}{l}\text { October-December } \\
2019\end{array}$} \\
\hline & Transcribe interviews & \\
\hline \multirow[t]{4}{*}{ Data Analysis } & $\begin{array}{l}\text { Provisional (a priori) and } \\
\text { values coding }\end{array}$ & \multirow[t]{2}{*}{$\begin{array}{l}\text { December } 2019- \\
\text { January } 2020\end{array}$} \\
\hline & Open coding & \\
\hline & Identify themes & February 2020 \\
\hline & Write results & February - March 2020 \\
\hline
\end{tabular}




\title{
Appendix B: Qualtrics Questionnaire for Participant Selection
}

\section{Dissertation Recruitment Questionnaire}

\author{
Q1 \\ Learning and Leading Across Difference: Student Leader Experiences Navigating Conflict and \\ Controversy on Campus
}

Thank you for completing this questionnaire. This questionnaire should take about 10 minutes to complete.

This questionnaire is being used to identify participants for a research study that explores student leaders' experiences with disagreement, conflict and/or controversy with a peer within their student leader role.

This study is being conducted by a doctoral student as part of dissertation research. For questions about the study, please contact the study team:

Jill Childress (doctoral student researcher and Primary Investigator): cjill@pdx.edu

Christine Cress, Ph.D. (doctoral dissertation advisor): cressc@pdx.edu

Eligible participants will be interviewed about their experiences with conflict while in college. All information collected will be kept private. All participants who participate in interviews will receive a \$20 gift card to Amazon.

To be eligible for this study, participants must have all of the following characteristics:

1. Enrolled at Oregon State University's Corvallis campus

2. Undergraduate student with junior or senior standing

3. Has participated in some form of student leadership experience, either paraprofessional (e.g., a Resident Assistant, Cultural Center staff member, or Orientation Leader), elected position, or through involvement in a student organization

4. Has had some experience with conflict or controversy with a peer since being enrolled.

\section{Q2 Special note:}

I am a Portland State University student researcher and I am also a full-time employee of Oregon State University. As an employee, if I receive disclosures of sexual assault, sexual harassment, certain crimes, or abuse of vulnerable populations, I am required to report such incidents to the responsible offices at Oregon State University's campus.

\section{Participant Eligibility}

Q3 Are you a currently-enrolled student at Oregon State University at the Corvallis campus?

Yes (1)

No (3) 
Q4 Are you junior or senior standing at Oregon State University?
Yes (1)
No (7)

Q5 Have you participated in any of the following student leadership experiences? (Select all that apply)

Elected student position (1)

Appointed student position (2)

Club or organization involvement (3)

Paraprofessional position (e.g. RA, CRF/DLA, ALA, Cultural Center student staff, Orientation Leader, etc.) (4)

None of the above (5)

Q6 Have you ever experienced a conflict or controversy with a peer while in a student leadership position and/or with a peer in any undergraduate student experience while at OSU?

Yes (1)

No (2)

\section{Screened In: Additional Information}

Q24 Based on your previous answers, you may qualify to participate in this study. Please answer a few more questions to help the student researcher understand a little bit more about your experience with leadership and conflict. These questions will also help the student researcher identify a diverse group of voices to reflect in this study.

Q8 Please provide your name.

First: (1)

Last: (2) 
Q9 What is your gender?

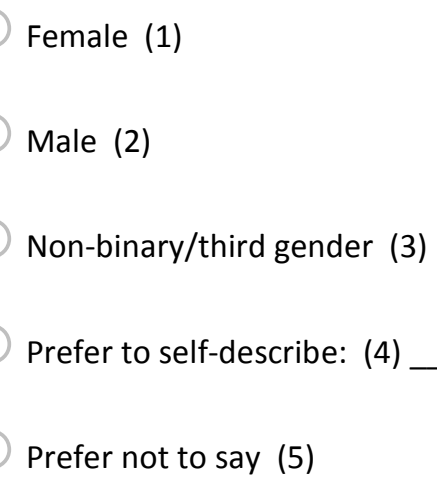

Q10 Are you Spanish, Hispanic, or Latino or none of these (select all that apply).

Spanish (1)

Hispanic (2)

Latino (3)

$\otimes$ None of these (4)

Q11 How would you describe your race? (Choose one or more, or write in your answer.)

American Indian or Alaska Native (1)

Asian (2)

Black or African American (3)

Native Hawaiian or Other Pacific Islander (4)

White (5)

Other racial identity - please describe: (6)

Prefer not to say (7) 
Q12 Are you an international student?

No (1)

Yes. I am from: (2)

Q25 Do you identify as having a disability?

Yes (4)

No (5)

Prefer not to say (6)

Q13 How old are you?

Q14 What year are you in college?

Junior (3)

Senior (4)

Other- Please describe: (5)

Q15 What is your major? (If multiple, list all)

Q16 Please list any student leadership experiences you have had since being at Oregon State University and any offices/positions held, and with which departments or organizations (e.g. "President, Interfraternity Council," or "Resident Assistant, University Housing and Dining Services," or "member, Active Minds").

Q17 Please briefly describe (in 1 - 3 sentences) an example of a conflict you have had with a peer while in a student leadership position at OSU. 
Q18 Please briefly describe (in 1 - 3 sentences) an example of a conflict you have had with a peer in any undergraduate student experience while at OSU.

Contact Information and Permission to Contact

Q19 What is your ONID email address?

Email Address (1)

Q20 What is the best telephone number to reach you at? (Please use dashes, e.g. 541-123-4567)

Best number: (1)

Q21 The student researcher will conduct confidential interviews with participants who meet the study criteria to learn about their experiences with conflict. Students who participate in interviews will receive a $\$ 20$ gift card to Amazon. Do you give permission to the student researcher to reach out to you regarding your availability and participation in this study?

Yes (1)

No (2) 


\section{Appendix C: Listserv Recruitment Email}

\section{龟 Portland State}

Hello student leaders!

My name is Jill and I am a doctoral candidate in Educational Leadership at Portland State University. For my dissertation, titled "Learning and Leading Across Difference: Student Leader Experiences Navigating Conflict and Controversy on Campus," I am studying how student leaders experience and navigate conflict and controversy with peers, and the extent to which those experiences facilitated their student leadership development.

I'll explore conflict through a student leader perspective by interviewing participants. Participants will be asked to participate in one to two 60- or 90-minute interviews discussing their student leadership roles, what their conflict resolution styles are, and how they have seen conflict and controversy play out in their own student experience. Participants will receive a \$20 gift card to Amazon at the conclusion of their interview(s).

I am looking for participants who meet the following criteria:

- Are a Junior/Senior at OSU

- Has student leadership experience (student clubs or orgs, serves in an elected position, or work in a paraprofessional role e.g. RA, cultural center staff member, or Orientation Leader)

- Has experienced conflict or controversy with a peer while in your student leadership role

If you think you are a good fit for this study, and are willing to give a few hours of your time to tell me about your experiences, please fill out this brief survey: http://bit.ly/conflictstudy.

If you have questions or want to know more, please feel free to email me at cjill@pdx.edu. Thank you for your consideration of this request, and best of luck with the rest of the quarter. Best, Jill

Jill Childress, M.Ed.

Educational Leadership Doctoral Candidate

Educational Leadership and Policy, College of Education

Portland State University | cjill@pdx.edu

Christine Cress, Ph.D. [Research Supervisor]

Educational Leadership and Policy, College of Education

Portland State University | cressc@pdx.edu 
Appendix D: Recruitment Flier
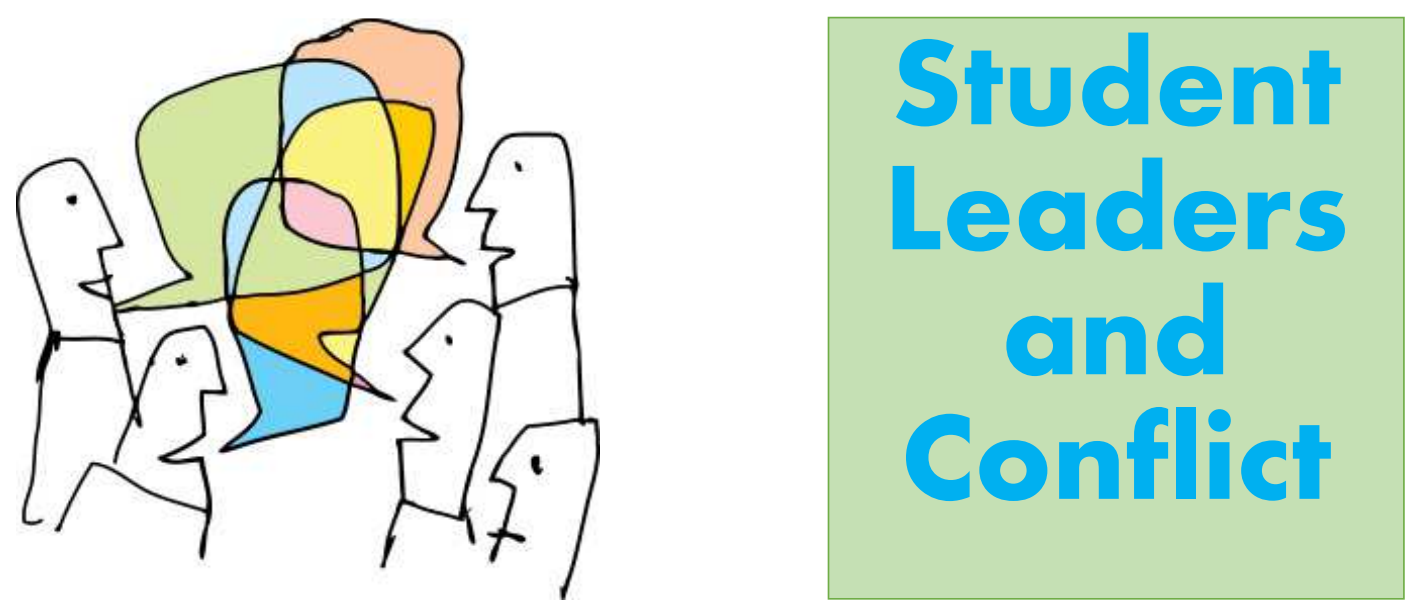

I am a doctoral candidate in Educational Leadership at Portland State University, and I am conducting interviews as part of a study titled “Learning and Leading Across Difference: Student Leader Experiences

\section{CALL FOR STUDY PARTICIPANTS}

Navigating Conflict and Controversy on Campus."

Participants will be asked to participate in one to two 60- or 90-minute interviews discussing their student leadership roles, what their conflict resolution styles are, and how they have seen conflict and controversy play out in their own student experience.

\section{Participants will receive a \$20 gift card to Amazon at the conclusion of their interview(s).}

Eligibility criteria

Junior/Senior at OSU * Student leadership experience (student clubs or orgs, serves in an elected position, or work in a paraprofessional role e.g. RA, cultural center staff member, or Orientation Leader) * Has experienced conflict or controversy with a peer while in your student leadership role

Think you're a good fit for this study?

Please fill out this brief survey: http://bit.ly/conflictstudy Have questions or want to learn more? Please contact me! Jill Childress I cjill@pdx.edu 


\section{Appendix E: Follow-Up Email - Participants Who Met Criteria}

RE: Student Leadership and Conflict Study: Criteria Met

\section{龟 Portland State}

Hello Participant Name,

Thank you for completing the questionnaire for the study "Learning and Leading Across Difference:

Student Leader Experiences Navigating Conflict and Controversy on Campus." The goal of this study is to explore how student leaders make sense of and navigate conflict and controversy on campus with their peers, and how these experiences have or have not impacted their learning and development. Because of this, participants that are invited to interview will be asked to reflect on a time in which they have experienced conflict or controversy in their student leadership role, and how they managed that conflict. Based on your questionnaire results, it appears that you meet the study criteria for participation. As part of the sampling method, I am seeking a range of genders, racial identities, and types of student leadership experiences in order to have diverse perspectives and insights. Because of the limited scope of this study and the goal of including a wide range of diverse experiences, not all eligible participants will be invited to interview; should you not be selected, this is not a reflection on you. I will be in touch soon to confirm if you have been selected to participate in the interviews, at which point we will set up a date, time, and public location on or near campus where we can meet to complete your interview.

As we are in the process of finalizing participant selection, I invite you to review the informed consent form for this study (attached), which provides more details about the study, what your participation means, and how information you share will be protected. This form will be signed by all participants at the time of their first interview. I am glad to answer any questions at the time of the first interview, or, if there are questions I can answer for you now, please feel free to reply to this email let me know.

If you have anyone else in mind who may be a good fit and want to participate in this study, please let me know and I can reach out to them. If you have any questions, don't hesitate to reach out. Thank you again for your interest.

Best,

Jill

Jill Childress, M.Ed.

Educational Leadership Doctoral Candidate

Educational Leadership and Policy, College of Education

Portland State University | cjill@pdx.edu

Christine Cress, Ph.D. [Research Supervisor]

Educational Leadership and Policy, College of Education

Portland State University | cressc@pdx.edu 


\section{Appendix F: Follow-Up Email - Invitation to Participate}

\section{क P Portland State}

RE: Student Leadership and Conflict Study: Invitation to Participate

Hello Participant Name,

I am pleased to share that you have been selected to participate in the study "Learning and Leading Across Difference: Student Leader Experiences Navigating Conflict and Controversy on Campus." The goal of this study is to explore how student leaders make sense of and navigate conflict and controversy on campus with their peers, and how these experiences have or have not impacted their learning and development. Because of this, participants that are invited to interview will be asked to reflect on a time in which they have experienced conflict or controversy in their student leadership role, and how they managed that conflict.

Please let me know as soon as you are able your availability for a 1.5-2-hour meeting in the next two weeks. The first part of our meeting will be spent reviewing the informed consent form (attached here for your reference) and answering any questions that you may have. The rest of our time together will be spent discussing your experiences with conflict and controversy as a student leader. At the conclusion of the interview, you will receive a \$20 gift card to Amazon.

If you have any questions, don't hesitate to let me know. Looking forward to confirming a time and meeting with you soon. Thank you again for your interest.

Best,

Jill

Jill Childress, M.Ed.

Educational Leadership Doctoral Candidate

Educational Leadership and Policy, College of Education

Portland State University $\mid$ cjill@pdx.edu

Christine Cress, Ph.D. [Research Supervisor]

Educational Leadership and Policy, College of Education

Portland State University | cressc@pdx.edu 


\section{Appendix G: Semi-Structured Interview Protocol}

\section{Introduction}

- Introduce myself. Explain what my project is about and what I hope to learn, and the structure of the interview.

- Remind students that they can end the interview at any point and withdraw their consent at any point.

- Remind students that I work full-time at OSU, and in my role I am a Responsible Employee under Title IX, a Campus Security Authority under the Clery Act, and a Mandatory Reporter of abuse under state law. Remind them that depending on what they share with me, I may be required to make reports to specific offices.

- Allow time for them to review the informed consent form. Draw their attention specifically to the resources available to them at OSU. Once they have read the form, answer any questions that they have, and then ask them to sign the form.

\section{Demographic Information and Rapport Building}

1. Collect (or confirm from the questionnaire) the following demographic information: Pseudonym preferred for the study, age, hometown/state, major, year in school, race, national origin, sexual orientation, and campus involvement, including student leadership positions, club/organization involvement, or jobs worked.

2. Tell me about yourself. Where are you from? How did you end up at Oregon State University?

\section{Student Leadership and Socially Responsible Leadership}

3. Tell me about your student leadership role(s). [Consciousness of Self, SLR]

4. How did you come to be in your role? Or Why did you choose to participate in this student leadership experience? [Pathway, values, Consciousness of Self, Commitment, LSE, motivations for leadership/involvement]

5. What, if anything, do you think you've gained so far from your participation in your student leader role? [Consciousness of Self, Congruence, knowledge, skills, attitudes]

6. What do you know now that you feel like you didn't know prior to your student leadership experience? [Knowledge, Consciousness of Self, behaviors/attitudes]

7. What skills, in your opinion, are important for student leaders to possess? Tell me about any skills that you are still trying to develop? [Consciousness of Self, Congruence, motivation, values, skills]

8. What would you say are your core values, and how do these show up in your student leadership roles? [values, Congruence, Commitment, Consciousness of Self]

9. Have you worked with any peers in your student leader experience who are really different from you? [role of peers] (Probes: questions a \& b)

a. If so, in what ways are they different? What has that been like? OR

b. If not, why do you think that is? 
10. What have you been able to accomplish in your student leadership experience? [LSE] (Probes: questions a \& b)

a. Did you have confidence before those accomplishments that you would be able to achieve those goals? [LSE, skills, knowledge, behavior/attitudes]

b. What factors do you think helped you to accomplish those goals?

\section{Conflict and Controversy}

11. Do you think conflict and controversy are different? How would you describe or define conflict? Controversy? [Conflict, controversy, Controversy with Civility]

12. How would you describe your conflict style? [Consciousness of Self, values, selfawareness]

13. Where would you say you learned how to navigate conflict and controversy? [Mentors, strategies]

14. Do you believe that the way you approach conflict is similar to how it was when you first started college? [student development, student learning, disorienting dilemmas, pluralism] (Probes: questions a \& b)

a. If yes, in what ways? Why do you think these aspects remained unchanging for you? [student learning, student development]

b. If no, what's different? What do you think contributed to this difference/shift? [student learning, student development]

\section{Direct Experiences with Conflict and Controversy and Strategies Used}

15. Can you remember an experience you've had with conflict or controversy with a peer while in a leadership role that you can describe in detail for me? [Controversy with Civility, Collaboration, Common Purpose, peers] (Probes: questions a-k)

a. Describe the steps you took to work through it? [process, Controversy with Civility]

b. What values guided how you responded? OR What factors were most important to you as you navigated the conflict? [Consciousness of Self, Controversy with Civility, values]

c. What strategies did you utilize that you think made it go well? [strategies]

d. Did you process with or seek help from anyone as you navigated the conflict/controversy? If so, who and why them? [mentors, peers, strategies, resources]

e. Did you use resources available to you to resolve the conflict? If so, which ones and how? [resources]

f. What was the outcome and what was your role? OR If you didn't participate, what were the reasons? What made you avoid participating? [strategies, process, Controversy with Civility, avoidance]

g. To what extent do you feel like in the conflict you used the following strategies: listening, critical thinking, empathy? Can you describe in what ways those came up? [strategies, empathy, student development] 
h. To what extent did a peer or peers influence your perspective or change your mind in the conflict/controversy you described? [peer influence, perspective-taking, pluralism, empathy]

i. How did you feel at the conclusion of the conflict? [Consciousness of Self, civility, Controversy with Civility, self-awareness, attitudes/behaviors]

j. What was your relationship like with others after the conflict/controversy? [Controversy with Civility, peers, relationships, civility]

k. Looking back, would you have done anything differently? [reflection, student learning, student development]

16. In what ways, if any, have you seen conflict or controversy impact a group that you were a part of? [peers, Controversy with Civility, student learning, student development]

17. Some people would say that people who engage in conflict or controversy are closed-minded or like drama. What would you say to them? [Attitudes/behaviors, civility]

\section{Conclusion}

18. That brings us to the end of the interview. Is there anything else you want to share or that you think would be helpful for me to know?

19. Do you have any questions for me regarding this study or next steps?

- I will be reaching out to you in the next few weeks to ask you to review a transcript of our time together to make sure it accurately reflects your experience. If you'd like to do this in person, please let me know.

- As a gesture of my gratitude for your participation, I would like to give you an Amazon gift card. I appreciate the time you spent with me today. 


\section{Appendix H: Rubrics to Inform Protocol Questions}

Consciousness of Self: "being aware of the beliefs, values, attitudes, and emotions that motivate a person to take action" (Tyree, 1998, p. 176).

\begin{tabular}{|c|c|c|c|c|}
\hline & Excelling & Achieving & Developing & $\begin{array}{l}\text { Needing } \\
\text { Improvement }\end{array}$ \\
\hline $\begin{array}{l}\text { Self- } \\
\text { awareness }\end{array}$ & $\begin{array}{l}\text { Demonstrates a } \\
\text { thorough } \\
\text { understanding of } \\
\text { personal } \\
\text { identity, social } \\
\text { identity, and } \\
\text { core values } \\
\text { Able to } \\
\text { accurately } \\
\text { describe self to } \\
\text { others } \\
\text { Understands } \\
\text { complex multiple } \\
\text { identities }\end{array}$ & $\begin{array}{l}\text { Understands } \\
\text { core values } \\
\text { and many } \\
\text { aspects of } \\
\text { social and } \\
\text { personal } \\
\text { identity } \\
\text { May struggle a } \\
\text { bit with } \\
\text { articulating } \\
\text { these values or } \\
\text { identity to } \\
\text { others } \\
\text { Still exploring a } \\
\text { more in-depth } \\
\text { sense of self }\end{array}$ & $\begin{array}{l}\text { Aware of some } \\
\text { aspects of } \\
\text { personality, } \\
\text { identity, and } \\
\text { core values but } \\
\text { struggling to } \\
\text { define and } \\
\text { articulate a } \\
\text { cohesive sense } \\
\text { of self }\end{array}$ & $\begin{array}{l}\text { Unaware of } \\
\text { personal } \\
\text { values or } \\
\text { identity } \\
\text { Struggles with } \\
\text { identifying } \\
\text { social identity } \\
\text { Unable to } \\
\text { describe self } \\
\text { accurately to } \\
\text { others }\end{array}$ \\
\hline $\begin{array}{l}\text { Conscious } \\
\text { Mindfulness }\end{array}$ & $\begin{array}{l}\text { Consistently } \\
\text { evaluates self } \\
\text { and actions } \\
\text { Is fully aware of } \\
\text { current } \\
\text { emotional state } \\
\text { and adjusts } \\
\text { actions } \\
\text { accordingly }\end{array}$ & $\begin{array}{l}\text { Makes an } \\
\text { effort to } \\
\text { observe } \\
\text { oneself in the } \\
\text { moment but is } \\
\text { inconsistent or } \\
\text { struggles } \\
\text { Tries to think } \\
\text { through the } \\
\text { situation } \\
\text { before acting }\end{array}$ & $\begin{array}{l}\text { Understands } \\
\text { the need to } \\
\text { consider one's } \\
\text { words and } \\
\text { actions but has } \\
\text { difficulty } \\
\text { actually doing } \\
\text { this } \\
\text { May } \\
\text { occasionally } \\
\text { evaluate } \\
\text { current } \\
\text { emotional } \\
\text { state but is } \\
\text { unsure what to } \\
\text { do about it }\end{array}$ & $\begin{array}{l}\text { Unable to } \\
\text { separate } \\
\text { emotion and } \\
\text { personal } \\
\text { feelings from } \\
\text { action } \\
\text { Lack of } \\
\text { awareness of } \\
\text { how one's } \\
\text { actions affect } \\
\text { others }\end{array}$ \\
\hline Feedback & $\begin{array}{l}\text { Open to positive } \\
\text { and negative } \\
\text { feedback }\end{array}$ & $\begin{array}{l}\text { Makes an } \\
\text { effort to seek } \\
\text { out some } \\
\text { positive and }\end{array}$ & $\begin{array}{l}\text { Able to take } \\
\text { some positive } \\
\text { and negative }\end{array}$ & $\begin{array}{l}\text { Unable to } \\
\text { take positive } \\
\text { and negative } \\
\text { feedback }\end{array}$ \\
\hline
\end{tabular}




\begin{tabular}{|c|c|c|c|c|}
\hline & $\begin{array}{l}\text { Seeks such } \\
\text { feedback and } \\
\text { further } \\
\text { clarification } \\
\text { Integrates advice } \\
\text { into how one } \\
\text { goes about } \\
\text { future activities } \\
\text { Uses discretion }\end{array}$ & $\begin{array}{l}\text { negative } \\
\text { feedback } \\
\text { Works on } \\
\text { taking negative } \\
\text { feedback as a } \\
\text { way to develop }\end{array}$ & $\begin{array}{l}\text { feedback that } \\
\text { is presented } \\
\text { Does not seek } \\
\text { out feedback } \\
\text { Does not use } \\
\text { feedback in } \\
\text { other } \\
\text { situations }\end{array}$ & $\begin{array}{l}\text { Pushes } \\
\text { feedback } \\
\text { away } \\
\text { Negatively } \\
\text { affects self- } \\
\text { confidence } \\
\text { and } \\
\text { motivation }\end{array}$ \\
\hline $\begin{array}{l}\text { Continual } \\
\text { Personal } \\
\text { Reflection }\end{array}$ & $\begin{array}{l}\text { Continually takes } \\
\text { time during each } \\
\text { day to reflect on } \\
\text { thoughts, } \\
\text { feelings, and } \\
\text { experiences } \\
\text { Integrates } \\
\text { learning and } \\
\text { uses it in } \\
\text { subsequent } \\
\text { experiences } \\
\text { Views } \\
\text { experiences from } \\
\text { other } \\
\text { perspectives } \\
\text { Reflects on big } \\
\text { questions such } \\
\text { as “Who am I?" }\end{array}$ & $\begin{array}{l}\text { Often sees the } \\
\text { benefit of } \\
\text { personal } \\
\text { reflection } \\
\text { Frequently } \\
\text { takes time to } \\
\text { reflect on self } \\
\text { and } \\
\text { experiences }\end{array}$ & $\begin{array}{l}\text { Sees some } \\
\text { benefit of } \\
\text { personal } \\
\text { reflection, such } \\
\text { as learning } \\
\text { from an } \\
\text { experience, } \\
\text { and sometimes } \\
\text { takes } \\
\text { opportunities } \\
\text { to reflect on } \\
\text { different } \\
\text { experiences }\end{array}$ & $\begin{array}{l}\text { Does not see } \\
\text { the need or } \\
\text { benefits of } \\
\text { taking time } \\
\text { out of the day } \\
\text { to reflect } \\
\text { Rarely, if } \\
\text { ever, takes } \\
\text { opportunities } \\
\text { to reflect } \\
\text { about daily } \\
\text { experiences } \\
\text { or pondering } \\
\text { big questions }\end{array}$ \\
\hline
\end{tabular}

Note: from text: "Source: Developed by Colette Fournier and Christina Colasanto." From Early and Fincher (2017), p. 63. In Komives, S. R., \& Wagner, W. E. (Eds.). (2017). Leadership for a better world: Understanding the social change model of leadership development (Second edition). San Francisco, CA: Jossey-Bass. 
Controversy with Civility: "Believing in two fundamental realities of any creative effort: (1) that differences in viewpoint are inevitable, and (2) that such differences must be aired openly but with civility" (Tyree, 1998, p. 176).

\begin{tabular}{|c|c|c|c|c|}
\hline & Excelling & Achieving & Developing & $\begin{array}{l}\text { Needing } \\
\text { Improvement }\end{array}$ \\
\hline $\begin{array}{l}\text { Respect for and } \\
\text { Courtesy to } \\
\text { Others }\end{array}$ & $\begin{array}{l}\text { Actively engages and } \\
\text { participates with others } \\
\text { Reciprocates respect of } \\
\text { values and opinions } \\
\text { Models a civil } \\
\text { atmosphere and } \\
\text { encourages others to do } \\
\text { so }\end{array}$ & $\begin{array}{l}\text { Shows respect } \\
\text { for others most } \\
\text { times and } \\
\text { actively helps to } \\
\text { facilitate a civil } \\
\text { atmosphere }\end{array}$ & $\begin{array}{l}\text { Begins to engage } \\
\text { with others } \\
\text { beyond his or her } \\
\text { interests and } \\
\text { understands that } \\
\text { own actions can } \\
\text { affect how others } \\
\text { feel } \\
\text { Occasionally } \\
\text { shows limited } \\
\text { courtesy }\end{array}$ & $\begin{array}{l}\text { Only engages in } \\
\text { conversations } \\
\text { related to his or } \\
\text { her interests } \\
\text { Expresses } \\
\text { negative attitudes } \\
\text { Speaks over and } \\
\text { interrupts others } \\
\text { Frequently } \\
\text { disrespectful to } \\
\text { others }\end{array}$ \\
\hline $\begin{array}{l}\text { Ability to Work } \\
\text { Cooperatively }\end{array}$ & $\begin{array}{l}\text { Engages with a win-win } \\
\text { philosophy and shared } \\
\text { purpose } \\
\text { Actively supports and } \\
\text { works with others } \\
\text { collaboratively }\end{array}$ & $\begin{array}{l}\text { Works } \\
\text { effectively as a } \\
\text { team member } \\
\text { Actively shares } \\
\text { in discussions } \\
\text { different from } \\
\text { own opinions }\end{array}$ & $\begin{array}{l}\text { Interacts with } \\
\text { hesitancy } \\
\text { Helps with work } \\
\text { rather than } \\
\text { engages } \\
\text { At times lets } \\
\text { conflict slow } \\
\text { progress }\end{array}$ & $\begin{array}{l}\text { Does not engage } \\
\text { as a member of } \\
\text { the community } \\
\text { Focuses only on } \\
\text { individual actions } \\
\text { and input }\end{array}$ \\
\hline Trust & $\begin{array}{l}\text { Asks intelligent } \\
\text { questions aimed at } \\
\text { starting good } \\
\text { conversations with the } \\
\text { purpose of seeking } \\
\text { understanding, solving } \\
\text { problems, and making } \\
\text { decisions }\end{array}$ & $\begin{array}{l}\text { Seeks out } \\
\text { opinions of } \\
\text { others even if } \\
\text { they differ from } \\
\text { his or her own }\end{array}$ & $\begin{array}{l}\text { Begins to open up } \\
\text { to others and } \\
\text { share thoughts } \\
\text { while using space } \\
\text { to hear others' } \\
\text { opinions } \\
\text { Questions about } \\
\text { others' ideas } \\
\text { seem superficial } \\
\text { or fake }\end{array}$ & $\begin{array}{l}\text { Shows physical } \\
\text { and verbal signs } \\
\text { of distrust for } \\
\text { group } \\
\text { Does not share } \\
\text { opinions or } \\
\text { thoughts but } \\
\text { expects to hear } \\
\text { from others }\end{array}$ \\
\hline Dialogue Skills & $\begin{array}{l}\text { Always participates in } \\
\text { constructive } \\
\text { conversation } \\
\text { Understands that } \\
\text { others' views might help } \\
\text { in developing his or her } \\
\text { own ideas as well as } \\
\text { those of the group }\end{array}$ & $\begin{array}{l}\text { Frequently } \\
\text { participates in } \\
\text { constructive } \\
\text { conversation } \\
\text { Analyzes ideas } \\
\text { fully and } \\
\text { coherently } \\
\text { before sharing } \\
\text { with the group }\end{array}$ & $\begin{array}{l}\text { Attempts to } \\
\text { understand why } \\
\text { he or she has } \\
\text { arrived at } \\
\text { thoughts } \\
\text { Some difficulty in } \\
\text { expressing own } \\
\text { ideas to others }\end{array}$ & $\begin{array}{l}\text { Does not seek to } \\
\text { help explain his } \\
\text { or her ideas to } \\
\text { group or try to } \\
\text { understand why } \\
\text { he or she has } \\
\text { come to these } \\
\text { ideas }\end{array}$ \\
\hline $\begin{array}{l}\text { Controversy } \\
\text { Versus Conflict }\end{array}$ & $\begin{array}{l}\text { Fully embraces } \\
\text { controversy as } \\
\text { important tool of } \\
\text { sharing in group } \\
\text { problem solving and } \\
\text { decision making }\end{array}$ & $\begin{array}{l}\text { Begins to } \\
\text { challenge } \\
\text { others' opinions } \\
\text { in a nonhostile } \\
\text { manner } \\
\text { No longer sees } \\
\text { controversy as a } \\
\text { negative impact }\end{array}$ & $\begin{array}{l}\text { Begins to } \\
\text { understand how } \\
\text { controversy can } \\
\text { help group } \\
\text { process } \\
\text { Sometimes } \\
\text { struggles with } \\
\text { conflict }\end{array}$ & $\begin{array}{l}\text { Does not } \\
\text { understand the } \\
\text { difference } \\
\text { between } \\
\text { controversy and } \\
\text { conflict } \\
\text { Sees conflict as a } \\
\text { hostile }\end{array}$ \\
\hline
\end{tabular}




\begin{tabular}{|l|l|l|l|l|}
\hline & on collaborative & & $\begin{array}{l}\text { environment with } \\
\text { no positive } \\
\text { attributes }\end{array}$ \\
\hline $\begin{array}{l}\text { Awareness of } \\
\text { Worldviews }\end{array}$ & $\begin{array}{l}\text { Shares own values fully } \\
\text { Deeply values others' } \\
\text { worldviews and } \\
\text { perceptions }\end{array}$ & $\begin{array}{l}\text { Actively shares } \\
\text { values and ideas } \\
\text { most times } \\
\text { Understands } \\
\text { alternate } \\
\text { viewpoints are } \\
\text { inevitable and } \\
\text { part of the } \\
\text { creative process }\end{array}$ & $\begin{array}{l}\text { Begins to share } \\
\text { own perspectives } \\
\text { with others } \\
\text { Limited } \\
\text { acceptance of } \\
\text { others' views as } \\
\text { being } \\
\text { constructive }\end{array}$ & $\begin{array}{l}\text { Does not value } \\
\text { the perspectives } \\
\text { of others } \\
\text { Only sees own } \\
\text { vies as } \\
\text { constructive and } \\
\text { does not evaluate } \\
\text { own perspectives }\end{array}$ \\
\hline
\end{tabular}

Note: from text: "Source: Developed by Heather S. Baruch and Christopher R. Boyle." From Alvarez (2017), p. 168. In Komives, S. R., \& Wagner, W. E. (Eds.). (2017). Leadership for a better world:

Understanding the social change model of leadership development (Second edition). San Francisco, CA: Jossey-Bass. 


\title{
Appendix I: Informed Consent Form
}

\section{S P P Porland State}

Consent to Participate in Research

\author{
Project Title: Learning and Leading Across Difference: Student Leader Experiences Navigating \\ Conflict and Controversy on Campus \\ Researcher(s): $\quad$ Christine Cress, Ph.D., Educational Leadership \& Policy - PSU \\ Jill Childress, M.Ed., Educational Leadership \& Policy - PSU
}

\begin{abstract}
You are being asked to take part in a research study. The purpose of this study is to understand the experience of undergraduate student leaders in navigating conflict and controversy, how they make meaning of those experiences, and if those experiences contributed to their learning and development in college. Specifically, this study will examine if and how student leaders navigate conflict and controversy in their undergraduate student roles, and how student leaders conceptualize or view conflict and controversy in the context of an increasingly diverse and polarized college campuses and societally, in order to add to the overall understanding of how conflict impacts student development. Information collected for this research will be used to answer research questions posed in the student researcher's doctoral dissertation.
\end{abstract}

You are being asked to participate because you are enrolled at Oregon State University's Corvallis campus; are between 18-23 years old; have participated in some form of formal leadership experience (paraprofessional, an elected position, or through a student organization); and have had some experience with conflict or controversy with a peer since being enrolled. About 8-12 people will take part in this research.

Who is conducting this research?

The researchers, student investigator Jill Childress from Portland State University, and Dr. Christine Cress from Portland State University, are asking for your consent to this research.

In addition to being a doctoral student at Portland State University, Jill also works as an Assistant Director in Student Affairs at Oregon State University in Corvallis, where the data collection will take place. In her professional role, she has the following state and federal compliance obligations: Campus Security Authority (CSA) under the Clery Act, Responsible Employee under Title IX, and a Mandatory Reporter under state law. Due to this, she is required to share certain types of disclosures as part of her employee responsibilities.

I (Jill) will make appropriate resource referrals to the participant and then contact the Office of Equal Opportunity and Access (EOA) in the case of a disclosure of sexual violence or harassment, and to the Counseling and Psychological Services (CAPS) office in the instance of ideation of harm to self or others. If there is imminent danger or threat of harm, I will contact Oregon State Police (OSP). If you have questions about what types and how disclosures are shared, please contact Jill at cjill@pdx.edu.

What happens if I agree to participate?

If you agree to be in this research, you will be contacted by the student researcher to schedule a time, place, and location for an in-person interview. We expect this to take between 60 and 90 minutes per interview, and a total of one to two interviews over a one- to four-month period of time between August and December. These interviews will be recorded and transcribed. The meeting will begin with a review together of this informed consent form and will be one opportunity for the student researcher to 


\section{龟 Portland State}

answer any questions you have about the project. If you consent to participate, you will be asked to select a pseudonym. The rest of the meeting will be the first interview; the student researcher will ask you questions and record your responses via audio recording and will take notes. The student researcher may contact you again for a follow up interview to gather additional information or to have you clarify or confirm your meaning from a previous interview. This research reviews potentially sensitive topics related to conflict and controversy, and participants will be asked to describe their experiences with conflict or controversy. Participants are requested to not use names of people with whom they have had conflicts and/or controversy when discussing their experiences. We will tell you about any new information that may affect whether or not you want to continue this research.

How will my privacy and data confidentiality be protected?

We will take measures to protect your privacy including removing identifying information from transcripts and using pseudonyms. Information collected in this study may be published; the student researcher will remove other identifying information prior to publication. Despite taking steps to protect your privacy, we can never fully guarantee that your privacy will be protected. Individuals and organizations that conduct or monitor this research may be permitted access to inspect research records. This may include private information. These individuals and organizations include the Institutional Review Board that reviewed this research at the study site and the Institutional Review Board at the student researcher's home institution. Data will not be used for future research or shared with other researchers.

\section{What are the risks if I participate?}

There are some risks you might experience from being in this study. There is a small risk that a data breach could lead to information you disclose being shared. This risk will be mitigated by removing identifying information from transcripts and using pseudonyms, keeping data electronically secured in the student researcher's Portland State University Google Drive, which requires double authentication to access, and keeping hard copies of transcripts locked in a cabinet when not used.

Another potential risk is psychological. Reflecting on conflict experiences may bring up feelings of stress, anxiety, anger, or shame. As an employee of Oregon State University, the student researcher is very familiar with campus resources and can make referrals as needed. Some resources are included below.

Oregon State University Campus Resources

Counseling and Psychological Services (CAPS) | CONFIDENTIAL

Location: Snell Hall $5^{\text {th }}$ floor

Contact: $541-737-2131$ (24/7 line)

Survivor Advocacy and Resource Center (SARC) | CONFIDENTIAL

Location: Plageman Student Health $3^{\text {rd }}$ floor

Contact: 541-737-2030 (24/7 line)

Department of Public Safety (DPS) I NOT CONFIDENTIAL

Location: Cascade Hall $2^{\text {nd }}$ floor Contact: 541-737-7000 (emergency) 541-737-3010 (non-emergency) 
What are the benefits if I participate?

You may experience indirect benefits of participating in this study through reflection and meaningmaking on your own experience. Others may benefit because the information learned will help administrators understand student experiences with conflict and controversy and how to facilitate supportive learning environments for students experiencing conflict or controversy.

What if I want to stop participating in this research?

Your participation is voluntary. You do not have to take part in this study, but if you do, you may stop at any time. You have the right to choose not to participate in any study activity or completely withdraw from participation at any point without penalty or loss of benefits to which you are otherwise entitled. Your decision whether or not to participate will not affect your relationship with the researchers or Portland State University.

Will it cost me money to take part in this research?

Taking part in this research will not require you to incur any costs.

Will I be paid for participating in this research?

Participants will not be paid to participate. Participants who complete all phases of the study will receive a token gift card to Amazon at the conclusion of data collection.

Who can answer my questions about this research?

If you have questions, concerns, or have experienced a research related injury, contact the research team at:

Jill Childress | phone: 717-779-8517 | email: cjill@pdx.edu

Christine Cress | phone: 503-725-4682 | email: cressc@pdx.edu

You can also contact the Human Research Protection Program with any concerns that you have about your rights or welfare as a study participant at:

Portland State University, Office of Research Integrity | 503-725-5484 | hsrrc@pdx.edu

Oregon State University, Office of Research Integrity | 541-737-8008 | irb@oregonstate.edu

\section{Consent Statement}

Your signature indicates that this study has been explained to you, that your questions have been answered, and that you agree to take part in this study You will receive a copy of this form.

Researcher Signature (to be completed at time of informed consent)

I have explained the research to the participant and answered all of his/her questions. I believe that he/she understands the information described in this consent form and freely consents to participate. 


\section{Appendix J: Codebook}

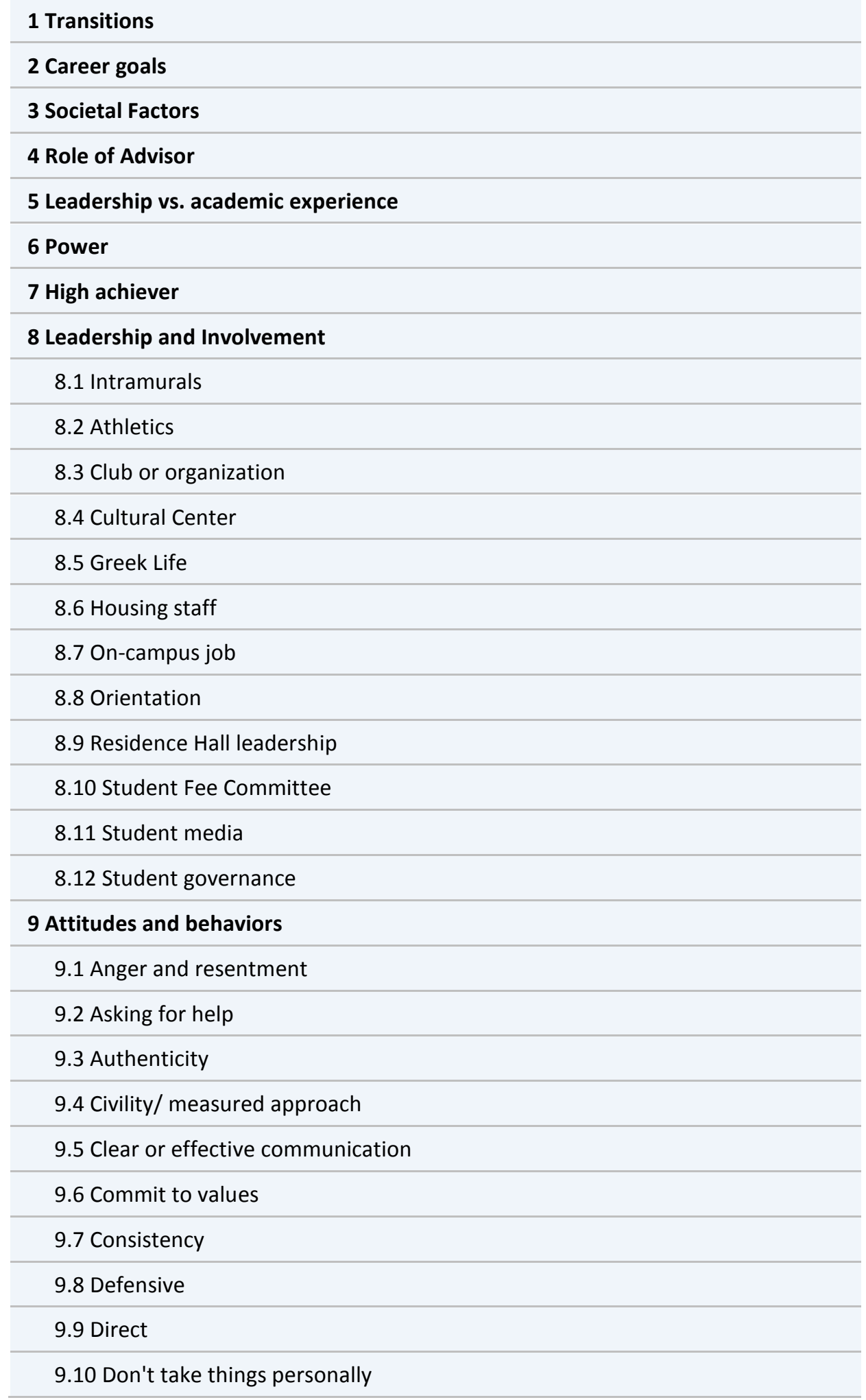


9.11 Emotional/passionate person

9.12 Empathy

9.13 Flexibility

9.14 Gossiping

9.15 Guarded

9.16 Incivility

9.17 Listening

9.18 Not putting in full effort/being avg/wanting to succeed

9.19 Openness

9.20 Patience

9.21 Perseverance

9.22 Personal responsibility

9.23 Perspective-taking

9.24 Positivity

9.25 Presumption of goodwill

9.26 Prioritizing

9.27 Professionalism

9.28 Respect

9.29 Regret

9.30 Risk taking

9.31 Shame

9.32 Skepticism

9.33 Think differently/creatively

9.34 Transparency

9.35 Vulnerability

9.36 Willingness to learn

10 Conflict

10.1 Choosing sides

10.2 Unethical

10.3 Frustrated

10.4 Conflict toolkit

10.5 Felt relief 
10.6 Trust issues

10.7 Can't talk about it

10.8 Loss of/ strain on friendship

10.9 Can't please everyone

10.10 Impacting group dynamic

10.11 Inevitable

10.12 Feeling caught off guard, unprepared, ambushed

10.13 Healing

10.14 Leads to growth/is healthy

10.15 Personal vs. professional

10.16 Conflict: Approach is different now

10.17 Conflict: Approach is the same now

10.18 Style: Avoid

10.19 Style: Compromise

10.20 Style: Don't shy away from it

10.21 Style: Engaged/Communicative

10.22 Style: Engage after someone else initiates

10.23 Style: Give in to resolve quickly

10.24 Style: Mediating

10.25 Style: Non-confrontational

10.26 Style: Pragmatic

10.27 Characteristic: Between individuals

10.28 Characteristic: Can be bad if it turns personal

10.29 Characteristic: Dispute, miscommunication

10.30 Characteristic: Opposing sides, negative, fighting

10.31 Characteristic: Shorter duration

10.32 Characteristic: Small scale

10.33 Cause: Budget or money

10.34 Cause: Fundamental difference of perspective

10.35 Cause: Not feeling valued

10.36 Cause: Not meeting expectations

10.37 Cause: Micromanagement 
10.38 Cause: Passive aggressiveness

10.39 Cause: Role conflict with personal feelings

$10.40 \mathrm{Job}$

10.41 Sports

10.42 Student leadership role

10.43 Parents

10.44 Peers

10.45 Siblings

\section{Controversy}

11.1 Can be productive

11.2 Can be bad

11.3 Characteristic: Challenging norms

11.4 Characteristic: Public

11.5 Characteristic: Longer time to resolution

11.6 Characteristic: Big scale

11.7 Difference of opinion or ideas

11.8 Truth in media

11.9 Polarization

12 Knowledge and skills

12.1 Ability to motivate peers/facilitate

12.2 Setting boundaries/balance

12.3 Critical thinking

12.4 Delegation

12.5 Emotional intelligence

12.6 Engage in difficult conversations

12.7 Interpersonal skills

12.8 Institutional knowledge

12.9 Maintaining confidentiality

12.10 Meeting management

12.11 Organizational skills

12.12 Problem solving

12.13 Role understanding 
12.14 Presenting

12.15 Public speaking

12.16 Self-advocacy

12.17 Taking initiative

13 LSE (Leadership Self Efficacy)

13.1 Trust myself

13.2 Empowerment

13.3 Gained experience

13.4 Imposter Syndrome

13.5 Low Level of LSE

13.6 High level of LSE

13.7 Ego

13.8 Confidence

13.9 Validation

14 Mental Health

14.1 Redirect energy, focus on other things

14.2 Focus on people who care about you

14.3 Burnout

14.4 Role of social media

14.5 Emotionally intensive

14.6 High-pressure environment

14.7 Trauma

14.8 Fear

14.9 Highly visible

14.10 Stressors/Anxiety

14.11 Resilience

15 Resources

15.1 Coursework

15.2 Supervisor

15.3 Mentor

15.4 CAPS

15.5 Campus Partners 
15.6 Administrator

15.7 Parents

15.8 Student Leader Training

15.9 Significant Other

15.10 Friends

15.11 Family

15.12 Advisor

15.13 Faculty

15.14 Ombuds

15.15 Other peer leaders

16 Role of peers

16.1 Sense of belonging

16.2 Relationships

16.3 Recruited by a peer

16.4 Grooming peers

16.5 Peer role models

16.6 Being supported by peers

16.7 Supporting peers

16.8 Supporting peers' development

17 SCM (Social Change Model)

17.1 Consciousness of Self

17.2 Congruence

17.3 Commitment

17.4 Common Purpose

17.5 Collaboration

17.6 Controversy with Civility

17.7 Citizenship

18 Social justice

18.1 Disability identity

18.2 Religious identity

18.3 Cultural differences

18.4 Organizing, speaking out 
18.5 Self-awareness and identity development

18.6 Allyship/ solidarity

18.7 Racial identity

18.8 Gender identity and/or expression

18.9 Campus climate

18.10 Learning about peers of color's perspectives

18.11 Socio-cultural conversations

19 Strategies

19.1 Asking questions to understand

19.2 Assume goodwill

19.3 Avoidance

19.4 Avoid spreading negativity

19.5 Compromise

19.6 Deciding resolution together

19.7 Distancing from conflict

19.8 Engagement in difficult conversations

19.9 Find common ground/agreement

19.10 Focus on the facts

19.11 Giving space

19.12 Letting people vent/feel heard

19.13 Listening to understand

19.14 Mediating peer

19.15 Neutralize

19.16 Open conversation/ don't bottle up

19.17 Picking a space that feels comfortable

19.18 Perspective-taking

19.19 Picking your battles

19.20 Providing positive feedback

19.21 Recognizing conflict exists

19.22 Standing firm in expectations or beliefs

19.23 Set expectations for next group

19.24 Third party perspective 
19.25 Taking responsibility/apologizing

19.26 Write out options/pathways for resolution

20 Student development

20.1 Having increased responsibility

20.2 Being away from home/independence from family

20.3 Multiple truths or perspectives

20.4 Having behavior modeled

20.5 Making mistakes

20.6 Using voice

20.7 Maturity

20.8 Trying something new, out of comfort zone

20.9 Disorienting dilemmas

20.10 Motivation

20.11 Pathway

20.12 Process

20.13 Reflection

21 Values and beliefs

21.1 Access

21.2 Accountability

21.3 Appreciation of diversity

21.4 Appreciation of others' talents

$21.5 \mathrm{Be}$ a role model

21.6 Belief in others, don't make assumptions

21.7 Consideration of future impact

21.8 Don't give up on people

21.9 Equity

21.10 Forgiveness

21.11 Honesty

21.12 Humor

21.13 Integrity

21.14 Love, kindness, care for others

21.15 Loyalty 
21.16 Make a positive change

21.17 Open-mindedness

21.18 Pluralistic orientation

21.19 Positive organizational climate

21.20 Understanding

21.21 Value of different perspectives

21.22 Working hard 


\section{Appendix K: Trustworthiness Criteria, Strategies, and Actions}

\begin{tabular}{|c|c|c|c|c|}
\hline $\begin{array}{c}\text { Trustworthiness } \\
\text { Criteria }\end{array}$ & $\begin{array}{l}\text { Trustworthiness } \\
\text { Strategies }\end{array}$ & $\begin{array}{l}\text { Data } \\
\text { Collection }\end{array}$ & $\begin{array}{c}\text { Data } \\
\text { Analysis }\end{array}$ & Specific Methods \\
\hline Credibility & Triangulation & $\checkmark$ & $\checkmark$ & $\begin{array}{l}\text { Maximum variation sampling } \\
\text { of several different types of } \\
\text { student leaders }\end{array}$ \\
\hline Confirmability & Peer debriefing & & $\checkmark$ & $\begin{array}{l}\text { Meet with advisor to review } \\
\text { emerging findings }\end{array}$ \\
\hline $\begin{array}{l}\text { Credibility } \\
\text { Dependability }\end{array}$ & Transcript review & $\checkmark$ & & $\begin{array}{l}\text { Review for errors } \\
\text { Review for syntax, pauses, and } \\
\text { other idiomatic indicators of } \\
\text { participant engagement }\end{array}$ \\
\hline $\begin{array}{l}\text { Credibility } \\
\text { Confirmability }\end{array}$ & $\begin{array}{l}\text { Rich, thick } \\
\text { description }\end{array}$ & $\checkmark$ & & $\begin{array}{l}\text { Test interview protocol } \\
\text { questions to ensure rich data } \\
\text { can be collected } \\
\text { Review for large blocks of text } \\
\text { from the participants }\end{array}$ \\
\hline Confirmability & $\begin{array}{l}\text { Disclosing } \\
\text { researcher bias } \\
\text { (reflexivity) }\end{array}$ & & $\checkmark$ & $\begin{array}{l}\text { Reflection via researcher } \\
\text { memos }\end{array}$ \\
\hline $\begin{array}{l}\text { Transferability } \\
\text { Confirmability }\end{array}$ & $\begin{array}{l}\text { Presentation of } \\
\text { negative or } \\
\text { discrepant cases }\end{array}$ & & $\checkmark$ & $\begin{array}{l}\text { Review text from transcripts } \\
\text { that don't seem to fit } \\
\text { emergent themes } \\
\text { Consider alternative } \\
\text { explanations for what may be } \\
\text { emerging from the analysis }\end{array}$ \\
\hline Dependability & $\begin{array}{l}\text { Thoroughly } \\
\text { document study } \\
\text { steps }\end{array}$ & $\checkmark$ & $\checkmark$ & $\begin{array}{l}\text { Appendices documenting } \\
\text { study steps }\end{array}$ \\
\hline Dependability & Create code book & $\checkmark$ & $\checkmark$ & $\begin{array}{l}\text { Write definitions for a priori } \\
\text { codes and codes that emerge } \\
\text { via other coding methods } \\
\text { Revisit codes and compare } \\
\text { across transcripts throughout } \\
\text { analysis phase to ensure there } \\
\text { is no code drift }\end{array}$ \\
\hline
\end{tabular}

